\title{
Growing up, getting drunk : development and prevention of adolescent alcohol use
}

Citation for published version (APA):

Schelleman-Offermans, K. (2012). Growing up, getting drunk : development and prevention of adolescent alcohol use. [Doctoral Thesis, Maastricht University]. Maastricht University. https://doi.org/10.26481/dis.20120614ks

Document status and date:

Published: 01/01/2012

DOI:

$10.26481 / \mathrm{dis} .20120614 \mathrm{ks}$

Document Version:

Publisher's PDF, also known as Version of record

\section{Please check the document version of this publication:}

- A submitted manuscript is the version of the article upon submission and before peer-review. There can be important differences between the submitted version and the official published version of record.

People interested in the research are advised to contact the author for the final version of the publication, or visit the DOI to the publisher's website.

- The final author version and the galley proof are versions of the publication after peer review.

- The final published version features the final layout of the paper including the volume, issue and page numbers.

Link to publication

\footnotetext{
General rights rights.

- You may freely distribute the URL identifying the publication in the public portal. please follow below link for the End User Agreement:

www.umlib.nl/taverne-license

Take down policy

If you believe that this document breaches copyright please contact us at:

repository@maastrichtuniversity.nl

providing details and we will investigate your claim.
}

Copyright and moral rights for the publications made accessible in the public portal are retained by the authors and/or other copyright owners and it is a condition of accessing publications that users recognise and abide by the legal requirements associated with these

- Users may download and print one copy of any publication from the public portal for the purpose of private study or research.

- You may not further distribute the material or use it for any profit-making activity or commercial gain

If the publication is distributed under the terms of Article $25 \mathrm{fa}$ of the Dutch Copyright Act, indicated by the "Taverne" license above, 


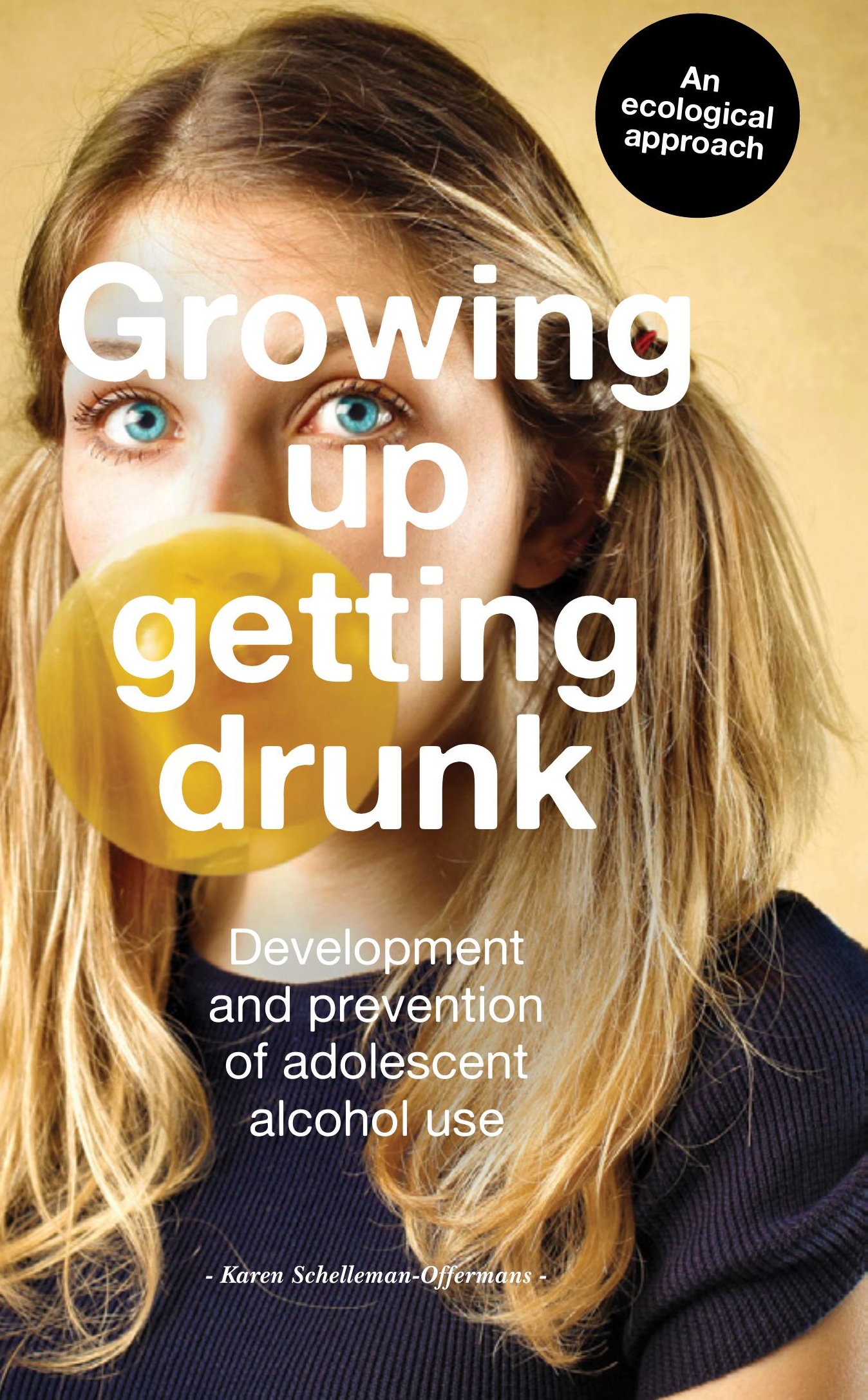




\title{
Growing up getting drunk
}

\author{
Development \\ and prevention \\ of adolescent \\ alcohol use
}




\section{Growing up getting drunk}

Development and prevention of adolescent alcohol use

\section{Colophon}

\section{Cover design and layout}

Ramon Schelleman

\section{Production}

www.BOXPress.nl / www.Proefschriftmaken.nl

(c) Karen Schelleman-Offermans, 2012

ISBN 978-90-8891-426-3

The research in this thesis was conducted at the School for Public Health and Primary Care: CAPHRI, Department of Health Promotion, Maastricht University. CAPHRI participates in the Netherlands School of Primary Care Research $(\mathrm{CaRe})$. CAPHRI was classified as

'excellent' by the external evaluation committee of leading international experts that

reviewed CAPHRI on December 2010. The research presented in this dissertation was

supported by a grant of the Netherlands organization for Scientific Research

(NWO, Grant No. 120610002).

All rights are reserved. No part of this book may be reproduced or transmitted in any form or by any means, without the written permission from the author or, were appropriate,

the publisher of the article.

\section{Proefschrift}

Ter verkrijging van de graad van doctor aan de Universiteit Maastricht, op gezag van de Rector Magnificus, Prof. mr. G. P. M. F. Mols

volgens het besluit van het College van Decanen in het openbaar te verdedigen op donderdag 14 juni 2012 om 14:00 uur

$$
\text { door }
$$

\section{Karen Schelleman-Offermans}

Geboren op 16 december 1981 Slenaken (Nederland) 
Promotoren

Prof. dr. Ronald A. Knibbe

Prof. dr. Rutger C. M. E. Engels

Prof. dr. Dike van de Mheen

Beoordelingscommissie

Prof. dr. Nanne K. de Vries (voorzitter)

Prof. dr. Peter Anderson

Dr. Patricia van Assema

Prof. dr. Stephan Van den Broucke

(Université Catholique de Nouveau Louvain) Prof. dr. Johan P. Mackenbach

(Erasmus MC Rotterdam) 


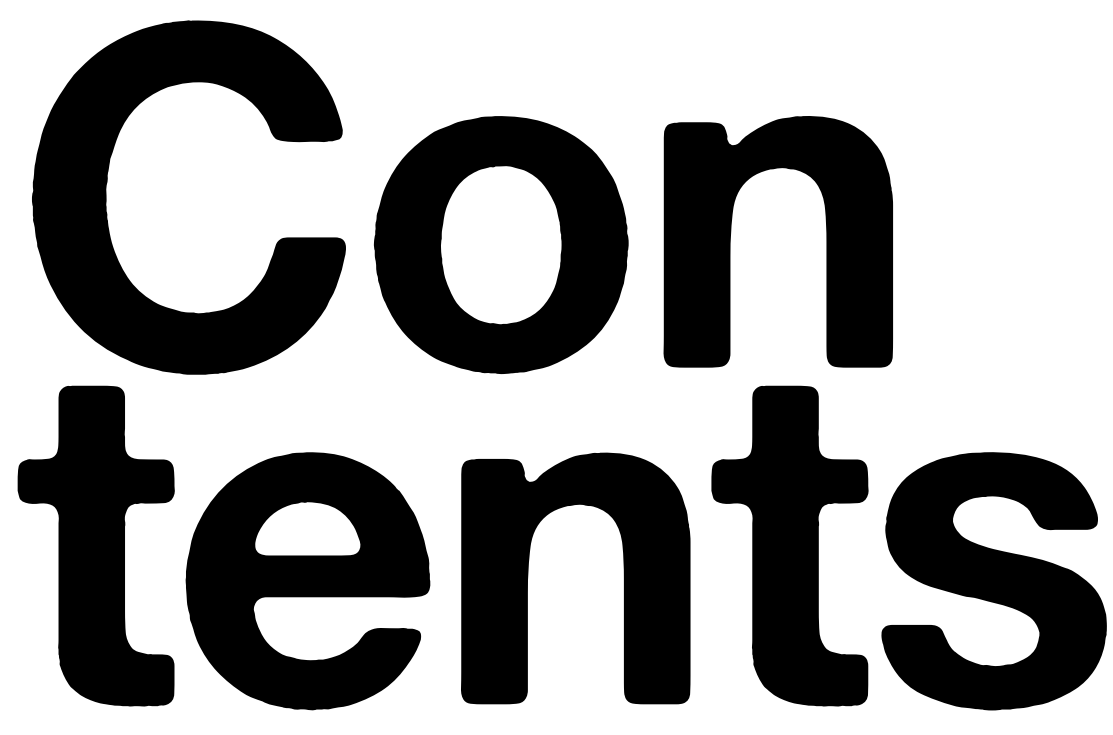

Summary

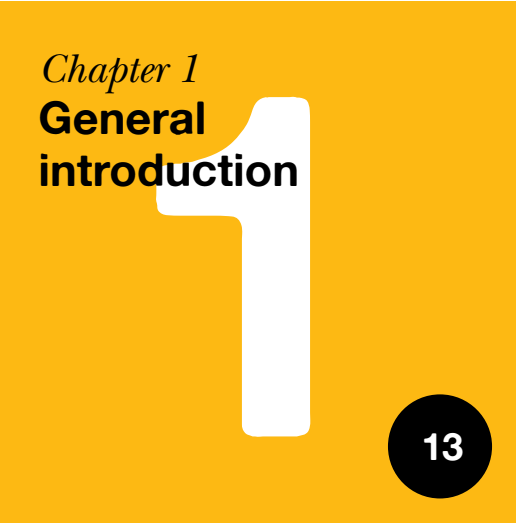

Chapter 3

Interplay between

intra- and inter-

personal level

of influence

The effects of pubertal and

psychosocial timing on

adolescents' alcohol use

and the role of alcohol-

specific parenting
Chapter 2

Intrapersonal level

of influence

Associations between

drinking motives and

changes in adolescents

alcohol consumption

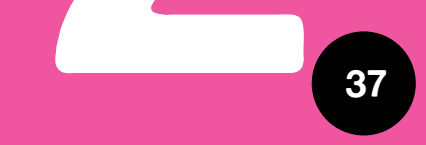

Chapter 4

Interplay between

intra- and inter-

personal level

of influence

Is the effect of early pubertal

timing on alcohol initiation

mediated by peers

and/or parents?

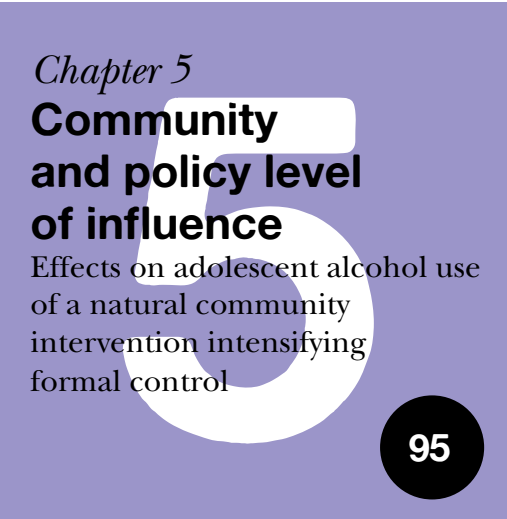

\section{Chapter 6}

Organizational, community and policy level of influence

Effects on adolescent alcohol use of a community intervention combining intensified formal and informal

control

\section{Chapter 7}

Organizational, community and policy level of influence

Effects on retailers and parents

of a community intervention

combining intensified

formal and informal

control

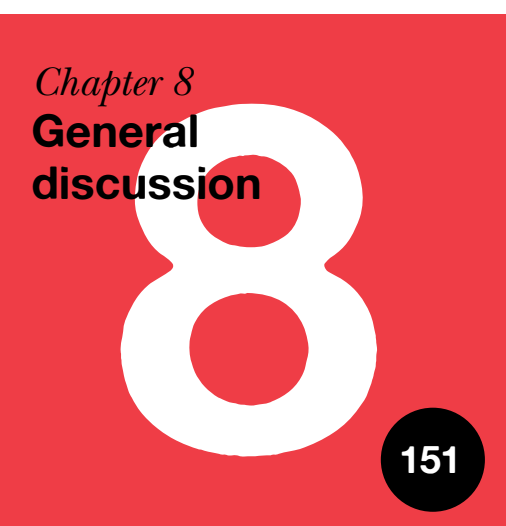




\section{Preface}

Adolescence

is the transition from

childhood to adulthood

where numerous

developmental changes

occur. It is also a period

where most people initiate

alcohol use and where the

foundations of later

drinking habits are laid.

Nevertheless,

that adolescents are at

high risk for harmful

consequences of alcohol

is undisputed.

The harm caused by the continuing high alcohol consumption of adolescents emphasizes the need for improvement of strategies for the prevention of adolescent alcohol use. In this thesis, the social ecological paradigm is used as an overarching theoretical framework. This paradigm, which combines intrapersonal and environmental factors at several ecological levels, is used to gain more insight into the development of adolescent alcohol use and effective alcohol prevention strategies. 


\section{Chapter 1 General introduction}




\section{Adolescent alcohol use and its consequences}

In high-income countries, alcohol use is one of the leading risk factors for burden of disease among adolescents aged 10-19 years (WHO, 2004). There are many risks involved when initiating alcohol and heavy drinking at a young age.

Early adolescent alcohol use has been associated with acute effects such as violent and delinquent behavior (Komro, Tobler, Maldonado-Molina, \& Perry, 2010; Van Der Linden \& Knibbe, 2006), risky sexual behavior (Hingson, Heeren, Winter, \& Wechsler, 2003; Tapert, Aarons, Sedlar, \& Brown, 2001; Wechsler, Davenport, Dowdall, Moeykens, \& Castillo, 1994), traffic accidents (Jones-Webb, Fabian, Harwood, \& Toomey, 2004; Sindelar, Barnett, \& Spirito, 2004), alcohol poisoning (Wilsterman, Dors, Sprij, \& Wit, 2004), and suicide attempts (Swahn, Bossarte, Ashby, \& Meyers, 2010). These effects are mostly due to heavy alcohol intake at one occasion. In addition, heavy alcohol use of adolescents is associated with impairment of brain development (executive functions) and related learning abilities (Bava \& Tapert, 2010; Clark, Thatcher, \& Tapert, 2008). On the long term, heavy adolescent alcohol use increases the risk for impairment of liver functions (Ramstedt, 2001; Rehm, Room, et al., 2003), later alcohol abuse and dependence (Grant, et al., 2006; Hingson, Heeren, \& Winter, 2006; Wells, Horwood, \& Fergusson, 2004), and diverse types of cancer (Rehm, Room, et al., 2003; Singletary \& Gapstur, 2001). Alcohol use additionally causes harm to the well-being and health of people around the drinker, such as in traffic accidents or violent behavior inflicted by the drinker (WHO, 2011). Furthermore, death, disease, violence, crime and injury caused by adolescent alcohol consumption have socioeconomic impacts, including medical costs for governments, financial and psychological burden to families, and costs for the justice and law enforcement sectors (WHO, 2011).

\section{Adolescent alcohol use in Dutch context}

In the Netherlands, the prevalence of drinking alcohol at young ages is high; $56 \%$ of adolescents already reported drinking alcohol at the age of 12 (Monshouwer, Verdurmen, Van Dorsselaer, Smit, \& Vollebergh, 2008). In the age group of 12-14 years, one out of three Dutch adolescents drink alcohol regularly and one out of five drink heavily (5+ glasses at one drinking occasion) (Monshouwer, et al., 2008). Also, compared with other adolescents in Europe, Dutch adolescents rank among the largest consumers of alcohol (Hibell, et al., 2007). This high drinking prevalence of young Dutch drinkers might be associated with the liberal social norms and policies in relation to adolescent alcohol use in the Netherlands (Brand, Saisana, Rynn, Pennoni, \& Lowenfels, 2007). In the Netherlands, the legal purchase age is 16 years for light alcoholic beverages $(<15 \%$ alcohol) and 18 years for strong alcoholic beverages ( $\geq 15 \%$ alcohol). This is the case for most European countries, such as Germany or Belgium, however, lower than the legal drinking age in the USA or legal purchase age in New Zealand. Furthermore, it is not illegal for Dutch adolescents to purchase alcohol, but it is illegal to sell alcoholic beverages to underage adolescents. Since 2000, retailers are obliged to verify the age of the customer before selling alcohol to them. Inspections under the Dutch Alcohol Licensing and Catering Act are conducted nationally by the Food and Consumer Product Safety Authority (FCPSA) in the Netherlands. With approximately 40 FCPSA inspectors nation-wide, enforcement efforts are generally low (frequency of inspection of maximum once a year). Pseudo-patron research in the Netherlands shows that it is very easy for underage adolescents to purchase alcohol themselves (Gosselt, Van Hoof, De Jong, \& Prinsen, 2007). Furthermore, it is rather common for parents in the Netherlands to drink together with their adolescent children at 
special occasions or family gatherings (Van Der Vorst, 2007). This illustrates that alcohol use is strongly embedded in Dutch culture and is mostly seen as socially accepted behavior, also for adolescents who not yet have reached the legal purchase age. Although in recent years there has been more attention for the prevention of underage drinking in the Netherlands, Dutch adolescents are still exposed to inconsistent messages in their environment and start to drink regularly and heavily at a relatively young age. The harm caused by the continuing high alcohol consumption of adolescents emphasizes the need for improvement of strategies for the prevention of adolescent alcohol use.

\section{Primary prevention of adolescent alcohol use:}

\section{What is effective?}

Primary prevention involves the prevention of harm before it occurs. Primary alcohol prevention efforts are aimed at directly reducing the prevalence and incidence of alcohol use or changing possible determinants of the prevalence and incidence of alcohol use (Staulcup, Kenward, \& Frigo, 1979). In the past decade, most primary alcohol prevention efforts were based on psycho-social

rences influencing the individual demand for alcohol (e.g., beliefs, behavioral intentions or attitudes towards drinking). These individual prevention efforts (see Table 1.1) are characterized by the catchment-area approach, in which the risk factors that individuals may posses are identified and prevention efforts (mostly education) are applied to reduce the individual risk (Holder, 1998). These health education programs directed at individuals have shown no or a limited impact on reducing adolescent alcohol use or harm caused by adolescent alcohol use (Anderson, Chisholm, \& Fuhr, 2009; Foxcroft, Ireland, Lowe, \& Breen, 2011; Foxcroft, Ireland, Lister-Sharp, \& Breen, 2003; Holder, 1998; Van de Luitgaarden, Knibbe, \& Wiers, 2010). Although health education programs play an important role in providing information, they are incomplete in light of the social nature of alcohol use (Skog, 1980). Individual approaches do not sufficiently take into account the drinking environment in which adolescents live, where drinking alcohol is a normative social behavior and is highly tolerated or even promoted. The fact that new cohorts of adolescents show the same risky drinking patterns as older cohorts also suggests that it is likely that deeper social systems attached to alcohol use, rather than individual characteristics, play an important role in explaining drinking behavior (Babor, Caetano, \& Casswell,

2010; Holder, 1998; Wagenaar \& Perry, 1994). Accordingly, the normative and widespread pattern of youth drinking in the Netherlands is most likely largely the result of social, cultural, and economical structures within the community system, such as liberal alcohol policies and social norms in relation to alcohol use. Research has indicated that environmental approaches are effective measures when aiming to minimize the detrimental health and social harm consequences of alcohol use. For instance, increases in the legal drinking age (Wagenaar \& Toomey, 2002), increases in alcohol prices and tax levels (Parry, Myers, \& Thiede, 2003; Wagenaar, Salois, \& Komro, 2009), or government monopolies for the sale of alcohol (Holder, 1998) have shown to reduce alcohol-related harm. These measures have in common that they influence the availability or supply of alcohol. Restricting the supply or availability of alcohol (supply measures) has shown to be a crucial factor in effective alcohol prevention. However, despite the evidence for effectiveness, supply measures are still less popular to be implemented in most western European countries, such as the Netherlands (Babor, et al., 2010).

Table 1.1 Differences between individual and environmental approaches Individual approach

Focus on selection of individuals Focus on the environment or community

Views community as catchment areas

Problem created by individuals Views community as a system

\section{Aim is reducing individual risk} Problem created by the system

Education and information measures Aim is reducing collective risk

Limited impact on alcohol use Supply measures and/or community mobilization

and related problems Long-term impact on alcohol use and related problems

To sum up, from previous research it can be concluded that, although there is much literature on individual risk factors of adolescent alcohol use and abuse, prevention efforts targeting individuals have shown a limited long-term impact on alcohol use and related harm. Furthermore, supply measures restricting alcohol availability have shown promising effects in reducing adolescent alcohol use and related harm in the long run. However, still unclear is through which mechanisms supply measures work and which role intrapersonal factors play in 
this. Also, the effect of more informal ways to restrict alcohol availability for adolescents in their social environment (through parents, schools, etc.) remains underexplored. It is important to deepen theoretical knowledge concerning the development of adolescent alcohol use to gain insight into potentially effective prevention strategies. When it comes to explaining and preventing adolescent alcohol use, a strategy which integrates intra-personal and environmental factors into a multi-level social ecological approach is needed.

\section{The social ecological paradigm}

In this thesis, the social ecological paradigm is used as an overarching framework to understand the interplay between adolescents, their social environments, the legal environment, and the community they live in. Rather than focusing exclusively on either environmental or intrapersonal determinants of behavior, the social ecological paradigm (McLeroy, Bibeau, Steckler, \& Glanz, 1988; Sallis, Owen, \& Fisher, 2008; Stokols, 1996) focuses on multiple levels of influence, and their interplay in relation to health behaviors (represented by the nested circles in Figure 1.1). The levels of influence include the intra-

personal, interpersonal, organizational, community and policy level. The most proximal level of influence, the intrapersonal level, relates to individual factors, such as characteristics, beliefs, perceptions or behavior. The interpersonal level relates to the direct social networks of the individual. Characteristics and processes of organizations are included in the organizational level of influence. The community and policy level is defined in geographical and political terms such that community refers to a population which is concurrent with its power structure (local authorities).

The interplay between the levels of influence can take several forms (Kremers, 2010; Kremers, et al., 2006; Wachs, 1992). First, factors at a given ecological level can directly influence behavior, without influencing related factors at the same or at other ecological levels (unmediated effects). For example, adolescents' early pubertal timing (intrapersonal) can directly affect the risk of adolescents to start drinking alcohol, without influencing (being mediated by) their social environment, such as parental alcohol-specific rule setting (interpersonal level). Secondly, the effects of factors at a given ecological level can be explained by factors at the same or at other ecological levels (mediated effects). For instance, the fact that early pubertal timing adolescents have a higher risk to initiate alcohol use might be explained by parents more quickly practicing lenient rules about alcohol for early pubertal timers. Third, factors at higher ecological levels can moderate the effect of factors at lower, more proximal, ecological levels (higher-order moderation). This means that a factor at a higher ecological level affects the direction and/or strength of the association between a predictor at a lower ecological level and the outcome variable. For example, adolescents in a community with strict alcohol policies might be at reduced risk for (heavy) alcohol use compared with adolescents in a community with liberal alcohol policies. Last, higher-order moderation effects can also be explained or mediated by factors at more proximal levels of influence. For instance, the preventive effect restrictive alcohol policies have on adolescent alcohol use (higher-order moderation effect) might be explained by adolescents perceiving it to be more difficult to purchase alcohol (intrapersonal level) in their community.

One of the limitations of social ecological approaches is that they have not been worked out in great detail because of their complexity (Green, Richard, \& Potvin, 1996). To limit the complexity of such approaches, it is necessary for social ecological models to be behavior-specific and only include the most relevant potential determinants on each level of influence (Sallis, et al., 2008; Stokols, 1996; Stokols, Allen, \& Bellingham, 1996). Insights into the interplay between the levels of influence are important in effective prevention. Although communities are complex, they are also adaptive systems (Holder, 1998).The social ecological paradigm constitutes that triangulation or multi-level interventions should be most effective in attaining behavioral change in complex systems such as communities (Sallis, et al., 2008). Therefore, there is a need for research investigating where the high leverage points in prevention lie; which combinations of interventions at different ecological levels result in the greatest decrease of adolescent alcohol use and related harm.

\section{There is a need for research investigating where the high leverage points in prevention lie.}


Figure 1.1 Social ecological paradigm based on McLeroy, et al. (1988)

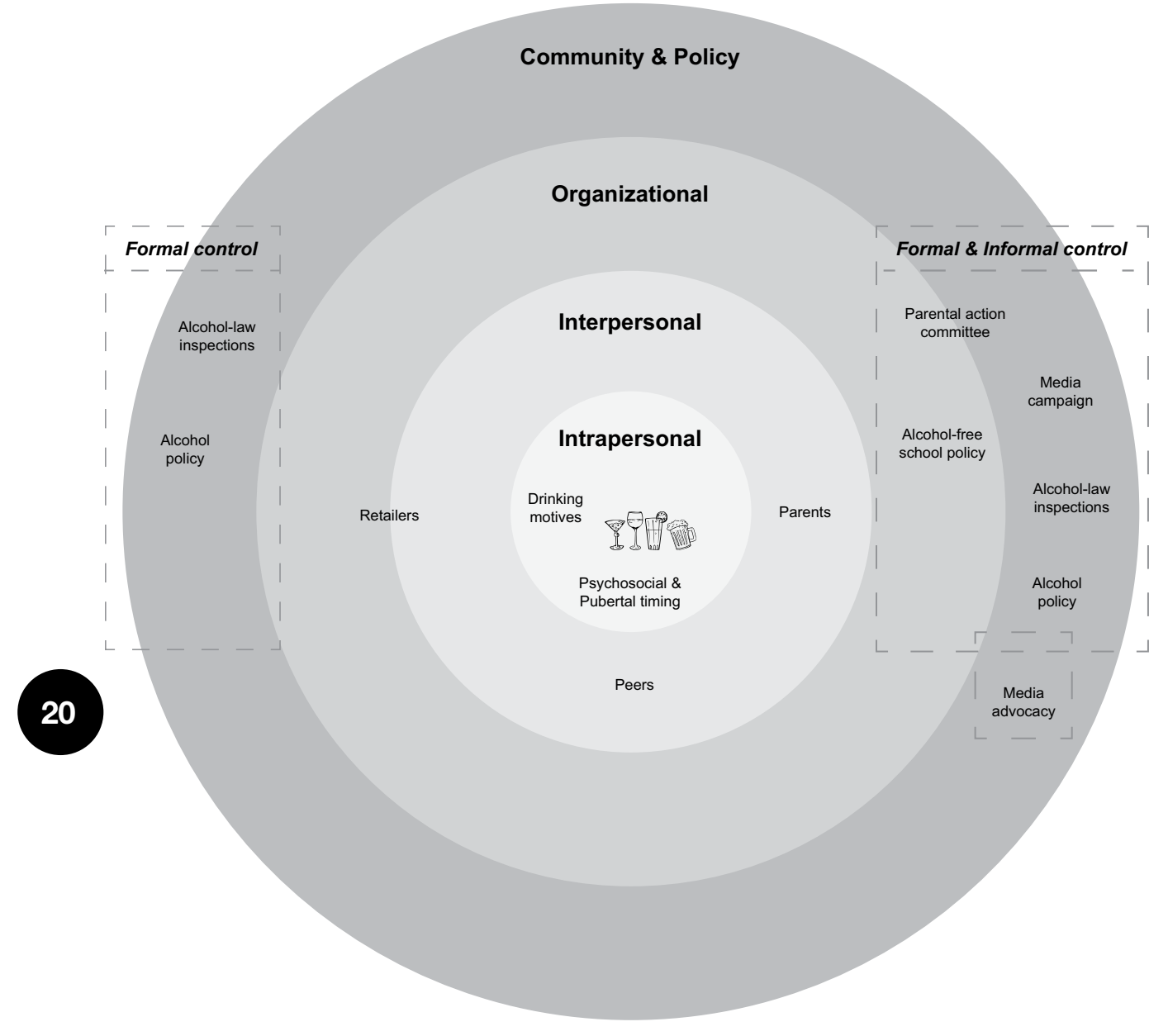

\section{Important determinants related to adolescent alcohol use}

It goes beyond the scope of this thesis to build a complete social ecology model which explains all relevant determinants at each level of influence related to the development and prevention of adolescent alcohol use. However, specific relevant determinants related to adolescent alcohol use were chosen at each level of influence (see Figure 1.1). The decision for relevant determinants on the intra- and interpersonal level of influence was influenced by my personal interest in putting adolescent alcohol use into a developmental perspective. Adolescence is for most people the most crucial period for the development of their drinking habits. Not only do most people initiate drinking in this period of their life, studies have also shown a profound increase in alcohol use between 13 and 17 year old adolescence (Rachal, et al., 1975). Therefore, adolescence is a critical period in relation to prevention, which could benefit from more detailed knowledge on the development of alcohol use. Why most people start drinking during adolescence, despite all the hazards involved with adolescent alcohol use, was of particular interest to me. Adolescence is the transitional phase from childhood to adulthood which normally takes place from around 10 until 18 years (Graber, Nichols, \& Brooks-Gunn, 2010). Numerous developmental and environmental changes occur during adolescence (Graber, et al., 2010; Lenz, 2001). As an adolescent, your body changes into an 'adult body' (pubertal development) which will incite different reactions from your social surroundings, you will feel the urge to get more autonomy, make your own choices independently from your parents (psychosocial development), you will process new environments (e.g., high school), widen your social circle (e.g., meet lots of new friends in high school), and begin to spend more time with your peers than your parents. Furthermore, also the brain goes through developmental changes during adolescence. Particularly during early adolescence, substantial changes take place in the maturation of the brain's dopaminergic systems associated with processing social information (Casey, Jones, \& Hare, 2008). Because during adolescence these dopaminergic systems are not yet fully developed, this leads to increased sensation seeking and reward sensitivity during early to mid adolescence. Cognitive control processes such as executive functions responsible for decision making and emotion regulation are 'under construction' across the adolescent decade and are fully developed at the age of approximately 24 years (Steinberg, 2008).

Conducting this thesis, I wanted to gain more insight into how the developmental changes uniquely related to adolescence, could influence the initiation and later use of alcohol. Therefore, at the intrapersonal level I choose to investigate the individual differences in the timing of puberty and psychosocial development in relation to alcohol use. Also, drinking motives were investigated in this thesis at the intrapersonal level, known as the most proximal factors related to alcohol use (Cooper, 1994; Cox \& Klinger, 1988, 1990, 2004; Kuntsche, Knibbe, Gmel, \& Engels, 2005). Other intrapersonal factors related to alcohol use, such as adolescents' behavioral intentions, alcohol expectancies, and attitudes towards drinking were not chosen as important determinants in the current 
thesis, for the reason that these factors have shown to be only limitedly usefu in adolescent alcohol prevention (Anderson, et al., 2009; Foxcroft, et al., 2011 Foxcroft, et al., 2003; Van de Luitgaarden, et al., 2010). This may be due to the fact that these concepts are used in preventive health education programs which require voluntary behavioral changes from adolescents. However, adolescents are not yet able to oversee the long-term consequences of their alcohol use due to the not (yet) completely developed brain's executive and decision making functions in adolescents (Graber, et al., 2010). Furthermore, alcohol use has also positive effects for adolescents, especially the feeling of being more sociable, self-confident, and more mature (Pape \& Hammer, 1996; Van Der Vorst, 2007). Therefore, most adolescents probably do not feel the need to intentionally change their drinking behavior.

At the interpersonal level, the influence of socialization processes in the direct environment of adolescents (peers and parents) were included in this thesis, since previous studies have shown that parents and peers are of great importance in the development of adolescent substance use (Bot, Engels, Knibbe, \& Meeus, 2007; Engels, Knibbe, De Vries, Drop, \& Van Breukelen, 1999; Van Der

Vorst, 2007).

At the organizational, community, and policy level, factors were chosen which are most promising in terms of alcohol prevention based on scientific literature, including factors which can influence the social (through parents) and legal (enforcement of the minimum purchase age) availability of alcohol for adolescents.

The intra- and interpersonal level of influence are investigated through observational studies. The organizational, community and policy levels of influence are investigated by means of an intervention study. In this intervention study, the preventive effects on adolescent alcohol use of two multi-component community-based interventions (at the organizational, community and policy levels of influence) will be evaluated. The interventions efforts were aimed at increasing formal (intensifying alcohol-law enforcement and local alcohol policy) and informal control (alcohol-free school policies and stimulating parents to remain strict in alcohol-specific rule setting) thereby reducing the alcohol availability for adolescents. Also, media advocacy and a media-campaign were part of the interventions. In the next sections the important determinants for adolescent alcohol use investigated in this thesis will be discussed for the intrapersonal level of influence, the interplay between the intra- and interpersonal level of influence, and the organizational, community and policy level of influence. Furthermore, for each of these levels will be discussed how this thesis contributed to current knowledge.

\section{Intrapersonal level of influence}

\section{Drinking motives}

Drinking motives are people's final decision to drink and are the most proximal factors to alcohol use (Cooper, 1994; Cox \& Klinger, 1988, 1990, 2004; Kuntsche, et al., 2005). Drinking motives are based on the affective change people expect to attain from drinking, which can be either gaining a positive or avoiding a negative affect (Cox \& Klinger, 1988, 2004). Furthermore, the source of drinking motives can be roused internally or externally. Accordingly, drinking motives are classified into four motive dimensions (Cooper, 1994): drinking to achieve social rewards (social motives: positive, external, e.g., to better enjoy a party), drinking to enhance positive moods (enhancement motives: positive, internal, e.g., to have fun or to get drunk), drinking to avoid social rejection (conformity motives: negative, external, e.g., to fit in with a peer group) and drinking to cope with negative emotions (coping motives; negative, internal, e.g., to forget about problems). These motive dimensions are characterized by unique patterns of drinking behavior (Cooper, 1994; Cooper, Agocha, \& Sheldon, 2000; Kuntsche, Knibbe, Gmel, \& Engels, 2006, 2007; Kuntsche, Stewart, \& Cooper, 2008). Social motives are associated with moderate drinking rates, enhancement motives with heavy drinking rates and coping motives with drinking problems, as well as heavy drinking rates (Cooper, 1994; Cooper, et al., 2000; Kuntsche, et al., 2006, 2007).

\section{Unresolved issues at the intrapersonal level of influence}

Although there are several cross-sectional studies indicating that drinking motives are associated with alcohol use, longitudinal studies are scarce. Furthermore, up to now no longitudinal study has tested the longitudinal power of drinking motives towards alcohol when additionally controlling for reversed causality (i.e. previous drinking behavior changing drinking motives over time). Thus, it is still unknown whether drinking motives predict future alcohol use, when controlling for previous behavior and reversed causality. In this thesis I aimed to answer this question by investigating the true predictive power of 
drinking motives, controlling for reversed causality, in a Dutch sample of drinking adolescents. As drinking motives are assumed to be the most proximal factors related to alcohol use it is expected that they are susceptible for change and could therefore be an important target for prevention.

\section{Interplay between the intrapersonal and interpersonal level of influence}

\section{Pubertal and psychosocial timing}

Pubertal and psychosocial development are two major developmental changes that occur during adolescence (Lenz, 2001; Pinyerd \& Zipf, 2005). The physical changes which take place during early adolescence are referred to as pubertal development. Puberty is a period marked by rapid changes in body size, shape, and composition. It also refers to the maturation of the reproductive system that occurs during adolescence. In normal puberty, hormone secretion changes dramatically, which regulates the growth, development and function of the testes in boys and the ovaries in girls. Under normal circumstances, the onset

of puberty usually corresponds to a biological age of approximately 11 years in girls and 13 years in boys (Pinyerd \& Zipf, 2005). Early pubertal timing (onset relative to same-aged and same-gender peers) has already been associated with an early initiation of alcohol use and increased alcohol use later in adolescence (Biehl, Natsuaki, \& Ge, 2007; Costello, Sung, Worthman, \& Angold, 2007; Lanza \& Collins, 2002; Pieters, Van Der Vorst, Burk, Wiers, \& Engels, 2010; Wichstrom, 2001).

Psychosocial development can be described by three capacities: individual adequacy, a person's ability to function effectively on their own; interpersonal adequacy, a person's ability to interact adequately with others; and social adequacy, the responsibility people take for their own survival and self-sufficiency (Greenberger, Josselson, Knerr, \& Knerr, 1975; Greenberger \& Sorensen, 1974). These capacities can be translated to specific developmental tasks, i.e. personal, relational, and socio-institutional tasks (Dekovic, Noom, \& Meeus, 1997; Palmonari, Kirchler, \& Pombeni, 1991). Personal tasks, relate to for example forming an own identity by acquiring autonomy through e.g., choosing own clothing and music style, and also relates to how people cope with everyday life situations. Establishing stable and intimate relationships are examples of relational tasks. Socio-institutional tasks are concerned with the completion of a school career, preparation of integration into a work setting, achieving economic independence, and the preparation for having an own family (Dekovic, et al., 1997). Up to know, there are no studies which investigated whether an earlier psychosocial timing (personal, relational, or socio-institutional timing) is related to adolescent alcohol use. However, some researchers imply that an important step for youths towards the adult social status could involve alcohol use, suggesting that early psychosocial timing, besides pubertal timing, might positively influence the initiation and development of alcohol use (Lanza \& Collins, 2002; Moffitt, 1993).

\section{The role of peers}

During adolescence, relationships with peers become more important for adolescents. In scientific literature, friends have shown to be similar in drinking behavior (Bot, et al., 2007; Engels, et al., 1999). From a peer socialization perspective, this similarity in drinking behavior is explained by the role model peers serve for their friends (Bandura, 1977). Peers may persuade their adolescent friends to use alcohol (Schulenberg, et al., 1999). On the other hand, from a peer selection perspective it is considered that peers select their friends based on similar drinking behavior (e.g., Abar, 2010; Engels, et al., 1999; Poulin, Kiesner, Pedersen, \& Dishion, 2011; Sieving, Perry, \& Williams, 2000; Urberg, Luo, Pilgrim, \& Degirmencioglu, 2002).

\section{The role of parents}

Although there has been a stronger focus on the influence of peers when it comes to adolescent alcohol use, parents also play an important role (Van Der Vorst, 2007). Parents can influence their child's drinking behavior by their own use, which is known as modeling (Bandura, 1977) or by their parenting practices (Duncan, Duncan, \& Strycker, 2006; Ellickson, Tucker, Klein, \& McGuigan, 2001; Van Der Vorst, Engels, Dekovic, Meeus, \& Vermulst, 2007). Parenting practices affect adolescents' developmental processes in several ways. Adolescent alcohol use can be shaped by the way their parents raise them (general parenting practices) (Barnes, Reifman, Farell, \& Dintcheff, 2000; Baumrind, 1980; Van Der Vorst, et al., 2007). In addition, alcohol-specific parenting practices, such as alcohol-specific rules (Jackson, Henriksen, \& Dickinson, 1999; Van Zundert, Van Der Vorst, Vermulst, \& Engels, 2006) play a specific important role when it comes to children's development of alcohol use. Longitudinal research indicated that alcohol-specific rule setting is directly related to the onset 
of adolescent alcohol use and seems to depend on the way parents generally monitor their children (Van Der Vorst, et al., 2007). Parents who set strict rules on alcohol could delay the initiation of alcohol use of their children. Providing alcohol-specific rules even seems to be the most influential form of alcoholspecific socialization on adolescent alcohol use (Van Der Vorst, Engels, Meeus, Dekovic, \& Van Leeuwe, 2005).

\section{Unresolved issues concerning the interplay between the intra- and interpersonal level}

Several studies have already indicated that early pubertal timers are more at risk to initiate alcohol use and have higher consumption levels as to non-early pubertal timers. However, no studies have investigated whether an earlier timing of psychosocial development (personal, relational, or socio-institutional) also increases the risk of adolescents to use alcohol. Therefore, in this thesis it is investigated whether both early pubertal and psychosocial timing are related to adolescent alcohol use.

It should be noted that pubertal and psychosocial timing in itself are normative

developmental transitions and therefore no targets for prevention. However, pubertal and psychosocial developmental transitions do not occur in a social vacuum but take place in a diverse and changing environment. Adolescents receive feedback on their developing bodies and minds from for instance their parents, peers, or their teachers. Parental monitoring, amongst other factors, varies by pubertal maturation (Westling, Andrews, Hampson, \& Peterson, 2008). Parents seem to alter their expectations for their children and grant greater independency based on adolescents' physical appearance alone (Bulcroft, 1991). Furthermore, it has been suggested that early pubertal timers affiliate more with older, already drinking peers (Patton, et al., 2004; Stattin \& Magnusson, 1990; Westling, et al., 2008). However, the exact social mechanisms potentially explaining the link between early pubertal and psychosocial timing and adolescent alcohol use still needs further clarification. In this thesis I focused on the interplay of these developmental processes within a broader social context, including parents and peers.

\section{Organizational, community and policy levels of influence}

\section{Formal control}

Perhaps the most important environmental factor which influences alcohol use is the availability or accessibility of alcohol. Alcohol availability has shown to be a strong predictor of alcohol use (Paschall, Grube, \& Kypri, 2009; Popova, Giesbrecht, Bekmuradov, \& Patra, 2009; Wagenaar \& Toomey, 2002). If alcohol is easy accessible, consumption will generally be higher than when the accessibility of alcohol is limited.

The extent to which alcohol is formally available is mostly determined by governments of a given country or region. Three types of formal alcohol availability can be distinguished; physical, economic and legal alcohol availability (Van Hoof, 2010). First, physical alcohol availability refers to the outlet density and operating hours in an environment. Most studies confirmed that higher outlet density is associated with higher alcohol consumption and increased incidences of assault, homicide, child abuse and neglect, and self-inflicted injuries in a given region (Chen, Gruenewald, \& Remer, 2009; Chikritzhs \& Stockwell, 2002; Kuntsche, Kuendig, \& Gmel, 2008b; Livingston, Chikritzhs, \& Room, 2007).

Secondly, price and tax regulations of alcohol are referred to as economical availability. There is much scientific evidence that higher prices of alcohol are associated with lower drinking levels and less alcohol-related harm (Farrell, Manning, \& Finch, 2003; Kuo, Wechsler, Greenberg, \& Lee, 2003; Markowitz \& Grossman, 1998, 2000; Van den Berg, et al., 2008; Wechsler, Kuo, Lee, \& Dowdall, 2000). Last, legal availability refers to official legislation measures and laws in relation to alcohol use and the conditions under which alcohol use are sold (Van Hoof, 2010). For example, age limits for drinking and/or purchasing alcohol are applied to decrease the legal alcohol availability of alcohol for underage adolescents to protect them from drinking alcohol. A review including 132 studies published between 1960 and 1999 (Wagenaar \& Toomey, 2002), indicated that higher age limits lead to decreases in adolescent alcohol consumption. Furthermore, a higher legal drinking age has shown to decrease alcohol-related harm, such as decreases in road fatalities, juvenile crime, assaults, and drunkenness convictions (Wagenaar, 1993).

However, when regulations such as the minimum drinking or purchase age are not enforced, they will unlikely be effective (Reynolds, Holder, \& Gruenewald, 1997). Prevention efforts aimed to decrease alcohol supply by intensifying 
enforcement on alcohol-laws have shown promising long-term alcohol prevention results (Anderson, et al., 2009; Babor, et al., 2010; Holder, 1998; Holder, et al., 2000; Stafström, Östergren, Larsson, Lindgren, \& Lundborg, 2006; Wagenaar, Murray, \& Gehan, 2000b; Wagenaar, et al., 2000a). Furthermore, next to enforcement, also social support is needed in order for formal and informal control measures to be effective and implemented.

\section{Informal control}

A type of alcohol availability which has received much less attention in research is the accessibility of alcohol in people's social networks and the standard norms and values in relation to alcohol in a given social environment. This type of alcohol availability is the informal type of alcohol availability called social availability.

Social sources (parents, peers, other adults) have shown to be the most common source of alcohol for young drinkers, whereas commercialized sources become more important at older ages (Harrison, Fulkerson, \& Park, 2000; Hearst, Fulkerson, Maldonado-Molinac, Perry, \& Komro, 2007; Hemphill, Munro, \&

Poh, 2007; Williams \& Mulhall, 2005). Parents can be an important social source for young adolescents to obtain alcohol (Harrison, et al., 2000; Hearst, et al., 2007; Wagenaar, et al., 1993). In the Netherlands, of the 13 until 15 year old Dutch adolescents almost $60 \%$ obtains alcohol from their parents (SchellemanOffermans, Knibbe, \& Derickx, 2009b). Furthermore, research has indicated that easy access to alcohol at home is related to increases in adolescent alcohol consumption (Van Der Vorst, et al., 2005; Williams \& Mulhall, 2005).

Measures to decrease social availability are referred to as informal control, such as advising parents to remain strict in general monitoring and alcohol-specific rule setting for their children, or schools to implement alcohol-free school policies. Preventative efforts specifically targeting parental rule setting (informal control) have shown to be effective in reducing and postponing adolescents alcohol use (Koning, et al., 2009; Koutakis, Stattin, \& Kerr, 2008; Smit, Verdurmen, Monshouwer, \& Smit, 2008).

\section{The role of the media}

Awareness of the problems caused by alcohol use can stimulate the community's support and need for implementing effective control measures. The media can play a crucial role in raising this awareness. Strategic use of the media, also called media advocacy, can increase public support and move policy goals forward, which in turn can facilitate structural changes within a community (Holder \& Treno, 1997). This is done by making use of local data to support news stories which can reframe public debate about alcohol use and alcohol policies (Wallack, 1990). Furthermore, media campaigns can also be used to stimulate the environment (e.g., parents or retailers) to restrict alcohol availability. However, although campaigns and media advocacy are of value in a wider prevention strategy, it is by itself not sufficient to reduce alcohol consumption and related harm.

\section{Community-based interventions to reduce adolescent alcohol use}

Community based interventions to reduce adolescent alcohol use consist of concerted action and/or policy to mobilize formal and informal control at the community and policy level. Prevention at the local or community level has several advantages. First, the intention of local communities to prevent alcohol-related harm can be seen as a personal matter, since they personally experienced the harm caused by alcohol use. For this reason, local communities could have higher intentions to implement effective alcohol policy. Secondly, to which extent alcohol-law enforcement is prioritized, is mostly determined at the local level. In the Netherlands, local authorities are responsible for alcohol licensing in their communities and can even apply complementary measures to restrict licensing procedures for retailers in their communities. Third, it is more feasible to intervene at community-level than at, for example, the national or even global level. Internationally, few community based interventions have focused on adolescent alcohol use. Most of them were conducted in the USA. The Communities Mobilizing for Change on Alcohol (CMCA) community intervention was a randomized-controlled trial including 15 communities in the USA (Wagenaar, et al., 2000b; Wagenaar, et al., 2000a). CMCA focused on reducing youth access to alcohol through a community-based approach including local authorities, enforcement agencies, alcohol retailers, the media, schools and other community stakeholders. CMCA showed to be effective in reducing alcohol consumption for 15-17 year old adolescents, arrests for driving under the influence, and disorderly conduct violations (Wagenaar, et al., 2000b; Wagenaar, et al., 2000a).

Another multi-component intervention called Project Northland conducted in the USA included classroom curricula on alcohol and other drug use, a parent training program and peer leadership (Stigler, Perry, Komro, Cudeck, 
\& Williams, 2006). The outcome of Project Northland was promising. In the intervention communities, the drinking onset age was delayed and young adolescents that had already started to drink did not increase their consumption (Perry, et al., 2002).

The 5 -year Community Trials Project (CTP), conducted in the USA, was originally designed to target the total population (Holder, et al., 2000; Holder, et al., 1997). The intervention components targeting adolescent alcohol use in the CTP involved (a) increased enforcement on underage sales of alcohol, (b) media-advocacy, and (c) responsible beverage server trainings for retailers. Decoy operations, where underage adolescents instigate retailers to sell alcohol to them, showed decreases in sales to underage adolescents in the intervention regions, however, the same decrease in underage sales was found in the control regions (Grube, 1997). Results of the population surveys revealed significant decline in heavy drinking and alcohol-related traffic accidents in the intervention regions, compared with the control regions (Holder, et al., 2000).

A regional community action intervention conducted in New Zealand focused on (a) monitoring alcohol sales made without age verification from off-license premises, (b) media advocacy, and (c) encouraging increased monitoring and enforcement the minimum purchase age legislation (Huckle, Conway, Casswell, \& Pledger, 2005). Results of this intervention showed decreased sales to minors, increased media coverage, and increased use of effective enforcement strategies. However, since no control region was included in this study, no firm conclusions can be drawn about the effectiveness of the intervention efforts.

In Europe, only few studies are conducted evaluating the effectiveness of intensifying formal and informal control to prevent adolescent alcohol use. Furthermore, all of these intervention studies were conducted in Nordic countries, known for their more restrictive alcohol policies compared with western European countries such as the Netherlands. One of these European community-based projects called PAKKA in Finland (Holmila \& Warpenius, 2007) used multiple prevention components targeting adolescent alcohol, including responsible server trainings, retail surveillance, and education to increase community awareness about heavy drinking. A decline in self-reported drinking was found, however, this decline did not differ from the decline in the matched control communities.

Another community-based intervention study conducted in Europe is the Swedish Trelleborg Project (Stafström, et al., 2006). This intervention study made use of a formal (intensified enforcement on the alcohol-laws) and informal (restrict social availability from parents) control measures and resulted in reductions in youth harmful drinking.

Overall, it can be concluded that most studies investigating restricting retail and/or social availability of alcohol for adolescents have shown promising results in terms of effectiveness. However, since all of these studies are conducted in countries with generally more restrictive alcohol policies than most western European countries (Brand, et al., 2007), validation in countries with more liberal alcohol policies is needed.

\section{Unresolved issues at the organizational, community and policy level}

There are studies which already have shown promising alcohol prevention results in relation to restricting the alcohol availability for adolescents at the organizational, community and policy level of influence. However, cultural coverage of this research is somewhat restricted. Community interventions using formal control measures aimed at preventing adolescent alcohol use are mostly conducted in Northern-American countries, New Zealand, and Northern European countries. Although there is a growing number of regional and local alcohol prevention initiatives in the Netherlands (e.g., in the regions Eindhoven, Deventer, and Winterswijk), none of these initiatives are accompanied by an effect evaluation including following a cohort of adolescent, parents and alcohol sellers, and making use of a control region. Thus, up to now, there are as yet no projects allowing evidence-based conclusions about the effectiveness of intensifying formal and informal control in the Netherlands. Also, most of the already conducted community studies investigating the effectiveness of control measures used multiple cross-sectional measurements to assess outcomes, which give limited insight into the intermediate processes causing the reported behavioral effects. Furthermore, the possible effectiveness of restricting community-wide the alcohol access for adolescents from social sources such as parents or caregivers has limited research evidence.

This is the first Dutch study which is able to draw evidence-based conclusions about the effectiveness of intensifying formal and informal control. Evidence from such intervention studies conducted in a country with relatively liberal alcohol policies (Brand, et al., 2007) and social norms is important for demonstrating the cross-national validity of the effectiveness of these control measures. 
In addition, the longitudinal data of this study allows for mediation analyses. Such analyses give more insight into how different ecological levels of influence are involved in prevention of adolescent alcohol use.

\section{Design of the main intervention study of this thesis}

In the main study of this thesis a quasi-experimental design was used including three Dutch communities; two intervention communities, and one comparison community (see Table 1.2). The first intervention community implemented intensified formal control only. The second intervention community used a combined approach including media advocacy and increasing both formal and informal control. We were not able to focus on all supply measures which have shown to be associated with adolescent alcohol use and related harm, since we had only restricted time (two years), resources, and political authorization. Furthermore, since this is an evaluation of multi-component interventions, it was only possible to investigate the combined effect of the intervention components.

Table 1.2 Intervention components for each community in the main intervention study

\begin{tabular}{|l|c|c|c|}
\hline & $\begin{array}{c}\text { Community I } \\
\text { region }\end{array}$ & $\begin{array}{c}\text { Community II } \\
\text { Cegion }\end{array}$ & $\begin{array}{c}\text { Community III } \\
\text { region }\end{array}$ \\
\hline Retail 'hotspot' inventory & + & + & + \\
\hline Media advocacy & - & + & - \\
\hline Formal control & & & - \\
\hline Restrictive alcohol policy & + & + & - \\
\hline Intensified alcohol-law inspections & + & + & - \\
\hline Informal control & & & - \\
\hline Media campaign & - & + & - \\
\hline Alcohol-free school policy & - & + & - \\
Mobilizing parents into & - & + & \\
a parental committee & & & \\
\hline
\end{tabular}

Formal control was enhanced by two intervention components at the community and policy level of influence (see Figure 1.1). First, the frequencies of inspections were intensified on the legal minimum purchase age in off- and onlicensed premises attracting adolescents (so-called retail 'hotspots').
Secondly, a restrictive local alcohol policy was implemented in which local authorities would withdraw liquor licenses of those retailers repeatedly infringing the law forbidding them to sell alcohol to underage adolescents. Inspections on the minimum legal purchase age were conducted by the Food and Consumer Product Safety Authority (FCPSA). Whenever a retailer does not comply with the law, the FCPSA can fine the retailer and will report the non-compliance to the local authorities. Before the intervention period started, an exploratory inspection (not followed up by warning or fines) was conducted in all three communities to make an inventory of all retail 'hotspots'. 'Hotspots' in the two intervention regions were visited at least 8 times during the two year intervention period. Informal control was enhanced by three intervention components, and was supported by the Dutch Institute for Alcohol Policy. First, at the community level of influence a group of parents in the community was mobilized to form a parental action committee. They used a website and several actions (e.g., at markets and high schools) to inform parents about the negative health consequences of adolescent drinking, to stimulate parents to maintain strict alcoholspecific rules, and communicate with other parents to create an informal network with shared restrictive norms towards adolescents alcohol use. Secondly, at the organizational level the local health professionals advised high schools in the community to formulate and implement an alcohol-free school policy, which entailed that alcohol use was no longer tolerated at school parties or other events. Third, at the community level of influence a local media campaign was implemented. This campaign aimed to provide parents with information on health consequences of adolescent drinking and alcohol-specific parenting guidelines, using posters, magazines, leaflets, gadgets (e.g., reusable shopping bags) and selective advertisements on Facebook.

At the community and policy level of influence media advocacy was used. Local authorities used the outcomes of community and enforcement actions for press releases (e.g., actions of the parental committee, alcohol-free school policies, or inspection results of the FCPSA). This was done to maintain political agenda setting, increasing social support, supporting acceptance of restrictive control measures, and increasing the perceived likelihood of apprehension for alcohol sellers to get fined for selling to underage adolescents.

Effects of the interventions were evaluated by following a cohort of adolescents, one of their parents and sellers of alcohol for a period of two years (baseline in 2008 and two yearly post-measurements) in all three communities. 
The adolescents were initially 13-15 years old. Adolescents were interviewed before the intervention started and one, respectively two years after the intervention started. Parents and sellers of alcohol were interviewed before the intervention started and two years later.

\section{Outline of this thesis}

This thesis describes six empirical studies (see Table 1.3 for an overview). The aim of the first three empirical studies (Chapter 2, 3, and 4) was to improve theory and implications for prevention regarding the links and interplay between important determinants at the intra- and interpersonal level and adolescent alcohol use. The aim of the last three empirical studies (Chapter 5,6 , and 7) was to investigate the effectiveness of two community interventions, one only intensifying formal control, and one intensifying both formal and informal control. The first empirical study (Chapter 2) investigates the longitudinal predictive power of drinking motives on adolescent alcohol use at the intrapersonal level of influence. The second empirical study (Chapter 3 ) is a cross-sectional study investigating the interplay between pubertal timing, psychosocial timing, pa-

rental alcohol-specific rule setting, and adolescent alcohol use. In this study i

is investigated whether the link between early pubertal and psychosocial timing (intrapersonal level of influence) and alcohol use is either mediated and/or moderated by the alcohol-specific rules parents set for their adolescent children (interpersonal level of influence). The third empirical study (Chapter 4) sheds more light onto the mechanism behind the link between early pubertal timing (intrapersonal level of influence) and alcohol initiation, by including two mediation paths through changes in parental alcohol-specific rules and the proportion of drinking peers in the peer group at the interpersonal level of influence. In the fourth empirical study (Chapter 5) the effects of intensifying formal control on adolescent alcohol use are investigated. In this study we included factors at community and policy levels of influence (intervention components) and a the intrapersonal level of influence (adolescent alcohol use, purchase behavior, and perceived ease of purchasing alcohol). Furthermore, mediation pathways were tested investigating whether the intervention effects were due to changes in intermediate intervention goals over time. In Chapter 6 the fifth empirical study is described, which investigated the effects of combining formal and informal control in a community-wide approach on adolescent alcohol use. Also, the effects of the intervention on intermediate intervention goals were investigated
Table 1.3 Overview of the empirical studies presented in this thesis

\begin{tabular}{|c|c|c|c|c|c|}
\hline Chapter & Subject & $\begin{array}{l}\text { Level of } \\
\text { influence }\end{array}$ & Participants & Design & $\begin{array}{l}\text { Data } \\
\text { waves }\end{array}$ \\
\hline 2 & $\begin{array}{l}\text { Longitudinal } \\
\text { associations between } \\
\text { drinking motives and } \\
\text { alcohol use }\end{array}$ & Intrapersonal & $\begin{array}{l}\text { Drinking } \\
\text { adolescents } \\
\text { aged 13-16 } \\
\text { years }\end{array}$ & Longitudinal & $\begin{array}{l}2008, \\
2009\end{array}$ \\
\hline 3 & $\begin{array}{l}\text { Associations between } \\
\text { pubertal timing, } \\
\text { psychosocial timing, } \\
\text { and parental alcohol- } \\
\text { specific rule setting } \\
\text { and alcohol use }\end{array}$ & $\begin{array}{l}\text { Intra- and } \\
\text { interpersonal } \\
\text { level }\end{array}$ & $\begin{array}{l}\text { Adolescents } \\
\text { aged 13-15 } \\
\text { years }\end{array}$ & $\begin{array}{l}\text { Cross- } \\
\text { sectional }\end{array}$ & 2008 \\
\hline 4 & $\begin{array}{l}\text { Longitudinal } \\
\text { associations between } \\
\text { pubertal timing, } \\
\text { parental alcohol- } \\
\text { specific rules, propor- } \\
\text { tion of drinking peers } \\
\text { in the peer group, } \\
\text { and alcohol initiation }\end{array}$ & $\begin{array}{l}\text { Intra- and } \\
\text { interpersonal } \\
\text { level }\end{array}$ & $\begin{array}{l}\text { Adolescents } \\
\text { aged 13-16 } \\
\text { years }\end{array}$ & Longitudinal & $\begin{array}{l}2008- \\
2010\end{array}$ \\
\hline 5 & $\begin{array}{l}\text { Effects of intensifying } \\
\text { formal control on } \\
\text { adolescent alcohol } \\
\text { use }\end{array}$ & $\begin{array}{l}\text { Intrapersonal, } \\
\text { community, } \\
\text { and policy level }\end{array}$ & $\begin{array}{l}\text { Adolescents } \\
\text { aged 13-17 } \\
\text { years }\end{array}$ & Longitudinal & $\begin{array}{l}2008- \\
2010\end{array}$ \\
\hline 6 & $\begin{array}{l}\text { Effects of intensifying } \\
\text { formal and informal } \\
\text { control on adolescent } \\
\text { alcohol use }\end{array}$ & $\begin{array}{l}\text { Intra- and } \\
\text { interpersonal, } \\
\text { organizational, } \\
\text { community, } \\
\text { and policy level }\end{array}$ & $\begin{array}{l}\text { Adolescents } \\
\text { aged 13-17 } \\
\text { years }\end{array}$ & Longitudinal & $\begin{array}{l}2008- \\
2010\end{array}$ \\
\hline 7 & $\begin{array}{l}\text { Effects of intensifying } \\
\text { formal control on } \\
\text { norms, attitudes and } \\
\text { behavior of parents } \\
\text { and retailers }\end{array}$ & $\begin{array}{l}\text { Intra- and } \\
\text { interpersonal, } \\
\text { organizational, } \\
\text { community, } \\
\text { and policy level }\end{array}$ & $\begin{array}{l}\text { Adolescents } \\
\text { aged 13-17 } \\
\text { years, one } \\
\text { of their } \\
\text { parents, and } \\
\text { retailers }\end{array}$ & Longitudinal & $\begin{array}{l}2008- \\
2010\end{array}$ \\
\hline
\end{tabular}


In this study, factors from all ecological levels of influence are included. In the last empirical study (Chapter 7) effects of combining formal and informal control on norms, attitudes, and behavior of retailers and parents were investigated. Also, in this study all ecological levels of influence are included. Chapter 8 provides an overview and discusses the results of the six empirical studies presented in chapter 2 to 7 . Additionally, limitations will be discussed, as well as implications and recommendations for alcohol prevention and policy. Last, a general

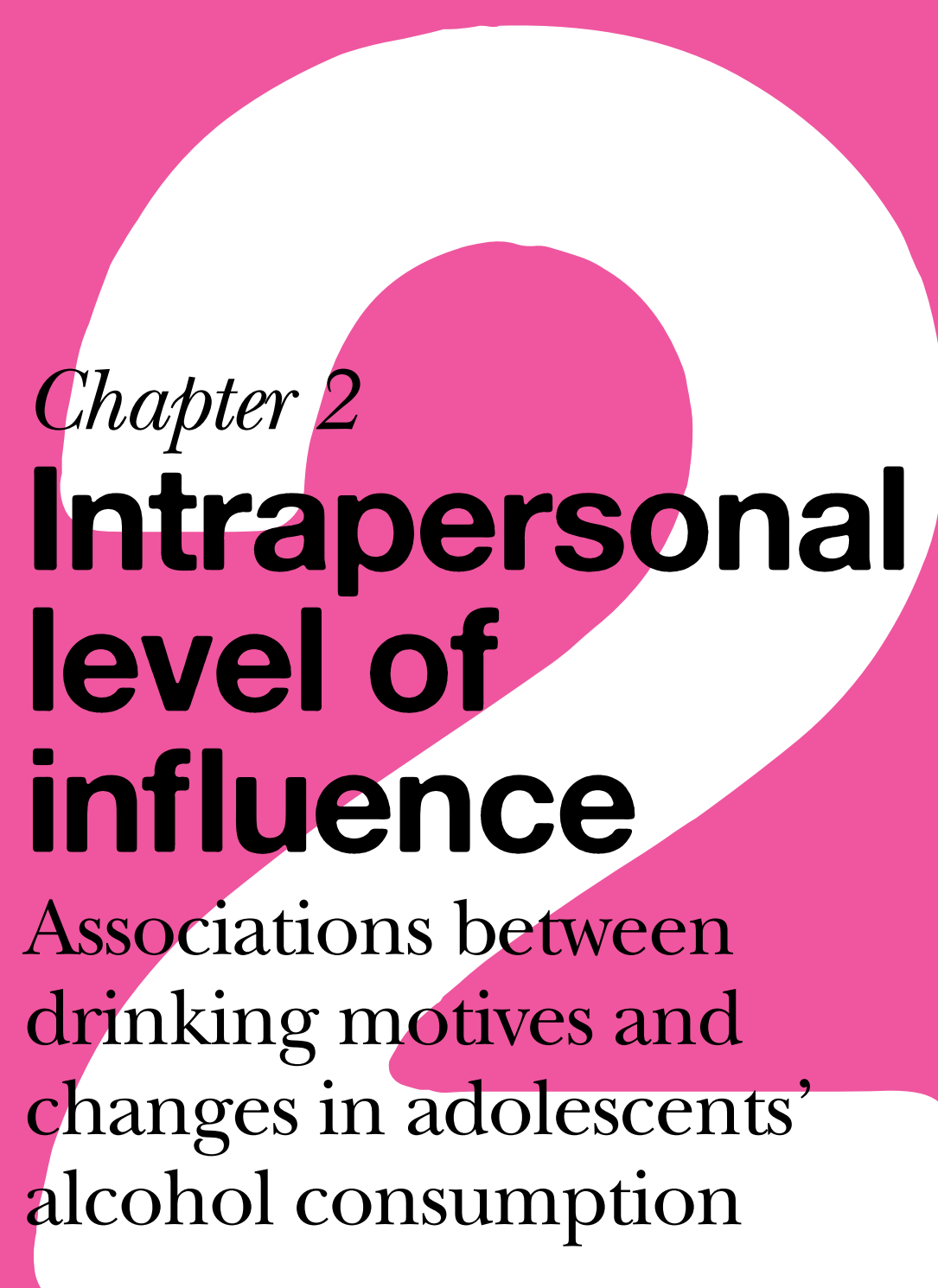

Published as

Schelleman-Offermans, K. Kuntsche, E. \& Knibbe, R. A. (2011). Associations between drinking motives and changes in adolescents' alcohol consumption: A full cross-lagged panel study. Addiction. 106, 1270-1278. 


\section{Abstract}

Aims Longitudinal full cross-lagged models are essential to test causal relationships. This study used such a model to test the predictive value of internal (enhancement and coping) and external (conformity and social) drinking motives for changes in alcohol use over time, and tested possible reversed causality (i.e. alcohol use explains later drinking motives).

Design Longitudinal data consisting of two waves (separated by one year) were used to estimate cross-lagged structural equation models.

Setting Three comparable (regarding urbanization and social stratification) Dutch communities.

Participants A total of 454 alcohol-using adolescents aged 13-16 years (mean $=14.8$ years, $\mathrm{SD}=.78$ ) at wave 1 .

Measurements Standardized questionnaires including the Drinking Motive Questionnaire Revised, and items on total weekly consumption and frequency of heavy episodic drinking.

Findings In adolescence, drinking motive preferences are already relatively stable over time. Also, only social motives significantly predicted increases in total weekly consumption and frequency of heavy episodic drinking. No feedback mechanisms by which alcohol consumption explains later drinking motives scores were found.

Conclusions Among drinking adolescents in a wet drinking culture, such as the Dutch drinking culture, social drinking motives, rather than enhancement or coping motives for drinking, appear to predict overall consumption and frequency of heavy episodic use a year later. Parents and other important social actors have an active role in reducing alcohol availability and monitoring adolescents' drinking.

\section{Introduction}

The personal risks and societal costs of adolescents' alcohol use are high (Gmel, Rehm, Room, \& Greenfield, 2000; Rachal, Guess, Hubbard, \& Maisto, 1982; Tapert, Schweinsburg, \& Barlett, 2004). Nevertheless, most people start drinking alcohol regularly and riskily during adolescence (Kuntsche, Rehm, \& Gmel, 2004).

The Motivation Model of Alcohol Use (MMAU) suggests that drinking motives, people's final decision to drink, are the most proximal factors to alcohol use (Cooper, 1994; Cox \& Klinger, 1988, 1990, 2004; Kuntsche, et al., 2005). Therefore, motives are assumed to be easier to change than more distal factors (Kuntsche, et al., 2006), and also reflect more distal factors related to alcohol use, such as alcohol expectancies and personality (Cooper, et al., 2000; Kuntsche, et al., 2007). Hence, drinking motives are important targets for the prevention of alcohol-related problems and abuse.

According to the MMAU, drinking motives are based on the affective change people expect to attain from drinking, which can be either gaining a positive or avoiding a negative affect (Cox \& Klinger, 1988, 2004). Furthermore, the source of drinking motives can be roused internally or externally. Accordingly, drinking motives are classified into four motive dimensions (Cooper, 1994): drinking to achieve social rewards (social motives: positive, external, e.g., to better enjoy a party), drinking to enhance positive moods (enhancement motives: positive, internal, e.g., to have fun or to get drunk), drinking to avoid social rejection (conformity motives: negative, external, e.g., to fit in with a peer group), and drinking to cope with negative emotions (coping motives; negative, internal, e.g., to forget about problems). These motive dimensions are characterized by unique patterns of drinking behaviour. Social motives are associated with moderate drinking rates, enhancement motives with heavy drinking rates, and coping motives with drinking problems as well as heavy drinking rates (Cooper, 1994; Cooper, et al., 2000; Kuntsche, et al., 2006, 2007; Kuntsche, Stewart, et al., 2008). 
However, regarding the associations between drinking motives and alcohol use, most evidence is based on cross-sectional data. Only few prospective studies are conducted. Three prospective studies confirmed the link between coping motives and increases in alcohol consumption or drinking problems for adolescents (Cooper, et al., 2008), medical students (Richman, Flaherty, \& Pyskoty, 1992), and adults (Carpenter \& Hasin, 1998). Two other longitudinal studies (Read, Wood, Kahler, Maddock, \& Palfai, 2003; Schulenberg, O’Malley, Bachman, Wadsworth, \& Johnston, 1996), in which parts of the MMAU were tested in a sample of college students, showed that only enhancement motives played an etiological role in heavy drinking; no significant results were found for social and coping motives. Another longitudinal study among adolescents showed that higher scores on enhancement motives predicted heavy drinking 5-12 years later (Cooper, et al., 2008). An additional longitudinal study confirmed the link between enhancement motives and drinking quantity among college student also for three week follow-up periods (Mohr, et al., 2005).

Although cross-sectional studies testing the association between drinking motives and alcohol use showed consistently strong links, none of the above lon-

gitudinal studies included these links in their tested models. To date, only two longitudinal studies (using a North-American and a Swiss sample) showed that enhancement motives predicted future heavy drinking, even after controlling for earlier drinking habits (Cooper, et al., 2008; Kuntsche \& Cooper, 2010). Yet, to test causality and make reliable statements about the predictive power of drinking motives for future drinking, both autoregressive and cross-lagged paths must be included when modelling the effects of motives on alcohol use and vice versa, to exclude the possibility of reversed causality (Taris, 2000). To our knowledge, no study has investigated drinking motives and alcohol use in a full cross-lagged model. Nevertheless, from a theoretical point of view, reversed causality from earlier alcohol use towards later drinking motives is plausible. In the MMAU, feedback processes are conceptualized that either foster or inhibit later drinking through modified drinking motives (Cox \& Klinger, 1988, 2004). It is suggested that drinking motives depend on, or might even be shaped by, past drinking experiences and reinforcement (Kuntsche, et al., 2006). Thus, it is plausible that adolescents first experience the psycho-active properties of alcohol before they use alcohol more functionally or habitually, e.g., as mood enhancer or stress reliever.

This study aims to replicate findings from previous cross-sectional and longitu- dinal studies on drinking motives and alcohol use in which auto-regressive paths from alcohol use and drinking motives were not included. Secondly, this study aims to investigate whether drinking motives predict future alcohol use when controlling for previous alcohol use and, finally, to examine reversed causality, i.e. to test the predictive power from prior alcohol use to changes in drinking motives. To our knowledge, this study is the first to test this important causality question using a full cross-lagged model, including all auto-regressive paths regarding alcohol use and drinking motives.

\section{Methods}

\section{Study design and participants}

This is a longitudinal study consisting of two data collection waves (T1, T2) separated by one year. A random sample of 6,944 adolescents, stratified on age (13-15 years) and gender, was drawn from the population registers of three comparable (regarding urbanization and social stratification) Dutch communities. All randomly sampled adolescents were approached until the intended sample size ( $\mathrm{N}=1,980$; about 660 respondents in each community) was reached, which required three approaches. After these three approaches, $20.4 \%$ of all randomly sampled adolescents actively refused to participate, $29.6 \%$ agreed to participate, and $50.0 \%$ was not further approached, because the intended sample size was reached.

Several inclusion criteria were used in this study. First, since drinking motives can only be assessed among drinkers, participants had to report drinking alcohol in the last six months. Second, participants had to report at least three out of five items within one motive dimension. These inclusion criteria resulted in an analytic sample of 641 adolescents (31.2\%) at T1 (Figure 2.1). At T2, 100 adolescents $(15.6 \%)$ from the initial analytic sample dropped out. Binary logistic regression analysis showed no selective response regarding total weekly consumption, frequency of heavy episodic drinking, drinking motives, gender, and age. However, significantly more attrition was found in one of the communities $(\mathrm{OR}=.54 ; \mathrm{p}=.04)$, and among adolescents with lower educational level $(\mathrm{OR}=$ $.54 ; \mathrm{p}=.02)$. In the remaining sample of 541 adolescents at T2, $58(10.7 \%)$ adolescents were excluded because they stopped drinking between $\mathrm{T} 1$ and $\mathrm{T} 2$, and $29(5.4 \%)$ adolescents provided insufficient information on drinking motives or frequency of heavy episodic drinking at T2. Adolescents who stopped drinking 
between $\mathrm{T} 1$ and $\mathrm{T} 2$ were mostly light drinkers at $\mathrm{T} 1$ showing a low prevalence $(\mathrm{N}=3 ; 5.2 \%)$ of frequency of heavy episodic drinking and low $(<2$ glasses a week) total weekly consumption $(\mathrm{N}=50 ; 87.2 \%)$. Finally, data from 454 Dutch adolescents (203 boys; $44.7 \%$ ), at baseline aged 13-16 (mean $=14.8$ years, SD $=.78$ ) years, were used in the analyses.

\section{Figure 2.1 Description of the excluded participants}

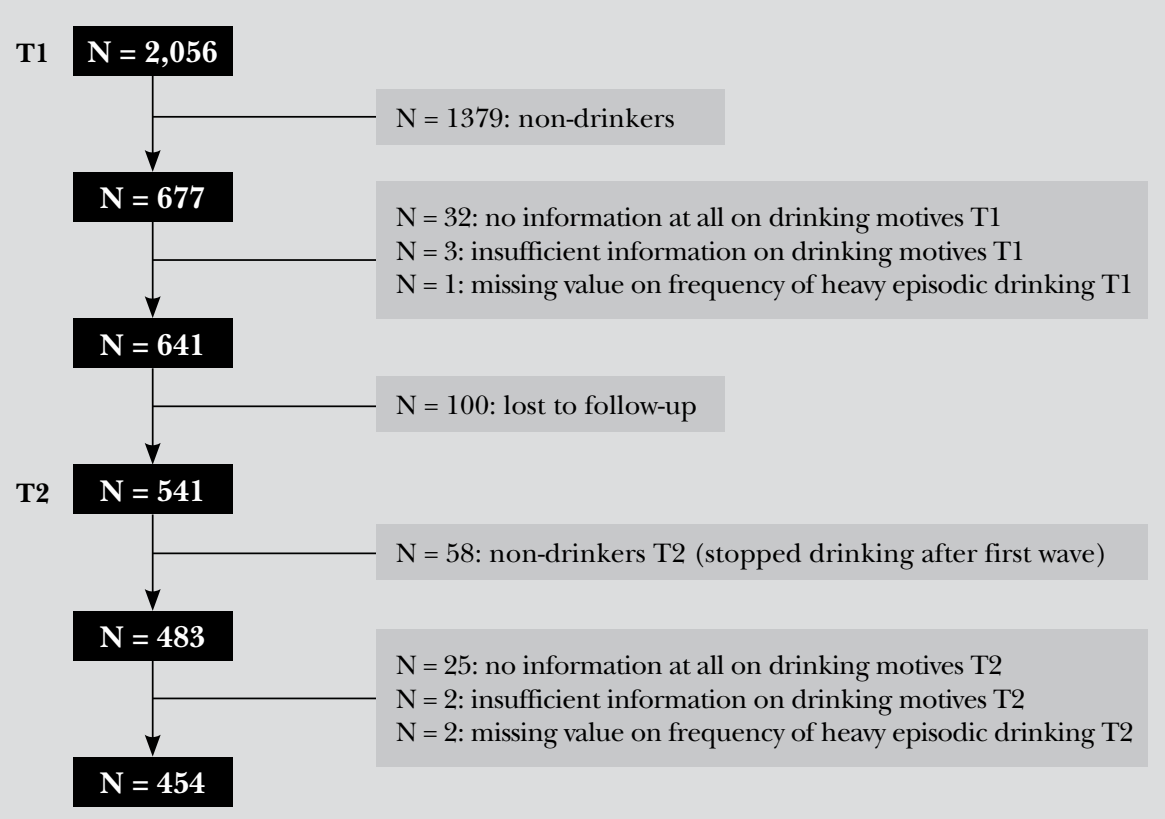

\section{Procedure}

Parental consent of either both parents or caregivers was necessary to participate in the study. In both waves, participants were instructed to complete the questionnaire at home in privacy, put their completed questionnaire in the provided envelop, and then seal it. At T1, fieldworkers were sent to the participant's home address to deliver the questionnaire and they returned later to collect the completed questionnaire in the sealed envelope. At T2, all questionnaires were sent to the participant's home address by mail. Participants were instructed to return the completed questionnaire by mail (gratis) in the reply envelope. At $\mathrm{T} 1$ five euro was given to each participant, and at $\mathrm{T} 2$ three iPods Touch were raffled.

\section{Measures}

\section{Drinking motives}

The Drinking Motive Questionnaire Revised (Cooper, 1994) has 20-items scored on a Likert scale: range $1=$ almost never/never (recoded into 0 ) to $5=$ almost always/always (recoded into 4). There are four different subscales of each five items measuring social motives (Cronbach's $\alpha_{\mathrm{t} 1}=.77 ; \alpha_{\mathrm{t} 2}=.77$ ), enhancement motives (Cronbach's $\alpha_{\mathrm{t} 1}=.82 ; \alpha_{\mathrm{t} 2}=.83$ ), conformity motives (Cronbach's $\alpha_{\mathrm{t} 1}=.78 ; \alpha_{\mathrm{t} 2}=.90$ ), and coping motives (Cronbach's $\alpha_{\mathrm{t} 1}=.88 ; \alpha_{\mathrm{t} 2}=.88$ ). All motive dimensions showed adequate internal consistencies with Cronbach's $\alpha>.70$ (Graham, 2006). Mean scores for motive dimensions were computed by dividing sum scores through the reported valid items.

\section{Total weekly consumption (TWC)}

TWC was measured using a quantity/frequency scale on which participants reported the number of drinking days during usual weekdays from Monday through Thursday: $1=$ I never drink on weekdays (recoded into 0 ), $2=$ less than 1 day (recoded into 0.5 ), $3=1$ day (recoded into 1 ), $4=2$ days (recoded into 2), $5=3$ days (recoded into 3 ), $6=4$ days (recoded into 4 ), and during usual weekend days from Friday through Sunday: $1=$ I never drink on weekend days (recoded into 0), 2 = less than 1 day (recoded into 0.5), $3=1$ day (recoded into 1), $4=2$ days (recoded into 2 ), $5=3$ days (recoded into 3 ), and the number of glasses alcohol they had consumed on a regular weekday and weekend day: range $1=<1$ glass (recoded into 0.5 ) to $16=\geq 15$ glasses (recoded into 15.5), during the last six months. TWC was computed by summing up the alcohol use during weekdays (number of drinking days during the week * number of glasses on weekdays) and during weekend days (number of drinking days during the weekend $*$ number of glasses on weekend days). A log transformation was used in the analyses, since TWC was positively skewed (Tabachnick \& Fidell, 2001).

\section{Frequency of heavy episodic drinking (HED)}

HED was measured by adolescents' self-reports on the frequency they consumed six or more glasses of alcohol on one drinking occasion in the last six months: $1=$ never (recoded into 0 ), $2=$ less than 1 time a month (recoded into 0.5), $3=$ 1 to 3 times a month (recoded into 1.5), $4=1$ to 2 times a week (recoded into 6 ), $5=$ three times or more a week (recoded into 15 ; highest category plus half 
the range to the mid-point of the adjacent category). The cut-off point of six or more glasses is in agreement with other Dutch studies (Van De Mheen, et al., 2006). A log transformation was applied for HED to adjust for positive skewness (Tabachnick \& Fidell, 2001).

\section{Analyses}

Paired sample t-tests were used to assess differences in mean scores of the model variables between the two waves. Maximum likelihood estimation was used to estimate Structural Equation Models with the Mplus 5.2 program (Muthén \& Muthén, 1998-2009) testing cross-sectional, longitudinal and full cross-lagged models including all four drinking motives and alcohol use (i.e. TWC and HED separately) at T1 and T2. All models were estimated excluding participants with missing values. In that case, however, the models were re-estimated using the full information maximum likelihood method in Mplus: any differences between model results are then reported. To control for possible community differences (such as differences in size, location, social stratification, etc.) two dummy variables were included in all tested models, using the largest commu-

\section{Drinking motives are the most proximal factors to alcohol use.}

\section{Results}

\section{Descriptives}

Except for conformity motives, mean scores of drinking motives in the present study were similar to those reported by 13- and 14-year-old adolescents in the study by Cooper (1994). Adolescents more strongly endorsed social and enhancement motives than coping and conformity motives (Table 2.1). Social, coping and enhancement motives significantly increased over time, whereas conformity motives did not.

Table 2.1 Mean frequencies of motives and alcohol use parameters for the first and second measurement

\begin{tabular}{|c|c|c|c|}
\hline $\begin{array}{l}\text { Motives parameters } \\
\text { mean scores }\end{array}$ & T1 mean (SE) & T2 mean (SE) & $t$ \\
\hline Enhancement motives & $.77(.71)$ & $.89(.74)$ & $3.39 * *$ \\
\hline Social motives & $1.04(.84)$ & $1.31(.90)$ & $6.36^{* * *}$ \\
\hline Coping motives & $.28(.55)$ & $.44(.67)$ & $5.20 * * *$ \\
\hline Conformity motives & $.06(.22)$ & $.08(.36)$ & 1.32 \\
\hline $\begin{array}{l}\text { Alcohol use parameters } \\
\text { sum scores }\end{array}$ & T1 mean (SE) & T2 mean (SE) & $\mathbf{t}$ \\
\hline $\begin{array}{l}\text { Total weekly consumption } \\
\text { Frequency of heavy episodic }\end{array}$ & $\begin{array}{r}4.69(7.11) \\
.38(1.34)\end{array}$ & $\begin{array}{r}7.25(8.47) \\
.69(1.60)\end{array}$ & $\begin{array}{l}6.71 * * * \\
4.64 * * *\end{array}$ \\
\hline
\end{tabular}

drinking per month

Note: ${ }^{* * *} p<.001 .{ }^{* *} p<.01 .{ }^{*} p<.05$. d.f. 453. Min $=0$ : (almost) never drank for this motive; $\max =4$ : (almost) always drank for this motive. Representative example: a mean score of 1.2 means between 'some of the time' (coded as 1) and 'about half of the time' (coded as 2).

\section{Cross-sectional structural equation model results}

Figure 2.2 shows the cross-sectional modelling results of TWC and HED at T1. Significant associations were found between enhancement, social and coping motives on the one hand, and TWC and HED on the other. High levels of these motives were associated with a high TWC and HED. However, high levels of conformity motives were significantly related to a low TWC. 
Figure 2.2 Two cross-sectional structural equation models concerning total weekly consumption (TWC) and frequency of heary episodic drinking (HED).

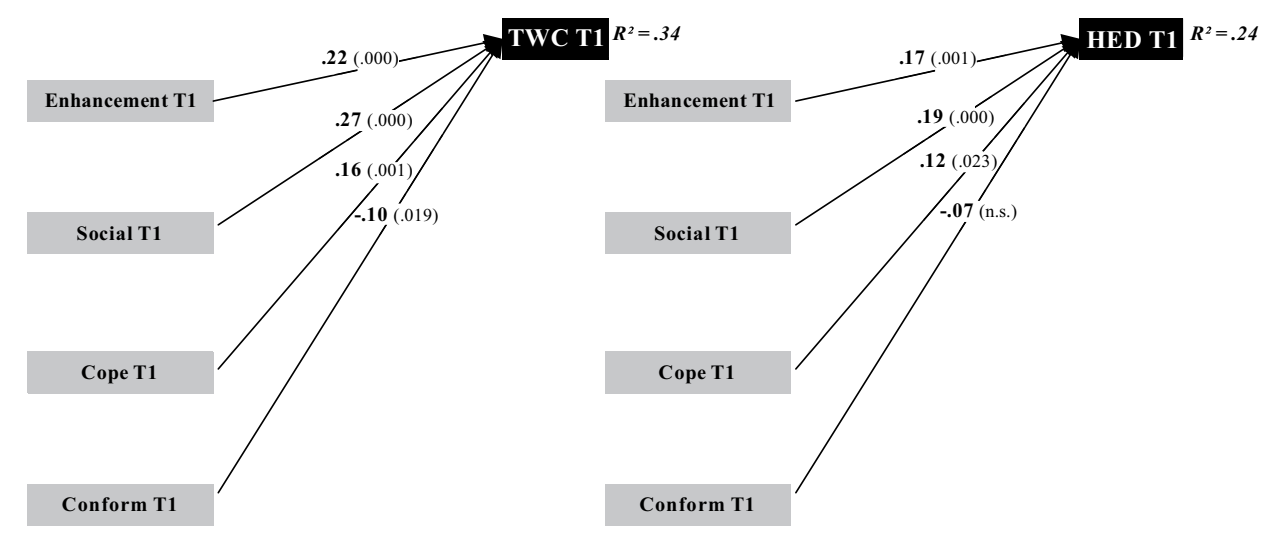

Note: Exact p-values are shown in parentheses. Co-variances between variables were inclu-

ded in the model but omitted from the figure. The covariates gender, education level, community and age of adolescents were included in the model but are omitted from the figure.

\section{Longitudinal structural equation model results}

Results from longitudinal models, excluding auto-regressive paths concerning alcohol use (Figure 2.3), showed that high levels of social and enhancement motives predicted a high TWC and HED one year later. Furthermore, high levels of conformity motives predicted a low future HED. Coping motives showed no longitudinal predictive value for the alcohol use variables in the longitudinal models.

\section{Full cross-lagged structural equation model results}

The final models are presented in Figures 2.4 and 2.5. The results showed that, even within this young age group, motive preferences are relatively stable over time. Furthermore, previous drinking, TWC and HED are the best predictors for drinking rates (TWC and HED) one year later. Regarding the predictive power of drinking motives, the models showed significant cross-paths from social motives at T1 towards TWC $(\beta=.15)$ and HED $(\beta=.14)$ at T2; high levels of social motives predicted a significant increase in TWC and HED one year later.
Figure 2.3 Two longitudinal structural equation models concerning total weekly consumption (TWC) and frequency of heavy episodic drinking (HED); excluding auto-regression paths concerning alcohol use

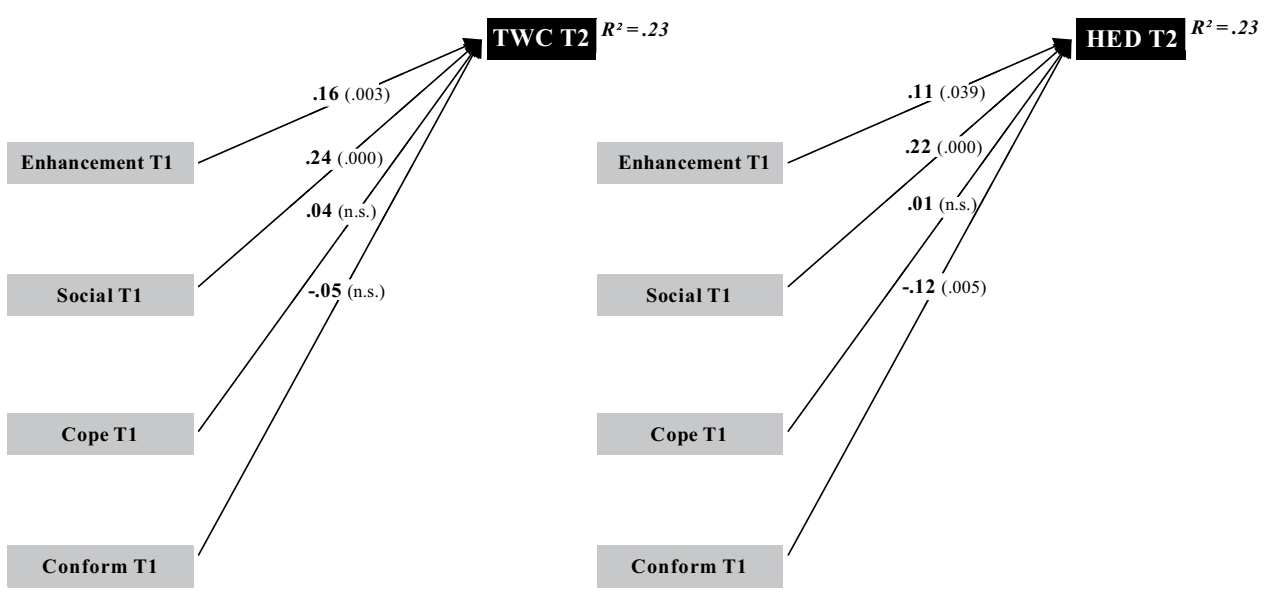

Note: Exact p-values are shown in parentheses. Co-variances between variables were included in the model but omitted from the figure. The covariates gender, education level, community and age of adolescents were included in the model but are omitted from the figure.

On the other hand, high levels of conformity motives $(\beta=-.10)$ predicted significant decreases in future HED. Thus, social and conformity motives predicted changes in TWC and HED one year later, over and above the large effects which previous TWC $(\beta=.33)$ and HED $(\beta=.41)$ had already predicted. Furthermore, within the TWC model, high levels of social motives at the first measurement predicted significant increases in the level of enhancement and coping motives at the second measurement. Also, high levels of coping motives predicted significant increases in the level of conformity motives one year later in both crosslagged models (TWC and HED). Moreover, no reversed causality from TWC and HED towards increases in drinking motives one year later was found. 
Figure 2.4 Full cross-lagged model regarding drinking motives and total weekly consumption $(T W C)$

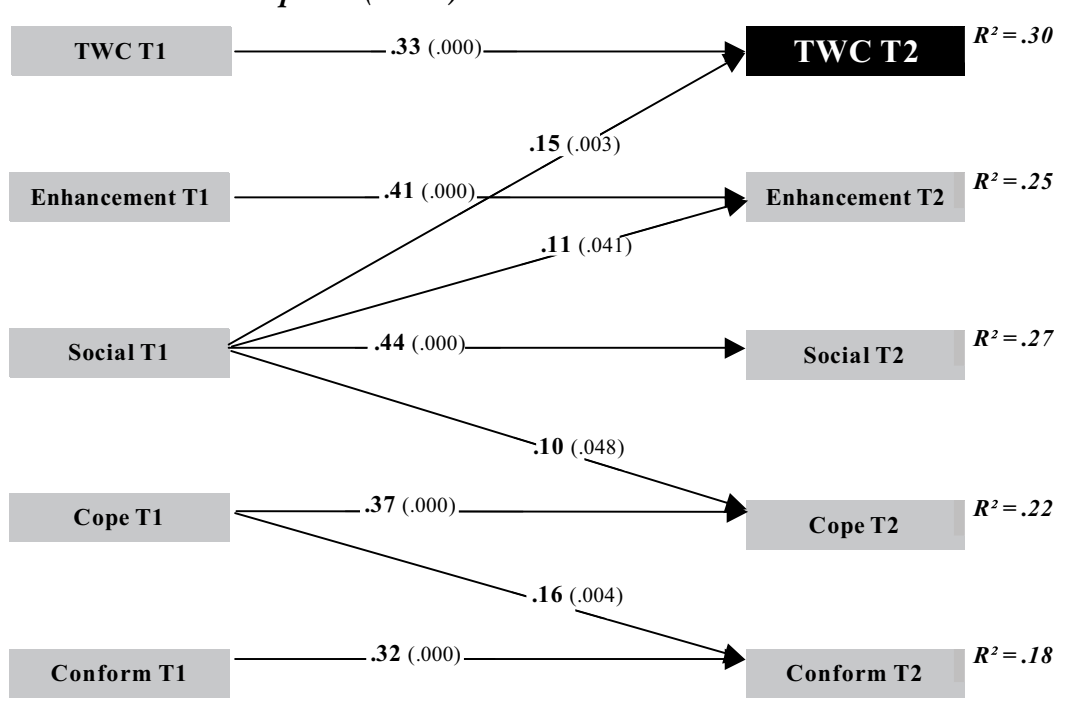

Figure 2.5 Full cross-lagged model regarding drinking motives and frequency of

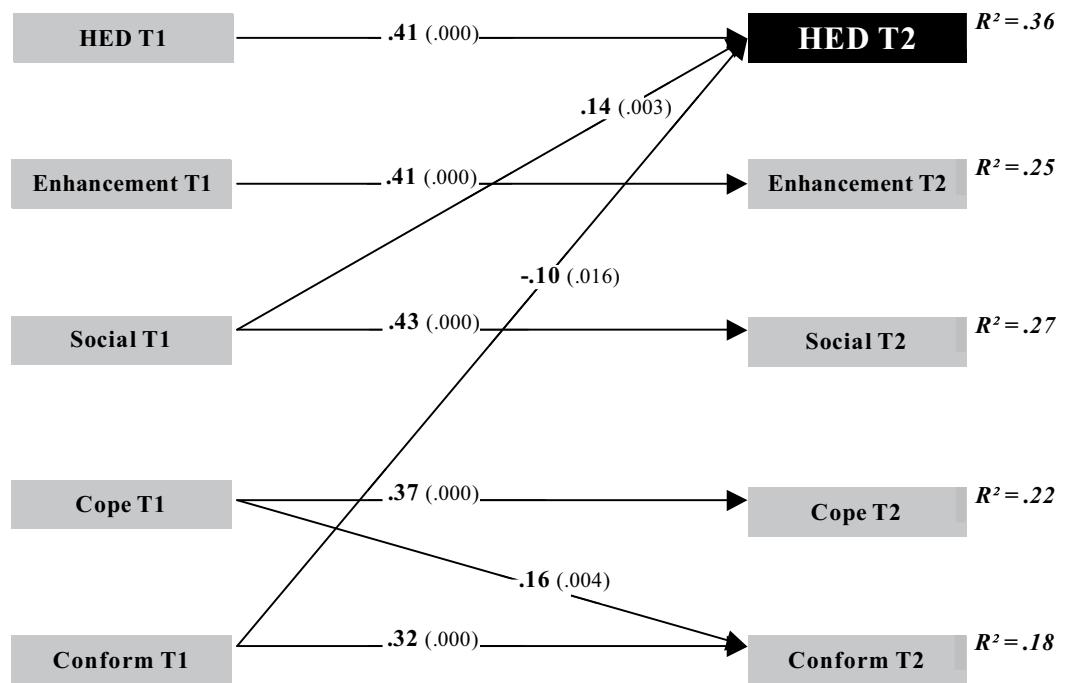

Note: Only significant paths are shown in the figures; exact p-values are shown in parentheses. Co-variances between variables were included in the model but omitted from the figures. The covariates gender, education level, community and age of adolescents were included in the model but are omitted from the figures.

\section{Discussion}

The present study focused on motives of drinking adolescents only. Because the role played by motives in the transference from non-drinking to drinking was not addressed, the results can only be generalized to drinking adolescents. This study aimed to replicate findings from previous cross-sectional and longitudinal studies and to investigate whether drinking motives predict future alcohol use (i.e. TWC and HED), even after controlling for previous alcohol use and possible reversed causality. The cross-sectional and longitudinal models used in this study revealed two results which are similar to earlier conducted studies (Bradizza, Reifman, \& Barnes, 1999; Kuntsche, et al., 2005; Mohr, et al., 2005; Read, et al., 2003). First, in cross-sectional models, the strongest positive associations were found between social, enhancement and coping motives and alcohol use. Second, the results of longitudinal models showed weaker associations between drinking motives and alcohol use than cross-sectional models. Results of the full cross-lagged models indicated that, already in adolescence, drinking motive preferences are relatively stable over time. In addition, no feedback mechanisms from earlier alcohol use towards later drinking motives were detected.

However, feedback mechanisms from earlier alcohol use towards future drinking motives might only be present in younger adolescents who have not yet established a stable drinking pattern or might be detectable only when using a shorter (e.g., $\leq 1$ year) follow-up period.

Drinking motives did indeed predict changes in drinking behaviour, even after controlling for previous alcohol use. The full cross-lagged models revealed that social motives were most predictive for changes in drinking behaviour. This latter result does not concur with findings from studies among North-American samples, where social motives were more associated with moderate alcohol use than with heavy drinking rates.

However, the North-American drinking culture is very different from the Dutch, especially among 13-17-year-olds (Johnston, O’Malley, Bachman, \& Schulenberg, 2009; Van Laar, Cruts, Verdurmen, Van Ooyen-Houben, \& Meijer, 2008). The peer drinking environment of Dutch adolescents is very 'wet'; the norm is to drink heavily in social situations and this is socially accepted (Van de Luitgaarden, et al., 2010). A study showing that $75 \%$ of the alcohol consumption of Dutch adolescents takes place in public drinking places underlines this assumption (Knibbe \& Oostveen, 1991). Another study showed that the 'wet' drinking environment in the Netherlands affects drinking motives; in Dutch 
adolescents social motives were related more strongly to heavy alcohol use than coping motives (Engels, Wiers, Lemmers, \& Overbeek, 2005). This could indicate that, when the drinking environment is wet, social motives are most predictive for future heavy drinking, whereas, when the drinking environment is less wet, enhancement and coping motives are most predictive for future heavy drinking (Kuntsche, et al., 2005).

Furthermore, our results give some insight into the developmental patterns of drinking motives. First, as suggested previously (Kuntsche, et al., 2006), an indication was found for a general development within drinking motives from social (external drinking motive) towards internal drinking motives (enhancement and coping). Younger adolescents might be more responsive to their environment and sensitive for external social rewards than older adolescents. However, this shift in the development of drinking motives was only visible in the cross-lagged model regarding TWC, which questions the robustness of this assumed development. Moreover, unlike suggestions from others (Cooper, 1994; Kuntsche, et al., 2006), in the present study no link from conformity motives (external) towards later internal drinking motives (enhancement or coping) was found. However, this link between conformity and internal drinking motives might only be detectable in adolescents who (unlike the adolescents in this study) have just started to drink and have not yet formed a stable drinking pattern. Second, a shift from coping motives towards future conformity motives was shown in both cross-lagged models (TWC and HED) of this study, which seemed to contradict the assumption that drinking motives generally develop from external towards internal drinking motives. This shift from coping motives towards future conformity motives might be restricted to a selective group of individuals who already in late childhood drink alcohol for coping motives. Studies have shown that youngsters who experienced externalizing difficulties (such as over-activity, aggression or conduct disorder) or social impairment in late childhood are more likely to initiate alcohol use early in life (Kaplow, Curran, \& Dodge, 2002), which might indicate that these individuals start using alcohol to cope with their problems. Later in adolescence, this selective group of individuals might use this (known to them) behaviour to fit in with their peers or to be part of a peer group (conformity motives).

To conclude, even when controlling for earlier drinking rates and possible reversed causality, drinking adolescents who are motivated by social motives (e.g., drinking to better enjoy a party) have a significantly higher TWC and HED one year later. Also, there are indications that the development of drinking motives shifts from social (external) drinking motives towards internal motives later in adolescence. Moreover, we believe this is the first study on drinking motives and alcohol to use cross-lagged modelling with all four drinking motives. Although the effect sizes of the predictive value of motives on drinking may seem modest, they do predict changes in drinking over and above the predictive power of previous alcohol use. From this viewpoint, the results can be considered robust and relevant. Therefore, the present study has made a substantial contribution to our understanding of the dynamics behind adolescent drinking.

\section{Limitations}

The present study has some limitations regarding non-response, attrition, validity of self-reports, theory and statistical generalizability of the results. After recruitment, the non-response within all randomly sampled adolescents may seem high $(70.4 \%)$. However, only $20.4 \%$ of these adolescents actively refused when approached, indicating a limited error due to selective response at T1. The other $50.0 \%$ of these adolescents, who did not respond to our invitations to participate, were not approached further because the intended sample size was reached. Also, the loss to follow-up was relatively small (15.6\%). Another limitation of this study was the selective attrition which was found for educational level and community. However, it is unlikely that this influenced the model results, because these variables were included as covariates in all tested models in this study. Also, no selective attrition was found for either drinking motives or alcohol use. Furthermore, we cannot confirm that the questionnaires were completed without the attendance of parents or caregivers, which could have affected the validity of the self-reports. In addition, this study has limitations from a theoretical viewpoint; the possible influence of implicit motives on alcohol use (Houben \& Wiers, 2008) was not included. Moreover, because only three Dutch communities were involved, it is questionable whether the results from this study can be generalized to all Dutch adolescents who drink alcohol. However, the variation between the three communities did not change the results, which suggests that the results can be generalized to all Dutch adolescents who drink alcohol. More generally it should be stated that, since this is the first study to investigate the predictive value of drinking motives using a full crosslagged model, replication from other countries is needed urgently. 


\section{Implications for prevention}

From a prevention viewpoint, the outcome that social motives strongly predict later drinking of adolescents is remarkable. In many studies, social drinking motives were associated with moderate drinking rather than with increased alcohol consumption (Kuntsche, et al., 2005). Also, the content of the items measuring social motives (e.g., being sociable or celebrating special occasions) seems to match a more responsible way of drinking than, for example, enhancement motives (e.g., drinking to get high) or coping motives (e.g., drinking to forget one's problems). Parents in the Netherland generally believe that socially motivated drinking is not really harmful for their children (Schelleman-Offermans, et al., 2009b). However, this study showed that, among Dutch adolescents, social motives are one of the major forces for adolescents to increase their alcohol consumption in the future. Social drinking among Dutch adolescents apparently takes a form where 'being sociable' or 'celebrating' means participating in situations where much alcohol is consumed. This implies that the general awareness, that also drinking for social drinking is harmful, should be increased in the Netherlands. In terms of preventive actions to reduce alcohol-related

harm, important actors in the external environment of adolescents should be stimulated to reduce alcohol availability and monitor adolescents' drinking as actively as possible. More specifically, parents should be advised to set and enforce sufficient alcohol-specific rules, which has shown to be effective in reducing adolescents' drinking (Van Der Vorst, Engels, Meeus, \& Dekovic, 2006). Another effective strategy to reduce alcohol use would be to implement or enforce more restrictive alcohol policy measures, such as raising the legal age to purchase alcohol, increasing alcohol taxes, and prohibition of financial discounts for, for example, 'happy hours' drinks (Klepp, Schmid, \& Murray, 1996; Maldonado-Molina \& Wagenaar, 2010; O’Malley \& Wagenaar, 1991; Van Hoof, Van Noordenburg, \& De Jong, 2008).
Chapter 3

Interplay between intraand interpersonal level of influence:

The effects of pubertal and psychosocial timing on adolescents' alcohol use and the role of alcoholspecific parenting

Published as

Schelleman-Offermans, K., Knibbe, R. A., Engels, R. C. M. E., \& Burk, W. J. (2011). The Effect of Pubertal and Psychosocial Timing on Adolescents' Alcohol Use: What Role does Alcohol-specific Parenting play? Journal of Youth and Adolescence, 40, 10, 1302-1314. 


\section{Abstract}

In scientific literature, early pubertal timing emerges as a risk factor of adolescents' drinking, whereas alcohol-specific rules (the degree to which parents permit their children to consume alcohol in various situations) showed to protect against adolescents' drinking. This study investigated whether alcohol-specific rules mediate and/or moderate the effect that early pubertal and psychosocial timing (personal, relational, socio-institutional) has on adolescents' alcohol use. Mediation and moderation models were tested conducting ordinal logistic structural equation modeling in a cross-sectional sample of 1,893 Dutch adolescents (49\% males), aged 13-15 years. Findings showed that early pubertal and socio-institutional timers were at greater risk to initiate alcohol use and for heavy episodic drinking. Alcohol-specific rules more often mediated, rather than moderated, the effect of early timing on alcohol use. Alcohol-specific rules are mostly relaxed when adolescents mature, rather than rein $\neg$ forced, indicating that parents partly facilitate adolescents' drinking.

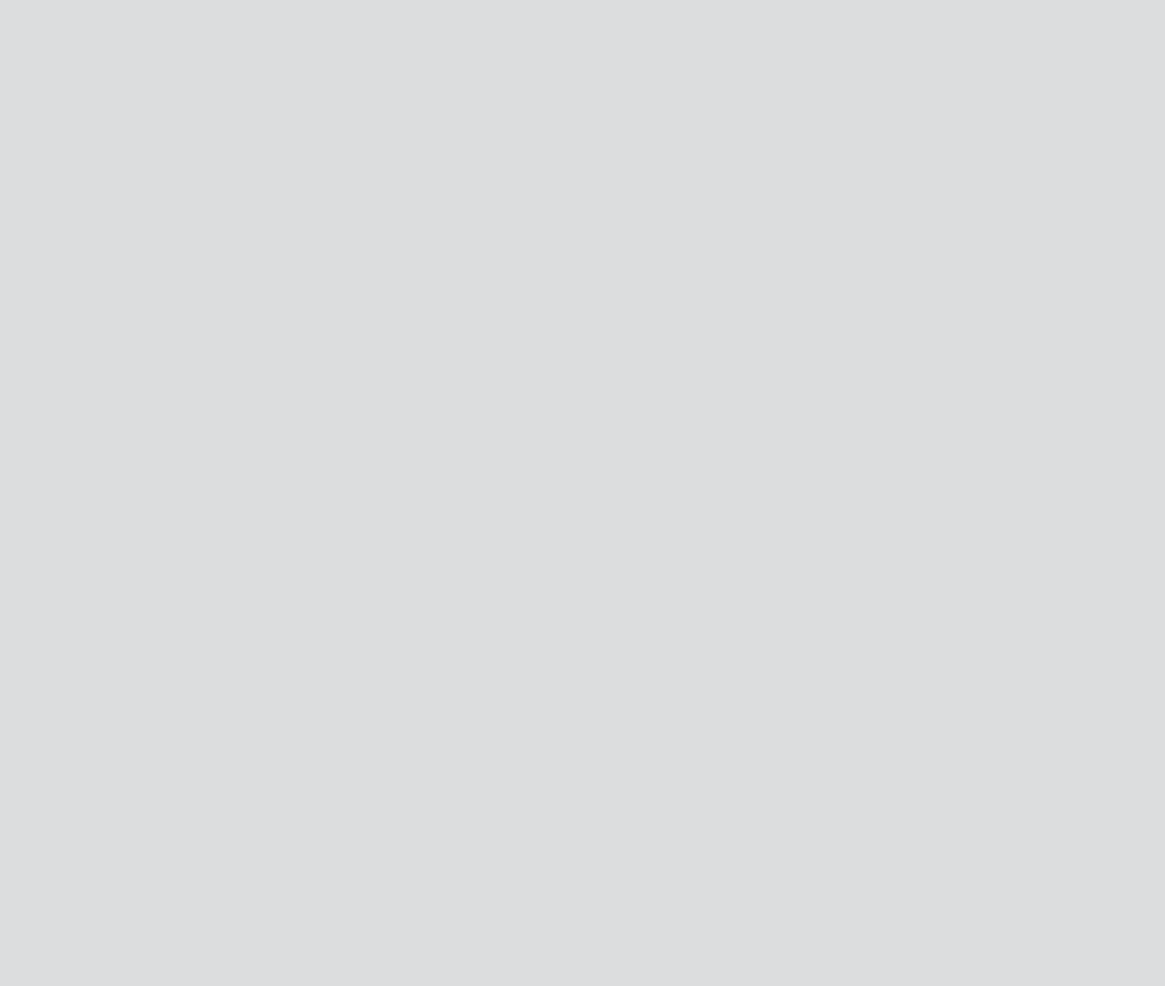

The personal risks and societal costs of adolescent alcohol use are high (Gmel, et al., 2000; Tapert, et al., 2004). Nevertheless, regular and heavy (e.g., heavy episodic drinking) drinking patterns emerge in adolescence (Kuntsche, et al., 2004).

Adolescence refers to the transitional phase from childhood to adulthood in which numerous developmental changes take place, such as pubertal and psychosocial development (Lenz, 2001; Pinyerd \& Zipf, 2005). Also, it is a period in which youngsters try to articulate and express their autonomy that can involve risk behaviors, such as alcohol use (Lenz, 2001; Moffitt, 1993). Among other factors, pubertal timing (stage of the development relative to the development of same-sex, same-age peers) (e.g., Biehl, et al., 2007; Costello, et al., 2007) and alcohol-specific parenting practices (e.g., Van Der Vorst, et al., 2007; Yu, 2003) are associated with adolescents' alcohol use. Furthermore, it seems plausible that psychosocial timing, besides pubertal timing, might influence the initiation and development of alcohol use. Nevertheless, nothing is known about the combined impact that timing (pubertal and psychosocial) and alcohol-specific parenting practices might have on adolescents' alcohol use. The current study tested the associations between alcohol-specific rules (the degree to which parents permit their children to consume alcohol in various situations), pubertal timing, and psychosocial timing, and their relationship with adolescents' alcohol use. More specifically, this study investigated whether alcohol-specific rules set by parents mediate and/or moderate the extent to which pubertal and psychosocial timing influence adolescents' alcohol use.

Pubertal and psychosocial development, alcohol-specific rules and adolescents' alcohol use

Pubertal and psychosocial development are two major developmental changes that occur during adolescence (Lenz, 2001; Pinyerd \& Zipf, 2005). Pubertal development refers to the physical changes occurring during adolescence (Lenz, 2001). Early pubertal timing has been associated with the early initiation of 
alcohol (Costello, et al., 2007; Lanza \& Collins, 2002; Tschann, et al., 1994) increased alcohol use (Lanza \& Collins, 2002; Pieters, et al., 2010), heavy episodic drinking or problem drinking (Biehl, et al., 2007; Costello, et al., 2007; Lanza \& Collins, 2002; Wichstrom, 2001), and increased alcohol use later in adolescence (Biehl, et al., 2007). Psychosocial development can be described by three capacities (Table 3.1): individual adequacy, a person's ability to function effectively on their own; interpersonal adequacy, a person's ability to interact adequately with others; and social adequacy, the responsibility people take for their own survival and self-sufficiency (Greenberger, et al., 1975; Greenberger \& Sorensen, 1974). These capacities can be translated to specific developmental tasks, i.e. personal, relational, and socio-institutional tasks (Dekovic, et al., 1997; Palmonari, et al., 1991). There are no studies on the association between psychosocial timing and adolescents' alcohol use. However, some researcher imply that an important step for youths towards the adult social status could involve alcohol use, suggesting that early psychosocial timing, besides pubertal timing, might positively influence the initiation and development of alcohol use (Lanza \& Collins, 2002; Moffitt, 1993).

Although earlier pubertal and psychosocial development could be possible risk factors for the initiation and use of alcohol, these developmental transitions are normative and should not be a target for the prevention of adolescents' alcohol use (Graber, et al., 2010). On the other hand, alcohol-specific parenting practices have a protective impact on the onset and use of alcohol by adolescents and can be used as a target for the prevention of adolescent drinking (Van Der Vorst, et al., 2007; Yu, 2003). Longitudinal research has shown that alcohol-specific rule setting by parents directly relates to the onset of adolescents' alcohol use (Van Der Vorst, et al., 2007). Parents who set strict rules on alcohol could delay the initiation of alcohol use of their children, and this seems to be the most influential form of alcohol-specific socialization on adolescents' drinking (Van Der Vorst, et al., 2005). The question arises as to what role alcohol-specific rules play regarding the effect that early pubertal and psychosocial timing (personal, relational, socio-institutional) has on adolescents' alcohol use.

\section{Mediating and/or moderating role of alcohol-specific rules}

The impact that alcohol-specific rules might have on the association between pubertal and psychosocial timing, on the one hand, and adolescents' alcohol use, on the other, can take two forms. First, if parents set strict alcohol-specific rules, these strict rules could moderate the effect of early pubertal and psychosocial timing on adolescents' alcohol use. Second, parents may react to early pubertal or psychosocial timing by relaxing their alcohol-specific rules. In such a case, alcohol-specific rules partly explain or mediate, rather than moderate, the effect that early pubertal and psychosocial timing has on adolescents' drinking.

Few studies have explored the potential mediating and/or moderating effects of parenting practices on the positive association between pubertal timing and adolescents drinking. Although no data are available on the mediating and/or moderating effects of parenting practices on psychosocial timing and adolescents' drinking, similar results are expected as for pubertal timing. A prospective study of North-American $4^{\text {th }}$ and $5^{\text {th }}$ graders (who were followed for four years) showed that parental monitoring (parents' accurately knowing where their children are and with whom) moderated the positive association between early pubertal timing and trying alcohol for both boys and girls (Westling, et al., 2008). Early biologically maturing children with low parental monitoring were 3.5 times more likely to start drinking compared with early maturing children with high parental monitoring. This result might also apply for alcohol-specific rules: adolescents with early pubertal timing and whose parents set a high number of alcohol-specific rules might be at reduced risk for alcohol use compared with early timing adolescents whose parents set a low number of alcohol-specific rules. This indicates that setting sufficient alcohol-specific rules might protect adolescents from the risk that early timing has on adolescents' drinking.

However, since families are dynamic systems, and bi-directional relationships might exist between parenting behaviors and adolescents' timing, it is also plausible that parenting practices mediate the impact of pubertal timing on adolescent drinking. Parents might set more liberal rules for early timing adolescents than for late timing adolescents, either because parents think that early timing adolescents make more sensible decisions or parents seek to avoid conflicts with their early timing children. In that case, parental alcohol-specific rules are set in reaction to the early timing level of their children and mediate the positive effect of early timing on adolescent drinking. A cross-sectional study among Canadian adolescents (aged 9-16 years) indeed showed that parental behavioral control (parents' control over their child's behaviors and activities) is sensitive to pubertal maturation; fathers exerted significantly less behavioral control on 
early pubertal timers than on late pubertal timers (Arim \& Shapka, 2008). A longitudinal study, which followed pubertal development and parent-child relationships among North-American boys from the 6th to 10th grade, indicated that parents alter their expectations for their children and grant greater independency based on adolescent's physical appearance alone (Bulcroft, 1991). These results indicate that the effect that pubertal timing has on adolescent drinking can be mediated by parenting practices. However, if alcohol-specific rules indeed mediate the effect of pubertal timing in such a way that parents set fewer rules for early timers, this increases the risk of these adolescents to become involved with alcohol use.

\section{The current study}

The main research question of the present study was to investigate whether the relationship between pubertal and psychosocial timing and adolescents' drinking behavior is either mediated and/or moderated by the alcohol-specific rules that parents set for their children. In addition, it is expected that adolescents with an earlier pubertal timing are more at risk to start drinking alcohol and to Also, an additional effect of psychosocial timing on adolescents' alcohol use is expected; adolescents who adopt personal, relational and socio-institutional tasks comparatively early are at higher risk to start drinking alcohol and to drink heavily.

\section{Method}

\section{Participants}

Participants were 2,056 (1003 boys; 48.8\%) adolescents aged 13-16 years. Adolescents $(\mathrm{N}=130,6.3 \%)$ who had already reached the legal age to purchase alcohol in the Netherlands (i.e. 16 years) were excluded from this study. Also, adolescents $(\mathrm{N}=33)$ who had incomplete information on the variables used in this study were excluded from the analyses. This resulted in a sample of 1,893 (927 boys; 49\%) adolescents, with roughly equal numbers of $13(\mathrm{~N}=569), 14$ $(\mathrm{N}=700)$, and 15 year olds $(\mathrm{N}=624)$.

\section{Procedure}

A random sample (stratified on age and gender) of 6,944 adolescents (aged

13-15 years) was drawn from the population registers of three Dutch communities that were comparable in terms of urbanization and social stratification. All randomly sampled adolescents were approached until the intended sample size ( $\mathrm{N}=1,980$; about 660 respondents in each community) was reached, which required three approaches. After these three approaches, $20.4 \%(\mathrm{~N}=1417)$ of all randomly sampled adolescents actively refused to participate, $29.6 \%(\mathrm{~N}=$ 2056) agreed to participate, and $50.0 \%(\mathrm{~N}=3472)$ was not further approached, because the intended sample size was reached. Participants were contacted by fieldworkers who delivered the questionnaire to participants' home addresses and gave the adolescents and one of their parents or caregivers instructions on how to complete the questionnaires individually at home. Fieldworkers also collected the questionnaires at the adolescents' home when the questionnaire was completed. Parental consent forms of either both parents or caregivers was necessary for participation and were signed before participants completed their questionnaires. All participants in the study received a five euro reward for their participation.

\section{Measures}

\section{Pubertal timing}

To measure pubertal development of adolescents, Dutch translations of the items in the Pubertal Developmental Scale (PDS) published by Petersen, Crockett, Richards and Boxer (1988) were used. The PDS, which is based on adolescents' self reports, is reported to be a reliable and valid measure of pubertal maturation (Brooks-Gunn, Warren, Rosso, \& Gargiulo, 1987; Carskadon \& Acebo, 1993; Petersen, et al., 1988). Females completed three items describing the development of breasts (item ranged from 1 = no development so far, to $4=$ development is finished), onset of menarche (no/yes), and age of menarche. Males completed two items describing changes in their voice and the development of facial hair (items ranged from $1=$ no development so far, to $4=$ development is finished). In each case, an overall pubertal development score was computed. For females, because each of the three items used a different scale, the items were standardized and summed to form one composite score. In accordance with Alsaker (1992), the ratings of pubertal development were transformed into z scores within gender and age groups. Participants with scores lower than -1 SD were considered late maturers and those with scores higher than +1 SD were 
considered early maturers. Cronbach's alphas based on standardized items for the pubertal timing measures were .73 for males and .60 for females.

\section{Psychosocial timing}

The Dutch translation of the Developmental Tasks during Adolescence questionnaire (Dekovic, et al., 1997; Noom, Dekovic, \& Meeus, 1996) was used to assess expectations for adolescents' mastery of personal, relational and socioinstitutional tasks (Table 3.1). Items were formulated asking participants at what age they had fulfilled, or would expect to fulfill, the proposed developmental task. Items were dichotomized according to whether participants fulfilled the developmental task or not, by comparing the age that they reported with their current age. For each participant, an overall psychosocial development score was computed separately for the three capacities, personal ( 7 items; Cronbach's alpha $=.67)$, relational $(2$ items; correlation $=.53)$, and socio-institutional tasks $(4$ items; Cronbach's alpha $=.61)$. The internal consistencies found in the present study are comparable with those reported by Dekovic et al. (1997). The ratings of the three capacities of psychosocial development were transformed

into z scores within gender and age groups. Participants with scores lower than $-1 \mathrm{SD}$ were considered late maturers and those with scores higher than $+1 \mathrm{SD}$ were considered early maturers. This classification resulted in three psychosocial timing scores: personal psychosocial timing, relational psychosocial timing, and socio-institutional psychosocial timing.
Table 3.1 Overview of the three general capacities of psychosocial development and the related developmental tasks (Dekovic, et al., 1997)

\begin{tabular}{|c|c|c|}
\hline Individual adequacy & Interpersonal adequacy & Social adequacy \\
\hline $\begin{array}{l}\text { the ability people have } \\
\text { to function effectively on } \\
\text { their own }\end{array}$ & $\begin{array}{l}\text { the ability people have to } \\
\text { interact adequately with } \\
\text { others }\end{array}$ & $\begin{array}{l}\text { the responsibility people } \\
\text { take for their own survi- } \\
\text { val and self-sufficiency }\end{array}$ \\
\hline Personal tasks & Relational tasks & Socio-institutional tasks \\
\hline $\begin{array}{l}\text { acquiring autonomy, } \\
\text { such as choosing own } \\
\text { clothing or curfew time } \\
\text { and independently ma- } \\
\text { nage your own money }\end{array}$ & $\begin{array}{l}\text { establishing stable relati- } \\
\text { onships with friends }\end{array}$ & $\begin{array}{l}\text { successfully completing } \\
\text { one's school career }\end{array}$ \\
\hline $\begin{array}{l}\text { coping successfully with } \\
\text { everyday life situations, } \\
\text { e.g., planning an appoint- } \\
\text { ment with your doctor }\end{array}$ & $\begin{array}{l}\text { establishing an intimate } \\
\text { relationship }\end{array}$ & $\begin{array}{l}\text { preparing oneself for } \\
\text { integration into a work } \\
\text { setting }\end{array}$ \\
\hline $\begin{array}{l}\text { accepting the bodily } \\
\text { changes which pubertal } \\
\text { development causes }\end{array}$ & & $\begin{array}{l}\text { achieving economic inde- } \\
\text { pendence }\end{array}$ \\
\hline $\begin{array}{l}\text { developing self-aware- } \\
\text { ness; knowing what your } \\
\text { weaknesses and strengths } \\
\text { are }\end{array}$ & & $\begin{array}{l}\text { preparing oneself for the } \\
\text { responsibility of having } \\
\text { one's own family }\end{array}$ \\
\hline $\begin{array}{l}\text { finding reference values; } \\
\text { knowing which stands } \\
\text { you think are good or } \\
\text { bad }\end{array}$ & & \\
\hline $\begin{array}{l}\text { Example of item: } \\
\text { "At what age do you } \\
\text { think you will make (or } \\
\text { did you make) your } \\
\text { own choices about what } \\
\text { clothes you wear, even } \\
\text { if your parents do not } \\
\text { agree?" }\end{array}$ & $\begin{array}{l}\text { Example of item: } \\
\text { "At what age do you } \\
\text { think you will have (or } \\
\text { have you had) your first } \\
\text { steady boy- or girlfriend?" }\end{array}$ & $\begin{array}{l}\text { Example of item: } \\
\text { "At what age do you } \\
\text { think you will live (or did } \\
\text { you live) financially on } \\
\text { your own, without your } \\
\text { parents or caregivers?" }\end{array}$ \\
\hline
\end{tabular}

\section{Adolescents' alcohol use}

Alcohol use was measured by self-reports on the onset of drinking (responses; yes, I already started to drink alcohol regularly; No, I have never drunk alcohol in my entire life; Yes, I have tried alcohol, but did not drink alcohol in the last six months) and the frequency of drinking six or more glasses of alcohol (heavy episodic drinking) in the last six months (responses ranged from $1=$ never to 
$5=$ three times or more a week). The distribution of the frequency of heavy episodic drinking measure was skewed to the right and bimodal to such a degree that the items on onset of drinking and heavy episodic drinking were combined to generate an ordinal outcome variable consisting of three different categories: non-drinkers included adolescents who reported never drinking alcohol $(63.7 \%)$; drinkers included those who drank alcohol at least once in the last six months, but did not report heavy episodic drinking (29.5\%); and heavy episodic drinkers included adolescents who drank at least 6 glasses of alcohol in one drinking occasion at least once in the last six months $(6.8 \%)$.

\section{Alcohol-specific rules}

A Dutch 5-point Likert scale of nine items (Van Der Vorst, et al., 2005) was used to measure how often adolescents think that they are allowed to drink inside and outside the home during week days and in the weekends (Cronbach's alpha $=.92$ ); this scale has shown to be a reliable and valid measure of alcohol-specific rules (Van Der Vorst, et al., 2007; Van Der Vorst, et al., 2005). Examples of the items are: "How often do your parents allow you to drink several glasses of al-

cohol when your parents are at home?", and "How often do your parents allow you to drink as much as you like outside the home?" (responses ranged from $5=$ never to $1=$ very often). Alcohol-specific rules summary scores were computed by dividing the sum score by the valid items reported by the respondent. Higher mean scores indicate stricter alcohol-specific rules.

\section{Educational level}

As there might be systematic differences in psychosocial development according to the level of education, in the analyses the level of secondary education (low and middle; individually supported applied and preparatory middle-level applied education, or high; preparatory higher-level general or university education) was included as a possible confounder in the analysis.

\section{Strength and Difficulties Questionnaire (SDQ)}

The SDQ (Goodman, 1997) is a brief, valid and reliable measure of the prosocial behavior and psychopathology of 4-16-year-olds (Muris, Meesters, \& Van Den Berg, 2003) and was completed by one of the parents (mothers $=85 \%$ ).

The internalizing $(5$ items; Cronbach's alpha $=.59$ ) and externalizing subscale $(5$ items; Cronbach's alpha $=.59)$, assessing emotional and conduct problems respectively, were used in the present study as control variables, since internalizing and externalizing problems are known to be related to the use of alcohol (e.g., Steele, Forehand, Armistead, \& Brody, 1995; Vanheusden, et al., 2008). Examples of questions are: "My child has many worries or often seems worried", and "My child often loses his or her temper" (responses ranged from $1=$ not true to 3 = certainly true). Mean scores of the internalizing and externalizing subscales were computed by dividing the sum score by the valid items reported by the respondent.

\section{Statistical analyses}

\section{Moderation model}

In the conceptual moderation model (Figure 3.1), it was suggested that alcoholspecific rules set by parents moderate the effect that pubertal and psychosocial timing has on adolescents' alcohol use. This model was tested using ordinal logistic structural equation modeling with robust maximum likelihood estimation (Muthén \& Muthén, 1998-2009). Interactions testing the moderation hypothesis were created using centered scores of alcohol-specific rules and dummy coded measures of the four timing measures, which compare early and late timers with modal timers. The covariates, gender, educational level, and SDQ mean scores were included in this analysis.

\section{Mediation model}

In the conceptual mediation model (Figure 3.2), alcohol-specific rules set by parents were expected to mediate the effect that pubertal and psychosocial timing has on adolescents' alcohol use. Ordinal logistic structural equation modeling, using bootstrapped standard errors, was conducted to test the mediation model, which is considered to be a most appropriate means of testing multiple mediation hypotheses (Hayes, 2009). In this analysis, gender, educational level, and SDQ mean scores were included. 
Figure 3.1 Conceptual moderation model of the associations between pubertal, psychosocial timing, alcohol-specific rules on adolescents' drinking behavior

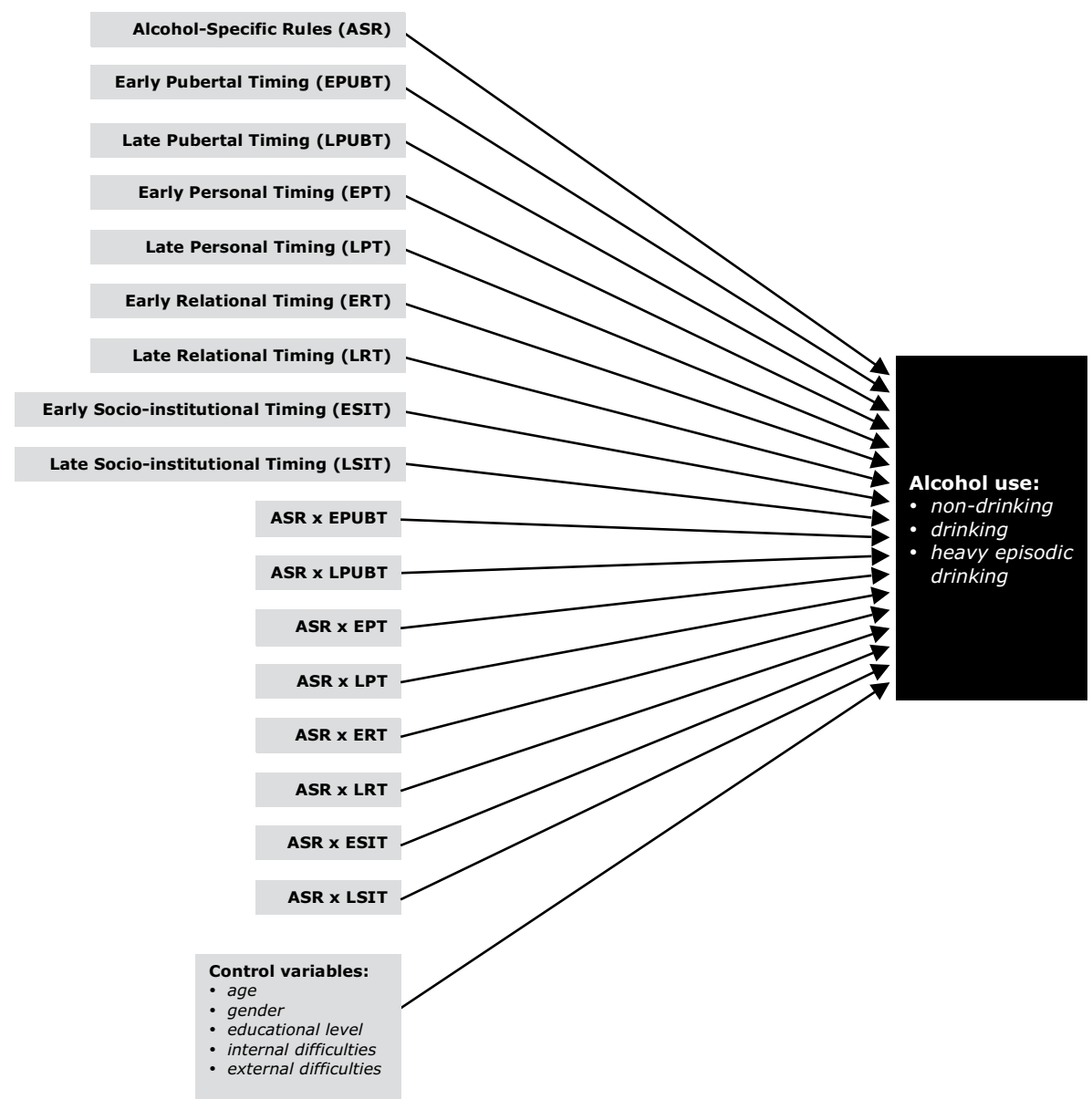

Note: Co-variances between model variables are included in the model but are omitted from the figure.
Figure 3.2 Conceptual mediation model of the associations between pubertal, psychosocial timing, alcohol-specific rules on adolescents' drinking behavior

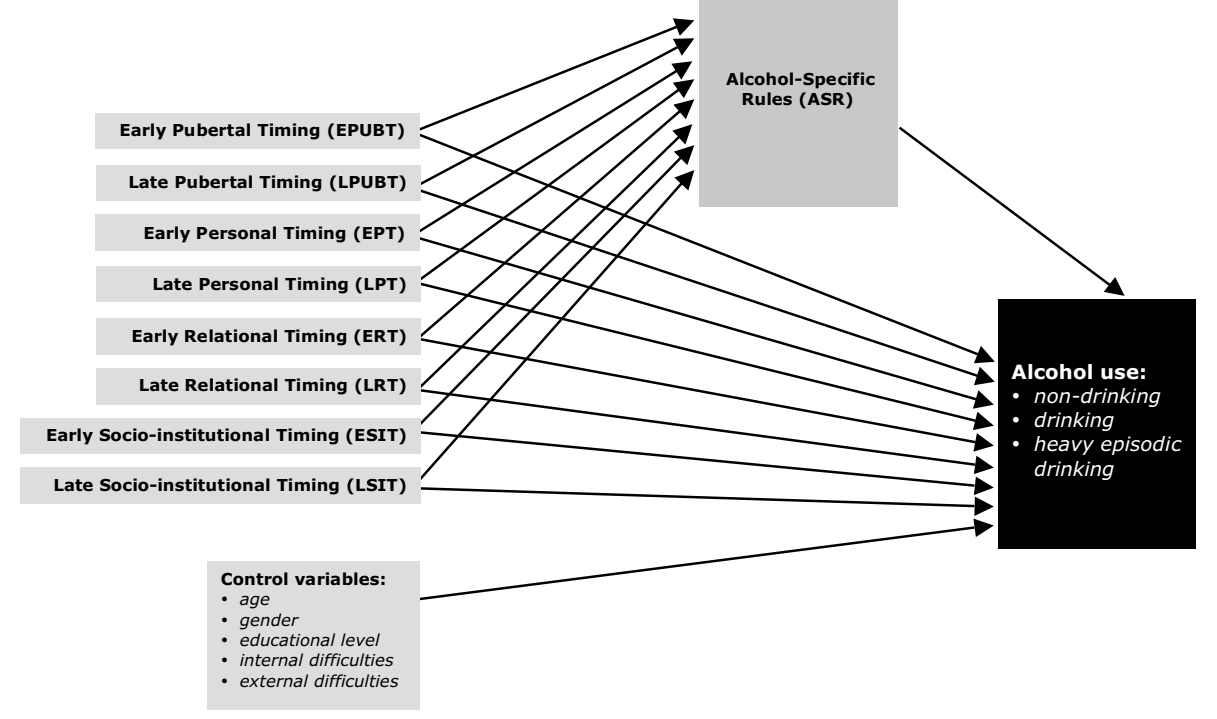

Note: Co-variances between model variables are included in the model but are omitted from the figure.

\section{Results}

\section{Descriptive results}

A series of Chi-square statistics and analyses of variances (ANOVAs) were performed to describe univariate differences in drinking categories as a function of gender, educational level, pubertal and psychosocial timing. These analyses identified significant types (overrepresented cell values) and antitypes (underrepresented cell values) using exact cell-wise tests (Bergman, Magnusson, \& El-Khouri, 2003). The overall Chi-square statistics were significant in each of the six analyses (Table 3.2). There were significantly more females in the drinking category than males and significantly more males in the non-drinking category than females. Adolescents in lower educational tracks were overrepresented in the heavy episodic drinking category and underrepresented in the non-drinking category. Also, results of the ANOVAs showed that adolescents in the drinking category, especially the heavy episodic drinking category reported a lower alcohol-specific rules mean score than adolescents in the non-drinking category; $\mathrm{F}(2,1893)=378.33, \mathrm{p}<.001$. 
With respect to the timing measures, the expected higher prevalence of nondrinking among those whose timing was late was found for all measures, although not significant for personal timing. Except for relational timing, a higher prevalence of heavy episodic drinking was found for earlier maturing adolescents compared with modal and late maturers. The association of relational timing with heavy episodic drinking was opposite to what was expected; early timers had a lower prevalence of heavy episodic drinking than modal timers.

Table 3.2 Observed percentages of alcohol use groups as a function of gender, educational level, pubertal and psychosocial timing

\begin{tabular}{|c|c|c|c|c|c|}
\hline & \multirow{2}{*}{ 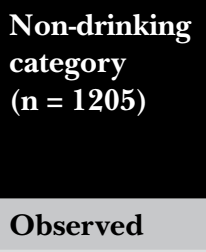 } & \multirow{2}{*}{$\begin{array}{l}\text { Drinking } \\
\text { category } \\
(\mathbf{n}=559)\end{array}$} & \multicolumn{2}{|l|}{$\begin{array}{l}\text { Heavy } \\
\text { episodic } \\
\text { drinking } \\
\text { category } \\
(\mathrm{n}=129)\end{array}$} \\
\hline & & & & Observed & $\chi^{2}$ \\
\hline Gender & $\begin{array}{l}\text { Male } \\
\text { Female }\end{array}$ & $\begin{array}{l}66.5 \% \mathrm{~T} \\
61.0 \% \mathrm{~A}\end{array}$ & $\begin{array}{l}25.9 \% \mathrm{~A} \\
33.0 \% \mathrm{~T}\end{array}$ & $\begin{array}{l}7.7 \% \\
6.0 \%\end{array}$ & $12.28 * *$ \\
\hline $\begin{array}{l}\text { Educational } \\
\text { level }\end{array}$ & $\begin{array}{l}\text { Low \& middle } \\
\text { High }\end{array}$ & $\begin{array}{l}60.1 \% \mathrm{~A} \\
66.2 \% \mathrm{~T}\end{array}$ & $\begin{array}{l}31.1 \% \\
28.4 \%\end{array}$ & $\begin{array}{l}8.7 \% \mathrm{~T} \\
5.4 \% \mathrm{~A}\end{array}$ & $11.17 * *$ \\
\hline $\begin{array}{l}\text { Pubertal } \\
\text { timing }\end{array}$ & $\begin{array}{l}\text { Early } \\
\text { Modal } \\
\text { Late }\end{array}$ & $\begin{array}{l}55.0 \% \mathrm{~A} \\
63.5 \% \\
76.5 \% \mathrm{~T}\end{array}$ & $\begin{array}{l}33.5 \% \\
30.1 \% \\
21.2 \% \mathrm{~A}\end{array}$ & $\begin{array}{l}11.5 \% \mathrm{~T} \\
6.4 \% \\
2.3 \% \mathrm{~A}\end{array}$ & $38.56^{* * *}$ \\
\hline $\begin{array}{l}\text { Personal } \\
\text { timing }\end{array}$ & $\begin{array}{l}\text { Early } \\
\text { Modal } \\
\text { Late }\end{array}$ & $\begin{array}{l}60.1 \% \\
63.8 \% \\
66.9 \%\end{array}$ & $\begin{array}{l}28.9 \% \\
30.2 \% \\
27.3 \%\end{array}$ & $\begin{array}{l}11.0 \% \mathrm{~T} \\
6.0 \% \\
5.9 \%\end{array}$ & $11.48^{*}$ \\
\hline $\begin{array}{l}\text { Relational } \\
\text { timing }\end{array}$ & $\begin{array}{l}\text { Early } \\
\text { Modal } \\
\text { Late }\end{array}$ & $\begin{array}{l}66.5 \% \\
57.7 \% \mathrm{~A} \\
75.4 \% \mathrm{~T}\end{array}$ & $\begin{array}{l}29.5 \% \\
33.2 \% \mathrm{~T} \\
20.6 \% \mathrm{~A}\end{array}$ & $\begin{array}{l}4.0 \% \mathrm{~A} \\
9.1 \% \mathrm{~T} \\
4.0 \% \mathrm{~A}\end{array}$ & $49.64 * * *$ \\
\hline $\begin{array}{l}\text { Socio-institu- } \\
\text { tional timing }\end{array}$ & $\begin{array}{l}\text { Early } \\
\text { Modal } \\
\text { Late }\end{array}$ & $\begin{array}{l}57.6 \% \\
61.4 \% \mathrm{~A} \\
70.3 \% \mathrm{~T}\end{array}$ & $\begin{array}{l}34.1 \% \\
30.5 \% \\
25.9 \% \mathrm{~A}\end{array}$ & $\begin{array}{l}8.3 \% \\
8.1 \% \mathrm{~T} \\
3.8 \% \mathrm{~A}\end{array}$ & $21.40 * * *$ \\
\hline
\end{tabular}

Note: ${ }^{* * *} p<.001 .{ }^{* * p}<<.01 . * p<.05 . T=$ Type. $A=$ Anti-type.

Expected percentages in non-drinking category: $63.7 \%$, in drinking category: $29.5 \%$ and in the heavy episodic drinking category: $6.8 \%$.
A series of one-way ANOVAs were performed to describe univariate differences on alcohol-specific rules as a function of pubertal and psychosocial timing levels (Table 3.3). An identical pattern of differences emerged for pubertal and personal timing, with early timers reporting fewer alcohol-specific rules than late timers. For relational timing, modal timers reported less alcohol-specific rules than early and late relational timers. For socio-institutional timing, late timers reported more alcohol-specific rules than modal and early timers.

Table 3.3 Descriptive statistics pubertal and psychosocial timing variables and alcohol-specific rules

\begin{tabular}{|l|l|l|l|l|}
\hline \multicolumn{5}{|c|}{ Alcohol-specific rules } \\
\hline $\begin{array}{l}\text { Pubertal } \\
\text { timing }\end{array}$ & Early & $4.57 \mathrm{~A}$ & .61 & $22.25^{* * * *}$ \\
& Modal & $4.72 \mathrm{~B}$ & .47 & \\
\hline $\begin{array}{l}\text { Personal } \\
\text { timing }\end{array}$ & Late & $4.83 \mathrm{C}$ & .38 & \\
& Early & $4.64 \mathrm{~A}$ & .58 & $5.23^{* *}$ \\
\hline $\begin{array}{l}\text { Relational } \\
\text { timing }\end{array}$ & Modal & $4.71 \mathrm{AB}$ & .49 & \\
& Late & $4.77 \mathrm{~B}$ & .40 & \\
\hline Socio-institutional & Early & $4.81 \mathrm{~B}$ & .34 & $24.87^{* * *}$ \\
timing & Modal & $4.63 \mathrm{~A}$ & .55 & \\
& Late & $4.78 \mathrm{~B}$ & .44 & \\
& Early & $4.66 \mathrm{~B}$ & .54 & $12.36^{* * *}$ \\
& Modal & $4.67 \mathrm{~B}$ & .53 & \\
& Late & $4.79 \mathrm{~A}$ & .38 & \\
\hline
\end{tabular}

Note: ${ }^{* * *} p<.001 .{ }^{* *} p<.01 .{ }^{*} p<.05 . d . f . .=2 . N=1,893$. For each timing measure different subscripts $(A, B, C)$ indicate statistically significant differences $(p<.05)$ with Bonferroni comparisons.

Ordinal logistic structural equation modeling of moderation model Table 3.4 presents the unstandardized regression coefficients, odds ratios, 95\% confidence intervals and regular fit indices of the moderation model. Three significant direct paths were found between the timing measures and adolescents' alcohol use. Early relational timing adolescents were more likely to report alcohol use and heavy episodic drinking than modal timers. Late relational and pubertal timing adolescents were less likely to report drinking alcohol and heavy 
episodic drinking compared with modal timing adolescents. Furthermore, a significant direct path from perceived alcohol-specific rules towards adolescents alcohol use was found; the more adolescents perceived alcohol-specific rules set by their parents, the less likely they were to report drinking alcohol and heavy episodic drinking. Of the eight moderation paths tested in this model (Figure 3.1), only two showed to be significant, namely between perceived alcohol-specific rules and late personal timing, and perceived alcohol-specific rules and early relational timing. However, no direct effect of early personal timing on adolescents' alcohol use was found. Therefore, the interaction effect found between late personal timing and alcohol-specific rules should be interpreted as late personal timing moderating the effect of alcohol-specific rules set by parents instead of vice versa. Later personal timing amplified the protective effect of alcohol-specific rules showed on adolescents' drinking, compared with modal personal timing (Figure 3.3). Unlike personal timing, early relation timing was directly related to a higher risk for drinking and heavy-episodic drinking. High numbers of alcohol-specific rules impeded the risk of early relational timing on adolescents' drinking. Early relational timing adolescents who perceive high al-

cohol-specific rules were at reduced risk to initiate drinking and heavy drinking,

compared with modal relational timers (Figure 3.4). Thus, only one interaction effect was found were alcohol-specific rules moderated the effect of timing.

\section{Ordinal logistic structural equation modeling of mediation model}

Table 3.5 presents the results of the mediation model. Regular fit indices showed a good fit (RMSEA < .05) (Browne \& Cudeck, 1993). Similar direct effects of adolescents' timing measures and perceived alcohol-specific rules on adolescents' alcohol use were found in the mediation model as in the moderation model. Furthermore, the effects of both early and late pubertal timing on adolescents' alcohol use were mediated by alcohol-specific rules. Early pubertal timing adolescents perceived less alcohol-specific rules set by their parents than modal timing adolescents while late pubertal timers perceived more alcohol-specific rules than modal timers. Also, the effect of early socio-institutional timing on adolescents alcohol use was mediated by the alcohol-specific rules set by parents. Early socioinstitutional timing adolescents perceived less alcohol-specific rules compared with modal socio-institutional timing adolescents. Thus, in contrast to only two significant moderation effect in the moderation model, of the eight tested mediation paths in the mediation model, three mediation paths were significant
Table 3.4 Estimated paths of the moderation model

\begin{tabular}{|c|c|c|c|}
\hline $\begin{array}{l}\text { Estimated direct paths } \\
\text { on adolescents' alcohol use }\end{array}$ & Estimate (SE) & OR & $\begin{array}{l}\text { 95\% CI of OR } \\
\text { (lower; upper) }\end{array}$ \\
\hline Gender & $.11(.12)$ & 1.1 & $(.93 ; 1.36)$ \\
\hline Age & $74^{* * *}(.09)$ & 2.1 & $(1.82 ; 2.43)$ \\
\hline Educational level & $-.23 *(.11)$ & .79 & $(.66 ; .96)$ \\
\hline Internalizing difficulties & $-.14 *(.06)$ & .87 & $(.78 ; .96)$ \\
\hline Externalizing difficulties & $.37 * * *(.06)$ & 1.44 & $(1.31 ; 1.59)$ \\
\hline Early Personal Timing (EPT) & $.02(.15)$ & 1.03 & $(.80 ; 1.32)$ \\
\hline Late Personal Timing (LPT) & $.12(.16)$ & 1.13 & $(.87 ; 1.47)$ \\
\hline Early Relational Timing (ERT) & $.38 *(.15)$ & 1.46 & $(1.15 ; 1.86)$ \\
\hline Late Relational Timing (LRT) & $-.41 * *(.16)$ & .67 & $(.52 ; .86)$ \\
\hline Early Socio-institutional Timing (ESIT) & $.29(.18)$ & 1.34 & $(1.00 ; 1.79)$ \\
\hline Late Socio-institutional Timing (LSIT) & $.09(.13)$ & 1.09 & $(.88 ; 1.34)$ \\
\hline Early Pubertal Timing (EPUBT) & $.22(.14)$ & 1.25 & $(.99 ; 1.57)$ \\
\hline Late Pubertal Timing (LPUBT) & $-.40 *(.18)$ & .67 & $(.50 ; .91)$ \\
\hline Alcohol-Specific Rules (ASR) & $-.93 * * *(.11)$ & .40 & $(.33 ; .48)$ \\
\hline $\begin{array}{l}\text { Estimated interaction paths (moderation) } \\
\text { on adolescents' alcohol use }\end{array}$ & Estimate (SE) & OR & $\begin{array}{l}\text { 95\% CI of OR } \\
\text { (lower; upper) }\end{array}$ \\
\hline EPT x ASR & $.01(.16)$ & 1.01 & $(.78 ; 1.32)$ \\
\hline LPT x ASR & $-.51 *(.22)$ & .60 & $(.42 ; .87)$ \\
\hline ERT $x$ ASR & $-.48 *(.19)$ & .62 & $(.45 ; .85)$ \\
\hline LRT $x$ ASR & $-.08(.24)$ & .92 & $(.62 ; 1.38)$ \\
\hline ESIT x ASR & $.07(.21)$ & 1.07 & $(.77 ; 1.50)$ \\
\hline LSIT x ASR & $-.13(.18)$ & .88 & $(.66 ; 1.18)$ \\
\hline EPUBT $x$ ASR & $.17(.16)$ & 1.19 & $(.92 ; 1.54)$ \\
\hline LPUBT x ASR & $-.04(.27)$ & .96 & $(.61 ; 1.51)$ \\
\hline Threshold 1 & $\begin{array}{l}10.88 * * * \\
(1.29)\end{array}$ & & \\
\hline Threshold 2 & $\begin{array}{l}13.80 * * * \\
(1.29)\end{array}$ & & \\
\hline $\begin{array}{l}\text { Rooted Mean Square Error of } \\
\text { Approximation (RMSEA) }\end{array}$ & .000 & & \\
\hline R-square adolescents' alcohol use & .40 & & \\
\hline
\end{tabular}

Note: $* * * p<.001 . * * p<.01 . * p<.05 ; N=1893$; Since this model is fully saturated, no other fit indices are reported. 
Figure 3.3 Interaction between personal timing and alcohol-specific rules

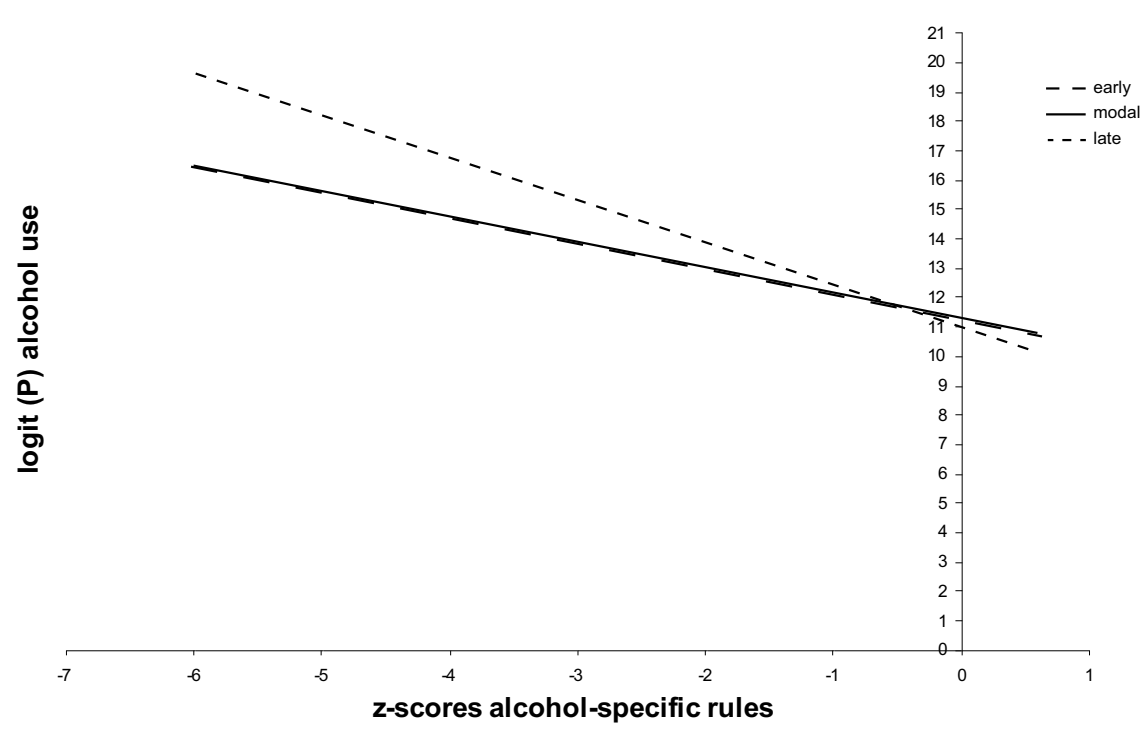

Note: Because early and modal personal timing have nearly the same slope, their regression

Figure 3.4 Interaction between relational timing and alcohol-specific rules

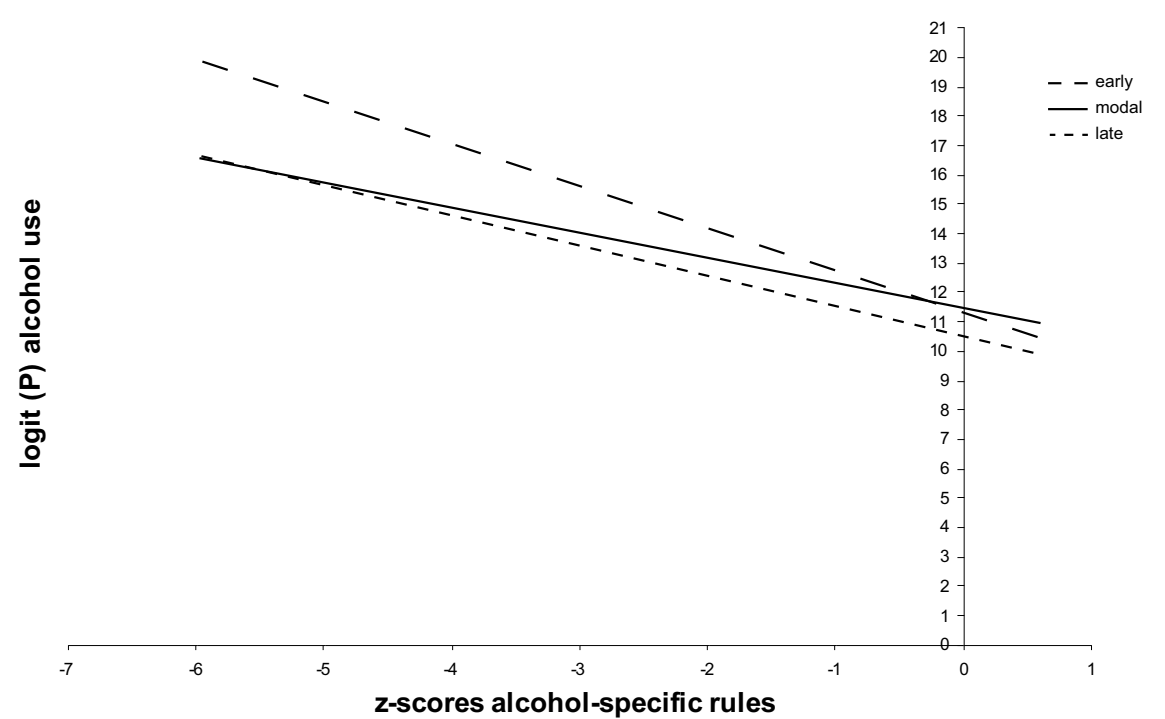

Table 3.5 Estimated paths of the mediation model

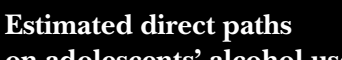

on adolescents' alcohol use

Estimate (SE) OR $\quad 95 \%$ CI of OR

Gender

Educational level

Internalizing difficulties

Externalizing difficulties

Early Personal Timing (EPT)

Late Personal Timing (LPT)

Early Relational Timing (ERT)

Late Relational Timing (LRT)

Early Socio-institutional Timing (ESIT)

Late Socio-institutional Timing (LSIT)

Early Pubertal Timing (EPUBT)

Late Pubertal Timing (LPUBT)

Alcohol-Specific Rules (ASR)

\section{Estimated direct paths}

on Alcohol-Specific Rules (ASR)

Gender

Age

Educational level

Internalizing difficulties

Externalizing difficulties

EPT

LPT

ERT

LRT

ESIT

LSIT

EPUBT

LPUBT $\begin{array}{llll}.08(.06) & 1.08 & (.98 ; 1.19)\end{array}$

$\begin{array}{lll}.44 *(.05) & 1.55 & (1.43 ; 1.67)\end{array}$

$\begin{array}{lll}-.11 *(.06) & .90 & (.81 ; .98)\end{array}$

\begin{tabular}{l|l|l}
$-.07 *(.03)$ & .93 & $(.89 ; .98)$
\end{tabular}

\begin{tabular}{l|l|l}
$.20 * * *(.03)$ & 1.22 & $(1.16 ; 1.28)$
\end{tabular}

\begin{tabular}{l|l|l|l}
$.01(.08)$ & 1.01 & $(.89 ; 1.15)$
\end{tabular}

\begin{tabular}{l|l|l}
$.06(.08)$ & 1.06 & $(.93 ; 1.20)$
\end{tabular}

\begin{tabular}{ll|l}
$.19 * *(.07)$ & 1.21 & $(1.08 ; 1.31)$
\end{tabular}

\begin{tabular}{l|l|l}
. $.21 * *(.08)$ & .81 & $(.71 ; .92)$
\end{tabular}

\begin{tabular}{l|l|l}
$.14(.09)$ & 1.15 & $(.98 ; 1.32)$
\end{tabular}

\begin{tabular}{l|l|l}
$.02(.07)$ & 1.02 & $(.91 ; 1.14)$
\end{tabular}

\begin{tabular}{l|l|l}
$.12(.07)$ & 1.13 & $(1.01 ; 1.27)$
\end{tabular}

\begin{tabular}{l|l|l}
$-.25^{* *}(.09)$ & .78 & $(.67 ; .90)$ \\
.$- .47 * *(.04)$ & .63 & $(.59 ; .66)$
\end{tabular}

$-.47 * * *(.04) \quad .63 \quad(.59 ; .66)$

Estimate (SE) $\quad \mathbf{9 5 \%}$ CI of estimate

$.01(.05)$ lower; upper)

$.06(.04) \quad(-.02 ; .13)$

$.00(.02) \quad(-.04 ; .04)$

$-.05 *(.02) \quad(-.09 ;-.01)$

$-.13(.07) \quad(-.24 ;-.02)$

$.08(.06) \quad(-.01 ; .17)$

$.08(.04)-(-.02 ; .15)$

$.07(.05) \quad(-.03 ; .15)$

$-.15 *(.08) \quad(-.27 ;-.03)$

$.02(.05) \quad(-.05 ; .09)$

$-.26 * * *(.06) \quad(-.36 ;-.15)$

$.17 * *(.05) \quad(.09 ; .26)$ 


\section{Table 3.5 (continued) Estimated paths of the mediation model}

\section{Estimated indirect paths (mediation)}

Estimate (SE) OR $\quad 95 \%$ CI of OR ohol use

EPT $\rightarrow$ ASR $\rightarrow$ Adolescents' alcohol use

$.06(.03)$

(lower; upper)

LPT $\rightarrow$ ASR $\rightarrow$ Adolescents' alcohol use

ERT $\rightarrow$ ASR $\rightarrow$ Adolescents' alcohol use

LRT $\rightarrow$ ASR $\rightarrow$ Adolescents' alcohol use

ESIT $\rightarrow$ ASR $\rightarrow$ Adolescents' alcohol use

LSIT $\rightarrow$ ASR $\rightarrow$ Adolescents' alcohol use

EPUBT $\rightarrow$ ASR $\rightarrow$ Adolescents' alcohol use

LPUBT $\rightarrow$ ASR $\rightarrow$ Adolescents' alcohol use

Threshold 1

Threshold 2

Rooted Mean Square Error of

Approximation (RMSEA)

R-square alcohol-specific rules

R-square adolescents' alcohol use \begin{tabular}{l|l|l}
$-.04(.03)$ & .96 & $(.92 ; 1.00)$
\end{tabular}

\begin{tabular}{l|l|l}
$-.04(.02)$ & .96 & $(.93 ; .99)$
\end{tabular}

\begin{tabular}{l|l|l}
$-.03(.03)$ & .97 & $(.93 ; 1.01)$ \\
\hline $.07 *(.03)$ & 1.07 & $(1.01 ; 1.14)$
\end{tabular}

\begin{tabular}{l|l|l}
$.07 *(.03)$ & $1.07 \quad(1.01 ; 1.14)$
\end{tabular}

\begin{tabular}{l|l|l|l}
$-.01(.01)$ & .99 & $(.96 ; 1.03)$
\end{tabular}

\begin{tabular}{l|l|l}
$.12 * * *(.03)$ & $1.13 \quad(1.08 ; 1.19)$
\end{tabular}

\begin{tabular}{l|l|l}
$-.08 * *(.03)$ & .92 & $(.88 ; .96)$
\end{tabular}

$6.46 * * *(.66)$

$7.80 * * *(.67)$

.000

.18

.41
Note: ${ }^{* * *} p<.001 . * * p<.01 . * p<.05 ; N=1,893$.

\section{Discussion}

The present study aimed to gain more insight into the associations between pubertal timing, psychosocial timing, alcohol-specific rules and adolescents' alcohol use. More specifically, this study investigated whether alcohol-specific rules function as a moderator and/or as a mediator of association between adolescents' pubertal and psychosocial timing and their alcohol use. Significant results were found for three of the eight tested mediation paths, whereas only one of the eight tested moderation paths showed a significant result. Thus, more evidence was found for a mediating role of alcohol-specific rules in the associations between pubertal and psychosocial timing and adolescent drinking.

Similar to findings from other studies (e.g., Biehl, et al., 2007; Costello, et al., 2007; Wichstrom, 2001), a positive linear association was found between early pubertal timing and adolescent drinking. Over and above the effect of pubertal timing, relational and socio-institutional timing additionally showed to be associated with adolescent alcohol use. Linear associations between these psychosocial timing measures and adolescent alcohol use were found: the earlier adolescents time, the greater the odds that they will initiate alcohol use and heavy episodic drinking. Furthermore, the risk of early pubertal, and socio-institutional timing on adolescents' alcohol use was, to a large extent, explained by parents relaxing the alcohol-specific rules for the early timing adolescents. Thus, the results indicate that parents partly facilitate adolescents' drinking by setting less alcohol-specific rules for early timers.

Only one outcome indicated the potential protective effect of parental alcoholspecific rules on the risk of early timing. The effect of early relational timing on adolescents' alcohol use interacted with the number of alcohol-specific rules set by parents. Early relational timing adolescents who perceived higher alcohol-specific rules were at lower risk for drinking alcohol and heavy episodic drinking, than early relational timing adolescents who perceived low alcoholspecific rules set by their parents. Furthermore, although no direct effect of personal timing on adolescents' alcohol use was found, late personal timing interacted with the frequency of alcohol-specific rules set by parents. Compared with modal personal timing, late personal timing amplified the protective effect that alcohol-specific rules have on adolescents' drinking.

\section{Strengths and limitations}

Despite the clear findings and strengths of the current study, such as the large sample size, the study has some limitations. In the current study, because crosssectional data were used, no definite conclusions regarding causality can be drawn. Another limitation is that no available information on the sanctions parents take if their children do not obey the alcohol-specific that have been set. If rules are not enforced by parents, they might be less effective. However, one could argue that the results regarding alcohol-specific rules would be even stronger if information on enforcement of rules was taken into account.

Furthermore, relational timing was constructed from only two items, which caused a limited variation within relational timing, especially within the oldest age group. A measure covering more variation within relational timing, using more items for relational development, might have produced stronger results for relational timing. In the current study, self-reported data from adolescents were used to assess their alcohol use. This might have caused underreporting of alcohol use due to a tendency to respond in a socially desirable manner. However, there is evidence that possible underreporting of alcohol use is generally linear, and that self-report methods offer a reliable and valid approach to measure alcohol consumption (Del Boca \& Darkes, 2003; Gruenewald \& Johnson, 
2006). Also, a multi-informant design (including parental reports) for the independent variables might have improved the robustness of the findings. However, parents might be more influenced by social desirability when reporting information on, e.g., alcohol-specific rules compared with adolescents. Furthermore, the results of this study may not be totally generalizable to countries with a different drinking culture: more specifically, where drinking alcohol is less a marker for adolescents to express their autonomy in the development to adulthood, such as in European Mediterranean countries (Knibbe, et al., 2007). Moreover, since this is the first study to investigate the mediating and/or moderating effect of alcohol-specific rules in relation to a positive association between adolescents' maturation and alcohol use, similar studies in other cultures and with a longitudinal design are needed.

\section{Conclusions and implications for prevention}

Only one outcome indicated a protective effect of parental alcohol-specific rules regarding the positive association between pubertal and psychosocial maturation and adolescent alcohol consumption. In most cases, parental alcohol-

specific rules are relaxed when adolescents mature rather than that they protect against the tendency of adolescents to use alcohol and to articulate their pubertal and psychosocial maturation. There is probably a cultural and historical variation in the extent to which parents tend to relax alcohol-specific rules once their children mature. For example, the study by Westling et al. (2008), conducted in the USA, showed that parental monitoring moderated the association between pubertal timing and experimenting with alcohol. A more indirect indication of cultural differences is the finding that parents in France much more criticize the drinking of their children than parents in the Netherlands, even though the prevalence of heavy drinking and intoxication is much higher among Dutch adolescents (Knibbe, et al., 2007). This indicates the potential effect of setting and enforcing restrictive rules on drinking, even if this requires criticizing the drinking behavior of offspring. In terms of prevention policy, the results seem to indicate that, in the Netherlands, one priority should be to encourage parents not to (or only slightly) relax alcohol-specific rules in the period that their children are becoming biologically and psychosocially mature. Parents should also be informed that early maturing adolescents are not yet able to make sensible choices regarding risk behaviors, such as drinking alcohol, and that parents need to set and enforce restrictive alcohol-specific rules, even if this might lead to some conflict.

\section{Parents need to} set and enforce restrictive alcohol-specific rules, even if this might lead to some conflict. 
Chapter 4

Interplay

between intraand interpersonal level of influence:

Is the effect of early pubertal timing on alcohol initiation mediated by peers and/or parents? 


\section{Abstract}

Background To investigate whether the link between early pubertal timing and initiation of alcohol use is mediated by changes in perceived parental alcohol-specific rule setting and changes in perceived proportion of drinkers in the peer group.

Method Longitudinal data including three annual waves were used to estimate the hazard of adolescents to initiate drinking alcohol using Cox proportional hazard structural equation models in 1,286 Dutch adolescents ( $50.2 \%$ boys) aged 13-14 years at baseline in 2008 .

Results Early pubertal timing increased the risk to initiate alcohol use. However, this risk was entirely mediated by a large increase in the perceived proportion of drinkers in the peer group, and a large decrease in the frequency of perceived alcohol-specific rules for early pubertal timers within a period of one year.

Conclusion There is no direct risk of early pubertal timers to initiate drinking per se, but an indirect one via changes in their social environments, i.e. a large increase in the perceived proportion of drinkers in their peer group, and parents becoming more lenient in their alcohol-specific rule setting. It is important to motivate parents not to relax their alcohol-specific rule setting over time, particularly parents of early pubertal timers.

\section{Introduction}

Many health risks are associated with early adolescent alcohol use, such as risky sexual behavior, intentional and unintentional injuries, and a higher risk of later alcohol abuse and dependence (Anthony \& Petronis, 1995; Rehm, Gmel, \& Sempos, 2003; Tapert, et al., 2004).

Despite these risks, most people start to drink at an early age (Kuntsche, et al., 2004). Early pubertal timing (stage of the physical development relative to the physical development of same-sex and same-aged peers) has been shown to correspond with, and to be a risk factor of, the initiation of alcohol use (Costello, et al., 2007; Dick, Rose, Pulkkinen, \& Kaprio, 2001; Lanza \& Collins, 2002; Patton, et al., 2004; Schelleman-Offermans, Knibbe, Engels, \& Burk, 2011; Tschann, et al., 1994).

Pubertal timing in itself is a normative biological developmental transition and therefore not a target for prevention (Graber, et al., 2010). However, it is likely that the effect of early pubertal timing on adolescent alcohol use is fully or partly mediated by other factors that might be more feasible and meaningful targets for prevention efforts. The mechanisms by which early pubertal timing relates (indirectly) to the initiation of drinking remain underexplored. Therefore, this study assessed possible mechanisms behind the link between early pubertal timing and adolescent alcohol use. More specifically, it will be investigated whether changes in the proportion of drinkers in the peer group and changes in parental alcohol-specific rule setting are mediating factors in the relation between early pubertal timing and initiation of alcohol use.

Possible mechanisms behind the link between early pubertal timing and alcohol use

Affiliation with drinking peers has shown to consistently correlate with adolescent alcohol use (Bauman \& Ennett, 1996; Fergusson, Swain-Campbell, \& Horwood, 2002). Also, it is suggested that affiliation with older peers, who are more likely to drink alcohol, plays a mediating role in the link between early pubertal 
timing and alcohol use (e.g., Patton, et al., 2004; Stattin \& Magnusson, 1990; Westling, et al., 2008). The peer socialization hypothesis (Stattin \& Magnusson, 1990) implies that early pubertal timers tend to affiliate with peers who are similar in biological status and, thus, most likely are older in age. Subsequently, this older peer group is more likely to already experiment with substances such as alcohol, which might be age normative for them, but not for the early pubertal timer affiliating with them. A cross-sectional study on 5,769 adolescents (aged 10-15 years) showed a decreased association between pubertal stage and substance use (alcohol, tobacco, or cannabis use) when controlling for peer substance use (Patton, et al., 2004). A longitudinal study by Dick et al. (2001) found that earlier maturing girls and boys reported more substance use by themselves and their peers. Furthermore, a prospective study, which followed 360 fourth and fifth graders for four years, found evidence for affiliation with deviant peers explaining the link between early pubertal timing and trying alcohol. However, this link was only significant for girls (Westling, et al., 2008).

None of the above-mentioned studies included the potential influence of parents as an additional factor explaining the link between early pubertal timing

and alcohol use. However, since pubertal timing occurs in a social environment in which (besides peers) parents are an important source of influence, parents are likely to play an important additional role. Parental alcohol-specific rule setting showed to be directly related to the onset of adolescents' alcohol use (Van Der Vorst, et al., 2007; Yu, 2003) and depends on the way parents generally monitor their children (Van Der Vorst, et al., 2005). Parents who set strict rules on alcohol could delay the initiation of their children's alcohol use. Alcoholspecific rule setting by parents even seemed to be to most important form of alcohol-specific socialization on adolescents' drinking (Van Der Vorst, et al., 2005). The older physical appearance of early pubertal timers may prompt parents to grant them more autonomy in various aspects (e.g., staying up later at night). Similarly, parents might also change their alcohol-specific rules to more permissive rules. Besides the affiliation with drinking peers, this might underlie the higher risk of early pubertal timers to become involved with alcohol use.

To our knowledge, no longitudinal study has tested whether the link between early pubertal timing and alcohol use is mediated by alcohol-specific rules, or included this mediating path in one model with the mediating path via drinking peers. Only one cross-sectional study, using the same sample as the current study, indicated that the link between early pubertal timing and alcohol use is mostly explained by parents setting more permissive alcohol-specific rules for early pubertal timers than for modal and late timers (Schelleman-Offermans, et al., 2011). However, the crucial question as to whether parents adapt their rule setting to their child's pubertal timing and what impact this adaption has on the likelihood to initiate drinking remains unanswered.

\section{Dutch alcohol policies and drinking culture}

The legal purchase age in the Netherlands is 16 years for light alcoholic beverages $(<15 \%$ alcohol $)$ and 18 years for strong alcoholic beverages $(\geq 15 \%$ alcohol). This is the case for most European countries, such as Germany or Belgium, however, lower than the legal purchase age in the USA or New Zealand. More important perhaps is that pseudo-patron research in the Netherlands indicated that it is very easy for underage adolescents to purchase alcohol themselves (Gosselt, et al., 2007). Furthermore, it is rather common for parents in the Netherlands to drink together with their adolescent children at special occasions or family gatherings (Van Der Vorst, 2007). This illustrates that alcohol use is strongly embedded in Dutch culture and is often seen as socially accepted behavior, indicating that it is a marker for adolescents to express their growing autonomy.

\section{The current study}

The present study investigated the link between early pubertal timing and alcohol initiation in several innovative ways. First, the current study explored two mediation pathways; through drinking peers and through alcohol-specific parenting, rather than including only one mediation path through deviant peers (Patton, et al., 2004; Westling, et al., 2008). Secondly, rather than only including the absolute level of, e.g., affiliation with deviant peers at a given moment in time (Patton, et al., 2004; Westling, et al., 2008), this study takes a developmental perspective by including changes in two important socialization agents (peers and parents) within a one-year time period ( $\mathrm{T} 1$ to $\mathrm{T} 2$ ), in reaction to early pubertal timing assessed the year before. Thus, in this study it was hypothesized that early pubertal timers show a higher risk to initiate alcohol use than non-early timers. Furthermore, it was expected that the increased risk to initiate alcohol use for early pubertal timers would be mediated by increases in the proportion of drinkers in the peer group and decreases in parental alcohol-specific rule setting. Moreover, there could be differences in the way girls and boys or 
different age groups are influenced by the effects of early pubertal timing in relation to peers, parents and alcohol initiation (Dick, et al., 2001). For this reason, it was explored whether the relationship between pubertal timing and peers, parents, and alcohol initiation differed for boys and girls and different age groups.

\section{Method}

\section{Study design and participants}

This longitudinal study consisted of three data collection waves (T1 in 2008, T2 in 2009, T3 in 2010). A random sample of 6,944 adolescents, stratified on age (13-15 years) and gender, was drawn from the population registers of three comparable (regarding urbanization and social stratification) Dutch communities. Within those communities, adolescents were randomly approached for participation (by mail and by telephone). Only $20.4 \%(\mathrm{~N}=1413)$ of all randomly sampled adolescents refused to cooperate. All others were three times randomly approached, until the intended sample size of approximately 2,000 participants was reached. Recruitment resulted in 2,056 (1,003 boys; 48.8\%) adolescents aged Netherlands within the first year of the study ( 15 and 16 year old adolescents; $37.4 \%$ ) were excluded from this study, because of the high percentage of adolescents already drinking at baseline within these age groups $(56.6 \%$ and $77.7 \%$ for 15 and 16 year olds respectively). Of the remaining sample aged 13 and 14 years at baseline, $118(9.2 \%)$ adolescents at T2 and another 68 (5.3\%) adolescents at T3 dropped out. Binary logistic regression analysis showed a lower dropout a T3 among adolescents with a higher perceived proportion of drinking friends in their peer group at $\mathrm{T} 2(\mathrm{OR}=0.74 ; \mathrm{p}<0.05)$. All other model outcome variables did not show selective dropout (results can be obtained from the first author upon request). The final analyses included 1,286 Dutch adolescents (645 boys; $50.2 \%)$ with a mean age of $13.6(\mathrm{SD}=0.5)$ years. All adolescents where enrolled in secondary education; $22.4 \%$ within individually supported applied and general applied education, $41.5 \%$ within preparatory intermediate or higher general education, and $36.1 \%$ within preparatory higher-level university education. Of all participating adolescents, $93.5 \%$ was born and raised in the Netherlands. In $90.0 \%$ of the cases both of their parents were born in the Netherlands, in $6.9 \%$ of the cases one parent was born in the Netherlands, and one was not, and in $3.1 \%$ of the cases both parents were born in a different country than the Netherlands.

\section{Procedure}

Parental informed consent of either both parents or caregivers was necessary to participate in the study. In all three waves, participants were instructed to complete the questionnaire at home in privacy, put their completed questionnaire in the provided envelope, and then seal it. At T1, fieldworkers were sent to the participant's home address to deliver the questionnaire and they returned later to collect the completed questionnaire in the sealed envelope. At T2 and T3, all questionnaires were sent to the participant's home address by mail. Participants were instructed to return the completed questionnaire by mail (gratis) in the reply envelope. As incentives, five euro was given to each participant at T1, three iPods Touch were raffled at T2, and three iPads were raffled at T3.

\section{Measures}

\section{Alcohol initiation}

A dichotomous drinking status variable was determined by responses of respondents on their total weekly consumption in glasses of alcohol in the last 6 months. Respondents reporting a total weekly consumption of greater than 0 were considered drinkers (coded as 1). All other respondents were considered non-drinkers (coded as 0 ). The survival time (at T1, T2 or T3) of the alcohol initiation was recoded into a Timing variable $(0,1$, or 2 years).

\section{Pubertal timing}

To measure pubertal development of adolescents, Dutch translations of the items in the Pubertal Developmental Scale (PDS) published by Petersen, Crockett, Richards and Boxer (1988) were used. The PDS is reported to be a reliable and valid measure of pubertal maturation (Brooks-Gunn, et al., 1987; Carskadon \& Acebo, 1993; Petersen, et al., 1988). Females completed three items describing the development of breasts (item ranged from $1=$ no development so far, to 4 = development is finished), onset of menarche (no/yes), and age of menarche (recoded into $1=$ no menarche, $2=$ menarche onset up to 1 year ago, 3 = menarche onset 2 to 3 years ago, $4=$ menarche onset 4 or more years ago) . Males completed two items describing changes in their voice and the development of facial hair (response options ranged from $1=$ no development so far, to 4 = development is finished). In each case, an overall pubertal development score was computed. In accordance with Alsaker (1992), the ratings of pubertal 
development were transformed into z scores within gender and age groups. Participants with scores higher than 1 SD above the mean within their gender and age group were considered early maturers. Cronbach's alphas based on standardized items for the pubertal timing measures were 0.73 for males and 0.60 for females.

\section{Perceived alcohol-specific rules}

A Dutch 5-point Likert scale of nine items (Van Der Vorst, et al., 2005) was used to measure how often adolescents think that they are allowed to drink inside and outside the home during week days and in the weekends (Cronbach's $\alpha_{t 1}$ $=0.92$; Cronbach's $\left.\alpha_{\mathrm{t} 2}=0.94\right)$; this scale is a reliable and valid measure of perceived alcohol-specific rules (Van Der Vorst, et al., 2007; Van Der Vorst, et al., 2005). Examples of the items are: "How often do your parents allow you to drink several glasses of alcohol when your parents are at home?", and "How often do your parents allow you to drink as much as you like outside the home?" (response options range from $4=$ never to $0=$ very often). Mean scores were computed by dividing the sum score of the inversely coded items by the valid items (at

least 5 items) reported by the respondent. Higher mean scores indicate stricte perceived alcohol-specific rules.

\section{Perceived proportion of drinkers in the peer group}

Information on drinkers in the peer group was measured using one item asking adolescents about the proportion in their peer group that drinks alcohol: answers are given on a five-point scale (nobody $=0$ some of them $=1$, about half of them $=2$, most of them $=3$, all of them $=4$ ).

\section{Statistical analyses}

The three communities participating in this study, were originally selected for a community intervention program (two intervention communities and one comparison community) not targeting the individual but the communities' alcohol policies. For this reason, besides including gender and age as covariates, all analyses were adjusted for community membership. Furthermore, models were also run separately in the communities; any differences in effect sizes compared with the overall model will be reported.

The analyses were done in several steps. First, to describe the results, Pearson's correlations between all variables were conducted, and a series of independen t-statistics and Chi-square statistics were performed to illustrate differences between early and non-early pubertal timers as a function of other model variables. Secondly, the longitudinal relationship between early pubertal timing at $\mathrm{T} 1$ and alcohol initiation was tested by means of a bivariate proportional hazard survival analysis. This method identifies which independent variables contain information about the hazards of an event in a given timeframe (i.e., the likelihood of alcohol initiation among those who have not yet initiated alcohol use for each year subsequent to baseline) which is expressed in a hazard ratio for each independent variable. Survival analyses was chosen (a) to overcome methodological problems involved with the non-normal distribution of the originally measured alcohol measure weekly (quantity/frequency) alcohol use, and (b) similar to pubertal timing, to use an alcohol 'timing' measure. To test whether changes in the perceived proportion of drinkers in the peer group and changes in the frequency of perceived alcohol-specific rules mediated the link between early pubertal timing at $\mathrm{T} 1$ and alcohol initiation (T1, T2, and T3), mediation paths were tested in a survival analysis combined with structural equation modeling (Figure 4.1). These mediation paths included the auto-regressive path of both perceived proportion of drinkers in the peer group and frequency of perceived alcohol-specific rules. By including these auto-regressive paths in the analyses, conclusions can be drawn about whether the link between early pubertal timing and alcohol initiation is mediated by changes in perceived alcohol-specific rules and changes in the perceived proportion of drinkers in the peer group, rather than their absolute numbers. Finally, to examine whether the effects of pubertal timing on perceived proportion of drinkers in the peer group, alcohol-specific rules, and alcohol initiation differ for gender and/or age, interactions between pubertal timing and gender and pubertal timing and age were tested on all three outcome measures separately.

Survival analyses were performed in Mplus (Muthén \& Muthén, 1998-2009), using Cox proportional hazard regression and Monte Carlo integration to fit a structural equation model on alcohol initiation. In both tested models Full Information Maximum Likelihood (FIML) was used to deal with dropout rates $(\mathrm{N}=118,9.2 \%)$ and missing data at $\mathrm{T} 2: \mathrm{N}=6(0.5 \%)$ for perceived proportion of drinkers in the peer group at T2, $\mathrm{N}=5(0.4 \%)$ for perceived alcohol-specific rules at T2. The indirect effects (mediation paths) were estimated by means of MacKinnon's Joint Significance Test (MacKinnon, Lockwood, Hoffman, West, $\&$ Sheets, 2002) using the Model Constraint command in Mplus. 
Figure 4.1 Conceptual model of the mechanism behind the link between early pubertal timing and alcohol initiation

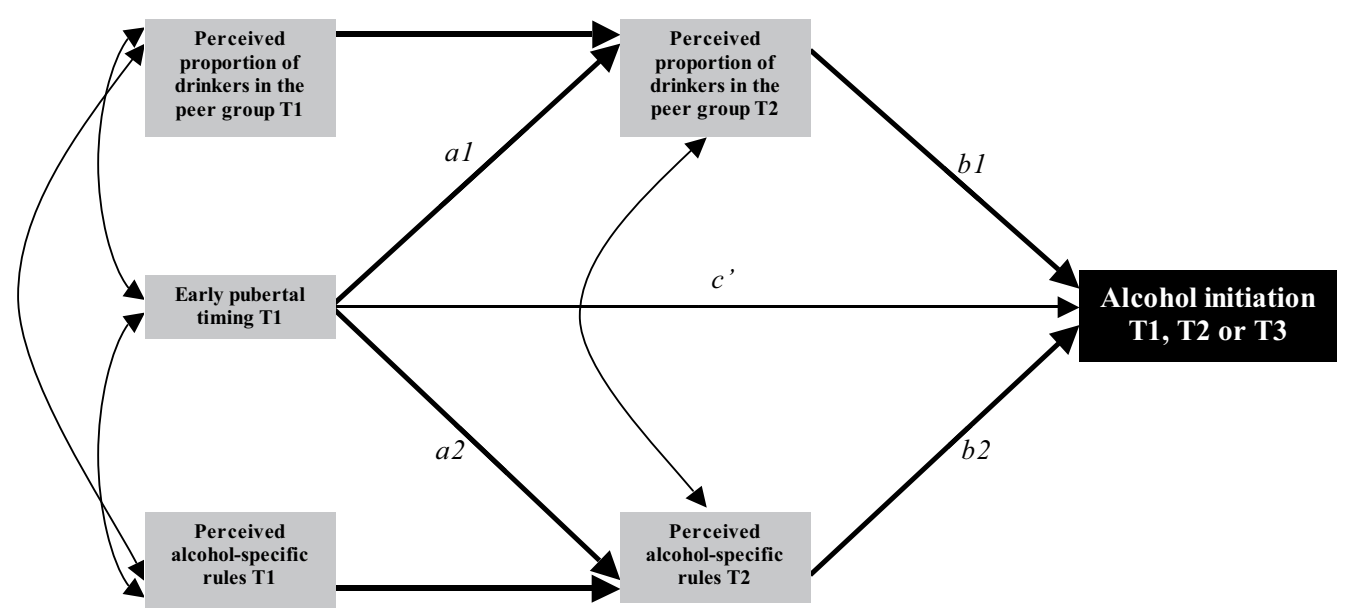

Note: Covariates age, gender, and community were included in the model but are not presented in the Figure.

\section{Results}

\section{Descriptive results}

The descriptive results regarding a series of independent t-statistics and Chisquare statistics are presented in Table 4.1 and Pearson's correlations between model variables are shown in Table 4.2. At all waves, early pubertal timing was associated with a significantly larger perceived proportion of drinkers in the peer group and a significantly lower frequency of perceived alcohol-specific rules than non-early pubertal timers. Also, at all waves, there were significantly more drinkers among early pubertal timers than non-early timers. The perceived proportion of drinkers in the peer group at $\mathrm{T} 2$ showed a strong positive association with drinking status at T2 and T3, whereas parental alcohol-specific rule setting showed a strong negative association with drinking status at T2 and T3. Furthermore, no significant interaction effects between early pubertal timing and gender on all three outcome measures were found (perceived proportion of drinkers in the peer group: $\beta=0.09, p=0.59$; perceived alcohol-specific rules: $\beta=0.05, p=0.49$; alcohol initiation: $\mathrm{HR}=1.00, \mathrm{p}=0.99)$. Also, no significant interaction effects between early pubertal timing and age on all three outcome

\section{Table 4.1 Pearson's correlations between the model variables}

\begin{tabular}{|c|c|c|c|c|c|c|c|c|}
\hline & & 1 & 2 & 3 & 4 & 5 & 6 & 7 \\
\hline 1 & Early pubertal timing & & & & & & & \\
\hline 2 & $\begin{array}{l}\text { Perceived proportion } \\
\text { drinkers in the peer group } \mathrm{T} 1\end{array}$ & 124 & & & & & & \\
\hline 3 & $\begin{array}{l}\text { Perceived proportion } \\
\text { drinkers in the peer group } \mathrm{T} 2\end{array}$ & 130 & .604 & & & & & \\
\hline 4 & Perceived alcohol-specific rules T1 & -.102 & -.340 & -.241 & & & & \\
\hline 5 & Perceived alcohol-specific rules $\mathrm{T} 2$ & -.143 & -.351 & -.374 & .581 & & & \\
\hline 6 & Drinking $(0=$ no. $1=$ yes $) \mathrm{T} 1$ & .095 & .440 & .345 & -.445 & -.383 & & \\
\hline 7 & Drinking $(0=$ no. $1=$ yes $) \mathrm{T} 2$ & 125 & .396 & 463 & -.301 & -.418 & .510 & \\
\hline 8 & Drinking $(0=$ no. $1=$ yes $) \mathrm{T} 3$ & .078 & .311 & .363 & -.212 & -.277 & 246 & 402 \\
\hline
\end{tabular}

Note: $N=1286$; All correlations are significant at the $1 \%$ level (2-tailed).

Table 4.2 Descriptive results of the model variables

\begin{tabular}{|c|c|c|c|c|}
\hline & $\begin{array}{l}\text { Early } \\
\text { pubertal } \\
\text { timers } \\
(17.5 \%)\end{array}$ & $\begin{array}{l}\text { Non-early } \\
\text { pubertal } \\
\text { timers } \\
(\mathbf{8 2 . 5 \% )}\end{array}$ & $\mathbf{t}$ & $x^{2}$ \\
\hline $\begin{array}{l}\text { Mean frequency perceived } \\
\text { alcohol-specific rules T1 } \\
\text { [Range: } 0-4]\end{array}$ & $\begin{array}{l}3.77 \\
(0.38)\end{array}$ & $\begin{array}{l}3.86 \\
(0.30)\end{array}$ & $3.14 * *$ & - \\
\hline $\begin{array}{l}\text { Mean frequency perceived } \\
\text { alcohol-specific rules T2 } \\
\text { [Range: } 0-4]\end{array}$ & $\begin{array}{l}3.59 \\
(0.53)\end{array}$ & $\begin{array}{l}3.76 \\
(0.43)\end{array}$ & $4.27 * * *$ & - \\
\hline $\begin{array}{l}\text { Mean perceived proportion of } \\
\text { drinkers in the peer group } T 1 \\
\text { [Range: } 0-4]\end{array}$ & $\begin{array}{l}1.21 \\
(0.97)\end{array}$ & $\begin{array}{l}0.94 \\
(0.90)\end{array}$ & $-3.93 * * *$ & - \\
\hline $\begin{array}{l}\text { Mean perceived proportion of } \\
\text { drinkers in the peer group T2 } \\
\text { [Range: } 0-4]\end{array}$ & $\begin{array}{l}1.92 \\
(1.04)\end{array}$ & $\begin{array}{l}1.54 \\
(1.10)\end{array}$ & $-4.49 * * *$ & - \\
\hline Mean percentage of drinkers $\mathrm{T} 1$ & 30.7 & 20.3 & - & $11.68^{* *}$ \\
\hline Mean percentage of drinkers $\mathrm{T} 2$ & 46.5 & 30.8 & - & $18.38^{* * *}$ \\
\hline Mean percentage of drinkers T3 & 69.1 & 59.0 & - & $6.73^{*}$ \\
\hline
\end{tabular}

Note: $N=1286 ; * p<.05 ; * * p<.01 ; * * * p<.001 ;$ Standard deviations are shown in parentheses. 
measures were found (perceived proportion of drinkers in the peer group: $\beta=$ $-0.14, p=0.37$; perceived alcohol-specific rules: $\beta=-0.08, p=0.29$; alcohol initiation: $\mathrm{HR}=0.90, \mathrm{p}=0.40)$

\section{Model results}

Separate analyses for the different communities did not show any differences in effect sizes compared with the overall model, indicating that results are most likely generalizable to the wider Dutch adolescent population. Only the effects of the overall model (including three communities) are reported. Early pubertal timers showed a higher risk $(\mathrm{HR}=1.15,95 \%$ CI $1.03 ; 1.23, \mathrm{p}<.05)$ to initiate alcohol use than non-early timers. Standardized model results (Table 4.3) showed that early pubertal timing significantly predicted decreases $(\beta=-0.07$, $95 \%$ CI $-0.12 ;-0.03, \mathrm{p}<.01)$ in the frequency of parental alcohol-specific rule setting at $\mathrm{T} 2$. Also, early pubertal timing at $\mathrm{T} 1$ significantly predicted increases $(\beta=0.06,95 \%$ CI $0.02 ; 0.10, p<.05)$ in the perceived proportion of drinkers in the peer group at T2. Furthermore, the perceived proportion of drinkers in the peer group at T2 significantly increased the risk to initiate alcohol use (HR $=1.27,95 \%$ CI 1.22; 1.32, $\mathrm{p}<.001)$. Parental alcohol-specific rule setting at T2 significantly decreased the risk of adolescents to initiate drinking ( $\mathrm{HR}=0.81$ $95 \%$ CI $0.73 ; 0.89, \mathrm{p}<.001)$.

Significant mediation paths of early pubertal timing on drinking initiation were found via both changes in alcohol-specific rule setting ( $\mathrm{HR}=1.02,95 \%$ CI 1.01; $1.03, \mathrm{p}<.05)$ and changes in the perceived proportion of drinkers in the peer group $(\mathrm{HR}=1.04,95 \%$ CI 1.01; 1.07, $\mathrm{p}<.05)$. The lack of a significant direct path from early pubertal timing towards drinking initiation indicates that the effect of early pubertal timing is mediated by changes in alcohol-specific rule setting and changes in the perceived proportion of drinkers in the peer group.

\section{Table 4.3 Standardized model results and hazard ratios}

\begin{tabular}{|c|c|c|}
\hline $\begin{array}{l}\text { Direct effects on } \\
\text { alcohol initiation at } \mathrm{T} 1, \mathrm{~T} 2 \text { or } \mathrm{T} 3\end{array}$ & HR $(95 \%$ CI $)$ & p-value \\
\hline Age & $1.28(1.17 ; 1.40)$ & 0.000 \\
\hline Gender & $0.95(0.88 ; 1.02)$ & 0.249 \\
\hline Community & $1.07(0.98 ; 1.17)$ & 0.189 \\
\hline Early pubertal timing $\mathrm{T} 1$ & $1.07(0.98 ; 1.18)$ & 0.220 \\
\hline Perceived proportion of drinkers in the peer group $\mathrm{T} 2$ & $1.27(1.22 ; 1.32)$ & 0.000 \\
\hline Perceived alcohol-specific rules T2 & $0.81(0.73 ; 0.89)$ & 0.000 \\
\hline $\begin{array}{l}\text { Direct effects on } \\
\text { perceived proportion drinkers in the peer group } \mathrm{T} 2\end{array}$ & $\beta(\mathbf{9 5} \% \mathbf{C I})$ & p-value \\
\hline Age & $0.15(0.11 ; 0.19)$ & 0.000 \\
\hline Gender & $-0.04(-0.08 ; 0.00)$ & 0.113 \\
\hline Community & $0.04(-0.00 ; 0.08)$ & 0.107 \\
\hline Perceived proportion of drinkers in the peer group $\mathrm{T} 1$ & $0.56(0.53 ; 0.60)$ & 0.000 \\
\hline Early pubertal timing $\mathbf{T} 1$ & $0.06(0.02 ; 0.10)$ & 0.017 \\
\hline $\begin{array}{l}\text { Direct effects on } \\
\text { perceived alcohol-specific rules } \mathrm{T} 2\end{array}$ & $\beta(\mathbf{9 5 \%} \mathbf{C I})$ & p-value \\
\hline Age & $-0.14(-0.17 ;-0.10)$ & 0.000 \\
\hline Gender & $0.04(0.00 ; 0.08)$ & 0.077 \\
\hline Community & $-0.03(-0.07 ; 0.01)$ & 0.198 \\
\hline Perceived alcohol-specific rules T1 & $0.55(0.49 ; 0.61)$ & 0.000 \\
\hline Early pubertal timing $T 1$ & $-0.07(-0.12 ;-0.03)$ & 0.008 \\
\hline Mediation effects & HR $(95 \%$ CI $)$ & p-value \\
\hline $\begin{array}{l}\text { Early pubertal timing } \mathrm{T} 1 \rightarrow \\
\text { perceived proportion drinkers in the peer group } \mathrm{T} 2 \rightarrow \\
\text { alcohol initiation } \mathrm{T} 1, \mathrm{~T} 2 \text { or } \mathrm{T} 3\end{array}$ & $1.04(1.01 ; 1.07)$ & 0.019 \\
\hline $\begin{array}{l}\text { Early pubertal timing } \mathrm{T} 1 \rightarrow \\
\text { perceived alcohol-specific rules } \mathrm{T} 2 \rightarrow \\
\text { alcohol initiation } \mathrm{T} 1, \mathrm{~T} 2 \text { or } \mathrm{T} 3\end{array}$ & $1.02(1.01 ; 1.03)$ & 0.035 \\
\hline
\end{tabular}

Note: $N=1286 ;$ HR = Hazard Ratio 


\section{Discussion}

This study used a developmental perspective to gain more insight into the mechanisms behind the link between early pubertal timing and alcohol initiation. It did so by investigating the pathways from early pubertal timing through changes in alcohol-specific parenting and changes in the perceived proportion of drinkers in the peer group towards adolescent alcohol use. As hypothesized, this study replicated results from earlier studies (e.g., Costello, et al., 2007; Lanza \& Collins, 2002; Patton, et al., 2004; Schelleman-Offermans, et al., 2011; Tschann, et al., 1994) showing that early pubertal timing increases the risk to initiate drinking. Furthermore, the perceived proportion of drinkers in the peer group and alcohol-specific rule setting were both powerful predictors of initiation of alcohol use. For all adolescents, a one unit increase of the perceived proportion of drinkers in the peer group resulted in a $27 \%$ higher risk to initiate alcohol use, whereas a one unit increase of the perceived alcohol-specific rules set by parents resulted in a $19 \%$ decreased risk to initiate alcohol use. Thus, although the direct impact of the perceived proportion of drinking peers in the peer group was $8 \%$ higher than the direct impact of perceived alcohol-specific rule setting,

The results of this study extend current knowledge by showing that the link between early pubertal timing and alcohol initiation was mediated by both increases in the perceived proportion of drinkers in the peer group, and by parents becoming more lenient in their alcohol-specific rule setting for early pubertal timers within a period of one year (T1 to T2). That parents relax their alcoholspecific rules to the early timing of their child can probably be explained by the older physical appearance of early pubertal timers. This effect should also be interpreted in the context of the association between alcohol-specific rules and more general parenting styles. Previous research has shown that the effect of the general parenting style behavioral monitoring on the initiation of alcohol use was mediated by parental alcohol-specific rule setting (Van Der Vorst, et al., 2005). This indicates that parents most likely tend to adapt their general parenting styles in response to early pubertal timing, in addition to adapting their alcohol-specific parenting. These changes in general parenting practices may also contribute to a possible greater autonomy parents grant their early pubertal timing adolescents in relation to other behaviors, such as the selection of friends.
The increase in the perceived proportion of drinkers in the peer group among early pubertal timers may be attributable to a de-selection of non-drinking friends and a selection of (new) drinking friends (peer selection processes), or to earlier pubertal timers and their friends changing more often in concert from non-drinking to drinking than do non-early pubertal timers and their friends (peer socialization processes). More support has been found for selection processes than for peer socialization processes in relation to adolescent alcohol use (e.g., Abar, 2010; Engels, et al., 1999; Poulin, et al., 2011; Sieving, et al., 2000; Urberg, et al., 2002). However, more specific research is needed to clarify this. Furthermore, the results of this study do not allow conclusions as to whether the social drift into a peer group with more drinkers can be explained by a social drift into older peer groups where alcohol use is normative, or a social drift into same-aged peer groups where drinking can be seen as deviant behavior. More research is needed to clarify this aspect of the peer socialization hypothesis (Stattin \& Magnusson, 1990). Moreover, no differences between boys and girls or different age groups were found in the way early pubertal timing affects the perceived proportion of drinkers in their peer group, alcohol-specific rules, and alcohol initiation. Hence, the mechanism behind the link between early pubertal timing and alcohol initiation works similarly for boys and girls and for 13 and 14 year olds.

\section{Strengths and limitations}

Although this study has several strengths, such as the large sample size, the longitudinal design, and the modest attrition over time (14.5\% at T3), there are several limitations. First, results of this study have to be confirmed by research from countries where drinking alcohol is less a marker for adolescents to express autonomy in the development to adulthood, such as in European Mediterranean countries (Knibbe, et al., 2007). Secondly, this study used, self-reported data on pubertal timing and could therefore be subject to bias compared with clinical assessment such as physician examination or hormone concentration measurements (Dorn \& Biro, 2011). However, the questionnaire used to assess pubertal development is reported to be a reliable and valid measure of pubertal maturation (Brooks-Gunn, et al., 1987; Carskadon \& Acebo, 1993; Petersen, et al., 1988). Third, it also should be noted that the proportion of drinking friends in the friend group and alcohol-specific rule setting are assessed by adolescent reports on the drinking behavior of their peers. Not using data on drinking 
behavior directly from peers might have attenuated the association between proportion of drinkers in the peer group and alcohol initiation (Jaccard, Blanton, \& Dodge, 2005). Furthermore, there might be differences in the way early and non-early pubertal timers perceive how many of their friends drink, or they might be differently influenced by their peers (Galambos, Barker, \& TiltonWeaver, 2003; Magnusson, Stattin, \& Allen, 1985). For instance, early pubertal timers might believe that more of their friends drink, to fit their perception of being more mature just like they perceive themselves as being older than their peers (Galambos, et al., 2003). Therefore, future studies should include data from the network of friends themselves to confirm the findings reported in this study. Fourth, adolescents reporting a lower perceived proportion of drinkers in their peer group showed a higher drop out than adolescents reporting a higher perceived proportion of drinking friends in their peer group. This selective drop out could have increased the risk of a type I error (false positive) regarding the mediation analyses on proportion of drinking peers. Fifth, the effect sizes of early pubertal timing on alcohol initiation $(\mathrm{HR}=1.15)$, perceived alcohol-specific rules at T2 $(\beta=-0.07)$, and on the perceived proportion

of drinkers in the peer group at T2 $(\beta=0.06)$ may seem modest. However, early pubertal timing did significantly predict changes in perceived alcohol-specific rules and the proportion of drinkers in the peer group one year later over and above the predictive value of previous perceived alcohol-specific rule setting or proportion of drinkers in the peer group. Finally, because the time span of this longitudinal study is somewhat limited, more studies, investigating long-term effects of early pubertal timing into adulthood are needed.

\section{Implications for prevention}

Perhaps the main relevance of this study is that is shows that the effect of a factor which is hardly accessible for intervention - pubertal timing - is mediated by two factors which might be accessible for prevention; the proportion of drinkers in the peer group and parental alcohol-specific rules. Results of this study showed that the increased risk of early pubertal timers to initiate drinking was due to the larger increase in the perceived proportion of drinkers in the peer group among early pubertal timers, and to parents granting their early pubertal timing children greater independence by relaxing their alcohol-specific rule setting. Therefore, preventive efforts to reduce the risk of early pubertal timers to initiate drinking should target the selection or influence of drinking peers, and/ or parental alcohol-specific rule setting. Interventions aimed at increasing adolescents' skills to resist peer pressure (peer socialization processes) have shown only minor to no effects on adolescents' alcohol use (Cuijpers, Jonkers, De Weerdt, \& De Jong, 2002). On the other hand, preventative efforts targeting parental rule setting have shown to be feasible and effective in reducing and postponing adolescent alcohol use (Koning, et al., 2009; Koutakis, et al., 2008; Smit, et al., 2008). For this reason, and in view of the results of this study, motivating parents to not decrease (or to a much less extent) their alcohol-specific rule setting over time is most likely to be effective in postponing adolescents' initiation of alcohol use. Moreover, since parents with early pubertal timing children also relax their alcohol-specific rule setting earlier in time, they should be targeted to adhere to (rather than relax) their alcohol-specific rule setting. 


\section{Chapter 5} Community and policy level of influence

Effects on adolescent alcohol use of a natural community intervention intensifying formal control

Accepted for publication

Schelleman-Offermans, K., Knibbe, R. A., Kuntsche, E., \& Casswell, S.

(in press). Effects of a natural community intervention intensifying alcohol law enforcement combined with a restrictive alcohol policy on adolescent alcohol use. Journal of Adolescent Health. 


\section{Abstract}

Purpose Determining whether intensified inspections on alcohol retailers combined with a policy withdrawing liquor licenses if retailers are fined twice per annum is effective in reducing adolescents' odds to initiate weekly drinking and drunkenness. Causal pathways by which the intervention was assumed to work were tested.

Methods A longitudinal (2008, 2009, 2010) quasi-experimental comparison group design was used including two Dutch communities; one intervention and one comparison community. Outcomes were assessed by following a cohort of 1,327 adolescents (aged 13-15 years at baseline).

Results The intervention resulted in increased retail inspections but only seven sanctions and no repeated sanctions in one year. The intervention did not reduce adolescents' odds to initiate weekly drinking. Weekly drinking adolescents in the intervention region were at reduced risk to initiate drunkenness. This effect was not mediated by smaller increases in the frequency of adoles-

cents' alcohol purchases or their perceived ease of purchasing alcohol.

Conclusions Intensified enforcement was effective in preventing adolescent drunkenness. No mediating causal pathways were detected. Effectiveness of enforcement could be increased by adopting enforcement methods with a high likelihood of apprehension, increasing social support for restrictive measures, and mobilizing the community to be more outspoken against adolescent (heavy) drinking.

\section{Introduction}

That adolescents are at high risk for harmful consequences of alcohol is undisputed (Rehm, Gmel, et al., 2003; Tapert, et al., 2004). In Europe, alcohol is the major cause of mortality and morbidity among adolescents (Anderson \& Baumberg, 2006). Hence, it is important to prevent adolescent drinking.

Restricting the availability of alcohol is a key element in effective alcohol prevention (Babor, et al., 2010; Holder, 1998; Reynolds, et al., 1997; Wagenaar \& Perry, 1994). Studies have consistently shown that decreased alcohol availability from commercialized resources (e.g., increases in the legal drinking age) is associated with decreased adolescent drinking and related problems (Babor, et al., 2010; Treno, Ponicki, Remer, \& Gruenewald, 2008; Wagenaar \& Toomey, 2002). In addition, it is important to enforce regulations in order for them to be effective (Babor, et al., 2010; Holder, 1998; Reynolds, et al., 1997). Supply behaviors of alcohol sellers can be changed by increased enforcement of the legal alcohol age limits (Holder, et al., 2000; Huckle, et al., 2005; Wagenaar, et al., 2000a). Community-wide prevention efforts restricting retailers' supply using enforcement of the legal alcohol age limits have shown to reduce adolescent heavy drinking and related harm (Holder, 1998; Stafström, et al., 2006; Wagenaar, et al., 2000b; Wagenaar, et al., 2000a).

\section{Dutch context}

The Dutch Alcohol Licensing and Catering Act (ALCA) prohibits retailers from selling soft alcoholic beverages $(<15 \%)$ to persons younger than 16 years and strong alcohol beverages $(\geq 15 \%)$ to persons younger than 18 years. Retailers are obliged by law to ask for age verification whenever it is questionable whether the buyer has reached the legal purchase age. Despite of this law, $82.6 \%$ of Dutch underage $(<16$ years) adolescents are able to buy alcohol themselves (Gosselt, et al., 2007).

Since 2000, inspections under the ALCA are conducted nationally by the Food and Consumer Product Safety Authority (FCPSA) in the Netherlands. The 
FCPSA uses undercover observations to inspect the retailers' compliance with the ALCA. In contrast with other countries (e.g., New Zealand or the United States), use of decoy operations to inspect compliance with the ALCA is not legally allowed in the Netherlands, even though this method has a high likelihood of apprehension (Gosselt, et al., 2007). The retailer gets a warning or is fined in case of non-compliance and sufficient proof. Proof is considered sufficient whenever inspectors (a) are able to justify that the buyer can be perceived as underage, (b) have observed money exchange, (c) have collected the passport number to identify the buyer. When an alcohol-retailer is fined, inspectors need to reveal their identity With approximately 40 inspectors nation-wide, enforcement efforts are generally low (frequency of inspection of maximum once a year).

In the Netherlands, there is no national alcohol policy in which liquor licenses can be withdrawn from retailers. Conversely, local authorities may implemen local policies in which, under certain circumstances, liquor licenses can be withdrawn. Liquor licenses are needed by retailers (a) allowing on-premise alcohol consumption or (b) selling strong alcoholic beverages.

\section{Factors explaining the effectiveness of enforcement}

Previous community-based intervention studies investigating the effectiveness of intensified enforcement on adolescent alcohol use used cross-sectional measurements to assess outcomes (Holder, 1998; Stafström, et al., 2006; Wagenaar, et al., 2000b; Wagenaar, et al., 2000a). However, cross-sectional measurements cannot give insight into intermediate factors or processes through which intensified enforcement reaches its effect on adolescent drinking. Previous research has indicated that two factors may play a role in explaining the effectiveness of enforcement of the legal alcohol age limits. First, increased enforcement on the legal purchase or drinking age has shown to reduce alcohol sales to minors (Grube, 1997; Huckle, et al., 2005; Wagenaar, et al., 2000a). It is reasonable to assume that these reductions contribute to reductions in adolescent (heavy) drinking (Holmila \& Warpenius, 2007). Secondly, adolescents might perceive alcohol to be less available from commercialized resources when enforcement is increased. A lower perceived ease of obtaining alcohol has already shown to be related to reductions in adolescent alcohol use (Knibbe, et al., 2005; Kuntsche, Kuendig, et al., 2008b; Paschall, Grube, Black, \& Ringwalt, 2007). Furthermore a cross-sectional study (Paschall, et al., 2007) suggested that the positive effect of compliance with underage alcohol sales laws on adolescent alcohol use may be mediated by adolescents perceiving it less easy to obtain alcohol. However, no intervention study has ever tested the underlying mechanisms through which enforcement is assumed to work.

\section{Current study}

Up to now, proof for the effect of intensified enforcement comes from studies in northern American and northern European countries. These countries are characterized by rather restrictive alcohol policies. The current study is the first to investigate whether intensified enforcement is of influence on adolescent drinking in a western European country characterized by more liberal alcohol policies (Brand, et al., 2007). More specifically, it was hypothesized that intensifying inspections on retailers' compliance with the ALCA combined with a policy wherein the local authority withdraws liquor licenses whenever retailers are sanctioned twice per annum would be effective in (a) reducing the odds for adolescents to initiate weekly drinking and (b) reducing the odds to initiate drunkenness among adolescents already initiated weekly drinking.

Another aim of this study was to test the causal pathways by which the intervention was intended to work. The outcomes of this intervention study were assessed by following a cohort of adolescents allowing for longitudinal mediation analyses. Based on previous research (Grube, 1997; Knibbe, et al., 2005; Kuntsche, Kuendig, et al., 2008b; Paschall, et al., 2007; Wagenaar, et al., 2000a), the intervention was expected to (a) impede the increase of adolescents' perceived ease of purchasing alcohol and (b) impede the increase in frequency of adolescents' alcohol purchases over time. Therefore, it was expected that the effect of the intervention was because of (a) smaller increases in alcohol purchases and/or (b) smaller increases in the perceived ease of purchasing alcohol by adolescents in the intervention compared with the control community.

\section{Method}

\section{Study design and description of communities}

This intervention study used a quasi-experimental comparison group design including two Dutch municipalities; one intervention and one comparison community. A cohort of 13- to 15-year-old adolescents was followed for 2 years, using one baseline measurement in November 2008 (T0), and two post-measurements in November 2009 (T1) and November 2010 (T2). The intervention community 
was purposely selected based on the cooperation of local politicians. Other selection criteria were that both communities needed to have (a) a central 'going out' area, (b) small chances that adolescents would go to other municipalities to buy alcoholic beverages (based on distances to other towns), and (c) similar retail density. Furthermore, the communities were matched on urbanization and social stratification and had populations between 100,000 and 150,000 each. Personal communication with stakeholders in the comparison community indicated that no activities were undertaken aiming to reduce the alcohol availability for adolescents before and during the intervention period.

\section{Intervention components}

\section{Intensified inspections}

Inspections in the current study were conducted by the FCPSA. To identify premises (on and off) attracting adolescents (so-called hotspots), information from local youth workers, community policeman, urban planning (e.g., distances from premises to high schools) and social media were used. Each community had approximately 25 hotspots. Hotspots in the intervention community were inspected at least 8 times in the 2-year intervention period. The FCPSA agreed to conduct no inspections in the comparison community during the intervention period. Inspection results (e.g., fines) from the FCPSA were reported to the local authority.

\section{'Two-strikes-out' policy}

In the intervention community, the 'Two-strikes-out' policy was implemented, such that if a retailer was fined by the FCPSA twice per annum, the local authority would start proceedings to withdraw the retailer's liquor license. Supermarkets do not sell strong alcoholic beverages and do not allow on-premise consumption. Therefore, they do not need a liquor license and were not subject to the 'Two-strikes-out' policy. All retailers (hotspot and non-hotspot) in the intervention community received a letter from the local authority announcing the intensified inspection and the 'Two-strikes-out' policy at the start of the intervention period. Furthermore, the first enforcement action in March 2009 was done in uniform (visible inspection). In the comparison community, no local alcohol policy plan was implemented.

\section{Participants}

A random sample of 4,643 adolescents, stratified on age (13-15 years) and gender, was drawn from the population registers of the communities. It was calculated that including approximately 660 participants per community in the baseline measurement would be needed to have sufficient power to detect a $5 \%$ reduction in drinking between the communities, while accounting for $20 \%$ drop-out rates. Adolescents in the sample population were approached three times (mail and telephone) until the intended sample size was reached. Twenty percent $(\mathrm{N}=929)$ of the total sample refused to cooperate, $28.6 \%(\mathrm{~N}=1,327)$ agreed to participate and $51.4 \%(\mathrm{~N}=2387)$ was not further approached because the intended sample size had been reached. Recruitment resulted in 688 adolescents $(49.1 \%$ boys; mean age $=14.1 ; \mathrm{SD}=0.80)$ in the intervention and 639 adolescents $(48.2 \%$ boys; mean age $=14.2 ; \mathrm{SD}=0.82)$ in the comparison community (Table 5.1). Adolescents in the intervention community had a significant $(\mathrm{p}<0.001)$ lower educational level than adolescents in the comparison community.

No significant difference was found between the two communities in the number of adolescents that was lost to follow-up after two years $(18.0 \%$ in the intervention vs. $15.5 \%$ in the comparison community). Binary logistic regression showed (Table 5.1) that a significantly higher number of older adolescents had dropped out in the intervention community. Furthermore, a significant selective lower drop-out was found for adolescents reporting drunkenness at baseline in the intervention community. In both communities, participants with a high educational level showed significantly smaller drop-out.

\section{Survey procedure}

This study was approved by the medical ethical committee of Maastricht University (MEC 07-4-043). Adolescent consent and consent of both parents or caregivers was provided before data collection started. At all data collection points, participants were instructed to complete the questionnaire at home in privacy. Questionnaires were collected by fieldworkers at the participant's home addresses at T0. At T1 and T2 participants were instructed to return the completed questionnaire by mail in a reply envelope. As an incentive, 5 euro was given to each participant at T0, three iPods Touch were raffled at T1, and three iPads were raffled at $\mathrm{T} 2$. 


\section{Measures}

\section{Initiation of weekly alcohol use}

A dichotomous weekly drinking status variable was determined by responses on total weekly consumption, in glasses of alcohol consumed in the past six months. Respondents reporting a total weekly consumption of $>0$ were considered weekly drinkers (Event coded as 1). All other respondents were considered non-drinkers (coded as 0 ). The survival time (at T0, T1 or T2) of the weekly alcohol initiation was recoded into a Time variable $(0,1$, or 2 years).

\section{Initiation of drunkenness among adolescents initiated weekly drinking}

Drunkenness was measured by adolescents' self-reports whether they had been drunk at least once in the past six months (Event coded as 1) or not (coded as 0 ). The survival time (at $\mathrm{T} 0, \mathrm{~T} 1$ or $\mathrm{T} 2$ ) from being a weekly drinker to getting drunk was recoded into a Time variable $(0,1$, or 2 years $)$.

\section{Frequency of alcohol purchases}

requency of alcohol purchases from commercialized resources (on- and offpremises) in the last month was measured using four items about how often adolescents purchased alcohol from snack bars or restaurants, supermarkets, liquor stores, and bars/disco's/cafes in the last month (response options ranged from $1=$ never to $6=$ eight times or more). Sum scores were computed using recoded (midpoints from responses) real frequencies. Sport canteens were not incorporated in this question because they account for an almost negligible part of the alcohol consumption of young people in the Netherlands (SchellemanOffermans, Knibbe, \& Derickx, 2009c).

\section{Perceived ease of purchasing alcohol}

Five items were used to assess how easy adolescents thought it would be for themselves to buy alcohol at a snack bar or restaurant, supermarket, liquor store, and bar or café, or a disco (response options ranged from 1 = very difficult to $5=$ very easy). This scale showed an adequate internal consistency in all measurements (Cronbach's $\alpha_{t 0}=0.79$, Cronbach's $\alpha_{t 1}=0.85$, Cronbach's $\alpha_{t 2}=0.85$ ).

\section{Implementation measures}

Inspection results and the number of times the 'Two-strikes-out' policy measure was undertaken in the time period of the intervention have been reported.

\section{Statistical analyses}

The analyses were done in several steps. First, to test the intervention effect on the initiation of weekly drinking and drunkenness, survival analyses were performed in Mplus (Muthén \& Muthén, 1998-2009) using Cox proportional hazard regression and Monte Carlo integration. When testing the intervention effect on drunkenness, only adolescents who reported weekly drinking at T0, $\mathrm{T} 1$, or T2 were included in the analyses $(\mathrm{N}=946)$. Secondly, to test if the effect of the intervention was mediated by either smaller increases in perceived alcohol availability or smaller increases in alcohol purchases over time targeted by the intervention (Figure 5.1), a linear growth model was incorporated within the survival analyses. The intercept represents the baseline measurement. The slopes of the proposed variables were expected to mediate the intervention effects on adolescent alcohol use. MacKinnon's Joint Significance Test (MacKinnon, et al., 2002) was used to determine the significance of the mediation paths. Furthermore, full information maximum likelihood was used to deal with missing data (2.8\% missing for perceived ease of purchasing alcohol; no missing data for purchases of alcohol). Covariates age, gender and educational level of the adolescent were included in all analyses. 
Figure 5.1 Conceptual mediation models of this study
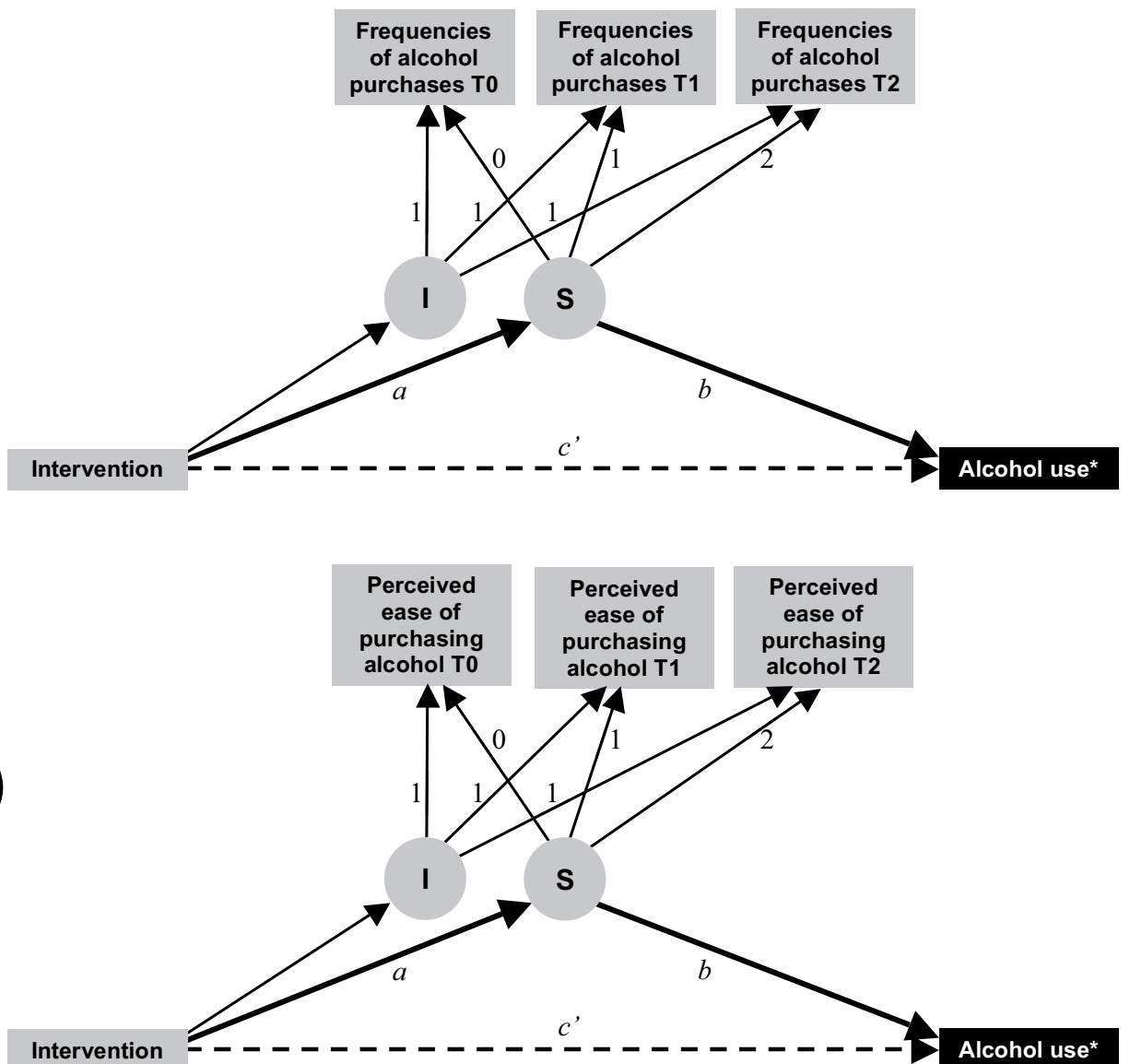

Note: Covariates age, gender, and educational level were included in the models, but not presented in the models. * Two alcohol use measures were tested: weekly alcohol initiation and drunkenness initiation among weekly drinkers. $I=$ Intercept, $S=$ Slope.

\section{Results}

\section{Intervention effects}

The percentage of weekly drinkers (Table 5.1) was higher in the intervention compared with the comparison community at $\mathrm{T} 0(41.0 \%$ vs. $33.8 \%)$ and $\mathrm{T} 1$ (57.4\% vs. $47.9 \%)$. The percentage of adolescents reporting drunkenness was lower in the intervention compared with the comparison community at $\mathrm{T} 0$ $(8.2 \%$ vs. $14.0 \%)$ and T2 $(31.5 \%$ vs. $39.2 \%)$. Adolescents in the intervention community had a 0.12 significant increased hazard to start drinking weekly compared with adolescents in the comparison community (Table 5.2). In contrast, adolescents in the intervention community were at reduced risk (Hazard Ratio $[\mathrm{HR}]=0.81$ ) to initiate drunkenness when already drinking (Table 5.3) compared with adolescents in the comparison community.

\section{Mediation analyses results}

For adolescents in both communities, increases in the frequency of alcohol purchases and the perceived ease of purchasing alcohol predicted a significantly higher hazard to initiate weekly drinking $(\mathrm{HR}=1.13$ and $\mathrm{HR}=1.20$, respectively) and to initiate drunkenness ( $\mathrm{HR}=1.32$ and $\mathrm{HR}=1.51$, respectively). Also, the baseline measurements of adolescents' frequency of alcohol purchases and their perceived ease of purchasing alcohol did not differ between the two communities. Results of mediation analyses (Table 5.2 and Table 5.3) showed no significant effects. Thus, the intervention effects found on adolescent drinking were neither because of (a) changes in adolescents' alcohol purchases nor because of (b) changes in adolescents' perceived ease of buying alcohol. 
Table 5.1 Descriptive results comparing the intervention and comparison community

\begin{tabular}{|c|c|c|c|c|c|c|}
\hline & \multicolumn{3}{|c|}{ Intervention community } & \multicolumn{3}{|c|}{ Comparison community } \\
\hline Demographic characteristics & \multicolumn{3}{|l|}{$N=688$} & \multicolumn{3}{|c|}{$N=639$} \\
\hline Mean age & \multicolumn{3}{|c|}{$14.1(.91)$} & \multicolumn{3}{|c|}{$14.2(.91)$} \\
\hline Percentage boys & & \multicolumn{3}{|c|}{48.2} \\
\hline $\begin{array}{l}\text { Percentage low and middle } \\
\text { / high education }\end{array}$ & \multicolumn{3}{|c|}{$54.5 / 45.5^{* * * *}$} & \multicolumn{3}{|c|}{$37.4 / 62.6$} \\
\hline Drop-out analyses at $\mathrm{T} 2$ & \multicolumn{3}{|c|}{ OR $(95 \% \mathrm{CI})$} & \multicolumn{3}{|c|}{ OR $(95 \%$ CI) } \\
\hline Age & \multicolumn{3}{|c|}{$1.57 *(1.11 ; 2.23)$} & \multicolumn{3}{|c|}{$1.38(0.94 ; 2.05)$} \\
\hline $\begin{array}{l}\text { Education } \\
{[0=\text { low \& middle; } 1=\text { high }]}\end{array}$ & \multicolumn{3}{|c|}{$0.50 *(0.29 ; 0.87)$} & \multicolumn{3}{|c|}{$0.45 * *(0.25 ; 0.82)$} \\
\hline $\begin{array}{l}\text { Gender } \\
{[0=\text { female; } 1=\text { male }]}\end{array}$ & \multicolumn{3}{|c|}{$1.71(0.98 ; 2.96)$} & \multicolumn{3}{|c|}{$1.09(0.60 ; 1.99)$} \\
\hline $\begin{array}{l}\text { Weekly drinker T1 } \\
{[0=\text { no; } 1=\text { yes }]}\end{array}$ & \multicolumn{3}{|c|}{$0.96(0.48 ; 1.93)$} & \multicolumn{3}{|c|}{$1.53(0.70 ; 3.35)$} \\
\hline $\begin{array}{l}\text { Weekly drinker } \mathbf{T} 2 \\
{[0=\text { no; } 1=\text { yes }]}\end{array}$ & \multicolumn{3}{|c|}{$0.84(0.42 ; 1.65)$} & \multicolumn{3}{|c|}{$0.60(0.27 ; 1.33)$} \\
\hline $\begin{array}{l}\text { Drunkenness T1 } \\
{[0=\text { no; } 1=\text { yes }]}\end{array}$ & \multicolumn{3}{|c|}{$0.50 *(0.01 ; 0.50)$} & \multicolumn{3}{|c|}{$0.23(0.04 ; 1.29)$} \\
\hline $\begin{array}{l}\text { Drunkenness T2 } \\
{[0=\text { no; } 1=\text { yes }]}\end{array}$ & \multicolumn{3}{|c|}{$1.54(0.67 ; 3.55)$} & \multicolumn{3}{|c|}{$1.04(0.35 ; 3.04)$} \\
\hline $\begin{array}{l}\text { Perceived ease of } \\
\text { purchasing alcohol T1 }\end{array}$ & \multicolumn{3}{|c|}{$1.11(0.94 ; 1.32)$} & \multicolumn{3}{|c|}{$1.10(0.90 ; 1.35)$} \\
\hline $\begin{array}{l}\text { Perceived ease of } \\
\text { purchasing alcohol T2 }\end{array}$ & \multicolumn{3}{|c|}{$0.98(0.87 ; 1.10)$} & \multicolumn{3}{|c|}{$0.90(0.73 ; 1.11)$} \\
\hline $\begin{array}{l}\text { Frequency of } \\
\text { alcohol purchases } \mathrm{T} 1\end{array}$ & \multicolumn{3}{|c|}{$1.32(0.95 ; 1.84)$} & \multicolumn{3}{|c|}{$1.19(0.80 ; 1.78)$} \\
\hline $\begin{array}{l}\text { Frequency of } \\
\text { alcohol purchases T2 }\end{array}$ & \multicolumn{3}{|c|}{$0.84(0.65 ; 1.09)$} & \multicolumn{3}{|c|}{$1.03(0.76 ; 1.39)$} \\
\hline $\begin{array}{l}\text { Testing differences } \\
\text { between communities }\end{array}$ & T0 & T1 & T2 & T0 & T1 & T2 \\
\hline $\begin{array}{l}\text { Cumulative percentage } \\
\text { lost to follow-up }\end{array}$ & - & 11.3 & 18.0 & - & 13.1 & 15.5 \\
\hline $\begin{array}{l}\text { Percentage } \\
\text { weekly drinking (no/yes) }\end{array}$ & $\begin{array}{l}41.0^{* *} \\
\chi^{2}=7.3\end{array}$ & $\begin{array}{l}57.4^{* *} \\
\chi^{2}=10.4\end{array}$ & $\begin{array}{l}71.2 \\
\chi^{2}=2.4\end{array}$ & 33.8 & 47.9 & 66.9 \\
\hline $\begin{array}{l}\text { Percentage } \\
\text { drunkenness (no/yes) }\end{array}$ & $\begin{array}{l}8.2^{* *} \\
\chi^{2}=8.0\end{array}$ & $\begin{array}{l}18.2 \\
\chi^{2}=3.0\end{array}$ & $\begin{array}{l}31.5^{*} \\
\chi^{2}=5.3\end{array}$ & 14.0 & 23.0 & 39.2 \\
\hline $\begin{array}{l}\text { Mean score perceived ease } \\
\text { of purchasing alcohol }\end{array}$ & $\begin{array}{l}2.19 \\
(0.81) \\
\mathrm{t}=-0.9\end{array}$ & $\begin{array}{l}2.52 \\
(1.13) \\
\mathrm{t}=-0.8\end{array}$ & $\begin{array}{l}2.95 \\
(1.27) \\
t=-1.5\end{array}$ & $\begin{array}{l}2.23 \\
(0.79)\end{array}$ & $\begin{array}{l}2.57 \\
(1.12)\end{array}$ & $\begin{array}{l}3.06 \\
(1.20)\end{array}$ \\
\hline $\begin{array}{l}\text { Mean score frequency of } \\
\text { alcohol purchases }\end{array}$ & $\begin{array}{l}0.62 \\
(2.16) \\
t=0.4\end{array}$ & $\begin{array}{l}1.51^{*} \\
(3.08) \\
t=2.2\end{array}$ & $\begin{array}{l}2.22 \\
(3.39) \\
t=-0.4\end{array}$ & $\begin{array}{l}0.58 \\
(1.79)\end{array}$ & $\begin{array}{l}1.16 \\
(2.45)\end{array}$ & $\begin{array}{l}2.31 \\
(3.56)\end{array}$ \\
\hline
\end{tabular}

Note: Standard deviations are shown in parentheses; $* * * p<.001 ; * * p<.01 ; * p<.05$.
Table 5.2 Standardized modeling results and hazard ratios on initiation of weekly drinking (IWD)

\begin{tabular}{|c|c|c|}
\hline Intervention effect $\rightarrow$ IWD & \multicolumn{2}{|r|}{ HR $(95 \%$ CI) } \\
\hline Age $\rightarrow$ IWD & & $1.28 * * *(1.22 ; 1.35)$ \\
\hline Education $\rightarrow$ IWD & & $1.09 *(1.02 ; 1.16)$ \\
\hline Gender $\rightarrow$ IWD & & $0.95(0.89 ; 1.01)$ \\
\hline Intervention effect $\rightarrow$ IWD & & $1.12 * *(1.05 ; 1.20)$ \\
\hline $\begin{array}{l}\text { Mediation model results } \\
\text { frequency of alcohol purchases }\end{array}$ & B $(95 \%$ CI $)$ & HR $(95 \%$ CI $)$ \\
\hline Age $\rightarrow$ IWD & & $1.22 * * *(1.16 ; 1.28)$ \\
\hline Education $\rightarrow$ IWD & & $1.08(1.00 ; 1.15)$ \\
\hline Gender $\rightarrow$ IWD & & $0.91 *(0.86 ; 0.97)$ \\
\hline Intervention effect $\rightarrow$ IWD & & $1.11 * *(1.04 ; 1.18)$ \\
\hline Slope frequency of alcohol purchases $\rightarrow$ IWD & & $1.13^{* * * *}(1.09 ; 1.17)$ \\
\hline $\begin{array}{l}\text { Intervention effect } \rightarrow \\
\text { Intercept frequency of alcohol purchases }\end{array}$ & $0.03(-.03 ; 0.08)$ & \\
\hline $\begin{array}{l}\text { Intervention effect } \rightarrow \\
\text { Slope frequency of alcohol purchases }\end{array}$ & $0.05(-.02 ; 0.11)$ & \\
\hline $\begin{array}{l}\text { Intervention effect } \rightarrow \\
\text { Slope frequency of alcohol purchases } \rightarrow \\
\text { IWD }\end{array}$ & & $1.01(0.99 ; 1.03)$ \\
\hline $\begin{array}{l}\text { Mediation model results } \\
\text { perceived ease of purchasing alcohol }\end{array}$ & $\beta(95 \%$ CI $)$ & HR (95\% CI) \\
\hline Age $\rightarrow$ IWD & & $1.24 * * *(1.17 ; 1.30)$ \\
\hline Education $\rightarrow$ IWD & & $1.08(1.00 ; 1.15)$ \\
\hline Gender $\rightarrow$ IWD & & $0.93(0.87 ; 1.00)$ \\
\hline Intervention effect $\rightarrow$ IWD & & $1.13^{* *}(1.06 ; 1.20)$ \\
\hline Slope perceived ease purchasing alcohol $\rightarrow$ IWD & & $1.20^{* * * *}(1.12 ; 1.30)$ \\
\hline $\begin{array}{l}\text { Intervention effect } \rightarrow \\
\text { Intercept perceived ease purchasing alcohol }\end{array}$ & $-0.02(-0.10 ; 0.06)$ & \\
\hline $\begin{array}{l}\text { Intervention effect } \rightarrow \\
\text { Slope perceived ease purchasing alcohol }\end{array}$ & $-0.01(-0.11 ; 0.09)$ & \\
\hline $\begin{array}{l}\text { Intervention effect } \rightarrow \\
\text { Slope perceived ease purchasing alcohol } \rightarrow \\
\text { IWD }\end{array}$ & & $1.00(0.99 ; 1.01)$ \\
\hline
\end{tabular}

IWD

Note: $N=1,327 ; * * * p<.001 ; * * p<.01 ; * p<.05$; Since all models are fully saturated, no further fit measures are presented. 
Table 5.3 Standardized modeling results and hazard ratios on initiation of drunkenness among drinkers (ID)

\section{Intervention effect $\rightarrow$ ID}

\section{Age $\rightarrow$ ID}

Education $\rightarrow$ ID

Gender $\rightarrow$ ID

Intervention effect $\rightarrow$ ID

Mediation model results

frequency of alcohol purchases

Age $\rightarrow$ ID

Education $\rightarrow$ ID

Gender $\rightarrow$ ID

Intervention effect $\rightarrow$ ID

Slope frequency of alcohol purchases $\rightarrow$ ID

Intervention effect $\rightarrow$

Intercept frequency of alcohol purchases

Intervention effect $\rightarrow$

Slope frequency of alcohol purchases

$.01(0.96 ; 1.07)$

Slope frequency of alcohol purchases $\rightarrow$

ID

Mediation model results

perceived ease of purchasing alcohol

B $(95 \%$ CI $)$

HR $(95 \%$ CI $)$

Age $\rightarrow$ ID

Education $\rightarrow$ ID

Gender $\rightarrow$ ID

Intervention effect $\rightarrow$ ID

Slope perceived ease purchasing alcohol $\rightarrow$ ID

Intervention effect $\rightarrow$

Intercept perceived ease purchasing alcohol

Intervention effect $\rightarrow$

Slope perceived ease purchasing alcohol

Intervention effect $\rightarrow$

Slope perceived ease purchasing alcohol $\rightarrow$

Note: $N=946 ; * * * p<.001 ; * * p<.01 ; * p<.05$; Since all models are fully saturated, no further fit measures are presented.

\section{Implementation results}

Within the 2-year intervention period, 248 inspections (approximately 9 inspections per hotspot; 4-5 times yearly) were completed in the intervention community versus none in the comparison community (Table 5.4). Adolescents who appeared to be younger than 16 years (subjective judgment of the inspector) were present in 171 inspections, whereas no underage group was present in 77 inspections. Within the 171 inspections where the underage group was present, FCPSA inspectors observed 53 purchase attempts by the underage group, with the most attempts in pubs, bars, or nightclubs $(\mathrm{n}=26)$ and supermarkets $(\mathrm{n}=$ 18). Supply to the underage group was observed 25 times. However, only 7 times did the supply to the underage group result in sanctions ( 3 written warnings and 4 fines), as 18 times the FCPSA inspector was not able to gather enough proof to fine or warn the retailer. Furthermore, no retailer was fined twice in one year, resulting in no withdrawals of alcohol licenses in the intervention community.

Table 5.4 Inspection results in the intervention community

\begin{tabular}{|c|c|c|c|c|c|c|c|}
\hline Number of & $\begin{array}{l}\text { Inspec- } \\
\text { tions }\end{array}$ & $\begin{array}{l}\text { Underage } \\
\text { group } \\
\text { present }\end{array}$ & $\begin{array}{l}\text { Observed } \\
\text { purchase } \\
\text { attemps by } \\
\text { underage } \\
\text { group }\end{array}$ & $\begin{array}{l}\text { Observed } \\
\text { supply to } \\
\text { underage } \\
\text { group }\end{array}$ & $\begin{array}{l}\text { Written } \\
\text { warnings }\end{array}$ & Fines & $\begin{array}{r}\text { License } \\
\text { with- } \\
\text { drawals }\end{array}$ \\
\hline Events* & 14 & 13 & 7 & 3 & 0 & 1 & 0 \\
\hline $\begin{array}{l}\text { Sport } \\
\text { canteens }\end{array}$ & 7 & 5 & 2 & 1 & 0 & 0 & 0 \\
\hline $\begin{array}{l}\text { Pubs/bars/ } \\
\text { night clubs }\end{array}$ & 101 & 82 & 26 & 15 & 1 & 3 & 0 \\
\hline $\begin{array}{l}\text { Super- } \\
\text { markets }\end{array}$ & 111 & 67 & 18 & 6 & 2 & 0 & 0 \\
\hline $\begin{array}{l}\text { Liqour } \\
\text { stores }\end{array}$ & 15 & 4 & 0 & 0 & 0 & 0 & 0 \\
\hline Total & 248 & 171 & 53 & 25 & 3 & 4 & 0 \\
\hline
\end{tabular}

* Events are local festivals or festivities where alcohol is served.

\section{Discussion}

The current study evaluated whether intensified inspections of retailers combined with implementation of the 'Two-strikes-out' alcohol policy reduced the odds for adolescents to initiate weekly drinking and drunkenness when already drinking weekly. Furthermore, this study investigated possible underlying factors through which the intervention was assumed to influence adolescent alcohol 
use. The intervention was ineffective in reducing the odds to initiate weekly drinking; adolescents in the intervention community were more likely to initiate weekly drinking. On the other hand, the intervention reduced the odds to initiate drunkenness among weekly drinkers. This finding is consistent with the preventative effect of alcohol-law enforcement on adolescent alcohol use, as reported in other studies (Holder, et al., 2000; Wagenaar, et al., 2000a). Thus, also in a country with relatively liberal alcohol policies, such as the Netherlands (Brand, et al., 2007), intensified enforcement effectively reduced adolescen drunkenness. When investigating the underlying factors through which the intervention was assumed to influence drinking, no significant mediation effects were found for adolescents' perceived ease of purchasing alcohol or frequencies of alcohol purchases. These variables may be less important for explaining adolescent drunkenness than previous studies led us to assume (Grube, 1997 Huckle, et al., 2005; Knibbe, et al., 2005; Kuntsche, Kuendig, et al., 2008b; Paschall, et al., 2007; Wagenaar, et al., 2000a).

The discrepancy in results on the two drinking outcome variables might be the result from differences in social availability between the two communities. Soci-

al sources for alcohol (such as parents, peers, or other adults) have been shown

to be a common source of alcohol for young drinkers (Hearst, et al., 2007) Thus, the social alcohol availability might have been greater for adolescents in the intervention than in the comparison community, increasing their odds to initiate weekly drinking. Further research is needed to investigate whether increased enforcement on the legal purchase age may result in substitution of alcohol from social sources.

The non-significance of the tested mediation paths through which the intervention was assumed to work indicated that there might be more complex mechanisms or other factors causing the reduced odds for adolescents to initiate drunkenness in the intervention community. For instance, it can be speculated, that on-premise retailers anticipated to the increased alcohol-law inspections by being more careful with over-serving alcohol (another law) to customers.

The methods of enforcement showed that there was a low likelihood of retailers being sanctioned. The inspections' likelihood of sanction was only $28 \%$; 7 warnings or fines resulting from 25 times observed supply to the underage group. To be able to fine a retailer twice in one year and to withdraw their liquor license as defined in the 'Two-strikes-out' policy, the likelihood of apprehension should have been at least $45 \%$ (based on 4 to 5 inspections annually). Indeed, personal communication with the FCPSA inspection coordinator indicated that during most inspections it was difficult for inspectors to fine retailers even though they may not have complied with the law. This was because of several reasons. First, adolescents who purchased alcohol were unwilling to cooperate, resulting in insufficient proof for the inspector and therefore no fine for the retailer. Secondly, some adolescents with a young appearance who purchased alcohol appeared to be much older than 16 years (e.g., $\geq 20$ years) which resulted in insufficient ground to fine the retailer.

Overall, it can be concluded that a community-based intervention intensifying enforcement on the legal purchase age is effective in reducing the odds for weekly drinking adolescents to initiate drunkenness. Thus, intensified enforcement effectively increases the health of adolescents at greatest risk (weekly heavy drinkers). This outcome becomes even more noteworthy considering the low likelihood of sanctions, which most likely weakened the results from this study on adolescent drinking. Using inspection methods with a higher likelihood of sanctions for alcohol sellers (e.g., decoy operations) is likely to increase the effectiveness of enforcement on adolescent drinking.

\section{Strengths and limitations}

Although this study has several strengths, such as the natural setting (high external validity) the large sample size and the longitudinal and comparison group design, it also has several limitations. First, because of restricted time and resources, no data at community level (e.g., alcohol induced hospitalization or crime) and no long term effects (e.g., after 5 years) were collected. Secondly, because $75 \%$ of the cohort followed in this study already reached the legal purchase age during the time period of the intervention, exposure to the intervention might have been too short for these adolescents. Third, the higher selective dropout among older adolescents in the intervention community could have reduced the likely number of (heavy) drinking adolescents in the remaining group of adolescents from this community. Therefore, the findings in relation to the effectiveness of the intervention might be overestimated.

\section{Implications for prevention and policy improvement}

From a prevention viewpoint it can be concluded that even modest increases in enforcement efforts increases the health of adolescents at greatest risk (weekly heavy drinkers). The effect of enforcement on adolescent alcohol use can most 
likely be increased when alcohol-law inspections with a high likelihood of apprehension are used, such as decoy operations (Gosselt, et al., 2007). However, as in the Netherlands and in many other European countries (e.g., Norway or Belgium) the use of decoy operations is (as yet) not legal, other initiatives to increase the effectiveness of inspections should be considered. One way is to enhance inspectors' authority to fine retailers based on only observed noncompliance with ALCA, without the need for further proof. Furthermore, to increase the likelihood for inspectors to be at the right place at the right time, it should be promoted that parents of adolescents (or other important actors) supply local authorities and inspectors with 'hotspot' information. Furthermore, losing alcohol licenses for a certain period (or permanently) is a much bigger threat for alcohol sellers than fines. To increase this threat for alcohol sellers, intensified enforcement can best be combined with a local alcohol policy, such as 'Two-strikes-out'. Moreover, to increase the effect of enforcement, it is important to increase social support for restrictive alcohol policy measures and mobilize parents, teachers, sport trainers and other relevant people in the direct environment of the adolescent to be more outspoken against adolescent drinking and drunkenness.

\section{To increase the effect of enforcement, it is important} to increase social support for restrictive alcohol policy

\section{measures.}


Chapter 6

Organizational, community,

and policy

level of

influence

Effects on adolescent

alcohol use of a community intervention combining intensified formal and informal control 


\section{Abstract}

Aims To determine the effect on adolescent alcohol use of a community intervention combining intensified formal control (restricting retail supply) and informal control (restricting social supply). Intervention effects on intermediate intervention goals were investigated. Analyses for different age groups were performed.

Design A longitudinal quasi-experimental design (baseline at 2008, plus two yearly post-measurements), including one intervention and one matched comparison community.

Setting Two Dutch communities of $\pm 150,000$ inhabitants each.

Participants Outcomes were assessed by following 1,368 Dutch adolescents aged 13-15 years at baseline.

Measurements Main dependent variables were weekly drinking status and progression into drunkenness among weekly drinkers. Additional dependent variables were formal control intermediate intervention goals (frequency of alcohol purchases and perceived ease of purchasing alcohol) and informal control intermediate intervention goals (frequency of alcohol-specific rules and parental alcohol supply).

Findings Survival analyses showed no significant reduction in the risk to drink weekly for adolescents in the intervention. In the intervention community, the risk to progress into drunkenness was reduced by $15 \%(\mathrm{p}=0.04)$ for adolescents drinking weekly. No intervention effects on the intermediate intervention goals were found among 14 and 15-year-olds. The intervention had a positive effect on two of four intermediate intervention goals (i.e. parental alcohol supply and alcohol-specific rules) among 13-year-olds.

Conclusion A combined formal and informal community intervention package is associated with a reduced risk to progress into drunkenness among weekly drinking adolescents. Interventions focusing on discouraging drinking below a certain age might cause a greater increase in the frequency of purchasing alcohol once reaching this age.

\section{Introduction}

Alcohol use is a major cause of mortality and morbidity among European adolescents (Hibell, et al., 2007), emphasizing the need to improve alcohol prevention strategies. Prevention programs focused on reducing the demand for alcohol at individual level via educational programs have limited or no impact on alcohol use and related problems (Cuijpers, et al., 2002; Foxcroft, et al., 2011).

Such programs rarely consider the drinking environment, in which alcohol is often tolerated and/or even promoted. Indeed, increased alcohol availability from commercialized and social sources is associated with increased adolescent drinking and related problems (Babor, et al., 2010; Treno, et al., 2008). Therefore, to achieve long-term changes in drinking behavior, prevention efforts should include reducing the availability and/or supply of alcohol (Babor, et al., 2010; Holder, 1998; Wagenaar \& Perry, 1994) by increasing formal control (e.g., alcohol law enforcement, or alcohol policy) and/or informal control (e.g., via parents or teachers).

Community-wide prevention efforts restricting retailers' alcohol supply to minors can reduce alcohol-related harm and adolescent heavy drinking (Holder, et al., 2000; Wagenaar, et al., 2000b; Wagenaar, et al., 2000a), whereas the evidence for the effectiveness of restricting adolescents' access from social sources (e.g., parents) is limited (Holder, 2004; Komro \& Toomey, 2002). Nevertheless, besides retail outlets, parents are an important source of alcohol (Harrison, et al., 2000; Hearst, et al., 2007; Hemphill, et al., 2007; Wagenaar, et al., 1993; Williams \& Mulhall, 2005). About 60\% of Dutch adolescents aged 13-15 years obtain alcohol from their parents (Schelleman-Offermans, et al., 2009b). Stimulating parents to maintain strict attitudes towards their children's alcohol use is effective in preventing adolescent alcohol use (Koning, et al., 2009; Koutakis, et al., 2008).

Although the potential for success improves when more social environment factors provide consistent messages discouraging adolescent drinking (Holder, 1998), 
interventions aimed at increasing community-wide both formal and informa control are rare. To our knowledge, the Swedish Trelleborg Project (Stafström, et al., 2006) is the only community-wide trial that actively involved parents to restrict social availability (informal control) combined with retail supply restrictions (formal control); this resulted in reduction of harmful drinking among youth. However, Sweden is a Scandinavian country with relatively strict alcohol policies. The current study is the first to investigate whether combining formal and informal control prevents adolescents from drinking in a western European country with more liberal alcohol policies.

\section{Intermediate intervention goals of formal and informal control}

As in most community-based prevention studies, the Trelleborg Project (Stafström, et al., 2006) used multiple cross-sectional measurements to assess outcomes, which provide limited insight into intermediate processes potentially explaining intervention effects. Four factors may contribute to explaining the effectiveness of formal or informal control. First, increased alcohol-law enforcement reduces the sale to minors (Grube, 1997; Huckle, et al., 2005; Wagenaar,

et al., 2000a), which is assumed to contribute to reduction in adolescent drinking (Holmila \& Warpenius, 2007). Secondly, whenever formal control is increased, adolescents might find it harder to purchase alcohol. A lower perceived ease of purchasing alcohol is associated with reduction in adolescent alcohol use (Knibbe, et al., 2007; Kuntsche, Kuendig, \& Gmel, 2008a; Paschall, et al., 2007). Third, parents can be stimulated to remain strict in their alcohol-specific rule setting (Koning, Van den Eijnden, Engels, Verdurmen, \& Vollebergh, 2011). In turn, strict parental alcohol-specific rule setting reduces the odds for adolescents to initiate drinking (Jackson, et al., 1999; Van Der Vorst, et al., 2005). Fourth, although parental alcohol supply is associated with adolescent risky drinking (Gillian, Kypri, Johnson, Lynagh, \& Love, 2012), the possibility to change this source of supply has not been investigated. However, since parental alcohol-specific rule setting can be changed (Koning, Van den Eijnden, Engels, Verdurmen, \& Vollebergh, 2011), it is plausible that a change in parental alcohol supply can also be achieved.

\section{The Dutch context}

Similar to other West-European countries, in the Netherlands the minimum age to legally purchase alcohol is 16 years for light alcoholic beverages $(<15 \%$ alcohol) and 18 years for strong alcoholic beverages ( $\geq 15 \%$ alcohol). This is lower than the legal purchase age in the USA or New Zealand; perhaps more important, however, is that it is easy for underage Dutch adolescents to purchase alcohol themselves (Gosselt, et al., 2007). Furthermore, it is relatively common for parents in the Netherlands to drink with their adolescent children at special occasions or family gatherings (Van Der Vorst, 2007; Van Der Vorst, et al., 2007), indicating the extent to which alcohol use is embedded in Dutch culture.

\section{Current intervention study}

This study aims to determine the preventive effect on adolescent alcohol use in the Netherlands of a community-wide increase of formal and informal control (see Figure 6.1). Combining formal and informal control was expected to reduce the risk of adolescents to drink weekly and reduce the risk in weekly drinkers to progress into drunkenness.

To gain more insight into intermediate factors explaining the preventive effect of the intervention, it was investigated whether the intervention and the comparison community differed over time regarding change in intermediate intervention goals (frequency of alcohol purchases, perceived ease of purchasing alcohol, frequency of alcohol-specific rules, and parental alcohol supply). It was expected that, compared with the control community, the intervention would: a) impede the increase in frequency of alcohol purchases, b) impede the increase in perceived ease of purchasing alcohol, c) impede the decrease in the frequency of alcohol-specific rules (parents remaining stricter), and d) impede the increase in frequency of parental alcohol supply. Moreover, because the effect of the intervention may vary by age, separate analyses were performed for different age groups of adolescents.

\section{Method}

\section{Study design}

This intervention study used a quasi-experimental comparison group design including one intervention and one comparison community. A cohort of 1,368 adolescents aged 13-15 years was followed for two years in both communities, using one baseline measurement in November 2008 (T0), and two post-measurements in November 2009 (T1) and November 2010 (T2). The intervention community was selected based on the cooperation of local politicians, civil servants, 
and professionals. Other a priori selection criteria were that both communities have: a) a central going-out area, b) a small chance that adolescents would go to another municipality to buy alcoholic beverages (due to the distance involved) and: c) a similar retail density. Furthermore, the communities were matched on urbanization, social stratification, and each had a population of $\pm 150,000$. Personal communication with stakeholders in the comparison community indicated that no activities aimed at reducing the retail or social alcohol availability for adolescents were undertaken in this community before/during the intervention period.

\section{Intervention components}

\section{Formal contro}

Formal control was enhanced by three intervention components. First, the Food and Consumer Product Safety Authority (FCPSA) identified on- and offpremises attracting adolescents (so-called hotspots) using information from local youth workers, community policemen, urban planning (e.g., proximity

to high schools) and social media. Each community had approximately 25 hotspots. The FCPSA intensified the frequency of alcohol-law inspections for hot spots in the intervention community only. Intensified inspections took place from February 2009, once every two weeks, until November 2010. Secondly, the local authorities in the intervention community implemented a new alcohol policy called 'Three-strikes-out'. This implied that if an on-premises retailer in the intervention community was fined by the FCPSA three times per annum, they would start proceedings to withdraw the retailer's liquor license. The 'Three strikes-out' alcohol policy was approved by the local council in May 2009. Third, outcomes of enforcement actions were used for press releases to raise community awareness and increase the perceived likelihood of apprehension (media advocacy). The first press release was in February 2009, announcing the planned intensified enforcement. Press releases were used throughout the remaining intervention period.
Figure 6.1 Conceptual intervention model of the present study

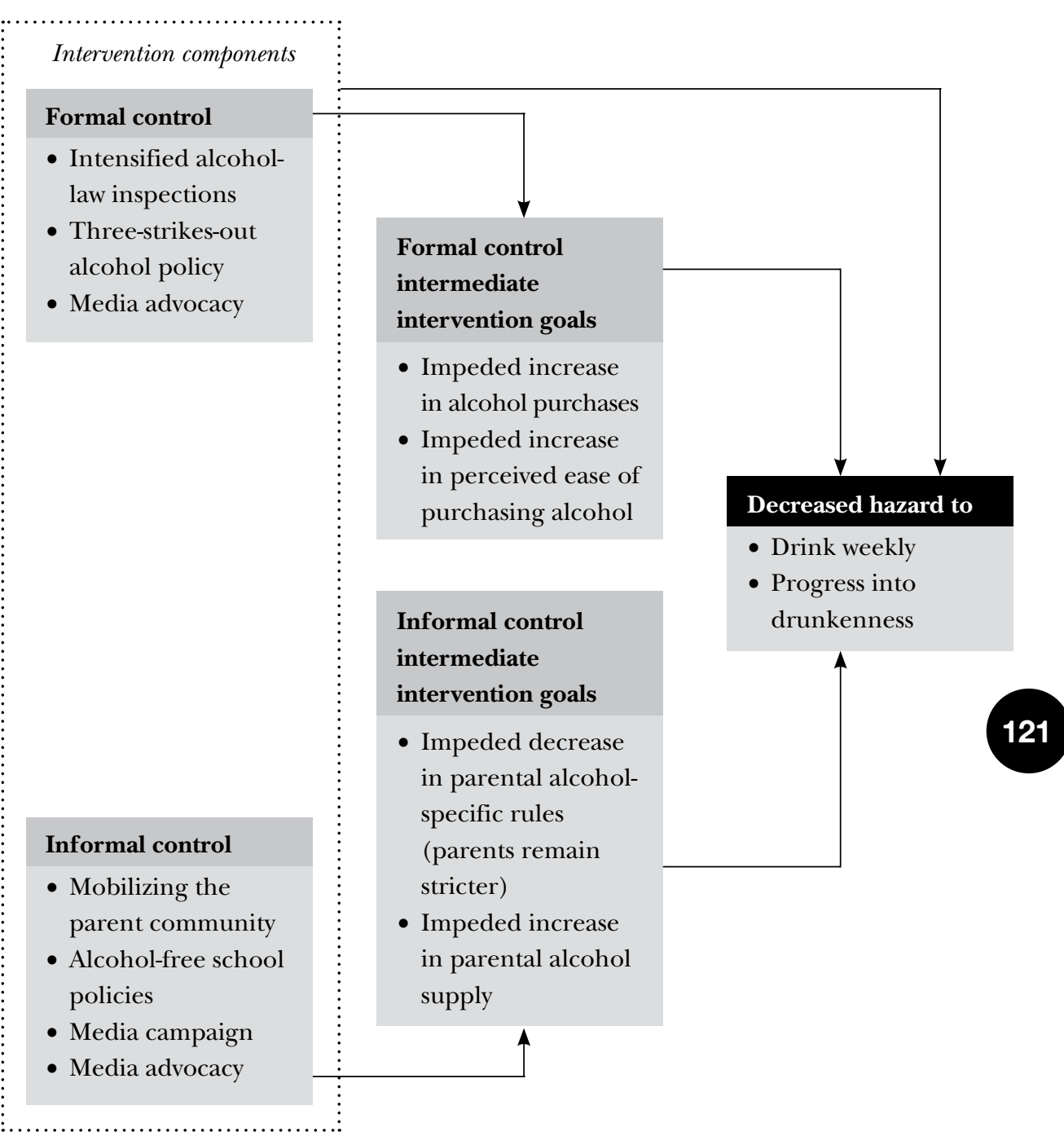




\section{Informal contro}

In the intervention community, informal control was enhanced by four intervention components. First, a local media campaign was developed by local health and communication professionals, the Dutch Institute for Alcohol Policy and a parental committee, to inform parents about the health consequences of adolescent drinking and alcohol-specific parenting guidelines. Posters, magazines, leaflets, gadgets (e.g., reusable shopping bags) and selective advertisements on Facebook were used to convey these messages to parents. The media campaign started with a public event in September 2009. Secondly, in January 2009 a parental action committee (meeting monthly during the intervention period) was mobilized. This committee developed a website for parents of adolescent to inform them about the negative health consequences of adolescent drinking and stimulate parents to maintain strict alcohol-specific rules. They also organized actions at local markets, malls, and high schools, where they distributed leaflets/gadgets and personally approached parents to create an informal network with shared restrictive norms towards adolescents alcohol use. Thirdly, local health professionals advised all 13 local high schools in the intervention

community to formulate and implement an alcohol-free school policy, i.e. that alcohol use was no longer tolerated at school parties or other events. Finally, outcomes of community actions, (e.g., actions of the parental committee or alcohol-free school policies) were used for press releases to raise awareness of the community (media advocacy).

\section{Participants}

A random sample of 4,468 adolescents, stratified by age (13-15 years) and gender, was drawn from the local population registers of the communities. It was calculated that \pm 660 participants per community would be needed in the baseline measurement to have sufficient power to detect a $5 \%$ reduction in drinking between the communities, while accounting for a $20 \%$ drop-out rate.

The randomly sampled adolescents were approached three times (mail and telephone) until the sample size was reached. After recruitment, $17.4 \%$ ( $\mathrm{n}=776)$ of all sampled adolescents refused to cooperate, $30.6 \%(n=1,368)$ agreed to participate and $52.0 \%(n=2,324)$ was not further approached because the intended sample size was reached. Recruitment resulted in 729 adolescents $(49.0 \%$ boys; mean age $=14.1$ years; $\mathrm{SD}=0.79)$ in the intervention and 639 adolescents $(48.2 \%$ boys; mean age $=14.2$ years; $\mathrm{SD}=0.80$ ) in the comparison community. After two years, $11.9 \%$ of the adolescents were lost to follow-up in the intervention community, and $15.5 \%$ was lost to follow-up in the comparison community. Logistic regression showed a higher drop-out for weekly drinking adolescents at baseline in the intervention community $(\mathrm{OR}=2.5 ; \mathrm{p}<0.05)$. A higher drop-out was also found for adolescents reporting higher frequencies of parental alcohol supply at baseline in the comparison community $(\mathrm{OR}=1.65 ; \mathrm{p}<0.05)$. No differences between communities in selective drop-out were found for any other mode variables (data available from the authors upon request)

\section{Survey procedure}

This study was approved by the medical ethical committee of Maastricht University (MEC 07-4-043) and consent of both parents/caregivers and their adolescent children was obtained before data collection started. Participants were instructed to complete the questionnaire at home in privacy. Questionnaires were collected by fieldworkers at the participant's home addresses at T0. At T1 and $\mathrm{T} 2$ participants were instructed to return the completed questionnaire by mail in a reply envelope. As an incentive, 5 euro was given to each participant at $\mathrm{T} 0$, three iPods Touch were raffled at T1, and three iPads were raffled at T2.

\section{Measures}

\section{Weekly drinking status}

A dichotomous weekly drinking status variable was determined based on responses regarding frequency of weekly drinking in the last 6 months. Respondents reporting a frequency of weekly consumption of $>0$ were considered weekly drinkers (coded as 1). All other respondents were considered as non-weekly drinkers (coded as 0 ). The survival time (at T0, T1 or T2) of the first state of weekly drinking was recoded into a Time variable $(0,1$ or 2 years)

\section{Progression into drunkenness among weekly drinkers}

Drunkenness was measured by adolescents' self-reports indicating whether they had been drunk at least once in the last 6 months (coded as 1) or not (coded as 0 ). The survival time from the first state of weekly drinking to getting drunk was calculated by subtracting the Time to first state of weekly drinking from the Time to the first state of drunkenness $(0,1$, or 2 years $)$. 


\section{Frequency of alcohol-specific rules}

A Dutch instrument with 9 items (response options: $5=$ never to $1=$ very often) was used to measure how often adolescents think that their parents allow them to drink inside/outside the home during week days and in the weekends (Van Der Vorst, et al., 2005) (Cronbach's $\alpha_{t 0}=0.92$, Cronbach's $\alpha_{t 2}=0.94$ ). This is a reliable and valid scale to measure alcohol-specific rules (Van Der Vorst, et al., 2007; Van Der Vorst, et al., 2005). Mean scores were used; higher mean scores indicating stricter rules.

\section{Alcohol provision by parents}

Participants were asked how often they received alcohol from their parents in the last month (response options: $1=$ never to $6=$ eight times or more). Midpoints (e.g., 4-5 times was recoded as 4.5) from responses were used.

\section{Frequency of alcohol purchases}

Frequency of alcohol purchases was measured using 4 items, asking the frequency of purchasing alcohol from snack bars/restaurants, supermarkets, liquor stores, or bars/discos/cafes in the last month (response options: 1=never to $6=$ eight times or more). Sum scores were computed using midpoints from the responses.

\section{Perceived ease of purchasing alcohol}

Based on 4 items, participants responded how easy they thought it would be for them to buy alcohol from snack bars/restaurants, supermarkets, liquor stores, or bars $/$ discos/cafes (Cronbach's $\alpha_{\mathrm{t} 0}=0.79 ; \alpha_{\mathrm{t} 2}=0.85$; Response options: $1=\mathrm{very}$ difficult to $5=$ very easy). Mean scores were computed using midpoints from the responses.

\section{Statistical analyses}

To test relationships between the intermediate intervention goals and weekly drinking and drunkenness Pearson correlations were estimated. To investigate whether the intervention reduced the risk of becoming a weekly drinker or the progression into drunkenness (first hypothesis) survival analyses with Cox proportional hazard regression and Monte Carlo integration in Mplus (Muthén \& Muthén, 1998-2009) were estimated. Survival analysis was chosen to overcome methodological problems regarding the heavily skewed distribution of the origi-
Chapter 6 Organizational, community and policy level of influence nally measured alcohol outcome measures. Adolescents not yet drinking weekly may differ in how they respond to increasing formal and informal control compared with adolescents who already drink weekly. Therefore, when testing the intervention effect on drunkenness, we investigated progression into drunkenness separately from starting to drink weekly, by focusing on the (smaller) group of weekly drinkers. To establish whether the intervention had different effects on different age groups of adolescents, each age group was analyzed separately. To describe whether the change over time in intermediate intervention goals differed for the intervention and comparison community, independent sample t-tests were performed using delta-scores (T0-T2). To test the second hypothesis, whether the intermediate intervention goals differed in change over time in the intervention compared with the comparison community (Figure 6.2) structural equation models with robust maximum likelihood estimation were used in Mplus (Muthén \& Muthén, 1998-2009). Differences in rates of change were concluded if interaction effects between intervention*intermediate intervention goals $\mathrm{T} 0$ were significant. Because the intervention elements were implemented over the entire intervention period, difference in change was also measured over the same period (T0-T2). Multi-group analyses were used to investigate differences between different age groups.

Adolescents who only responded at baseline were excluded from the analyses $(\mathrm{n}=74 ; 5.4 \%)$. Thereafter, full information maximum likelihood was used to deal with the remaining drop-out rates $(n=114 ; 8.3 \%)$ and missing data $(n=42 ; 3.07 \%$ for alcohol-specific rules: $n=6 ; 0.44 \%$ for parental alcohol supply: $n=10 ; 0.73 \%$ for perceived ease of purchasing alcohol, no missing data for alcohol purchases).

Figure 6.2 Conceptual model testing the effects of the intervention on changes in intermediate intervention goals over time

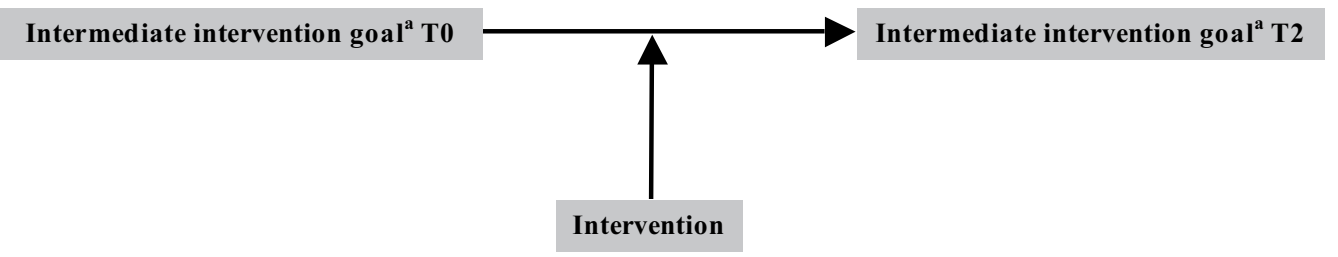

Note: Covariances between model variances and covariates age, gender, and educational level were included in the models, but are not presented in the Figures. ${ }^{a}$ Four intermediate intervention goals were tested: 1) Frequency of alcohol-specific rules, 2) Frequency of parental alcohol supply, 3) Perceived ease of purchasing alcohol, 4) Frequency of alcohol purchases. 


\section{Results}

\section{Process of implementation}

Intensified inspections by the FCPSA resulted in 285 inspections, 7 written warnings and 11 fines during the entire intervention period. No retailers were sanctioned three times per annum during the intervention period. Media advocacy efforts resulted in 8 items in local newspapers on enforcement and 12 items on informal control actions during the entire intervention period. All high schools revised their alcohol policy by making it more restrictive, e.g., by implementing stricter rules on alcohol use at school events for underage $(<16$ years) students. However, only 3 of the 13 local high schools in the intervention community implemented an entirely alcohol-free school policy during the intervention period, also for students who had already reached the legal purchase age.

\section{Descriptive results adolescent alcohol use}

Correlations between intermediate intervention goals and weekly drinking and drunkenness showed that high frequencies of alcohol-specific rules were nega-

tively related to weekly drinking and drunkenness status (Appendix 1). Higher

frequency of parental alcohol supply, alcohol purchases, and perceived ease of purchasing alcohol were positively related to weekly drinking and drunkenness status.

\section{Intervention effect on adolescent alcohol use}

The intervention did not reduce the risk to drink weekly among 13-15 year old adolescents (Table 6.1), but did reduce the risk to progress into drunkenness by $15 \%(\mathrm{HR}=0.85 ; \mathrm{p}=0.04)$ among adolescents already weekly drinking, i.e. a small effect size (Rosenthal, 1996). Analyses of the different age groups showed no significant results for both alcohol outcome measures.

\section{Descriptive results intermediate intervention goals}

Among 13-15 year olds, only perceived ease of purchasing alcohol showed a smaller increase over time $(\mathrm{p}=0.05)$ in the intervention compared with the comparison community, indicating a potential intervention effect (Table 6.2). Comparing the changes in intermediated intervention goals over time among 13-year-olds, all intermediate intervention goals changed more in the hypothesized direction in the intervention than in the comparison community.
Table 6.1 Standardized survival analyses direct intervention results

\begin{tabular}{|c|c|c|c|c|c|c|c|c|}
\hline $\begin{array}{l}\text { Age at } \\
\text { base- } \\
\text { line }\end{array}$ & $\begin{array}{r}13 \\
{[N=348]}\end{array}$ & & $\begin{array}{r}14 \\
{[N=462]}\end{array}$ & & $\begin{array}{r}15 \\
{[N=484]}\end{array}$ & & $\begin{array}{r}13-15 \\
{[N=1,294]}\end{array}$ & \\
\hline WD & $\begin{array}{r}\text { HR } \\
(95 \% \mathrm{CI})\end{array}$ & p & $\begin{array}{r}\text { HR } \\
(95 \% \text { CI })\end{array}$ & p & $\begin{array}{r}\text { HR } \\
(95 \% \text { CI })\end{array}$ & p & $\begin{array}{r}\text { HR } \\
(95 \% \text { CI })\end{array}$ & P \\
\hline Age & n.a. & n.a. & n.a. & n.a. & n.a. & n.a. & $\begin{array}{r}1.41 \\
(1.32 ; 1.48)\end{array}$ & 0.00 \\
\hline $\begin{array}{l}\text { Educa- } \\
\text { tional } \\
\text { level }\end{array}$ & $\begin{array}{r}0.88 \\
(0.72 ; 1.07)\end{array}$ & 0.59 & $\begin{array}{r}0.92 \\
(0.83 ; 1.03)\end{array}$ & 0.04 & $\begin{array}{r}1.04 \\
(0.97 ; 1.10)\end{array}$ & 0.51 & $\begin{array}{r}1.07 \\
(1.00 ; 1.14)\end{array}$ & 0.08 \\
\hline Gender & $\begin{array}{r}0.94 \\
(0.76 ; 1.15)\end{array}$ & 0.27 & $\begin{array}{r}1.15 \\
(1.03 ; 1.30)\end{array}$ & 0.22 & $\begin{array}{r}1.03 \\
(0.96 ; 1.09)\end{array}$ & 0.36 & $\begin{array}{r}0.97 \\
(0.91 ; 1.03)\end{array}$ & 0.42 \\
\hline $\begin{array}{l}\text { Inter- } \\
\text { vention }\end{array}$ & $\begin{array}{r}0.90 \\
(0.74 ; 1.09) \\
\end{array}$ & 0.37 & $\begin{array}{r}1.07 \\
(0.96 ; 1.20)\end{array}$ & 0.27 & $\begin{array}{r}1.07 \\
(1.00 ; 1.14)\end{array}$ & 0.08 & $\begin{array}{r}1.04 \\
(0.98 ; 1.11)\end{array}$ & 0.30 \\
\hline $\begin{array}{l}\text { Age at } \\
\text { base- } \\
\text { line }\end{array}$ & $\begin{array}{r}13 \\
{[N=163]}\end{array}$ & & $\begin{array}{r}14 \\
{[N=341]}\end{array}$ & & $\begin{array}{r}15 \\
{[N=425]}\end{array}$ & & $\begin{array}{r}13-15 \\
{[N=929]}\end{array}$ & \\
\hline DRU & $\begin{array}{r}\text { HR } \\
(95 \% \mathrm{CI})\end{array}$ & p & $\begin{array}{r}\text { HR } \\
(95 \% \mathrm{CI})\end{array}$ & p & $\begin{array}{r}\text { HR } \\
(95 \% \text { CI) }\end{array}$ & p & $\begin{array}{r}\text { HR } \\
(95 \% \text { CI })\end{array}$ & $\mathbf{P}$ \\
\hline Age & n.a. & n.a & n.a. & n.a & n.a. & n.a & $\begin{array}{r}1.48 \\
(1.33 ; 1.65)\end{array}$ & 0.00 \\
\hline $\begin{array}{l}\text { Educa- } \\
\text { tional } \\
\text { level }\end{array}$ & $\begin{array}{r}0.82 \\
(0.53 ; 1.28)\end{array}$ & 0.47 & $\begin{array}{r}0.93 \\
(0.70 ; 1.23)\end{array}$ & 0.67 & $\begin{array}{r}0.93 \\
(0.80 ; 1.09)\end{array}$ & 0.46 & $\begin{array}{r}0.90 \\
(0.79 ; 1.03)\end{array}$ & 0.22 \\
\hline Gender & $\begin{array}{r}0.65 \\
(0.42 ; 1.01)\end{array}$ & 0.11 & $\begin{array}{r}1.78 \\
(1.35 ; 2.33)\end{array}$ & 0.00 & $\begin{array}{r}1.39 \\
(1.19 ; 1.63)\end{array}$ & 0.00 & $\begin{array}{r}1.37 \\
(1.20 ; 1.56)\end{array}$ & 0.00 \\
\hline $\begin{array}{l}\text { Inter- } \\
\text { vention }\end{array}$ & $\begin{array}{r}0.76 \\
(0.50 ; 1.15)\end{array}$ & 0.28 & $\begin{array}{r}0.75 \\
(0.58 ; 0.96)\end{array}$ & 0.06 & $\begin{array}{r}0.94 \\
(0.80 ; 1.10)\end{array}$ & 0.51 & $\begin{array}{r}0.85 \\
(0.75 ; 0.97)\end{array}$ & 0.04 \\
\hline
\end{tabular}

Note: $W D=$ weekly drinking; $D R U=$ progression into drunkenness among weekly drinkers.

For 14-year-olds, no difference in change in intermediate intervention goals between the intervention and comparison community was found. Among 15-year-olds, there was an unexpected intervention effect for the frequency of alcohol purchases $(p=0.03)$, which showed a greater increase in the intervention community. On the other hand, perceived ease for purchasing alcohol showed a smaller increase over time $(p=0.08)$ in the intervention than in the comparison community. 
Table 6.2 Independent sample t-statistics for differences in delta scores on intermediate intervention goals between intervention and comparison community

\begin{tabular}{|c|c|c|c|c|c|c|}
\hline \multirow{2}{*}{\multicolumn{2}{|c|}{ Age at baseline (years): }} & \multirow{3}{*}{$\begin{array}{l}\text { Intervention } \\
\text { community }\end{array}$} & \multirow{3}{*}{$\begin{array}{l}\begin{array}{l}\text { Comparison } \\
\text { community }\end{array} \\
\begin{array}{l}\text { Mean dif- } \\
\text { ference } \\
\text { T0- T2 }\end{array} \\
-0.21(0.46)\end{array}$} & \multicolumn{3}{|l|}{$\begin{array}{l}\text { Intervention } \\
\text { vs. } \\
\text { comparison } \\
\text { community }\end{array}$} \\
\hline & & & & $\begin{array}{l}\Delta \text { mean } \\
\text { difference } \\
\text { T0-T2 }\end{array}$ & $\mathbf{T}$ & $\mathbf{P}$ \\
\hline \multirow[t]{4}{*}{13} & $\begin{array}{l}\text { Frequency alcohol- } \\
\text { specific rules }\end{array}$ & & & -0.09 & -1.86 & 0.06 \\
\hline & $\begin{array}{l}\text { Frequency of parental } \\
\text { alcohol supply }\end{array}$ & $0.05(0.41)$ & $0.16(0.61)$ & 0.11 & 1.85 & 0.07 \\
\hline & $\begin{array}{l}\text { Frequency alcohol } \\
\text { purchases }\end{array}$ & $0.43(1.09)$ & $0.58(2.91)$ & 0.15 & 0.66 & 0.51 \\
\hline & $\begin{array}{l}\text { Perceived ease of } \\
\text { purchasing alcohol }\end{array}$ & $0.16(0.83)$ & $0.37(0.91)$ & 0.22 & 2.25 & 0.03 \\
\hline \multirow[t]{4}{*}{14} & $\begin{array}{l}\text { Frequency alcohol- } \\
\text { specific rules }\end{array}$ & $-1.06(0.70)$ & $-0.93(0.78)$ & 0.12 & 1.64 & 0.10 \\
\hline & $\begin{array}{l}\text { Frequency of parental } \\
\text { alcohol supply }\end{array}$ & $0.50(1.20)$ & $0.32(1.03)$ & -0.18 & -1.65 & 0.10 \\
\hline & $\begin{array}{l}\text { Frequency alcohol } \\
\text { purchases }\end{array}$ & $2.25(3.21)$ & $2.01(3.03)$ & -0.24 & -0.76 & 0.45 \\
\hline & $\begin{array}{l}\text { Perceived ease of } \\
\text { purchasing alcohol }\end{array}$ & $1.03(1.37)$ & $0.97(1.29)$ & -0.06 & -0.48 & 0.63 \\
\hline \multirow[t]{4}{*}{15} & $\begin{array}{l}\text { Frequency alcohol- } \\
\text { specific rules }\end{array}$ & $-1.13(0.79)$ & $-1.13(0.85)$ & 0.00 & 0.02 & 0.99 \\
\hline & $\begin{array}{l}\text { Frequency of parental } \\
\text { alcohol supply }\end{array}$ & $0.33(1.40)$ & $0.35(1.13)$ & 0.02 & 0.17 & 0.86 \\
\hline & $\begin{array}{l}\text { Frequency alcohol } \\
\text { purchases }\end{array}$ & $3.23(4.30)$ & $2.34(4.06)$ & -0.90 & -2.26 & 0.03 \\
\hline & $\begin{array}{l}\text { Perceived ease of } \\
\text { purchasing alcohol }\end{array}$ & $0.85(1.49)$ & $1.10(1.38)$ & -0.25 & 1.77 & 0.08 \\
\hline \multirow[t]{4}{*}{$13-15$} & $\begin{array}{l}\text { Frequency alcohol- } \\
\text { specific rules }\end{array}$ & $-0.81(0.79)$ & $-0.82(0.83)$ & -0.00 & -0.09 & 0.93 \\
\hline & $\begin{array}{l}\text { Frequency of parental } \\
\text { alcohol supply }\end{array}$ & $0.31(1.13)$ & $0.29(0.98)$ & -0.02 & -0.32 & 0.74 \\
\hline & $\begin{array}{l}\text { Frequency alcohol } \\
\text { purchases }\end{array}$ & $2.07(3.44)$ & $1.76(3.52)$ & -0.31 & -1.53 & 0.13 \\
\hline & $\begin{array}{l}\text { Perceived ease of } \\
\text { purchasing alcohol }\end{array}$ & $0.71(1.33)$ & $0.86(1.27)$ & 0.15 & 1.93 & 0.05 \\
\hline
\end{tabular}

Note: Standard deviations are shown in parentheses.

\section{Intervention effect on intermediate intervention goals}

For all adolescents (13-15 years), the frequency of alcohol purchases showed a greater increased in the intervention community $(B=0.10 ; p=0.03)$ (Table 6.3). All other intermediate intervention goals showed no difference in change between the two communities for 13-15 year olds.

Among 13-year-olds, rates of change in the frequency of alcohol-specific rule setting $(B=-3.93 ; p=0.03)$ and parental alcohol supply $(B=-0.35 ; p=0.04)$ showed a significant difference between the two communities. Parents in the intervention community remained stricter in their alcohol-specific rule setting, and their alcohol supply to their adolescent children showed a smaller increase than in the comparison community. Among 14 and 15 year olds no differences in rates of change in intermediate intervention goals was found between the two communities.

In summary, among the 13-year-olds, two of four intermediate intervention goals showed a significant difference in rates of change between the two communities in the expected direction. In the older age groups, no significant intervention effects were found on the intermediate intervention goals. For the total group (13-15 years), one significant negative intervention effect was found for the frequency of alcohol purchases. 


\begin{tabular}{|c|c|c|c|c|c|c|c|c|c|}
\hline Age at & $13(N=34$ & & $14(N)=40$ & & $15(N=48$ & & $15-15(N=$ & 494) & \\
\hline ASR T2 & B (95\% CI) & $\mathbf{p}$ & B (95\% CI) & $\mathbf{p}$ & B (95\% CI) & $\mathbf{p}$ & B $(95 \%$ CI) & $\mathbf{p}$ & \\
\hline Age & n.a. & n.a & n.a. & n.a & n.a. & n.a & $\begin{array}{l}-0.51 \\
(-0.54 ;-0.47)\end{array}$ & 0.00 & \\
\hline Educational level & $\begin{array}{l}-0.07 \\
(-0.15 ; 0.01)\end{array}$ & 0.17 & $\begin{array}{l}-0.06 \\
(-0.15 ; 0.02)\end{array}$ & 0.22 & $\begin{array}{l}-0.02 \\
(-0.09 ; 0.05)\end{array}$ & 0.61 & $\begin{array}{l}-0.04 \\
(-0.08 ;-0.00)\end{array}$ & 0.07 & \\
\hline Gender & $\begin{array}{l}0.07 \\
(-0.01 ; 0.15)\end{array}$ & 0.15 & $\begin{array}{l}-0.16 \\
(-0.24 ;-0.08)\end{array}$ & 0.00 & $\begin{array}{l}-0.18 \\
(-0.25 ;-0.11)\end{array}$ & 0.00 & $\begin{array}{l}-0.10 \\
(-0.14 ;-0.07)\end{array}$ & 0.00 & \\
\hline ASR T0 & $\begin{array}{l}0.64 \\
(0.45 ; 0.82)\end{array}$ & 0.00 & $\begin{array}{l}0.37 \\
(0.26 ; 0.47)\end{array}$ & 0.00 & $\begin{array}{l}0.47 \\
(0.37 ; 0.57)\end{array}$ & 0.00 & $\begin{array}{l}0.35 \\
(0.29 ; 0.41)\end{array}$ & 0.00 & \\
\hline Intervention & $\begin{array}{l}4.02 \\
(0.96 ; 7.07)\end{array}$ & 0.03 & $\begin{array}{l}0.63 \\
(-0.31 ; 1.57)\end{array}$ & 0.27 & $\begin{array}{l}0.06 \\
(-0.39 ; 0.50)\end{array}$ & 0.84 & $\begin{array}{l}0.17 \\
(-0.15 ; 0.49)\end{array}$ & 0.39 & \\
\hline Intervention *ASR TO & $\begin{array}{l}-3.93 \\
(-6.99 ;-0.90)\end{array}$ & 0.03 & $\begin{array}{l}-0.70 \\
(-1.66 ; 0.25)\end{array}$ & 0.23 & $\begin{array}{l}-0.07 \\
(-0.52 ; 0.38)\end{array}$ & 0.80 & $\begin{array}{l}0.18 \\
(-0.51 ; 0.14)\end{array}$ & 0.35 & \\
\hline PAS T2 & B (95\% Cl) & $\mathbf{p}$ & B (95\% CI) & $\mathbf{p}$ & B (95\% CI) & p & B (95\% CI) & $\mathbf{p}$ & \\
\hline Age & n.a. & n.a & n.a. & n.a & n.a. & n.a & $\begin{array}{l}0.22 \\
(0.18 ; 0.26)\end{array}$ & 0.00 & \\
\hline Educational level & $\begin{array}{l}-0.02 \\
(-0.12 ; 0.08)\end{array}$ & 0.75 & $\begin{array}{l}0.05 \\
(-0.04 ; 0.13)\end{array}$ & 0.38 & $\begin{array}{l}0.04 \\
(-0.04 ; 0.12)\end{array}$ & 0.29 & $\begin{array}{l}0.03 \\
(-0.02 ; 0.08)\end{array}$ & 0.29 & \\
\hline Gender & $\begin{array}{l}0.02 \\
(-0.06 ; 0.10)\end{array}$ & 0.74 & $\begin{array}{l}0.12 \\
(0.05 ; 0.18)\end{array}$ & 0.00 & $\begin{array}{l}0.14 \\
(0.07 ; 0.21)\end{array}$ & 0.00 & $\begin{array}{l}0.10 \\
(0.06 ; 0.15)\end{array}$ & 0.00 & \\
\hline PAS T0 & $\begin{array}{l}0.59 \\
(0.21 ; 0.97)\end{array}$ & 0.01 & $\begin{array}{l}0.18 \\
(0.05 ; 0.31)\end{array}$ & 0.03 & $\begin{array}{l}0.07 \\
(-0.07 ; 0.21)\end{array}$ & 0.40 & $\begin{array}{l}0.15 \\
(0.03 ; 0.26)\end{array}$ & 0.04 & \\
\hline Intervention & $\begin{array}{l}-0.07 \\
(-0.15 ; 0.02)\end{array}$ & 0.19 & $\begin{array}{l}0.08 \\
(0.01 ; 0.17)\end{array}$ & 0.09 & $\begin{array}{l}0.06 \\
(-0.02 ; 0.14)\end{array}$ & 0.22 & $\begin{array}{l}0.04(0.01 ; \\
0.09)\end{array}$ & 0.13 & \\
\hline Intervention *PAS TO & $\begin{array}{l}-0.35 \\
(-0.62 ;-0.08)\end{array}$ & 0.04 & $\begin{array}{l}-0.02 \\
(-0.0 .13 ; 0.10)\end{array}$ & 0.83 & $\begin{array}{l}0.09 \\
(-0.06 ; 0.23)\end{array}$ & 0.34 & $\begin{array}{l}0.02(-0.09 ; \\
0.12)\end{array}$ & 0.80 & \\
\hline AP T2 & B (95\% CI) & $\mathbf{p}$ & B (95\% CI) & $\mathbf{p}$ & B (95\% CI) & $\mathbf{p}$ & B (95\% CI) & $\mathbf{p}$ & \\
\hline Age & n.a. & n.a & n.a. & n.a & n.a. & n.a & $\begin{array}{l}0.31 \\
(0.27 ; 0.36)\end{array}$ & 0.00 & \\
\hline Educational level & $\begin{array}{l}0.01 \\
(-0.12 ; 0.10)\end{array}$ & 0.90 & $\begin{array}{l}0.11 \\
(0.03 ; 0.19)\end{array}$ & 0.02 & $\begin{array}{l}-0.01 \\
(-0.08 ; 0.07)\end{array}$ & 0.91 & $\begin{array}{l}0.03 \\
(-0.02 ; 0.07)\end{array}$ & 0.37 & \\
\hline Gender & $\begin{array}{l}-0.03 \\
(-0.09 ; 0.03)\end{array}$ & 0.44 & $\begin{array}{l}0.13 \\
(0.05 ; 0.20)\end{array}$ & 0.00 & $\begin{array}{l}0.20 \\
(0.13 ; 0.26)\end{array}$ & 0.00 & $\begin{array}{l}0.11 \\
(0.07 ; 0.15)\end{array}$ & 0.00 & \\
\hline AP T0 & $\begin{array}{l}0.68 \\
(-0.05 ; 1.40)\end{array}$ & 0.13 & $\begin{array}{l}0.10 \\
(0.04 ; 0.16)\end{array}$ & 0.01 & $\begin{array}{l}0.21 \\
(0.11 ; 0.31)\end{array}$ & 0.00 & $\begin{array}{l}0.16 \\
(0.10 ; 0.23)\end{array}$ & 0.00 & \\
\hline Intervention & $\begin{array}{l}-0.01 \\
(-0.08 ; 0.05)\end{array}$ & 0.78 & $\begin{array}{l}0.00 \\
(-0.08 ; 0.08)\end{array}$ & 0.96 & $\begin{array}{l}0.06 \\
(-0.01 ; 0.14)\end{array}$ & 0.17 & $\begin{array}{l}0.02 \\
(-0.02 ; 0.06)\end{array}$ & 0.40 & \\
\hline Intervention *AP TO & $\begin{array}{l}-0.33 \\
(-0.92 ; 0.26)\end{array}$ & 0.36 & $\begin{array}{l}0.05 \\
(-0.06 ; 0.17)\end{array}$ & 0.44 & $\begin{array}{l}0.11 \\
(0.00 ; 0.23)\end{array}$ & 0.10 & $\begin{array}{l}0.10 \\
(0.02 ; 0.18)\end{array}$ & 0.03 & \\
\hline PEPA T2 & B (95\% CI) & $\mathbf{p}$ & B (95\% CI) & $\mathbf{p}$ & B (95\% CI) & $\mathbf{p}$ & B (95\% CI) & $\mathbf{p}$ & \\
\hline Age & n.a. & n.a & n.a. & n.a & n.a. & n.a & $\begin{array}{l}0.34 \\
(0.30 ; 0.38)\end{array}$ & 0.00 & \\
\hline Educational level & $\begin{array}{l}-0.07 \\
(-0.16 ; 0.03)\end{array}$ & 0.26 & $\begin{array}{l}-0.01 \\
(-0.10 ; 0.07)\end{array}$ & 0.79 & $\begin{array}{l}0.01 \\
(-0.07 ; 0.09)\end{array}$ & 0.82 & $\begin{array}{l}-0.00 \\
(-0.05 ; 0.04)\end{array}$ & 0.91 & \\
\hline Gender & $\begin{array}{l}0.04 \\
(-0.05 ; 0.13)\end{array}$ & 0.45 & $\begin{array}{l}0.15 \\
(0.07 ; 0.23)\end{array}$ & 0.00 & $\begin{array}{l}0.19 \\
(0.11 ; 0.27)\end{array}$ & 0.00 & $\begin{array}{l}0.13 \\
(0.09 ; 0.18)\end{array}$ & 0.00 & \\
\hline PEPA T0 & $\begin{array}{l}0.19 \\
(0.01 ; 0.36)\end{array}$ & 0.08 & $\begin{array}{l}0.14 \\
(0.01 ; 0.26)\end{array}$ & 0.08 & $\begin{array}{l}0.11 \\
(0.00 ; 0.21)\end{array}$ & 0.09 & $\begin{array}{l}0.13 \\
(0.06 ; 0.19)\end{array}$ & 0.00 & \\
\hline Intervention & $\begin{array}{l}-0.18 \\
(-0.52 ; 0.16)\end{array}$ & 0.38 & $\begin{array}{l}-0.52 \\
(-0.32 ; 0.28)\end{array}$ & 0.91 & $\begin{array}{l}-0.15 \\
(-0.37 ; 0.06)\end{array}$ & 0.24 & $\begin{array}{l}-0.06 \\
(-0.20 ; 0.07)\end{array}$ & 0.45 & \\
\hline Intervention * PEPA TO & $\begin{array}{l}0.06 \\
(-0.32 ; 0.44)\end{array}$ & 0.79 & $\begin{array}{l}0.04 \\
(-0.28 ; 0.35)\end{array}$ & 0.85 & $\begin{array}{l}0.06 \\
(-0.17 ; 0.28)\end{array}$ & 0.69 & $\begin{array}{l}0.01 \\
(-0.14 ; 0.15)\end{array}$ & 0.95 & \\
\hline
\end{tabular}

\section{Discussion}

This study evaluated the effectiveness of a community intervention, increasing both formal and informal control, on adolescent drinking behavior. Furthermore, intermediate processes by which the intervention might have influenced adolescent alcohol use were investigated. Although the intervention was not effective in reducing the risk of adolescents to drink weekly, it significantly decreased the risk in weekly drinkers to progress into drunkenness with $15 \%$. This finding is consistent with the preventive effect of combined formal and informal control on adolescent heavy drinking reported in the Trelleborg study (Stafström, et al., 2006). Thus, a combined formal and informal control intervention package reduces the risk of weekly drinking adolescents to progress into drunkenness, also in a country with relatively liberal alcohol policies.

No intervention effect on the intermediate intervention goals was found among older adolescents (14-15 years). However, among 13-year-olds the intervention had a positive effect on two of four intermediate intervention goals (i.e. parental alcohol supply and alcohol-specific rules). Thus, since the intervention aimed to discourage underage drinking, the intervention showed a stronger positive effect on adolescents not yet reaching the legal purchase age (16 years) than on those who reached that age during the intervention period.

In the intervention community, a larger increase in the frequency of alcohol purchases among 15-year-olds indicated a negative intervention effect. The strong focus of the intervention on discouraging drinking below a certain age (e.g., the legal purchase age) may lead to a stronger response in exercising one's (new) right to purchase alcohol once reaching this age.

Of the 16 tested intervention effects on intermediate intervention goals, only two showed a significant positive result. This may indicate that more complex mechanisms lead to the reduced risk in weekly drinkers to progress into drunkenness. Also, the intermediate intervention goals used in this study might be less important for elucidating how formal and informal control influences adolescent drinking behavior than previous studies led us to assume (Gillian, et al., 2012; Grube, 1997; Holmila \& Warpenius, 2007; Huckle, et al., 2005; Jackson, et al., 1999; Knibbe, et al., 2005; Koning, Van den Eijnden, Engels, Verdurmen, \& M., 2011; Kuntsche, Kuendig, et al., 2008b; Paschall, et al., 2007; Van Der Vorst, et al., 2005; Wagenaar, et al., 2000a). 


\section{Strengths and limitations}

Apart from several strengths (e.g., large sample size, longitudinal comparisons) our study also has limitations. First, although communities were matched on important determinants for alcohol use, other differences between the communities may have contributed to the observed effects. Secondly, trends in the Netherlands towards more restrictive norms regarding adolescent alcohol use (Van Laar, et al., 2011) might have reduced the power to detect significant intervention effects. Nevertheless, the intervention was effective in intensifying the strength of this trend. Third, the effect size for the reduced risk in weekly drinkers to progress into drunkenness was rather small $(\mathrm{HR}=0.85)$. This might be due to the relatively short duration (set-up plus implementation) of the community intervention. Generally, such an intervention takes longer than 2 years to be implemented to develop, and to achieve sufficient impact. Furthermore, the small effect size might have resulted from specifically discouraging underage $(<16$ years) drinking. Adolescents not reaching the legal purchase age during the intervention period (13-year-olds) indeed showed stronger intervention effects on intermediate intervention goals compared with older adoles-

cents. However, the public health impact of an intervention with a small effect can still be high if it reaches a large group of people, as realized using the community approach in the present study (Glasgow, Vogt, \& Boles, 1999).

\section{Implications for prevention}

To prevent adolescents from progressing into drunkenness, future interventions should aim to combine increased formal and informal control of adolescent drinking. Also, an unintended effect was found on the intermediate intervention goal frequency of alcohol purchases (i.e. among 15-year-olds). This was probably caused by the strong focus in the intervention community on discouraging underage $(<16$ years) drinking which may have encouraged adolescents to buy alcoholic beverages once they reached the legal purchase age. Therefore, interventions should aim to avoid that alcohol is even more perceived and/or being used as a marker for adulthood.
Combining formal and informal control reduces the risk for drinking adolescents to progress into drunkenness. 
Chapter 7

Organizational, community,

and policy

level of

influence

Effects on retailers and parents of a community intervention combining intensified formal and informal control

Based on

Schelleman-Offermans, K., Knibbe, R. A., \& Van de Mheen, D. Effects of a

community intervention restricting retail and social alcohol availability for adolescents on retailers and parents: A quasi-experimental study. 


\section{Abstract}

Background Restricting alcohol availability is a key element in effective alcohol policy. This study evaluated the attitudinal and behavioral effects on parents of adolescents and retailers of a two-year community intervention increasing formal control (restricting retail alcohol availability) and informal control (restricting social alcohol availability).

Method A longitudinal quasi-experimental design (baseline at 2008, postmeasurements in 2009 and 2010) was used, including one intervention and one matched comparison community. Outcomes were assessed by following a cohort of adolescents $(n=1,368)$, one of their parents $(n=1,368)$, and of retailers $(\mathrm{n}=34)$.

Results In the intervention community, retailers showed a greater increase in their perceived likelihood of sanctions, rated alcohol-law enforcement as more effective to reduce adolescent drinking, and more often checked age identification before supplying adolescents with alcohol. More parents in the interven-

ton community perceived local media items about adolescent drinking, as well as actions from local authorities/parents to reduce adolescent drinking, and conversations between parents about adolescent drinking. Also, parents in the intervention community became significantly more restrictive in their attitude towards underage alcohol use at home.

Conclusion A community intervention aimed at intensifying formal and informal control of availability of alcohol can effect a change in the attitudes and behaviors of retailers and parents of adolescents.

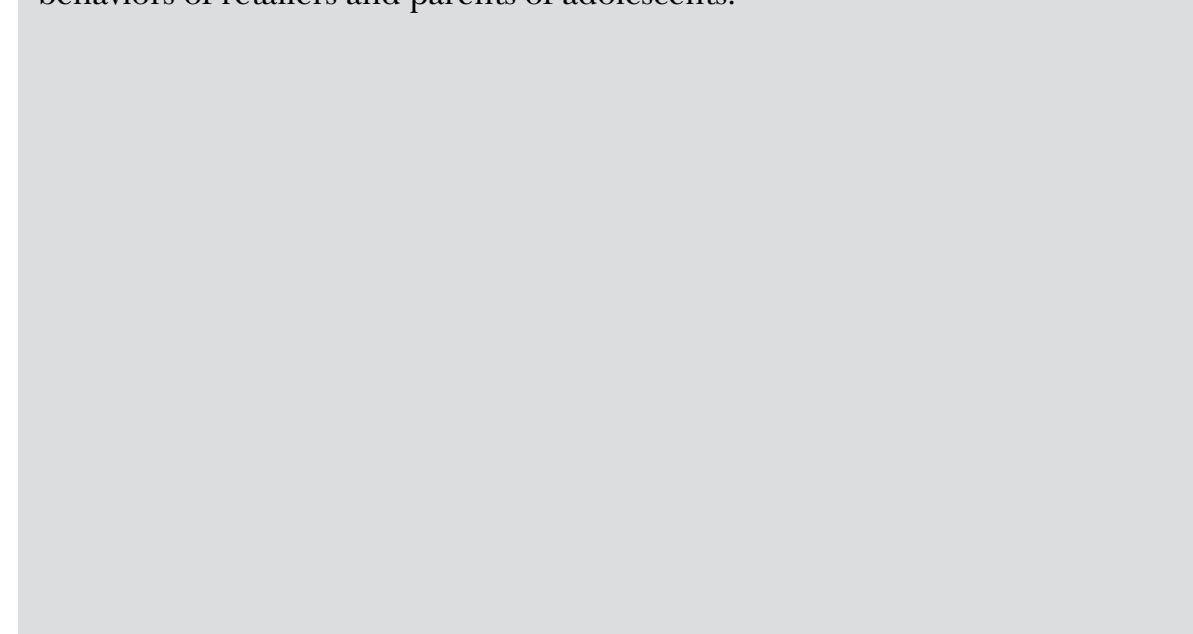

\section{Introduction}

Alcohol is widely available for adolescents in the Netherlands, e.g., among underage adolescents $<$ 16 years) $86 \%$ can buy alcohol themselves (Gosselt, et al., 2007). Parents are also an important source for obtaining alcohol (Harrison, et al., 2000; Hearst, et al., 2007; Hemphill, et al., 2007; Schelleman-Offermans, et al., 2009b). This high level of availability of alcohol has contributed to one of the highest frequency of drinking (worldwide) among Dutch adolescents aged 15-16 years (Hibell, et al., 2007).

Despite evidence for the preventive effect of reducing the supply and/or availability of alcohol on alcohol use and related problems (Babor, et al., 2010; Holder, 1998), community interventions aimed at reducing the availability of alcohol for adolescents are relatively new in the Netherlands. This study describes the effects of a community intervention aimed at increasing formal control and informal control on alcohol retailers and parents of adolescents. The elements of the intervention aimed at increasing formal control were: a) intensified alcohol-law inspections on retailers' obligation to check legal alcohol purchase ages of customers (16 years for alcoholic beverages with $<15 \%$ alcohol, and 18 years for alcoholic beverages with $\geq 15 \%$ alcohol), b) a local alcohol policy in which liquor licenses are revoked when fined 3 times per annum, and c) media advocacy. The main elements of the community intervention aimed at increasing informal control were: a) a parental action committee and b) a media campaign for parents motivating them to remain strict in their alcohol-specific rule setting, c) promoting alcohol-free school policies, and d) media advocacy. Actively combining formal and informal control in a community intervention showed promising results in reducing adolescent drinking (Stafström, et al., 2006). However, it remains unclear in which way retailers and parents are affected by community interventions intensifying formal and informal control. The present study differs from similar studies in that: i) this is the first European study to investigate the effects of a community intervention intensifying both 
formal and informal control on retailers and parents; and ii) this study uses multi-informant data from adolescents, their parents and retailers, thus allowing to draw more valid conclusions.

Studies in the USA and New Zealand have examined the effect of community interventions on retailers and/or parents. In New Zealand, community interventions proved successful in changing the attitude of populations by increasing their public support for restrictive alcohol policy measures (Casswell, Gilmore, Maguire, \& Ransom, 1989). Furthermore, making use of media advocacy (enforcement communication) could increase retailers' perceived likelihood of sanctions, which could lead to more cautious supply behaviors (Holder \& Treno, 2007). Indeed, in the USA, one trial reported in the intervention regions a $5 \%$ and $12 \%$ increase in the perceived likelihood of being cited to serve/sell to underage adolescents for on- and off-sale outlets, respectively (Wagenaar, et al., 2000a). Also, in the intervention regions a $24 \%$ and $8 \%$ decrease was found in the proportion of selling to confederate buyers in on- and off-sale outlets, respectively (Wagenaar, et al., 2000a).

In the present study, besides following a cohort of adolescents, a cohort of re-

tailers and parents was followed in a comparison-group design. In the comparison community no alcohol-law inspections were conducted, no stricter alcohol policy plan was implemented (formal control), and no initiatives to mobilize parents into controlling adolescent drinking were undertaken. The study investigated whether retailers and parents in the intervention community: (H1) perceived more intervention efforts, $(\mathrm{H} 2)$ became more restrictive in their norms and attitudes towards alcohol and restrictive alcohol policy measures, and (H3) made behavioral changes in reaction to the intervention efforts. Furthermore, it was assessed whether retailers in the intervention community reported less nuisance caused by adolescents in and around their premises over time (H4) than in the comparison community. Acquiring data from multiple stakeholder (adolescents, parents, and retailers) within such a design can provide more insight into how the intervention affects various stakeholders and can elucidate how the intervention actually worked.

\section{Method}

\section{Intervention components}

\section{Formal control}

Formal control was enhanced by three intervention components. First, in the intervention region, the Food and Consumer Product Safety Authority (FCPSA) intensified the frequency of alcohol-law inspections in off- and on-licensed premises attracting adolescents (so-called 'hotspots'; n=25-30 in each region), resulting in 285 inspections, 7 written warnings, and 11 fines over a two-year period. No inspections were conducted in the comparison region. Second, the local authority implemented a new alcohol policy called 'Three-strikes-out', i.e., if an on-premises retailer in the intervention region was fined by the FCPSA three times per annum, the local authority would start proceedings to withdraw the retailer's liquor license. During the intervention period, no on-premise retailers were sanctioned three times per annum. Third, outcomes of enforcement actions were used for press releases to raise community awareness and increase the perceived likelihood of apprehension (media advocacy), resulting in 8 items in local newspapers on enforcement efforts.

\section{Informal control}

Informal control was enhanced by four intervention components. First, a group of parents was mobilized to form a parental action committee. They used a website and several actions (e.g., at high schools) to inform parents about the negative health consequences of adolescent drinking, to stimulate parents to maintain strict alcohol-specific rules, and communicate with other parents to create an informal network with shared restrictive norms towards adolescents alcohol use. Second, local health professionals advised local high schools to formulate and implement an alcohol-free school policy, which entailed that alcohol use was no longer tolerated at school parties or other events. During the intervention period, 3 out of 13 local high schools were categorized as an 'alcohol-free school'. Third, a local media campaign was implemented which provided parents with information on health consequences of adolescent drinking and alcohol-specific parenting guidelines, using posters, leaflets, gadgets (e.g., reusable shopping bags), and selective advertisements on Facebook. Finally, outcomes of community actions, (e.g., actions of the parental committee 
or alcohol-free school policies) were used for press releases to raise awareness of the community (media advocacy), resulting in 12 items on community actions in local newspapers.

\section{Intervention design, selection, and description of regions}

This intervention study used a quasi-experimental comparison-group design including an intervention and a comparison community. A cohort of adolescents aged $13-15$ years $(n=729$ in the intervention and $n=639$ in the comparison community), one of their parents $(n=729$ in the intervention and $n=639$ in the comparison community), and retailers of 'hotspots' ( $\mathrm{n}=16$ in the intervention and $n=18$ in the comparison community) were followed for three years. One baseline measurement (T0; 2008) and one post-measurement (T2; 2010) was used for retailers and parents. For adolescents, one baseline and two postmeasurements (T1; 2009 and T2; 2010) were used. The intervention community was selected based on the cooperation of local politicians, civil servants, and professionals. For both regions, selection criteria were that i) there was a minimal chance that adolescents would go to other municipalities to buy alcohol be-

verages, and that ii) the communities were comparable in terms of urbanization and social stratification. Each community was located in the central part of the Netherlands and each had $\pm 150,000$ inhabitants.

\section{Recruitment and procedure for parents and adolescents}

A random sample of 4,468 adolescents, stratified on age (13-15 years) and gender, was drawn from the population registers of the communities. These adolescents and one of their parents were approached three times (by mail and telephone) until the sample size was reached. After recruitment, only $17.4 \%$ $(n=776)$ of all randomly sampled adolescent-parent dyads refused to cooperate. All others were randomly approached until the intended sample size $( \pm$ 660 adolescent-parent dyads in each community) had been reached. In total, $30.6 \%$ ( $\mathrm{n}=1,368)$ agreed to participate. Recruitment resulted in 729 adolescents $(49.0 \%$ boys; mean age $=14.1$ years; $\mathrm{SD}=0.79)$ and one of their parents $(87.9 \%$ mothers) in the intervention; and 639 adolescents ( $48.2 \%$ boys; mean age $=14.2$ years; $\mathrm{SD}=0.80)$ and one of their parents $(85.6 \%$ mothers $)$ in the comparison region. After two years, $11.9 \%$ of the adolescent-parent dyads was lost to followup in the intervention region, and $15.5 \%$ in the comparison region. Binary logistic regression showed a significantly higher drop-out in both communities for parents reporting a lower educational level $(\mathrm{p}<0.01)$. No selective drop-out was found for any of the outcome measures at $\mathrm{T} 0$ of parents or adolescents (data available from the first author on request).

This study was approved by the medical ethical committee of Maastricht University (MEC 07-4-043). At all data collection points, participants were instructed to complete the questionnaire at home in privacy. Questionnaires were collected by fieldworkers at the participant's home address at T0. At T1 and T2 participants were instructed to return the completed questionnaire by mail in a (prepaid) reply envelope. As an incentive, 5 euro was given to parents and adolescents at T0, three iPods for adolescents were raffled at T1, and six iPads for parents and adolescents were raffled at $\mathrm{T} 2$.

\section{Recruitment and survey procedure for retailers}

Together with the FCPSA and the local authorities, a list of on- and off-premises 'hotspots' for adolescents was established at baseline. All managers from hotspots (25-30 in each community) were approached by telephone to invite them to participate in a structured telephone interview of \pm 20 minutes. In the intervention region 16 retailers and in the comparison region 18 retailers agreed to participate. Non-participation was mostly due to difficulty in contacting the management of hotspots. After two years, all hotspot managers were approached again by telephone. At T2, 6 of the 16 retailers dropped-out in the intervention region, and 6 of the 18 retailers in the comparison region. In the two communities, retailers showed no differences in terms of age, gender or size of their premises. Furthermore, no significant selective drop-out was found in relation to the tested outcome measures in this study (data available from the first author on request). 
Table 7.1 Measures and examples of items used in the present study

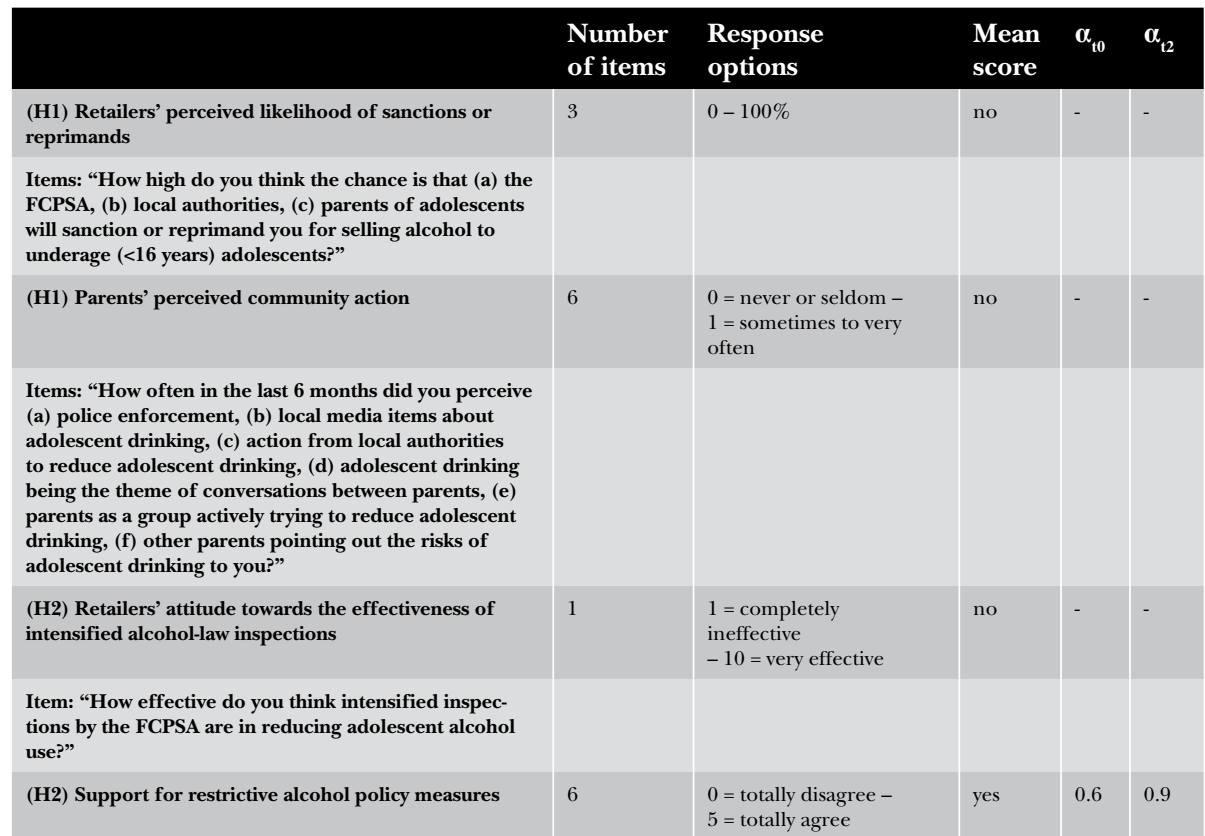

Examples of items: "Retailers who sell alcohol to minors must be highly sanctioned" or "The legal drinking age in the Netherlands should be raised from 16 to 18 years or "lappy houss and other prite actions for alcoho (H2) Parental attitudes towards restricting underage

Items: "In my home my child(ren) are not allowed undere $(<16$ pers), alcohol at home"; "It is my opinion that my child(ren) $<$ 16 years can best learn how to handle alcohol at home"

(H2) Parental alcohol-specific norm Examples of items: "How acceptable is it for your child
(a) to have a small glass of wine during a family dinner (b) to get drunk when drinking alone?"

(H3) Adolescents' reports on retail supply without age identification

Item: "How often in the last month did retailers sell you

without asking for your official age ID?"

(H3) Parental monitoring of adolescent drinking

Examples of items: "How often in the last month did

you pay

alcohol or (b) the amount of alcohol your child drinks?

(H4) Frequency of nuisance caused by adolescents

Item: "How often in the last month did adolescent
cause nuisance in and around your premises?"

\section{Statistical analyses}

The measures used in the present study are presented in Table 7.1. Because of the low number of hotspot retailers in each measurement, only descriptive analyses and frequencies are reported for this category of respondents. Changes in retailers' outcome measures over time (T0 to T2) are compared between the intervention and comparison community. Differences between the intervention and comparison community in reports of adolescents on the frequency of retail supply without age identification, were tested by independent sample t-tests at each measurement. Furthermore, Chi-square tests were used to investigate whether parents in the intervention community perceived more community action than parents in the comparison community. Paired sample t-tests were performed to describe changes over time (T0 to T2) in parents' outcome measures for the intervention and comparison region, separately. Linear regression analyses were used to investigate whether changes over time in parental outcome measures $(\mathrm{X})$ differed for the intervention $(\mathrm{Z})$ and comparison region by testing interaction effects; i.e. $\mathrm{Y}=\mathrm{b} 0+\mathrm{b} 1 \mathrm{X}+\mathrm{b} 2 \mathrm{Z}+\mathrm{b} 3 \mathrm{XZ}$. In all linear regression analyses age of the adolescent, and gender and educational level of the parent, were included as covariates.

\section{Results}

\section{Results for retailers}

H1: For the likelihood of sanctions by the FCPSA a far larger change is observed from $\mathrm{T} 0$ to $\mathrm{T} 2$ for the retailers in the intervention community compared with those in the comparison community ( +37.3 vs. +13.0 , respectively) (Table 7.2 ). The increase in the likelihood of sanction by the local authorities between $\mathrm{T} 0$ and T2 is slightly larger for the intervention than the comparison community (+11.82 vs. +9.61 , respectively). Contrary to our expectation, the increase in the likelihood of being reprimanded by parents was somewhat larger in the comparison community $(+8.73)$ than in the intervention community $(+6.14)$.

H2: In line with the hypothesis, the support for restrictive alcohol policies $(+0.29$ vs. -0.25$)$ and attitude towards the effectiveness of intensified enforcement $(+3.12$ vs. +0.06$)$ showed a greater increase in the intervention than in the comparison community. 
Table 7.2 Comparison of retailers in the intervention and comparison community in relation to changes in their behavior

\begin{tabular}{|c|c|c|c|c|}
\hline & \multicolumn{2}{|c|}{$\begin{array}{l}\text { Intervention } \\
\text { community }\end{array}$} & \multicolumn{2}{|c|}{$\begin{array}{l}\text { Comparison } \\
\text { community }\end{array}$} \\
\hline & $\begin{array}{l}\text { T0 } \\
(\mathbf{n}=16)\end{array}$ & $\begin{array}{l}\text { T2 } \\
(\mathrm{n}=10)\end{array}$ & $\begin{array}{l}\text { T0 } \\
(\mathrm{n}=18)\end{array}$ & $\begin{array}{l}\text { T2 } \\
(n=12)\end{array}$ \\
\hline $\begin{array}{l}\text { Mean perceived likelihood of sanctions by FCPSA } \\
{[0-100 \%]}\end{array}$ & $\begin{array}{l}15.06 \\
(19.70)\end{array}$ & $\begin{array}{l}52.40 \\
(36.21)\end{array}$ & $\begin{array}{l}17.17 \\
(22.48)\end{array}$ & $\begin{array}{l}30.17 \\
(31.89)\end{array}$ \\
\hline $\begin{array}{l}\text { Mean perceived likelihood of sanctions by local } \\
\text { authorities }[0-100 \%]\end{array}$ & $\begin{array}{l}7.88 \\
(10.60)\end{array}$ & $\begin{array}{l}19.60 \\
(26.31)\end{array}$ & $\begin{array}{l}9.56 \\
(12.08)\end{array}$ & $\begin{array}{l}20.17 \\
(25.54)\end{array}$ \\
\hline $\begin{array}{l}\text { Mean perceived likelihood of reprimands by parents } \\
{[0-100 \%]}\end{array}$ & $\begin{array}{l}10.06 \\
(14.22)\end{array}$ & $\begin{array}{l}16.20 \\
(21.86)\end{array}$ & $\begin{array}{l}10.44 \\
(19.37)\end{array}$ & $\begin{array}{l}19.17 \\
(18.69)\end{array}$ \\
\hline $\begin{array}{l}\text { Mean degree of support for restrictive alcohol } \\
\text { policy measures }[0-4]\end{array}$ & $\begin{array}{l}2.06 \\
(0.83)\end{array}$ & $\begin{array}{l}2.35 \\
(1.03)\end{array}$ & $\begin{array}{l}2.61 \\
(0.78)\end{array}$ & $\begin{array}{l}2.36 \\
(0.67)\end{array}$ \\
\hline $\begin{array}{l}\text { Mean attitude towards effectiveness of intensified } \\
\text { inspections by FCPSA [1-10] }\end{array}$ & $\begin{array}{l}3.38 \\
(3.03)\end{array}$ & $\begin{array}{l}6.50 \\
(3.34)\end{array}$ & $\begin{array}{l}4.94 \\
(2.78)\end{array}$ & $\begin{array}{l}5.00 \\
(3.59)\end{array}$ \\
\hline $\begin{array}{l}\text { Mean frequency nuisance by adolescents in and } \\
\text { around retailers' premises in the last month }\end{array}$ & $\begin{array}{l}1.47 \\
(2.90)\end{array}$ & $\begin{array}{l}0.60 \\
(1.35)\end{array}$ & $\begin{array}{l}2.00 \\
(2.77)\end{array}$ & $\begin{array}{l}1.67 \\
(2.06)\end{array}$ \\
\hline
\end{tabular}

Note: standard deviations are shown in parentheses

H3: As expected, adolescent reports showed that retailers in the intervention region less frequently supplied alcohol to adolescents without age identification at $\mathrm{T} 1$ and T2 (T1: $\mathrm{t}=2.01, \mathrm{p}<0.05$; T2: $\mathrm{t}=3.60, \mathrm{p}<0.001)$ than in the comparison region (Figure 7.1). Moreover, the differences between the intervention and control community become greater over time.

H4: In line with our hypothesis, the frequency of nuisance showed a greater decrease in the intervention community $(-0.87)$ than in the comparison community $(-0.33)$.

\section{Results for parents}

H1: As expected, during the intervention period more parents in the intervention than in the comparison community perceived (sometimes, to very often): a) local media items about adolescent drinking $\left(\chi^{2}=16.7 ; \mathrm{p}<0.001\right)$, b) action from local authorities to reduce adolescent drinking $\left(\chi^{2}=33.8 ; p<0.001\right)$, c) adolescent drinking being the theme of conversation between parents $\left(\chi^{2}=18.0 ; p<0.01\right)$, and $d)$ parents as a group actively trying to reduce adolescent drinking $\left(\chi^{2}=7.5\right.$; $\mathrm{p}<0.01$ ) (Figure 7.2). In the intervention period, the percentage of parents perceiving (sometimes, to very often) police enforcement on adolescent drinking, and other parents pointing out the risks of adolescent drinking, was similar in the intervention and comparison region. Thus, for 4 of the 6 items, parents in the intervention community noticed that they were exposed to the intervention efforts.

Figure 7.1 Comparison of the intervention and comparison community in relation to mean retailers' alcohol supply to adolescents without asking for age identification

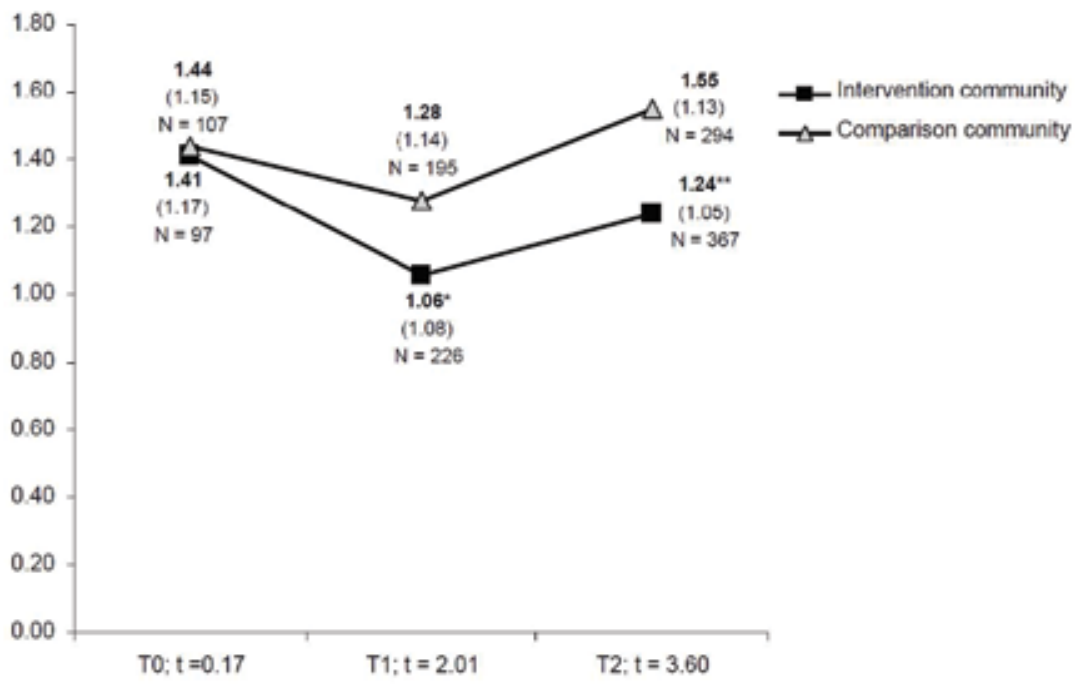

Note: Standard deviations are shown in parentheses; $* * p<0.001 ; * p<0.05$; mean score of e.g., $1.41=$ mean score lies between sometimes and most of the times 
Figure 7.2 Percentage of parents noticing different intervention-related efforts in the last 6 months

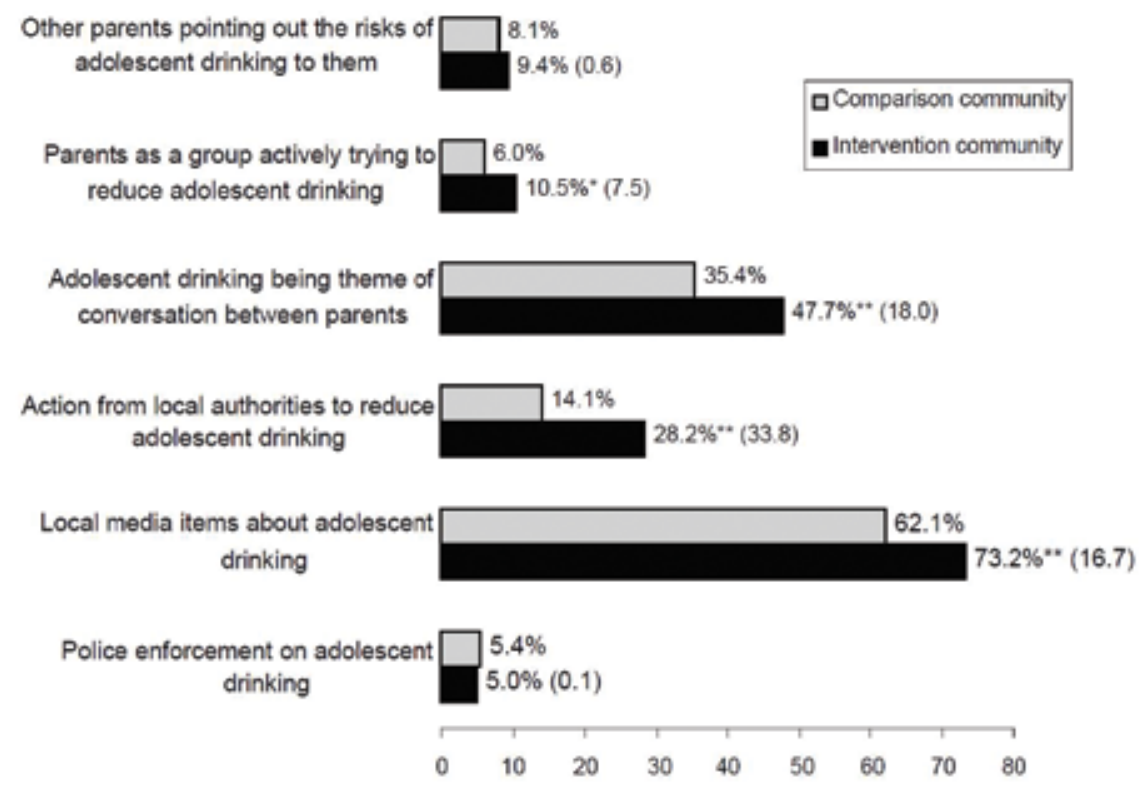

Note: $\chi^{2}$ is shown in parentheses; $* * p<0.001 ; * p<0.01$

H2: Table 7.3 presents data on parental attitudes, norms towards alcohol, and support for restrictive alcohol policy measures. As expected, a significant interaction effect was found between intervention (no/yes) and parental attitudes towards restricting underage drinking at home $(\mathrm{B}=0.11, \mathrm{p}<0.05)$. This interaction effect indicates a greater increase in the attitude towards restricting underage alcohol use at home for parents in the intervention than in the comparison community (Table 7.3). Unexpectedly, no significant interaction effects were found between intervention (no/yes) and support for restrictive alcohol policy measures $(\mathrm{B}=0.03, \mathrm{p}=0.54)$, or parental alcohol-specific norms $(-0.04, \mathrm{p}=0.44)$. H3: The interaction effect between intervention (no/yes) and parental monitoring was not significant $(\mathrm{B}=0.04, \mathrm{p}=0.34)$; the decrease in monitoring of adolescent drinking behavior was similar in both the intervention and comparison community (Table 7.3).
Table 7.3 Paired differences sample statistics: parents of adolescents

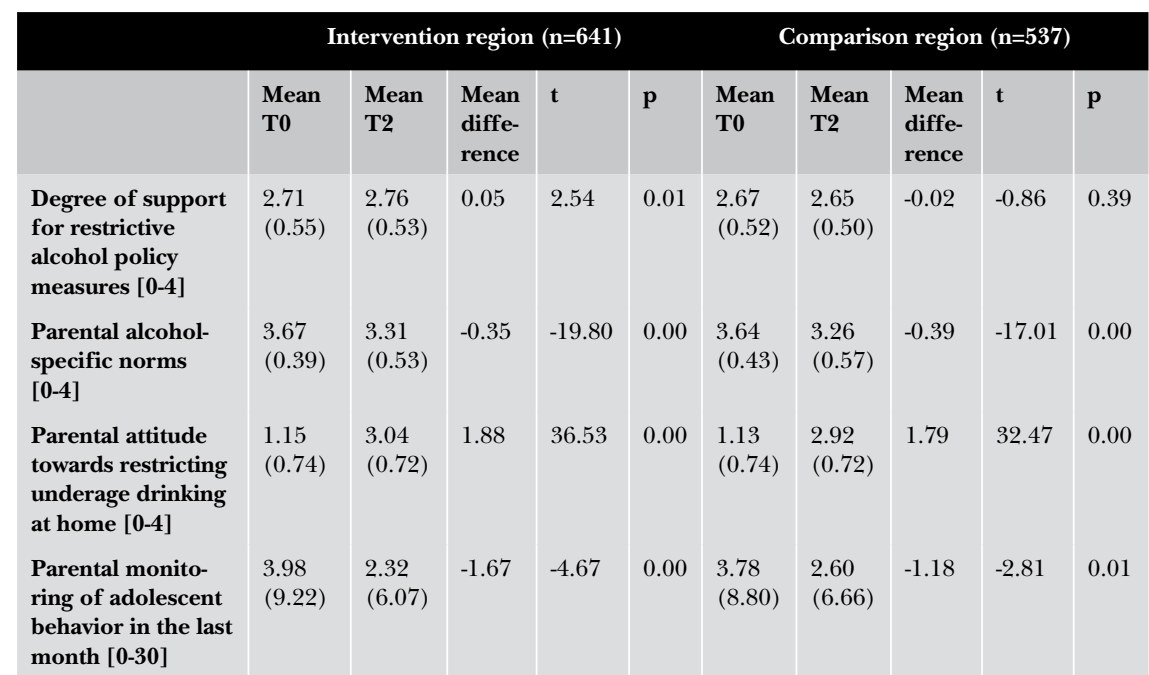

Note: Standard deviations are shown in parentheses

\section{Discussion}

This study aimed to gain more insight into the way parents and retailers were affected by an intervention intensifying formal and informal alcohol control. First, the results show that both parents and retailers in the intervention community noticed the intervention efforts which were implemented (H1). Among retailers in the intervention region, the perceived likelihood of sanctions by the FCPSA increased to a greater extent than in the control community. Also, in 4 out of 6 items assessing perceived community action, parents in the intervention region reported to have noticed community action more often than parents in the comparison community. Secondly (H2), both retailers and parents in the intervention region became more restrictive in their norms/attitudes towards alcohol, and more supportive for restrictive policy measures. Particularly retailers in the intervention compared with the control community became more positive over time in their attitudes towards the effectiveness of intensified enforcement. 
Parents in the intervention community became significantly more restrictive in their attitudes towards restricting underage children from drinking alcohol at home. Third (H3), retailers adjusted their selling behavior, as indicated by a significantly higher proportion of the adolescents in the community intervention reporting that they were asked for age identification before they could buy alcohol. Parents in the intervention community showed no change in the monitoring behavior of their child's drinking behavior compared with the comparison community. Finally (H4), retailers in the intervention region reported less nuisance caused by adolescents in and around their premises compared with the comparison community (H4).

Overall, it can be concluded that, although more effects were found for retailers than for parents, both parents and retailers were positively influenced by the intervention. The consistency within positive findings in favor of the effectiveness of the intervention from retailers, parents, and adolescents reinforces their relevance. However, whether the exact combination of intervention components resulted in the attained effect, or whether some components were more effective than others, remains unclear. Regarding the clearly increased likelihood of

sanctions for retailers and the high media coverage in relation to adolescent drinking reported by parents, we conclude that the media played a substantial role in attaining the intervention effects. Nonetheless, it is established that intensifying alcohol-law enforcement, making use of media campaigns and media advocacy, and supporting parents in the community to remain strict in their alcohol-specific rule setting and supply behavior, are useful tools to achieve attitudinal and behavioral changes among retailers and parents. Furthermore, although the changes achieved by intensifying formal and informal control are relatively small, the reach of such a community intervention is so wide that even small changes can result in large improvements in community health.

\section{Strengths and limitations}

The main strengths of the current study are the longitudinal comparison-group design and the use of multi-informant data to evaluate the effects of the intervention. However, the study has some limitations. First, the number of retailers included in the descriptive analyses is low ( $\mathrm{n}=34$ at T0, and $\mathrm{n}=22$ at T2). However, it is a considerable proportion $( \pm 50 \%)$ of the 'hotspot' retailers in the communities under study. Secondly, only $30.6 \%$ of all randomly sampled adolescentparent dyads were included in this study. On the other hand only $17.4 \%$ actively refused to participate, all others were randomly approached until the intended sample size was reached, indicating a limited error due to selective response. Finally, a significantly higher drop-out in both communities was found for parents reporting a lower educational level, thus limiting generalization of the outcomes to populations with lower educational levels. However, an absence of selective drop-out for any of the outcome measures indicates that conclusions based on the presented outcome measures are not biased.

\section{Implications for practice and policy changes}

There is an ongoing debate among health professionals and policymakers in the Netherlands, as to whether retailers and parents support restrictive alcohol policy measures. Perhaps the most important finding of this study is that it is feasible to change retailers' and parents' attitudes and behavior by increasing formal and informal control using a community-wide approach. Considering the forthcoming decentralization of the responsibility for alcohol-law enforcement from the national to the local level in the Netherlands, the results of this study show promising practical implications for Dutch local authorities. However, for such a community approach to be successful, strong guidance from local authorities is crucial, in which they take responsibility for the process of attaining increased formal and informal control. Moreover, it is recommended to adopt media advocacy in an alcohol policy, in order to mobilize important stakeholders for the community. 


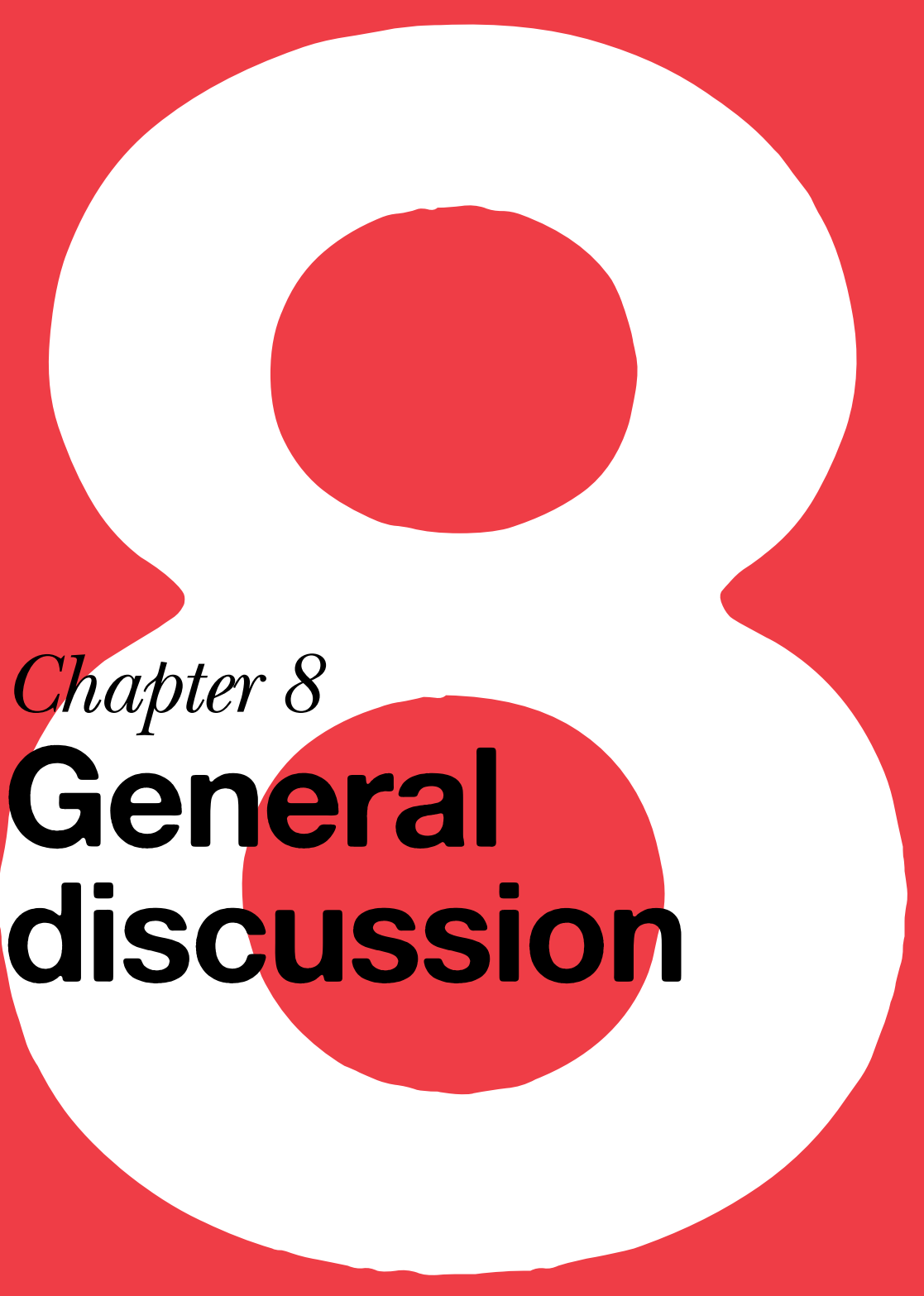




\section{Introduction}

Dutch adolescents start drinking alcohol regularly and heavily at a relatively young age which puts them at risk for alcohol-related problems throughout adolescence and into adulthood (Grant, et al., 2006; WHO, 2004). This stresses the necessity to determine important factors predicting the development of alcohol use and to develop effective alcohol prevention strategies.

Drinking alcohol is not only a personal choice; it is also strongly influenced by environmental factors. Therefore, when it comes to explaining and preventing adolescent alcohol use, I have argued (Chapter 1) that a strategy which integrates intrapersonal and environmental factors into a multi-level social ecological approach is needed.

The aim of this thesis was to examine adolescent drinking from a social ecological perspective. In the first three empirical studies (Chapter 2, 3, and 4) the links and interplay between determinants for adolescent alcohol use at the intra- and interpersonal level were studied. The last three studies described in Chapter 5, 6, and 7 investigated the effectiveness of two community interventions and focused more on the organizational, community and policy level. First this chapter will provide an overview of the main findings of this thesis in relation to the social ecological paradigm. Also, the forms of interplay between levels of influence of the social ecological paradigm (unmediated or mediated effects, higher-order moderation, and mediated higher-order moderation) are discussed. Secondly, issues regarding the process of implementation and the general limitations of this thesis will be discussed. Last, general conclusions wil be drawn and implications for prevention and future research are presented.

\section{Overview of the main findings}

In the next sections, an overview of the main findings is presented for each level of influence. Furthermore, the main results are summarized in Figure 8.1 which gives a descriptive overview of all findings in relation to the social ecological paradigm.

Figure 8.1 Overview of the main findings of this thesis displayed in the social ecological paradigm (McLeroy, et al., 1988)

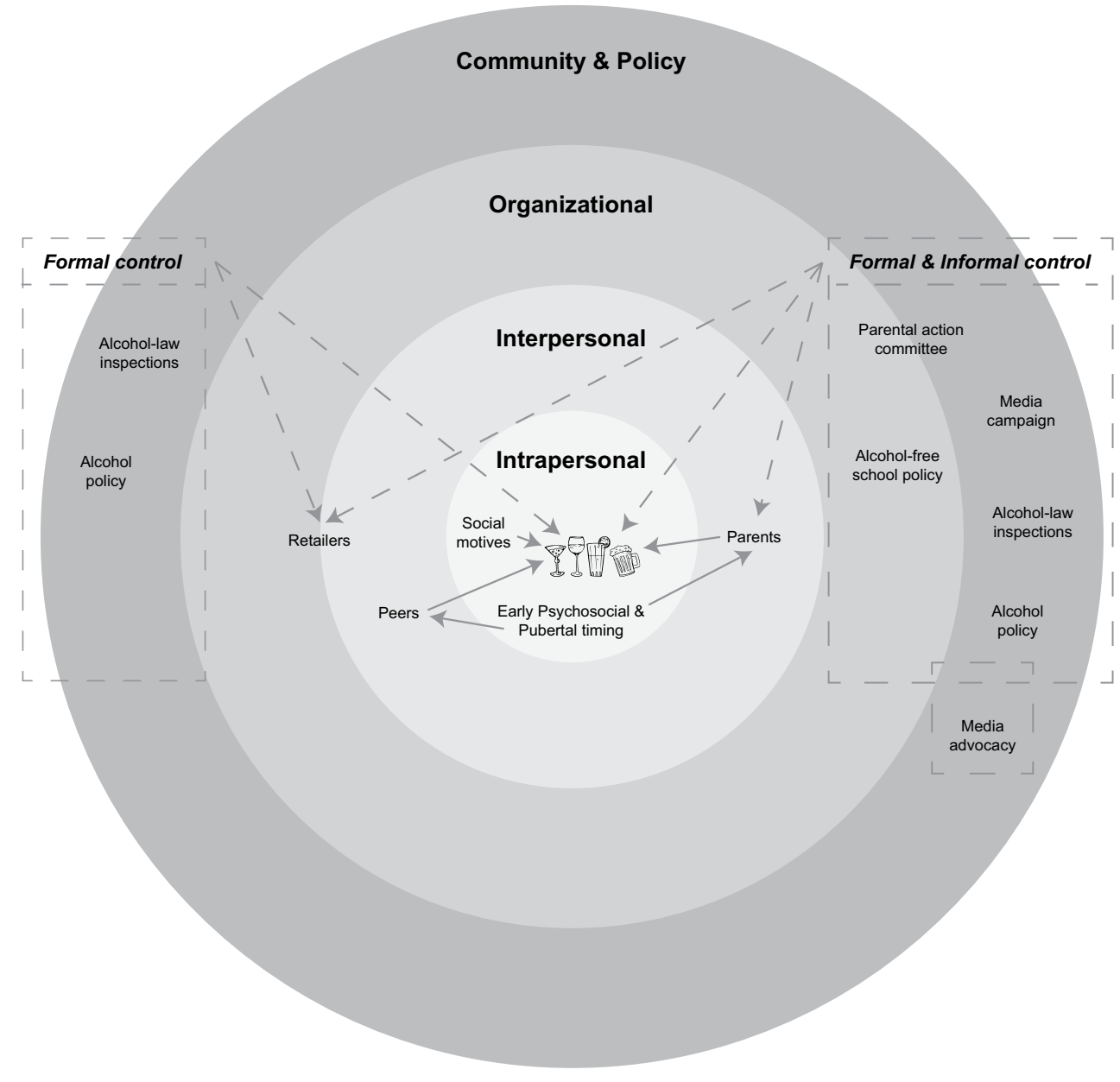

Note: Dashed lines represent higher-order moderation effects. 


\section{Intrapersonal level of influence}

\section{Drinking motives}

The most proximal factors to alcohol use are drinking motives (Cooper, 1994 Cox \& Klinger, 1988, 1990, 2004; Kuntsche, et al., 2005). Several cross-sectiona studies have shown that drinking motives are related to drinking behavior (Cooper, 1994; Cooper, et al., 2000; Kuntsche, et al., 2006, 2007; Kuntsche, Stewart, et al., 2008), however, longitudinal studies are scarce. Chapter 2 of this thesis presented the first study investigating the longitudinal predictive value of drinking motives for adolescent weekly alcohol use and frequency of heavy episodic (6+ glasses at one drinking occasion) drinking. Results showed that drinking motives were already rather stable during adolescence. No feedback mechanisms from earlier alcohol use towards future drinking motives were detected. Furthermore, results showed that social motives (rather than enhancement or coping motives) were most predictive for increases in weekly drinking and the frequency of heavy episodic alcohol use among Dutch drinking adolescents.

Interplay between intrapersonal and interpersonal level of influence

\section{Pubertal and psychosocial timing and parental alcohol-specific rules}

Early pubertal timing has already shown to be a risk factor for adolescents alcohol use (Costello, et al., 2007; Lanza \& Collins, 2002; Patton, et al., 2004; Schelleman-Offermans, et al., 2011). However, Chapter 3 of this thesis provides the first study also including the effect on adolescent alcohol use of psychosocial development during adolescence. Chapter 3 provides evidence that besides early pubertal timing, also early socio-institutional timing adolescents are at greater risk to initiate alcohol use and for heavy episodic drinking.

Furthermore, Chapter 3 provided more insight into the environmental factor that explain the increased risk of early timers to initiate (heavy) alcohol use. More evidence was found for a mediating role, rather than a moderating role of alcohol-specific rules set by parents in this cross-sectional study. Results indicated that alcohol-specific rules are relaxed when adolescents mature, rather than that parents remain strict to protect against the tendency of their early maturing children to use alcohol.

The results of Chapter 4 confirmed the mediating role of parents in the link between early pubertal timing and alcohol initiation using longitudinal data.
In this study, also the interplay with drinking peers was investigated. Results indicated that not only the decrease in alcohol-specific rule set by parents, but additionally the increase in the proportion of drinkers in the peer group explained the higher likelihood of early pubertal timing adolescents to start alcohol use. Furthermore, these social mechanisms explaining the effect of early pubertal timing on adolescent alcohol initiation were the same for boys and girls and across age groups.

\section{Organizational, community and policy level of influence}

\section{Effects of intensified formal control}

In Chapter 5 the effects on adolescent alcohol use of intensified inspections on the legal purchase age combined with a more restrictive alcohol policy (i.e. intensified formal control) were investigated. Results indicated that intensifying formal control increased the risk to start drinking weekly for adolescents, however, effectively reduced the risk in weekly drinking adolescents to progress into drunkenness. The reduced risk in weekly drinking adolescents to progress into drunkenness could neither be explained by changes in the frequency of adolescents' alcohol purchases nor perceived ease for purchasing alcohol. The low likelihood of sanctions observed in Chapter 5 , indicated that effectiveness of formal control could be increased by adopting enforcement methods with a higher likelihood of apprehension (e.g., decoy operations) than the applied observational inspection methods.

\section{Effects of combining intensified formal and informal control}

A community intervention in which both formal and informal control was increased showed to be effective in reducing the risk in weekly drinking adolescents to progress into drunkenness (Chapter 6). No intervention effect was found on weekly drinking status.

Additionally, effects on intermediate intervention goals were investigated. For 13-year-old adolescents at baseline in the intervention compared with the control community, an impeded decrease in the frequency of parental alcohol-specific rules and parental alcohol supply was found. For older adolescents (i.e. 15-year-olds at baseline) in the intervention compared with the control community, a greater increase in the frequency in alcohol purchases from on- and off-premise retailers was found. Thus, for 13-year-olds at baseline (not reaching 
the legal purchase age during the intervention period) positive intervention effects on intermediate intervention goals were found, whereas for 15-year-olds a negative intervention effect was found for one of the intermediate intervention goals. This latter finding was most likely caused by the strong focus on discouraging underage $(<16$ years) drinking in the intervention community which may have encouraged adolescents to buy alcoholic beverages once they reached the legal purchase age.

The effects of combining intensified formal and informal control on parents of adolescents and retailers were presented in Chapter 7. Results of this study showed that the intervention was effective in changing the attitudes and behaviors of retailers and parents of adolescents. Parents in the intervention became more restrictive in their attitudes towards underage alcohol use at home than parents in the comparison community. Retailers in the intervention community showed a greater increase in their perceived likelihood of sanctions, rated alcohol-law enforcement as more effective to reduce adolescent drinking, and more often checked age identification of adolescents before supplying alcohol to them, relative to the comparison community.

\section{Intensifying formal control vs. combining intensified formal and informal} control

The social ecological paradigm constitutes that triangulation or multi-level interventions are most effective in attaining behavioral change in complex systems such as communities (Sallis, et al., 2008). Therefore, there is a need for research investigating where the high leverage points in prevention lie; which combinations of interventions at different ecological levels result in the greatest decrease of adolescent alcohol use and related harm. Table 8.1 provides an overview of the differences between intensifying formal control only and combining intensified formal and informal control in effects on primary outcomes (weekly drinking and drunkenness) and intermediate intervention goals (e.g., parental alcohol-specific rules, frequency of alcohol purchases). In the current thesis, no study is included which directly compared the two intervention studies. However, Table 8.1 contains outcomes of additional analyses in which the community with intensified formal control was compared with the control community on intermediate and behavioral outcome indicators in relation to behavior and cognitions of parents and retailers. Additional analyses showed that, only when intensified formal and informal control were combined, parents changed their behavior for 13-year-old adolescents at baseline and their attitudes towards underage alcohol use at home. Furthermore, increasing both formal and informal control showed to result in more changes in retailers' behavior. A greater decrease in retailers' alcohol supply to adolescents without identification check was found in the community where formal and informal control were combined, whereas in the community with only intensified formal control this did not change compared with the control community. Also, more changes in retailers' perceptions were found when increasing both formal and informal control. Retailers in the intervention community combining intensified formal and informal control showed a greater increase in their perceived likelihood of sanctions, whereas in the community with only intensified formal control this did not change compared with the control community. Moreover, another effect found for combining formal and informal control but not for only increasing formal control was a greater decrease in retailers' perceived frequency of nuisance caused by adolescents in and around their premises compared with the control community.

To conclude, results from the studies presented in Chapter 5, 6 and 7 and the results of the additional analyses indicated that in terms of effectiveness, intervening on more social ecological levels of influence simultaneously (by e.g., combining formal and informal control) is likely to be more effective for the prevention of adolescent alcohol use and related harm.

\section{Forms of interplay between different levels of influence}

The social ecological paradigm (see Figure 8.1) focuses on multiple levels of influence and their interplay in relation to health behaviors. As discussed in Chapter 1, the interplay between the levels of influence can take several forms. Factors at a given ecological level can directly influence behavior, without influencing or being mediated by related factors at the same or at other ecological levels (unmediated effects). On the other hand, the effects of factors at a given ecological level can be explained by factors at the same or other ecological levels (mediated effects). Furthermore, factors at higher ecological levels can moderate the effect of factors at lower, more proximal ecological levels (higherorder moderation). Last, higher-order moderation effects can also be explained or mediated by factors at more proximal levels of influence. In the next sections, the results of the studies conducted in this thesis will be presented in the light of these forms of interplay. 
Table 8.1 Overview of community intervention results compared with the comparison community for different levels of influence

\begin{tabular}{|c|c|}
\hline $\begin{array}{l}\text { Intensified formal control } \\
\text { vs. comparison community }\end{array}$ & $\begin{array}{l}\text { Combining intensified formal } \\
\text { and informal control } \\
\text { vs. comparison community }\end{array}$ \\
\hline \multicolumn{2}{|c|}{ Intrapersonal level of influence } \\
\hline Increased risk to initiate weekly alcohol use [-] & $\begin{array}{l}\text { No increased or decreased risk to initiate weekly } \\
\text { alcohol use [0] } \\
\text { Reduced risk to progress into drunkenness [+] }\end{array}$ \\
\hline No differences in change in frequency of & Greater increase in frequency of purchasing alcohol \\
\hline $\begin{array}{l}\text { No differences in change in perceived ease of } \\
\text { purchasing alcohol }[0]\end{array}$ & $\begin{array}{l}\text { No differences in change in perceived ease of } \\
\text { purchasing alcohol }[0]\end{array}$ \\
\hline $\begin{array}{l}\text { Greater decrease in perceived frequency of } \\
\text { parental alcohol-specific rules for } 13 \text { year old } \\
\text { adolescents [-]* }\end{array}$ & $\begin{array}{l}\text { Impeded decrease in perceived frequency of paren- } \\
\text { tal alcohol-specific rules for } 13 \text { year old adolescents } \\
{[+]}\end{array}$ \\
\hline $\begin{array}{l}\text { Greater increase in alcohol supply for } 13 \text { year } \\
\text { old adolescents [-]* }\end{array}$ & $\begin{array}{l}\text { Impeded increase in alcohol supply for } 13 \text { year old } \\
\text { adolescents [+] }\end{array}$ \\
\hline \multicolumn{2}{|c|}{ Interpersonal level of influence } \\
\hline Greater decrease in restrictiveness of parental at- & Greater increase in restrictiveness of parental attitu- \\
\hline No difference in change in parents' degree of sup- & No difference in change in parents' degree of sup- \\
\hline port for restrictive alcohol policy measures $[0]^{*}$ & port for restrictive alcohol policy measures $[0]$ \\
\hline $\begin{array}{l}\text { No difference in change in parental alcohol- } \\
\text { specific norms }[0]^{*}\end{array}$ & $\begin{array}{l}\text { No difference in change in parental alcohol-specific } \\
\text { norms }[0]\end{array}$ \\
\hline $\begin{array}{l}\text { No difference in change in parental monitoring } \\
\text { of adolescent behavior in the last month }[0]^{*}\end{array}$ & $\begin{array}{l}\text { No difference in change in parental monitoring of } \\
\text { adolescent behavior in the last month [0] }\end{array}$ \\
\hline $\begin{array}{l}\text { Greater decrease in retailers' perceived likeli- } \\
\text { hood of sanctions [- }]^{*}\end{array}$ & $\begin{array}{l}\text { Greater increase in retailers' perceived likelihood of } \\
\text { sanctions [+] }\end{array}$ \\
\hline Greater increase in retailers' degree of support & Greater increase in degree of support for restrictive \\
\hline for restrictive alcohol policy measures [+]* & alcohol policy measures [+] \\
\hline Greater increase in retailers' ratings of effec- & Greater increase in retailers' ratings of effectiveness \\
\hline $\begin{array}{l}\text { tiveness of intensified inspections on the legal } \\
\text { purchase age }[+]^{*}\end{array}$ & $\begin{array}{l}\text { of intensified inspections on the legal purchase age } \\
{[+]}\end{array}$ \\
\hline $\begin{array}{l}\text { No difference in change in retailers' alcohol } \\
\text { supply to adolescents without ID check [0]* }\end{array}$ & $\begin{array}{l}\text { Greater decrease in retailers' alcohol supply to } \\
\text { adolescents without ID check [+] }\end{array}$ \\
\hline \multicolumn{2}{|c|}{ Community level of influence } \\
\hline $\begin{array}{l}\text { No difference in change in retailers' perceived } \\
\text { frequency of nuisance caused by adolescents in } \\
\text { and around their premises [0]* }\end{array}$ & $\begin{array}{l}\text { Greater decrease in retailers' perceived frequency of } \\
\text { nuisance caused by adolescents in and around their } \\
\text { premises [+] }\end{array}$ \\
\hline
\end{tabular}

Note: $[0]=$ no intervention effect, $[+]=$ positive intervention effect, $[-]=$ negative intervention effect, ${ }^{*}=$ Results from additional analyses comparing formal control and comparison community.

\section{Mediated effects vs. unmediated effects}

The effect of early pubertal and psychosocial timing on adolescent alcohol use was explained (mediated) by parents becoming more lenient in their alcoholspecific rule setting and early pubertal timing adolescents more rapidly increasing the proportion of drinkers in their peer group (Chapter 3 and 4). Thus, Chapter 3 and Chapter 4 provided evidence for mediation; changes in factors at the interpersonal level of influence (i.e. alcohol-specific rules set by parents and the proportion of drinkers in the peer group) respond to factors at the lower intrapersonal level (early pubertal and psychosocial timing). The change in the factors at the interpersonal level of influence, in turn, explained the increases in adolescent drinking behavior. It is important to note that results of Chapter 4 showed that even biological effects (pubertal timing) on adolescent alcohol use are completely mediated by the social environment (rules of parents and the drinking behavior of peers). This means that there is a potential for preventive action to mitigate the effect of biological factors by focusing on the environmental factors mediating these effects. However, it should also be noticed that in the study presented in Chapter 3, a moderating effect of for example parents was not observed.

Moreover, there is interplay between the different levels of the social ecological paradigm. Furthermore, the interplay between different levels of influence does not necessarily takes a form where higher ecological levels influence lower ecological levels (so-called outside-in effect). It can also take a form where lower ecological levels influence higher ones (inside-out effects).

\section{Higher-order moderation}

Evidence was found for a higher-order moderation of intensified formal alcohol on adolescents' progression into drunkenness. Also, higher-order moderation was found for combining intensified formal and informal control on adolescents' progression into drunkenness. Furthermore, other intermediate outcome measures were changed in the intervention compared with the control community by combining formal and informal control. For example, an impeded decrease in perceived frequency of parental alcohol-specific rules and alcohol supply for 13-year-old adolescents, a greater increase in restrictiveness of parental attitudes towards underage alcohol use at home, and a greater increase in the perceived likelihood of sanctions of retailers was found. Thus, the context of higher ecological levels (e.g., community) can influence perceptions 
and behaviors at lower ecological levels, which can be called outside-in effects. Furthermore, results of the intervention studies (Chapter 5-7) showed that in terms of effectiveness, intervening at more social ecological levels of influence simultaneously seemed to result in stronger higher-order moderation effects; i.e. was more effective in terms of preventing adolescent alcohol use.

\section{Mediated higher-order moderation}

Mediated higher-order moderation deserves attention for both theory and prevention. Theoretically, it is not satisfying to know that an intervention at community level has effect without being able to specify in more detail which mechanisms are involved in attaining such effects. From a prevention point of view, it is important to know at which specific factors one needs to focus in community interventions to attain effective reduction in health hazards. Whether the effects of the interventions (higher-order moderation) could be explained by intermediate intervention goals (such as, adolescents` frequency or perceived ease of purchasing alcohol) was directly tested in the study investigating the effects of intensifying formal control (Chapter 5). In Chapter 6, where the ef-

fects of combining intensified formal and informal control were investigated, no direct mediation paths were tested. However, it was investigated whether the intermediate intervention goals differed in rates of change between the intervention and comparison community (Chapter 6 )

When investigating the effect of intensified formal control (Chapter 5), none of the tested mediation paths showed to be relevant. The decreased risk in weekly drinking adolescents to progress into drunkenness could neither be explained by an impeded increase in adolescents` frequency nor by an impeded perceived ease of purchasing alcohol for adolescents. Results of combining intensified formal and informal control (Chapter 6) showed that parents remained stricter in their alcohol-specific parenting in the intervention community, however, only for 13-year-olds at baseline. The intermediate intervention goals adolescents frequency of alcohol purchases and perceived ease of purchasing alcohol did not differ in rates of change between the intervention and comparison community (Chapter 6)

Thus, there were only very few indications for mediated higher-order moderation effects. Not finding evidence for mediated higher-order moderation could indicate that: 1) the duration (2 years) or the intensity of the intervention was not sufficient to result in changes in intermediate intervention goals; 2) the intermediate intervention goals did not explain enough variance in adolescent alcohol use to be able to function as mediators on their own; 3) possibly other factors than the tested intermediate intervention goals were relevant for the attained intervention effect; 4) possibly more complex mechanisms (e.g., interactions between intermediated intervention goals) are causing the decreased risk in weekly drinkers to progress into drunkenness (higher-order moderation) found in this thesis.

\section{Implementing community interventions}

The community-based intervention studies included in this thesis were natural experiments which are generally seen as 'messy' from a scientific point of view. Although serious efforts were undertaken to standardize the intervention studies as much as possible (e.g., matched comparison-group design), there are many developments over which a scientist has no control. Formal control measures on legal retail products such as alcohol use are not easily appreciated by community representatives. This makes implementation of such measures difficult and time consuming. During the intervention period, not only were there local elections, but also the national Alcohol Act in the Netherlands was under revision, without it being clear in which way and when exactly the Alcohol Act would change. The main changes in the Act that were discussed among national Dutch politicians were: 1 ) whether the legal purchase age should be increased from 16 to 18 years; 2) whether the enforcement of the Alcohol Act should be decentralized from the national to the local level; 3) whether underage adolescents should be prosecuted for buying or possessing alcohol. This led to a situation in which the local authorities in the intervention communities were on the one hand willing to formulate and implement additional local alcohol policies based on the existing Dutch Alcohol Act. On the other hand, however, they were more careful to formulate and implement new local alcohol policies, because of their concern to implement policies which were not of use anymore in case the national Alcohol Act would be changed.

Another difficulty for implementation was that the local authorities in the intervention communities did not necessarily perceive it as their responsibility to prevent adolescents from alcohol use (Schelleman-Offermans, Knibbe, \& Derickx, 2009a). The local authorities perceived this to be more of a responsibility for the local health professionals, parents of adolescents, and retailers in their community. However, adolescent alcohol use is in terms of both determinants and 
consequences of use, to such an extent a public issue, that any intervention in which local authorities do not take the responsibility and lead to make the environment safer is destined to have no or little effect.

\section{Limitations}

Specific limitations for the studies presented in the previous chapters are discussed in the relevant chapters. In this paragraph, more general limitations of the current thesis are discussed. First, community interventions generally take more time to be implemented than standardized interventions that use a priori chosen intervention protocols. One question is whether the time period of the intervention was long enough to be able to fully implement all the elements of the intervention. This, of course, is necessary to achieve the expected changes in behavioral and intermediate outcomes. The results of the effect studies presented in Chapter 5, 6, and 7 indeed showed that not all of the expected changes, especially on the intermediate intervention goals, could be observed. One example of an incomplete implementation is that there was no realistic threa that retailers would loose their liquor license due to the new alcohol policy plan

('Three-'or 'Two-strikes-out'). It appeared that inspections revealed such few cases of non-compliance of retailers, that there was no chance that retailers could get fined twice or three times per annum. Also, in the community that combined intensified formal and informal control, only 3 of 13 local high schools implemented the alcohol-free school policy. Thus, there were indications that the completeness and intensity of implementation of some elements of the interventions was rather low. Nevertheless, a reduced risk in weekly drinking adolescents to progress into drunkenness was found in both intervention studies despite shortcomings in implementation and the rather short duration of the interventions. This indicates a potential for success of community interventions, especially if implementations of intervention elements could be enhanced and the intervention is continued over a longer period of time.

Secondly, in the intervention studies no outcome indicators at the aggregated level (community and policy level) are used to evaluate the effect of the intervention, such as the number of adolescents treated in hospitals because of their alcohol use or the number of police reports on aggression due to alcohol use. From this point of view, the evaluation of the interventions can be seen as incomplete. It is likely that the community interventions evaluated in this thesis also had effects on the aggregated level and that these effects are more easily detected of the whole population is monitored, rather than a sample of a community (Holder, 1998; Holder, et al., 2000; Wagenaar, et al., 2000b; Wagenaar \& Toomey, 2002).

Third, although structural equation modeling (used in this thesis) is a sophisticated analytic technique, trying to capture the effects in one statistical model might be a too simplistic way of evaluating effects of such interventions. For instance, there might be more complex mechanisms explaining the higher-order moderation effects of the intervention (mediated higher-order moderation). For future research it is important to address these possible mediated higherorder moderation effects. It might be useful to, next to using longitudinal panel data, include more observational data (from e.g., parents or other community stakeholders) to gain more insight into the underlying mechanisms through which community interventions work.

\section{Implications for prevention}

Results in Chapters 5, 6, and 7 indicate that it is possible to prevent adolescent alcohol use by consistently discouraging adolescent alcohol use throughout several ecological levels. This can be done by intensifying formal and informal control. At the interpersonal level of influence, parents could play an important role. Parents should be made aware that drinking for social motives, which is generally accepted behavior in the Netherlands, is mostly responsible for the increase in adolescent alcohol consumption and, for the associated increase in alcohol-related health risks. To increase informal control for adolescent alcohol use, parents of adolescents can increase their frequency of alcohol-specific rule setting, refrain from providing their children with alcohol and more closely monitor their children's drinking behaviour. Increasing parental informal control for adolescent alcohol use should especially be stimulated for parents with early pubertal and psychosocial timing children who are at increased risk for alcohol use and abuse.

At the organization level of influence, parents and also high-schools can play an important role. Parents can get organized into an informal network of parents with shared restrictive norms and shared monitoring of their children's behaviour. High schools can discourage adolescent drinking by implementing alcohol-free school policies. Local health professionals can educate and stimulate parents and high schools to consistently discourage adolescent drinking. At the community and policy level of influence, local authorities can increase 
formal control for adolescent drinking by implementing restrictive alcohol policies and increase enforcement on these restrictive alcohol policies. However, in order for politicians to implement restrictive alcohol policies, the general support for these measures should increase. Furthermore, results of the study evaluating the effect of formal control (Chapter 5) showed that observational enforcement methods have a low likelihood of sanctions. To increase the likelihood of sanctions more efficient enforcement methods should be used such as decoy operations. Moreover, since adolescent alcohol use and its consequences is to such an extent a public health problem, it is important for local authorities to take up their responsibilities and take a leading role in preventing adolescent alcohol use.

The media can play a profound role at several ecological levels of influence. By stimulating the media to write about the negative consequences of adolescent alcohol use, the general support for restrictive alcohol measures could be increased. The results of the study presented in Chapter 7 showed that making use of enforcement communication in the local media increased retailer's perceived likelihood of apprehension. Thus, the effect of enforcement can be

creased by adequately making use of enforcement communication in the local media.

\section{General conclusions}

There are three general conclusions which can be drawn from the results of the studies presented in this thesis. First, the results of this thesis indicate that the social environment of adolescents plays a profound role in explaining the development of their alcohol use; even when it comes to explaining the effect of psycho-social and biological factors on adolescent alcohol use. At the intrapersonal level of influence, the externally roused social drinking motives were most predictive for increases in adolescent drinking. This indicates that even at the intrapersonal level of motives, social environmental influences appear to be most important for understanding increases in adolescent alcohol consumption. Furthermore, adolescents' early pubertal and psychosocial timing at the intrapersonal level influence how their social environment at the interpersonal level (i.e. behavior of parents and/or peers) reacts to them, which in turn influences their alcohol use. Therefore, from a scientific point of view, to fully understand the development of adolescent alcohol use an integrated multi-level approach is needed.
Secondly, the results of this thesis showed that it is possible to change adolescent alcohol use by intervening at higher social ecological levels. Actively changing communities in such a way that availability of alcohol (social and/or retail) is reduced for adolescents effectively prevents weekly drinking adolescents from progression into drunkenness (higher-order moderation).This is in contrast with the effects found for health education programs directed at individuals, which have shown no or a limited impact on reducing adolescent alcohol use or related harm (Anderson, et al., 2009; Foxcroft, et al., 2011; Foxcroft, et al., 2003; Holder, 1998).

Third, combining intensified formal and informal control seems to be more effective than only intensifying formal control for adolescent alcohol use. This indicates that consistently discouraging adolescent alcohol use throughout several ecological levels (e.g., by multi-level interventions) is likely to be more effective in terms of preventing adolescent alcohol use. Therefore, to reduce adolescent alcohol use and related harm, important actors in the social environment of adolescents at several social ecological levels should be stimulated to reduce alcohol availability and monitor adolescents' drinking as actively as possible. 
In high-income countries, alcohol use is one of the leading risk factors for burden of disease among adolescents. This stresses the necessity to determine important factors predicting the development of adolescent alcohol use and to develop effective alcohol prevention strategies.

From previous research it can be concluded that, although there is much literature on individual risk factors of adolescent alcohol use and abuse, prevention efforts targeting individuals have shown a limited long-term impact on alcohol use and related harm. On the other hand, supply measures restricting alcohol availability have shown promising effects in reducing adolescent alcohol use and related harm in the long run. However, still unclear is through which mechanisms supply measures work and which role intrapersonal factors play in this. Also, the effect of more informal ways to restrict alcohol availability for adolescents in their social environment (through parents, schools, etc.) remains underexplored.

In this thesis, the social ecological paradigm is used as an overarching framework to understand the interplay between adolescents, their social environments, the legal environment and the community they live in. Rather than focusing exclu-

sively on either environmental or intrapersonal determinants of behavior, the social ecological paradigm focuses on multiple levels of influence, and their interplay in relation to health behaviors. The levels of influence include the intrapersonal, interpersonal, organizational, community and policy level.

At the intrapersonal level of influence it was investigated whether drinking motives predict increases in adolescent alcohol use. Results showed (Chapter 2) that externally roused social motives (rather than the internally roused drinking motives such as enhancement or coping motives) were most predictive for increases in weekly drinking and the frequency of heavy episodic alcohol use among Dutch drinking adolescents. This indicates that even at the intrapersonal level of motives, social environmental influences appear to be most important for understanding increases in adolescent alcohol consumption.

In Chapter 3 and 4 the interplay between factors at the intrapersonal (early pubertal and psychosocial timing) and interpersonal level of influence (parental alcohol-specific rule setting and proportion of drinkers in the peer group) were investigated. A mediating role of environmental factors explaining the link between early pubertal and psychosocial development and adolescent alcoho use was found. The effect of early pubertal and psychosocial timing on adolescent alcohol use was explained (mediated) by parents becoming more lenien in their alcohol-specific rule setting and early pubertal timing adolescents more rapidly increasing the proportion of drinkers in their peer group.

The organizational, community, and policy levels of influence were investigated by evaluating the effect of two community intervention studies limiting the retail and/or social alcohol availability for adolescents. In this thesis, the first Dutch studies were presented which are able to draw evidence-based conclusions about the effectiveness of control measures. Evidence from such intervention studies conducted in a country with relatively liberal alcohol policies and social norms is important for demonstrating the cross-national validity of the effectiveness of these control measures.

In the first community intervention only formal control (intensified inspections on the legal purchase age combined with a stricter local alcohol policy) was intensified in order to decrease the retail alcohol availability for adolescents. Results indicated (Chapter 5) that intensifying formal control increased the risk to start drinking weekly for adolescents, however, significantly reduced the risk in weekly drinking adolescents to progress into drunkenness. The reduced risk in weekly drinking adolescents to progress into drunkenness could neither be explained by changes in the frequency of adolescents' alcohol purchases nor perceived ease for purchasing alcohol.

In the second community intervention both formal (restricting retail supply) and informal control (restricting social supply from e.g., parents) were intensified. Combining both formal and informal control (Chapter 6) showed to be effective in reducing the risk in weekly drinking adolescents to progress into drunkenness. No intervention effect was found on weekly drinking status. Furthermore, intervention effects were evaluated on intermediate intervention goals. Only few of the tested effects on intermediate intervention goals showed a positive effect (Chapter 6). Parents in the intervention community combining formal and informal control versus the comparison community became more restrictive in their attitudes towards underage alcohol use at home (Chapter 7). Retailers in the combined formal and informal control intervention community compared with the control showed: 1) a greater increase in their perceived likelihood of sanctions, 2) rated alcohol-law enforcement as more effective to reduce adolescent drinking and 3) more often checked age identification of adolescents before supplying alcohol to them (Chapter 7).

To conclude, the results of this thesis indicate that the social environment of adolescents plays a profound role in explaining the development of their 
alcohol use; even when it comes to explaining the effect of psycho-social (e.g., drinking motives) and biological factors (e.g., pubertal timing) on adolescent alcohol use. Furthermore, it is possible to change adolescent alcohol use by intervening at higher social ecological levels. Combining intensified formal and informal control seemed to be more effective than only intensifying formal control to prevent adolescent alcohol use. However, since the exact underlying mechanism though which control measures (formal and informal) work could not be identified in this thesis, more research is needed to gain more insight in this In terms of prevention, consistently discouraging adolescent alcohol use throughout several ecological levels (e.g., by multi-level interventions) is likely to be effective in terms of preventing adolescent alcohol use. Therefore, to reduce adolescent alcohol use and related harm, important actors in the social environment of adolescents at several social ecological levels should be stimulated to reduce alcohol availability and monitor adolescents' drinking as actively as possible.
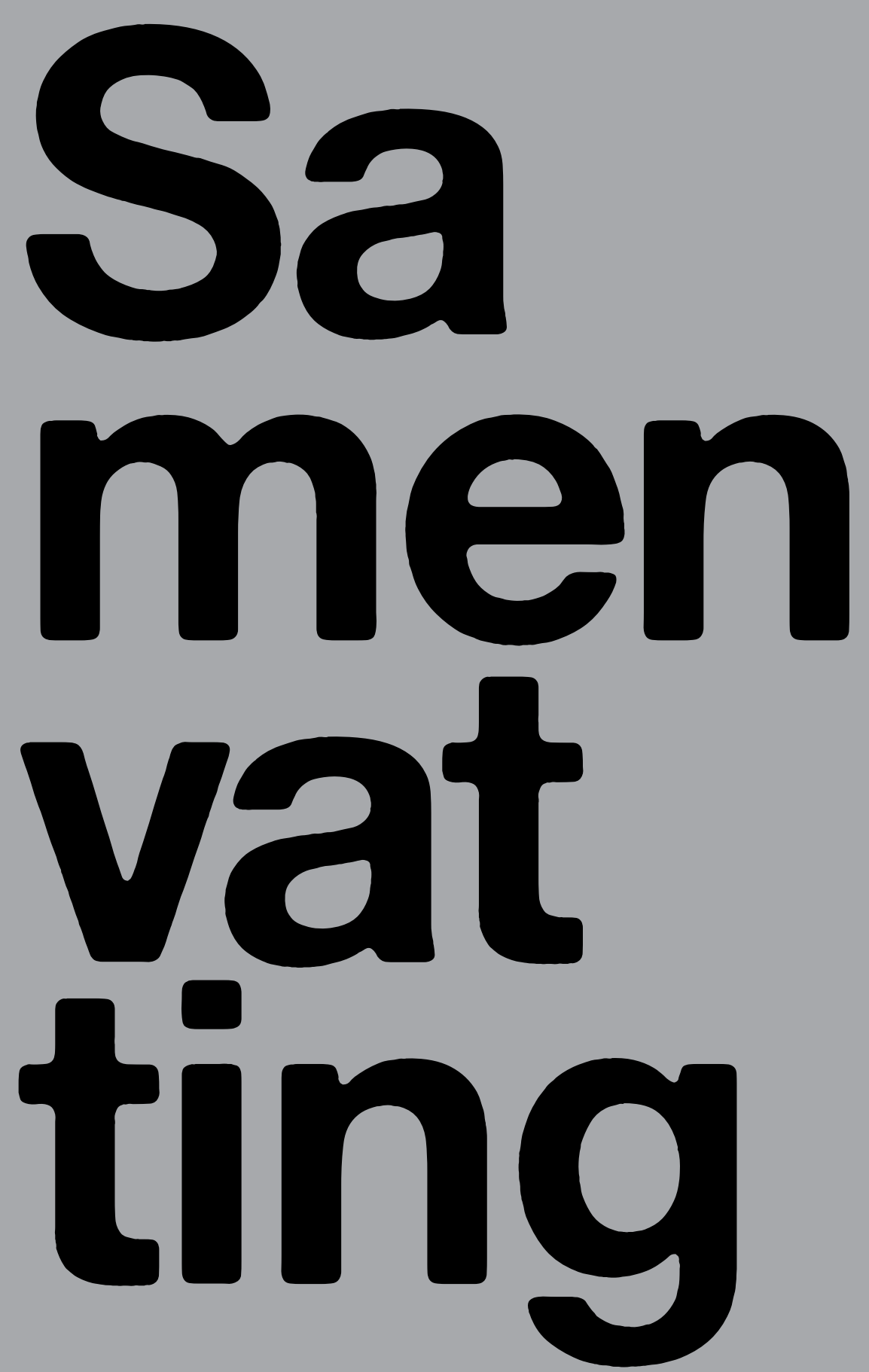
In welvarende landen is alcoholgebruik een van de belangrijkste factoren voor de ziektelast van adolescenten. Dit onderschrijft de noodzaak om factoren die belangrijk zijn in het verklaren van het drankgebruik onder jongeren vast te stellen en effectieve alcoholpreventie strategieën te ontwikkelen.

Eerder onderzoek heeft laten zien dat strategieën voor alcoholpreventie die gericht zijn op het individu geen of een minimaal effect hebben op het drankgebruik van jongeren en gerelateerde problemen. Het verminderen van de beschikbaarheid van alcohol heeft daarentegen veelbelovende effecten laten zien om het alcoholgebruik van jongeren en gerelateerde problemen te verminderen, zelfs op de lange termijn. Echter, het is nog steeds niet duidelijk welke processen ten grondslag liggen aan de effectiviteit van het verminderen van de beschikbaarheid van alcohol en welke rol intrapersoonlijke factoren hierin spelen. De effecten van informele manieren om de beschikbaarheid van alcohol voor jongeren te verminderen (door ouders, scholen, etc.) zijn ook nog steeds onderbelicht in wetenschappelijk onderzoek.

In dit proefschrift wordt het sociale ecologische paradigma gebruikt als een overkoepeld kader om de wisselwerkingen te begrijpen tussen adolescenten,

hun sociale omgeving, de juridische omgeving en de gemeenschap of community waarin adolescenten opgroeien. Het sociale ecologische paradigma richt zich niet uitsluitend op het intrapersoonlijke of omgevingsniveau, maar richt zich op meerdere ecologische niveaus die van invloed zijn op gezondheidgerelateerde gedragingen. De ecologische niveaus die van invloed zijn op gedrag zijn het intrapersoonlijke, interpersoonlijke, organisatorische, en community en beleidsniveau.

Op het intrapersoonlijk niveau werd onderzocht of drinkmotieven een toename in het alcoholgebruik van jongeren voorspellen. De resultaten toonden aan dat de extern gegenereerde sociale drinkmotieven (in tegenstelling tot intern gegenereerde drinkmotieven zoals enhancement of coping motieven) het meest voorspellend waren voor toenames in de totale week consumptie van jongeren en in de frequentie waarmee jongeren veel alcohol (6+ glazen) drinken per drinkgelegenheid (Hoofdstuk 2). Dit onderschrijft dat, zelfs op intrapersoonlijk niveau, sociale omgevingsfactoren belangrijk zijn om toenames in het alcoholgebruik van jongeren te kunnen begrijpen.

In Hoofdstuk 3 en 4 werd de wisselwerking tussen factoren op het intrapersoonlijke (vroege timing van de puberteit en psychosociale ontwikkeling) en interpersoonlijk niveau (alcoholspecifieke regels van ouders, en de proportie drin- kers in de vriendengroep) onderzocht. Omgevingsfactoren op interpersoonlijk niveau bleken een mediërende rol te spelen in de associatie tussen een vroege timing van de puberteit en psychosociale ontwikkeling en het alcoholgebruik van jongeren. Dit betekent dat adolescenten met een vroege timing van de puberteit en psychosociale ontwikkeling een verhoogd risico op alcoholgebruik toonden omdat: 1) ouders minder streng werden ten aanzien van hun alcoholgebruik en 2) doordat het deel van hun vriendengroep dat alcohol drinkt steeg. De organisatorische, community en beleidsniveaus werden onderzocht door middel van de effectevaluaties van twee community-interventie studies gericht op het beperken van de beschikbaarheid van alcohol via alcoholverstrekkers (horeca en detailhandel) en de sociale omgeving van jongeren (via ouders, scholen, etc.). In dit proefschrift worden de eerste Nederlandse studies gepresenteerd die in staat zijn om gefundeerde conclusies te trekken met betrekking tot de effectiviteit van maatregelen die de beschikbaarheid van alcohol verminderen. Bewijs van dergelijke maatregelen uitgevoerd in een land met relatief liberaal alcoholbeleid en sociale normen ten aanzien van alcohol is belangrijk om cross-nationale validiteit van de effectiviteit van zulke maatregelen aan te kunnen tonen.

In de eerste community-interventie werd formele controle geïntensiveerd (geintensiveerde handhaving van de leeftijdsgrenzen voor alcohol in combinatie met een strenger locaal alcoholbeleid) om de beschikbaarheid van alcohol voor jongeren via alcoholverstrekkers te verminderen. Resultaten (Hoofdstuk 5) gaven aan dat het risico om te beginnen met wekelijks drinken voor adolescenten verhoogd werd door geïntensiveerde formele controle. Echter, geïntensiveerde formele controle verlaagde het risico voor al drinkende jongeren om dronken te worden. Het verminderde risico voor de al drinkende jongeren op dronkenschap kon niet worden verklaard door een minder grote toename in de frequentie van alcoholaankopen of het waargenomen gemak waarmee jongeren alcohol konden aankopen.

In de tweede community-interventie werd zowel formele (beperken van de beschikbaarheid van alcohol via alcoholverstrekkers) als informele controle (beperken van de beschikbaarheid van alcohol via de sociale omgeving) geintensiveerd. Deze combinatie van formele en informele controle (Hoofdstuk 6) bleek effectief te zijn in het verminderen van het risico voor drinkende jongeren op dronkenschap. Er werd geen effect gevonden van deze communityinterventie op het wekelijks drinken van alcohol. Tevens werd het effect van de 
interventie onderzocht op tussenliggende interventiedoelen. Bij enkele tussenliggende interventiedoelen werd een positief effect van de interventie aangetoond (Hoofdstuk 6). In vergelijking met de controle gemeente bleven ouders in de interventie gemeente waar formele en informele controle werd geïntensiveerd restrictiever in hun attitude ten aanzien van het thuis drinken van alcohol door jongeren onder de 16 jaar (Hoofdstuk 7). Verstrekkers in de gemeente met geïntensiveerde formele en informele controle toonden 1) een grotere toename in kans die zij waarnamen beboet te worden voor het verkopen van alcohol aan minderjarigen, 2) beoordeelden handhaving van de leeftijdsgrenzen als effectiever, en 3) controleerden vaker het identiteitsbewijs van jongeren alvorens hen alcohol te verkopen dan in de controle gemeente (Hoofdstuk 7). Samenvattend kan worden gesteld dat de sociale omgeving van jongeren een grote rol speelt in het verklaren van de ontwikkeling van alcoholgebruik, zelfs als het gaat om het verklaren van het effect op alcoholgebruik van psychosociale (drinkmotieven) of biologische (timing van puberteit) factoren. De resultaten geven ook weer dat het mogelijk is om alcoholgebruik van jongeren te reduceren door op hogere sociale ecologische niveaus de beschikbaarheid van alcohol

te verminderen. De combinatie van intensievere formele en informele controle lijkt effectiever te zijn als het gaat om preventie van alcoholgebruik onder jongeren dan alleen een intensivering van formele controle. Echter, in dit proefschrift konden de exacte onderliggende factoren of processen die het effect van formele en informele controle verklaren niet worden geïdentificeerd. Meer onderzoek is nodig om inzicht te krijgen in deze onderliggende processen.

Vanuit het oogpunt van preventie is het consistent ontmoedigen van het alcoholgebruik van jongeren op meerdere ecologische niveaus (bijvoorbeeld door het implementeren van multi-level community-interventies) effectief om het alcoholgebruik onder jongeren en gerelateerde problemen te kunnen reduceren. Om deze reden zouden belangrijke actoren in de sociale omgeving van jongeren gestimuleerd moeten worden om zo actief mogelijk de beschikbaarheid van alcohol voor jongeren te verminderen en hun drinkgedrag te monitoren.
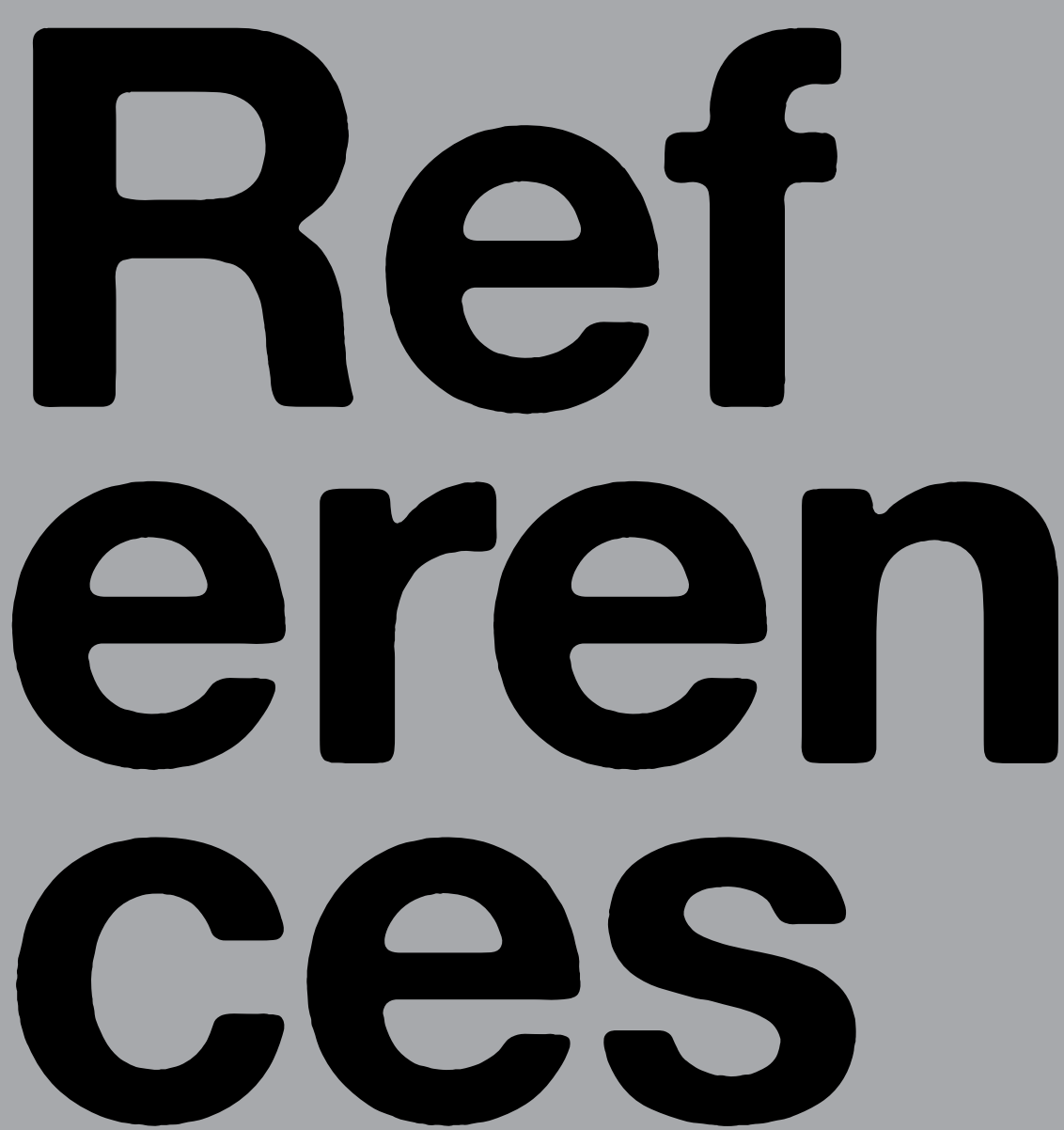
Abar, C. C. (2010). Social influence and selection processes as predictors of normative perceptions and alcohol use across the transition to college. Journal of College Student Development, 51, 496-508.

Alsaker, F. D. (1992). Pubertal timing, overweight, and psychological adjustment. The Journal of Early Adolescence, 12, 396-419.

Anderson, P., \& Baumberg, B. (2006). Alcohol in Europe: A public health perspective. London: Institute of Alcohol Studies.

Anderson, P., Chisholm, D., \& Fuhr, D. C. (2009). Effectiveness and cost-effectiveness of policies and programmes to

reduce harm caused by alcohol. Lancet, 373, 2234-2246.

Anthony, J. C., \& Petronis, K. R. (1995). Early-onset drug use and risk of later drug problems. Drug and Alcohol Dependence, 40, 9-15.

Arim, R. G., \& Shapka, J. D. (2008). The impact of pubertal timing and parental control on adolescent problem behaviors. Journal of Youth and Adolescence $37,445-455$

Babor, T. F., Caetano, R., \& Casswell, S. (2010). Alcohol: No ordinary commodity : Research and public policy (Vol. 2nd Revised edition). Oxford: Oxford University Press.

Bandura, A. (1977). Social learning theory. Englewood Cliffs, NJ: Prentice-Hall.
Barnes, G. M., Reifman, A. S., Farell, M.

P., \& Dintcheff, B. A. (2000). The effects

of parenting on the development of adolescent alcohol misuse: A six wave laten growth model. Journal of Marriage and the Family, 62, 175-186.

Bauman, K. E., \& Ennett, S. T. (1996) On the importance of peer influence for adolescent drug use: Commonly neglected considerations. Addiction, 91, 185-198.

Baumrind, D. (1980). New directions in socialization research. American Psychologist, 35, 639-652

Bava, S., \& Tapert, S. F. (2010). Adolescents brain development and the risk for alcohol and other drug problems. Neuropsychological Review, 20, 398-413.

Bergman, L. R., Magnusson, D., \& ElKhouri, B. M. (2003). Studying individual development: A person-oriented approach. In D. Magnusson (Ed.), Paths through life (Vol. 4). Mahwah, NJ: Lawrence Erlbaum Associates.

Biehl, M. C., Natsuaki, M. N., \& Ge, X. (2007). The influence of pubertal timing on alcohol use and heavy drinking trajectories. Journal of Youth and Adolescence, 36, 153-167.

Bot, S. M., Engels, R. C. M. E., Knibbe, R. A., \& Meeus, W. H. J. (2007). Sociometric status and social drinking: Observations of modelling and persuasion in young adult peer groups. Journal of Abnormal Child Psychology, 35, 929-941.
Bradizza, C. M., Reifman, A., \& Barnes, G. M. (1999). Social and coping reasons for drinking: Predicting alcohol misuse in adolescents. Journal of Studies on Alcohol, 60, 491-499.

Brand, D. A., Saisana, M., Rynn, L. A., Pennoni, F., \& Lowenfels, A. B. (2007). Comparative analysis of alcohol control policies in 30 countries. PLoS Medicine, 4, 449-363.

Brooks-Gunn, J., Warren, M. P., Rosso, J., \& Gargiulo, J. (1987). Validity of selfreport measures of girls' pubertal status. Child Development, 58, 829-841.

Browne, M. W., \& Cudeck, R. (1993). Alternative ways of assessing fit. In K. A. Bollen \& J. S. Long (Eds.), Testing structural equation models (pp. 136-162). Beverly Hills, CA: Sage.

Bulcroft, R. A. (1991). The value of physical change in adolescence: Consequences for the parent-adolescent exchange relationship. Journal of Youth and Adolescence, 20, 89-105.

Carpenter, K. M., \& Hasin, D. S. (1998). Reasons for drinking alcohol: Relationships with DSM-IV alcohol diagnoses and alcohol consumption in a community sample. Psychology of Addictive Behaviors, 12, 168-184.

Carskadon, M. A., \& Acebo, C. (1993). A self-administered rating scale for pubertal development. Journal of Adolescent Health, 190-195.
Casey, B., Jones, R., \& Hare, T. (2008). The adolescent brain. The year in $\operatorname{cog}$ nitive neuroscience (pp. 111-126). Malden, MA: Blackwell Publishing.

Casswell, S., Gilmore, L., Maguire, V., \& Ransom, R. (1989). Changes in public support for alcohol policies following a community-based campaign. British Journal of Addiction, 84, 515-522.

Chen, M. J., Gruenewald, P. J., \& Remer L. G. (2009). Does alcohol outlet density affect youth access to alcohol? Journal of Adolescent Health, 44, 582-589.

Chikritzhs, T., \& Stockwell, T. (2002) The impact of later trading hours for Australian public houses (hotels) on levels of violence. Journal of Studies on Alcohol, 63, 591-599.

Clark, D. B., Thatcher, D. L., \& Tapert, S. F. (2008). Alcohol, psychological dysregulation, and adolescent brain development. Alcohol Clinical and Experimental Research, 32, 375-385.

Cooper, M. L. (1994). Motivations for alcohol use among adolescents: Deve-

lopment and validation of a four-factormodel. Psychological Assessment, 6, 117 128.

Cooper, M. L., Agocha, V. B., \& Sheldon, M. S. (2000). A motivational perspective on risky behaviors: the role of personality and affect regulatory processes. Journal of Personality, 68, 1058-1088.

Cooper, M. L., Krull, J. L., Agocha, V. B. Flanagan, M. E., Orcutt, H. K., Grabe, S., et al. (2008). Motivational pathways 
to alcohol use and abuse among black and white adolescents. Journal of Abnormal Psychology, 117, 485-501.

Costello, E. J., Sung, M., Worthman, C., \& Angold, A. (2007). Pubertal maturation and the development of alcohol use and abuse. Drug and Alcohol Dependence, $88,50-59$

Cox, W. M., \& Klinger, E. (1988) . A motivational model of alcohol use. Journal of Abnormal Psychology, 97, 168-180.

Cox, W. M., \& Klinger, E. (1990). Incentive motivation, affective change, and alcohol use: A model. In W. M. Cox Why people drink: Parameters of alcohol use as a reinforcer (pp. 291-314). New York: Oxford: Gardner Press.

Cox, W. M., \& Klinger, E. (2004). A motivational model of alcohol use: determinants of use and change. In W. M. Cox \& E. Klinger (Eds.), Handbook of motivational counseling: Concepts, approaches, and assesment (pp. 121-138). Chichester: John Wiley \& Sons, Ltd.

Cuijpers, P., Jonkers, R., De Weerdt, I., \& De Jong, A. (2002). The effects of drug abuse prevention at school: the 'Healthy School and Drugs' project. Addiction, 97, 67-73.

Dekovic, M., Noom, M. J., \& Meeus, W. (1997). Expectations regarding development during adolescence: Parental and adolescent perceptions. Journal of Youth and Adolescence, 26, 253-272.
Del Boca, F. K., \& Darkes, J. (2003). The validity of self-reports of alcohol consumption: state of the science and challenges for research. Addiction, 98, 1-12. Dick, D. M., Rose, R. J., Pulkkinen, L., \& Kaprio, J. (2001). Measuring puberty and understanding its impact: a longitudinal study of adolescent twins. Journal of Youth and Adolescence, 30, 385-399. Dorn, L. D., \& Biro, F. M. (2011). Pu berty and its measurement: A decade in review. Journal of Research on Adolescence, 21, 180-195.

Duncan, S. C., Duncan, T. E., \& Strycker, L. A. (2006). Alcohol use from ages 9 to 16: A cohort-sequential latent growth model. Drug and Alcohol Dependence,

81, 71-81.

Ellickson, P. L., Tucker, J. S., Klein, D. J., \& McGuigan, K. A. (2001). Prospective risk factors for alcohol misuse in late adolescence. Journal of Studies on Alcohol, 62, 773-782.

Engels, R. C. M. E., Knibbe, R. A., De Vries, H., Drop, M. J., \& Van Breukelen, G. J. P. (1999). Influences of parental and best friends' smoking and drinking on adolescent use: A longitudinal study. Journal of Applied Social Psychology,

29, 337-361.

Engels, R. C. M. E., Wiers, R., Lemmers, L., \& Overbeek, G. (2005). Drinking motives, alcohol expectancies, self-efficacy, and drinking patterns. Journal of Drug Education, 35, 147-166.
Farrell, S. G., Manning, W. G., \& Finch, M. D. (2003). Alcohol dependence and the price of alcoholic beverages Journal of Health Economics, 22, 117-147.

Fergusson, D. M., Swain-Campbell, N. R., \& Horwood, L. J. (2002). Deviant peer affiliations, crime and substance use: A fixed effects regression analysis. Journal of Abnormal Child Psychology, 30, 419-430.

Foxcroft, D. R., Ireland, D., Lowe, G., \& Breen, R. (2011). Primary prevention for alcohol misuse in young people. Cochrane Database of Systematic Reviews. Foxcroft, D. R., Ireland, D. J., ListerSharp, G. L., \& Breen, R. (2003). Longer-term primary prevention for alcohol misuse in young people: a systematic review. Addiction, 98, 397-411.

Galambos, N. L., Barker, E. T., \& TiltonWeaver, L. C. (2003). Who gets caught at maturity gap? A study of pseudomature, immature and mature adolescents. International Journal of Behavioral Development, 27, 253-263.

Gillian, C., Kypri, K., Johnson, N., Lynagh, M., \& Love, S. (2012). Parental supply of alcohol and adolescent risky drinking. Drug and Alcohol Review, DOI: 10.1111/j.1465-3362.2012.00418.x.

Glasgow, R. E., Vogt , T. M., \& Boles, S. M. (1999). Evaluating the public health impact of health promotion interventions: the RE-AIM framework. American Journal of Public Health, 89, 1322-1327.
Gmel, G., Rehm, J., Room, R., \& Greenfield, T. K. (2000). Dimensions of alcohol-related social and health consequences in survey research. Journal of Substance Use, 12, 113-138.

Goodman, R. (1997). The Strengths and Difficulties Questionnaire: A research note. Journal of Child Psychology and Psychiatry, 38, 581-586.

Gosselt, J. F., Van Hoof, J. J., De Jong, M. D. T., \& Prinsen, S. (2007). Mystery shopping and alcohol sales: do supermarkets and liquor stores sell alcohol to underage customers? Journal of Adolescent Health, 41, 302-308.

Graber, J. A., Nichols, T. R., \& BrooksGunn, J. (2010). Putting pubertal timing in developmental context: implications for prevention. Developmental Psychology, 52, 254-262.

Graham, J. M. (2006). Congeneric and (essentially) tau-equivalent estimates of score reliability: What they are and how to use them. Educational and Psychological Measurement, 66, 930-944.

Grant, J. D., Scherrer, J. F., Lynskey, M. T., Lyons, M. J., Eisen, S. A., Tsuang, M T., et al. (2006). Adolescent alcohol use is a risk factor for adult alcohol and drug dependence: Evidence from a twin design. Psychological Medicine, 36.

Green, L. W., Richard, L., \& Potvin, L. (1996). Ecological foundations of health promotion. American Journal of Health Promotion, 10, 270-281. 
Greenberger, E., Josselson, R., Knerr, C., \& Knerr, B. (1975). The measurement and structure of psychosocial maturity. Journal of Youth and Adolescence, 4, 127-143.

Greenberger, E., \& Sorensen, A. B. (1974). Towards a concept of psychosocial maturity. Journal of Youth and Adolescence, 3, 329-358.

Grube, J. W. (1997). Preventing sales of alcohol to minors: Results from a community trial. Addiction, 92, S251-S260.

Gruenewald, P. J., \& Johnson, F. W. (2006). The stability and reliability of self-reported drinking measures. Journal of Studies on Alcohol, 67, 738-745.

Harrison, P., Fulkerson, J., \& Park, E (2000). The relative importance of social versus commercial sources in youth access to tobacco, alcohol, and other drugs. Preventive Medicine, 31, 39-48.

Hayes, A. F. (2009). Beyond Baron and Kenny: Statistical mediation analysis in the new millennium. Communicatio Monographs, 76, 408-420.

Hearst, M., Fulkerson, J., MaldonadoMolinac, M., Perry, C., \& Komro, K. A (2007). Who needs liquor storeswhen parents will do? The importance of social sources of alcohol among young urban teens. Preventive Medicine, 44, 471-476.

Hemphill, S. A., Munro, G., \& Poh, S. (2007). Adolescents' expenditure on alcohol: A pilot study. Australian Journal of Social Issues, 42, 623-636.

Hibell, B., Guttormsson, U., Ahlström, S., Balakireva, O., Bjarnasson, T., Kokkevi, A., et al. (2007). The 2007 ESPAD report: Substance use among students in 35 European countries. Stockholm: The Swedish Council for information on $\mathrm{Al}-$ cohol and Other Drugs (CAN).

Hingson, R. W., Heeren, T., \& Winter, M. R. (2006). Age at Drinking Onse and Alcohol Dependence; Age at Onset, Duration, and Severity. Archive of Pediatrics \& Adolescent Medicine, 160, 739-746.

Hingson, R. W., Heeren, T., Winter, $M$ R., \& Wechsler, H. (2003). Early age of first drunkenness as a factor in college students' unplanned and unprotected

sex attributable to drinking. Pediatrics, 111

Holder, H. D. (1998). Alcohol and the community: A systems approach. Cambridge: Cambridge University Press.

Holder, H. D. (2004). Supply side approaches to reducing underage drinking. An assessment of the scientific evidence. In R. J. Bonnie \& M. E. O.Connell (Eds.), Reducing underage drinking: A collective responsibility. Washington DC: Natrional Academies Press.

Holder, H. D., Gruenewald, P. J., Ponicki, W. R., Treno, A. J., Grube, J. W. Saltz, R. F., et al. (2000). Effect of community-based Interventions on high-risk drinking and alcohol-related injuries. American Medical Association, 284 2341-2347.
Holder, H. D., Saltz, R. F., Grube, J. W., Voas, R. B., Gruenewald, P. J., \& Treno, A. J. (1997). A community prevention trial to reduce alcohol-involved accidental injury and death: Overview. Addiction, 92, S155-S171.

Holder, H. D., \& Treno, A. J. (1997). Media advocacy in community prevention: news as a means to advance policy change. Addiction, 92, 189-199.

Holder, H. D., \& Treno, A. J. (2007). Media advocacy in community prevention: news as a means to advance policy change. Addiction, 92, 189-199.

Holmila, M., \& Warpenius, K. (2007). A study on effectiveness of local alcohol policy: Challenges and solutions in the PAKKA project. Drugs: education, prevention and policy, 14, 529-541.

Houben, K., \& Wiers, R. W. (2008). Implicitly positive about alcohol? Implicit positive associations predict drinking behavior. Addictive Behaviors, 33, 979-986. Huckle, T., Conway, K., Casswell, S., \& Pledger, M. (2005). A regional community action intervention succeeds in improving age checks at off-license premises. Health Promotion International, 20, 147-155.

Jaccard, J., Blanton, H., \& Dodge, T. (2005). Peer influences on risk behavior: An analysis of the effects of a close friend. Developmental Psychology, 41, 135-147. Jackson, C., Henriksen, L., \& Dickinson, D. (1999). Alcohol-specific socialization, parenting behaviors and alcohol use by children. Journal of Studies on Alcohol, 60, 362-367.

Johnston, L. D., O’Malley, P. M., Bachman, J. G., \& Schulenberg, J. E. (2009). Monitoring the future. National survey results on drug use, 1975-2008. Volume 1: Secondary school students (Vol. NIH Publication No. 09-7402). Bethesda, MD: National Institute on Drug Abuse.

Jones-Webb, R., Fabian, L. E. A., Harwood, E. M., \& Toomey, T. L. W., A. C. (2004). Fatal injuries associated with alcohol use among youth and adults: 1990-1998. Journal of Child and Adolescent Substance Abuse, 14

Kaplow, J. B., Curran, P. J., \& Dodge, K A. (2002). Child, parent, and peer predictors of early-onset substance use: A multisite longitudinal study. Journal of Abnormal Child Psychology, 30, 199-216. Klepp, K. I., Schmid, L. A., \& Murray, D. M. (1996). Effects of the increased minimum drinking age law on drinking and driving behavior among adolescents. Addiction Research, 4, 237-244.

Knibbe, R. A., Joosten, J., Choquet, M., Derickx, M., Morin, D., \& Monschouwer, K. (2007). Culture as an explanation for substance-related problems: A cross-national study among French and Dutch adolescents. Social Science and Medicine, 64, 604-616. 
Knibbe, R. A., Joosten, J., Derickx, M., Choquet, M., Morin, D., Monshouwer, K., et al. (2005). Perceived availability of substances, substance use, and substance related problems: A cross national study among French and Dutch adolescents. Journal of Substance Use, 10, 151-163.

Knibbe, R. A., \& Oostveen, T. (1991)

Young people's alcohol consumption in public drinking places: reasoned behaviour or related to the situation? British Journal of Addiction, 86, 1425-1433

Komro, K. A., Tobler, A., MaldonadoMolina, M. M., \& Perry, C. (2010). Effects of alcohol use initiation patterns on high-risk behaviors among urban low-income, young adolescents. Preven-

tion Science, 11, 14-23.

Komro, K. A., \& Toomey, T. L. (2002). Strategies to prevent underage drinking. Alcohol, Research \& Health, 2002, 5-14. Koning, I. A., Vollebergh, W. A. M., Smit, F., Verdurmen, J. E. E., Van Den Eijnden, R. J. J. M., Ter Bogt, T. F. M., et al. (2009). Preventing heavy alcohol use in adolescents (PAS): cluster randomized trial of a parent and student intervention offered separately and simultaneously. Addiction, 104, 1669-1678.

Koning, I. M., Van den Eijnden, R. J. J. M., Engels, R. C. M. E., Verdurmen, J. E. E., \& M., V. W. A. (2011). Why target early adolescents and parents in alcohol prevention? The mediating effects of self-control, rules and attitudes bout alcohol use. Addiction, 106, 538-546.
Koning, I. M., Van den Eijnden, R. J. J. M., Engels, R. C. M. E., Verdurmen, J. E. E., \& Vollebergh, W. A. M. (2011). Why target early adolescents and parents in alcohol prevention? The mediating effects of self-control, rules and attitudes bout alcohol use. Addiction, 106, 538-546. Koutakis, N., Stattin, H., \& Kerr, M. (2008). Reducing youth alcohol drinking through a parent-targeted intervention: the Örebro Prevention Program. Addiction, 103, 1629-1637.

Kremers, S. P. J. (2010). Theory and practice in the study of influences on energy balance-related behaviors. Patient Education and Counseling, 79, 291-298.

Kremers, S. P. J., De Bruijn, G., Visscher, T. L. S., Van Mechelen, W., De Vries, N. \& Brug, J. (2006). Environmental influences on energy balance-related behaviors: A dual-proces view. International Journal of Behavioral Nutrition and Physical Activity, 3, doi:10.1186/1479 5868-1183-1189.

Kuntsche, E., \& Cooper, M. L. (2010) Drinking to have fun and to get drunk: Motives as predictors of weekend drinking over and above usual drinking habits. Drug and Alcohol Dependence, 10, 259-262.

Kuntsche, E., Knibbe, R. A., Gmel, G., \& Engels, R. C. M. E. (2005). Why do young people drink? A review of drinking motives. Clinical Psychology Review, 25, 841-861.
Kuntsche, E., Knibbe, R. A., Gmel, G., \& Engels, R. C. M. E. (2006). Who drinks and why? A review of socio-demographic, personality, and contextual issues behind the drinking motives in young people. Addictive Behaviors, 31, 1844-1857.

Kuntsche, E., Knibbe, R. A., Gmel, G., \& Engels, R. C. M. E. (2007). Drinking motives as mediators of the link between alcohol expectancies and alcohol use among adolescents. Journal of Studies on Alcohol and Drugs, 68, 76-85.

Kuntsche, E., Kuendig, H., \& Gmel, G. (2008a). Alcohol outlet density, perceived availability and adolescent alcohol use: A multilevel structural equation model. Journal of Epidemiology and Community Health, 61, 811-816.

Kuntsche, E., Kuendig, H., \& Gmel, G. (2008b). Alcohol outlet density, perceived availability and adolescent alcohol use: A multilevel structural equation model. Journal of Epidemiology and Community Health, 62, 811-816.

Kuntsche, E., Rehm, J., \& Gmel, G. (2004). Characteristics of binge drinkers in Europe. Social Science Medicine, 59, 113-127.

Kuntsche, E., Stewart, S. H., \& Cooper, M. L. (2008). How stable is the motivealcohol use link? A cross-national validation of the drinking motives questionnaire revised among adolescents from Switzerland, Canada, and the United States. Journal of Studies on Alcohol and Drugs, 69, 388-396.
Kuo, M., Wechsler, H., Greenberg, P., \& Lee, H. (2003). The marketing of alcohol to college students: The role of low prices and special promotions. American Journal of Preventive Medicine, 25, 204-211

Lanza, S. T., \& Collins, L. M. (2002). Pubertal Timing and the Onset of Substance Use. Prevention Science, 3, 69-81.

Lenz, B. (2001). The transition from adolescence to young adulthood: A theoretical perspective. The Journal of School Nursing, 17, 300-306.

Livingston, M., Chikritzhs, T., \& Room, R. (2007). Changing the density of alcohol outlets to reduce alcohol-related problems Drug and Alcohol Review, 26, $557-566$

MacKinnon, D. P., Lockwood, C. M. Hoffman, J. M., West, S. G., \& Sheets, V. (2002). A comparison of methods to test mediation and other intervening variable effects. Psychological Methods, 7, 83-104.

Magnusson, D., Stattin, H., \& Allen, V. L. (1985). Biological maturation and social development: A longitudinal study of some adjustment processes from midadolescence to adulthood. Journal of Youth and Adolescence, 14, 267-283

Maldonado-Molina, M. M., \& Wagenaar, A. C. (2010). Effects of alcohol taxes on alcohol-related mortality in Florida: Time-series analyses from 1969 to 2004. 
Alcoholism: Clinical and Experimental Research, 34, 1-7.

Markowitz, S., \& Grossman, M. (1998). Alcohol regulation and domestic violence towards children. Contemporary Economic Policy, 16, 309-321.

Markowitz, S., \& Grossman, M. (2000) The effects of beer taxes on physica child abuse. Journal of Health Economics, 19, 271-282.

McLeroy, K. R., Bibeau, D., Steckler, A. \& Glanz, K. (1988). An ecological perspective on health promotion programs. Health Education Quaterly, 15, 351-377. Moffitt, T. E. (1993). Adolescence-Limited and Life-Course-Persistent Antisocial Behavior: A developmental Taxo-

nomy. [review]. Psychological Review, 100, 674-701.

Mohr, C. D., Armeli, S., Tennen, H., Temple, M., Todd, M., Clark, J., et al. (2005). Moving beyond the keg party: A daily process study of college student drinking motivations. Psychological Reports, 73, 96-962.

Monshouwer, K., Verdurmen, J., Van Dorsselaer, S., Smit, E., \& Vollebergh, W. (2008). Jeugd en riskant gedrag 2007: Kerngegevens uit het Peilstationsonderzoek scholieren: roken, drinken, drugsgebruik en gokken onder scholieren vanaf tien jaar. Utrecht: Trimbos Institute.

Muris, P., Meesters, C., \& Van Den Berg, F. (2003). The Strengths and Difficulties Questionnaire (SDQ): Further evidence for its reliability and validity in a community sample of Dutch children and adolescents. European Child and Adolescent Psychiatry, 12, 1-8

Muthén, L. K., \& Muthén, B. O. (1998 2009). Mplus User's Guide (5th ed.). Los Angeles, CA: Muthén \& Muthén.

Noom, M. J., Dekovic, M., \& Meeus, W. H. J. (1996). Opvoeding en ontwikkeling tijdens de adolescentie. In J. Rispens, Hermanns, J. \& Meeus, W.H.J. (Ed.), Opvoeden in Nederland (pp. 207226). Assen: Van Gorcum

O'Malley, P. M., \& Wagenaar, A. C. (1991). Effects of minimum drinking age laws on alcohol use, related behaviors and traffic crash involvement among American youth: 1976-1987. Studies on Alcohol, 52, 478-491.

Palmonari, A., Kirchler, E., \& Pom beni, M. L. (1991). Differential effects of identification with family and peers on coping with developmental tasks in adolescence. European Journal of Social Psychology, 381-402.

Pape, H., \& Hammer, T. (1996). Sober adolescence - predictor of psychosocia maladjustment in young adulthood? Scandinavian Journal of Psychology, 37, 362-377.

Parry, C. D. H., Myers, B., \& Thiede, M. (2003). The Case for an Increased Tax on Alcohol in South Africa. South African Journal of Economics, 71, 137-145.
Paschall, M. J., Grube, J. W., Black, C., \& Ringwalt, C. L. (2007). Is commercial alcohol availability related to adolescent alcohol sources and alcohol use? Findings from a multi-level study. Journal of Adolescent Health, 41, 168-174.

Paschall, M. J., Grube, J. W., \& Kypri, K. (2009). Alcohol control policies and alcohol consumption by youth: a multi-national study. Addiction, 104, 1849-1855. Patton, G. C., McMorris, B. J., Toumbourou, J. W., Hemphill, S. A., Donath, S., \& Catalano, R. F. (2004). Puberty and the onset of substance use and abuse. Pediatrics, 114, 300-306.

Perry, C. L., Williams, C. L., Komro,

K. A., Veblen-Mortenson, S., Stigler, M. H., Munson, K. A., et al. (2002). Project Northland: Long-term outcomes of community action to reduce adolescent alcohol use. Health Education Research, 17, 117-132.

Petersen, A. C., Crockett, L., Richards, M., \& Boxer, A. (1988). A self report measure of pubertal status: Reliability, validity, and internal norms. Journal of Youth and Adolescence, 17, 117-133.

Pieters, S., Van Der Vorst, H., Burk, W. ., Wiers, R. W., \& Engels, R. C. M. E. (2010). Puberty-Dependent Sleep Regulation and Alcohol Use in Early Adolescents. Alcoholism: Clinical and Experimental Research. 34, 1512-1518.

Pinyerd, B., \& Zipf, W. B. (2005). PubertyTiming Is Everything! Journal of Pediatric Nursing, 20, 75-82.
Popova, S., Giesbrecht, N., Bekmuradov, D., \& Patra, J. (2009). Hours and days of sale and density of alcohol out lets: impacts on alcohol consumption and damage: a systematic review. Alcohol and Alcoholism, 44, 500-516.

Poulin, F., Kiesner, J., Pedersen, S., \& Dishion, T. J. (2011). A short-term longitudinal analysis of friendship selection on early adolescent substance use. Journal of Adolescence, 34, 249-256.

Rachal, J. V., Guess, L. L., Hubbard, R. L., \& Maisto, S. A. (1982). Facts for planning no. 4: Alcohol misuse by adolescents. Alcohol Health and Research World, 6, 61-68.

Rachal, J. V., Williams, J. R., Brehm, M. L., Cavanaugh, B., Moore, R. P., \& Eckerman, W. C. (1975). A national study of adolescent drinking behavior, attitudes and correlates. Washington, DC: National Institute on Alcohol Abuse and Alcoholism.

Ramstedt, M. (2001). Per capita alcohol consumption and liver cirrhosis mortality in 14 European countries. Addiction, 96, S19-S34

Read, J. P., Wood, M. D., Kahler, C. W. Maddock, J. E., \& Palfai, T. P. (2003). Examining the role of drinking motives in college student alcohol use and problems. Psychology of Addictive Behaviors, 17, 13-23.

Rehm, J., Gmel, G., \& Sempos, C. T. (2003). Alcohol related morbidity and 
mortality. Alcohol Research and Health, 27, 39-51.

Rehm, J., Room, R., Graham, K., Monteiro, M., Gmel, G., \& Sempos, C. T. (2003). The relationship of average volume of alcohol consumption and patterns of drinking to burden of disease: An overview. Addiction, 98, 1209-1228.

Reynolds, R. I., Holder, H. D., \& Gruenewald, P. J. (1997). Community prevention and alcohol retail access. Addiction, 92, 261-272.

Richman, J. A., Flaherty, J. A., \& Pyskoty, C. (1992). Shifts in problem drinking during a life transition: Adaptation to medical school training. Journal of Studies on Alcohol, 53, 17-24.

Rosenthal, J. A. (1996). qualitative descriptors of strength of association and effect size. Journal of Social Service Research, 21, 37-59.

Sallis, J. F., Owen, N., \& Fisher, E. B. (2008). Ecological models of health behavior. In K. Glanz, B. K. Rimer \& K Viswanath (Eds.), Health Behavior and Health Education: Theory, Research, and Practice (4 ed., pp. 465-485). San Francisco: Jossey-Bass.

Schelleman-Offermans, K., Knibbe, R. A., \& Derickx, M. (2009a). Aanpak drankgebruik van jongeren: Meningen van ouders en professionals uit gemeenten en gezondheidszorg: Een onderzoek in drie Nederlandse gemeenten. [Tackling adolescent alcohol use: opinions of parents and proffessionnals from loca authorities and health care: A study in three Dutch municipalities]. Maastricht: Maastricht University.

Schelleman-Offermans, K., Knibbe, R. A., \& Derickx, M. (2009b). Jongeren van 13 tot en met 15 jaar in Amersfoort: Drankgebruik, en wat ouders ervan vinden [Adolescents of 13 until 15 years old in Amersfoort: their alcohol use and the opinion of their parents]. Maastricht: Maastricht University.

Schelleman-Offermans, K., Knibbe, R. A., \& Derickx, M. (2009c). Jongeren van 13 tot en met 15 jaar in Arnhem: Drankgebruik, en wat ouders ervan vinden [Adolescents of 13 until 15 years old in Arnhem: their alcohol use and the opinion of their parents]. Maastricht: Maastricht University.

Schelleman-Offermans, K., Knibbe, R. A., Engels, R. C. M. E., \& Burk, W. J. (2011). The effect of pubertal and psychosocial timing on adolescents' alcohol use: What role does alcohol-specific parenting play? Journal of Youth and Adolescence, 40, 1302-1314.

Schulenberg, J. E., Maggs, J. L., Dielman, T. E., Leech, S. L., KLoska, D. D. \& Laetz, V. B. (1999). On peer infuences to get drunk: A panel study of young adolescents. Merrill-Palmer Quaterly, $45,108-142$

Schulenberg, J. E., O'Malley, P. M. Bachman, J. G., Wadsworth, K. N., \&
Johnston, L. D. (1996). Getting drunk and growing up: Trajectories of frequent binge drinking during the transition to young adulthood. Journal of Studies on Alcohol, 57, 289-304.

Sieving, R. E., Perry, R. N. C. C. L., \& Williams, C. L. (2000). Do Friendships Change Behaviors, or Do Behaviors Change Friendships? Examining Paths of Influence in Young Adolescents' Alcohol Use. Journal of Adolescent Health, 26, 27-35.

Sindelar, H. A., Barnett, N. P., \& Spirito, A. (2004). Adolescent alcohol use and injury. A summary and critical review of the literature. Minerva Pediatrica, 56.

Singletary, K. W., \& Gapstur, S. M. (2001). Alcohol and breast cancer: Review of epidemiologic and experimental evidence and potential mechanisms. Journal of the American Medical Association, 286, 2143-2151.

Skog, O. J. (1980). Social interaction and the distribution of alcohol consumption. Journal of Drug Issues, 10, 71-92.

Smit, E., Verdurmen, J., Monshouwer, K., \& Smit, F. (2008). Family interventions and their effect on adolescent alcohol use in general populations; a meta-analysis of randomized controlled trials. Drug and Alcohol Dependence, 97, 195-206.

Stafström, M., Östergren, P., Larsson, S., Lindgren, B., \& Lundborg, P. (2006).
A community action programme for reducing harmful drinking behaviour among adolescents: The Trelleborg Proect. Addiction, 101, 813-823.

Stattin, H., \& Magnusson, D. (1990). Pubertal Maturation in Female Development. In D. Magnusson (Ed.), Path Through Life (Vol. 2). Hillsdale, New Jersey: L. Erlbaum associates.

Staulcup, H., Kenward, K., \& Frigo, D. (1979). A review of federal primary alcoholism prevention projects. Journal of Studies on Alcohol, 40, 943-968

Steele, R. G., Forehand, R., Armistead, L., \& Brody, G. (1995). Predicting alcohol and drug use in early adulthood: the role of internalizing and externalizing behavior problems in early adolescence. American Journal of Orthopsychiatry, 65, 380-388

Steinberg, L. (2008). A social neuroscience perspective on adolescent risk-taking. Developmental Review, 28, 78-106. Stigler, M. H., Perry, C. L., Komro, K. A., Cudeck, R., \& Williams, C. L. (2006). Teasing apart a multiple component approach to adolescent alcohol prevention: What worked in Project Northland? Prevention Science, 7, 269-280. Stokols, D. (1996). Translating social ecological theory into guidlines for community health promotion. American Journal of Health Promotion, 10, 282-298.

Stokols, D., Allen, J., \& Bellingham, R.

L. (1996). The social ecology of health 
promotion: Implications for research and practice. American Journal of Health Promotion, 10, 247-251.

Swahn, M. H., Bossarte, R. M., Ashby, J. S., \& Meyers, J. (2010). Pre-teen alcohol use initiation and suicide attempt among middle and high school students: Findings from the 2006 Georgia Student Health Survey. Addictive Behaviors, 35, 4452-4458.

Tabachnick, B. G., \& Fidell, L. S. (2001). Using multivariate statistics, fourth edition. Needham Heights, MA: Allyn \& Bacon.

Tapert, S. F., Aarons, G. A., Sedlar, G. R., \& Brown, S. A. (2001). Adolescent substance use and sexual risktaking behaviour. Journal of Adolescent Health 28, 181-189.

Tapert, S. F., Schweinsburg, A. D., \& Barlett, V. C. (2004). Blood oxygen level dependent response and spatial working memory in adolescents with alcohol use disorders. Alcoholism: Clinical and Experimental Research, 28, 1577-1586.

Taris, T. W. (2000). A primer in longitudinal data analyses. London: SAGE Publications Ltd.

Treno, A. J., Ponicki, W. R., Remer, L G., \& Gruenewald, P. J. (2008). Alcohol outlets, youth drinking, and selfreported ease of access to alcohol: A constraints and opportunities approach. Alcoholism: Clinical and Experimental Research, 32, 1372-1379.
Tschann, J. M., Adler, N. E., Irwin, C. E., Millstein, S. G., Turner, R. A., \& Kegeles, S. M. (1994). Initiation of substance use in early adolescence: The roles of pubertal timing and emotional distress. Health Psychology, 13, 326-333.

Urberg, K. A., Luo, Q., Pilgrim, C., \& Degirmencioglu, S. M. (2002). A twostage model of peer influence in adolescent substance use: individual and relationship-specific differences in susceptibility to influence. Addictive Behaviors, 28, 1243-1256.

Van de Luitgaarden, J., Knibbe, R. A., \& Wiers, R. W. (2010). Adolescents binge drinking when on holiday: An evaluation of a community intervention based on self-regulation. Substance Use and Misuse, 45, 190-203.

Van De Mheen, H., Toet, J., Knibbe, R. A., Garretsen, H. F. L., Spruit, I. P., \& Van De Berg, M. (2006). A local and regional Alcohol and Drugs Monitor in the Netherlands: a tale of three cities. Drug and Alcohol Review, 25, 259 - 267. Van den Berg, M., Van Baal, P. H. M., Tariq, L., Schuit, A. J., De Wit, G., \& Hoogenveen, R. T. (2008). The cost-effectiveness of increasing alcohol taxes: modelling study. BMC Medicine, 6, 36.

Van Der Linden, J., \& Knibbe, R. A. (2006). Alcohol, agressie en uitgaan bevolkingsonderzoek onder 16-35-jarigen in Utrecht, Rotterdam en Parkstad
Limburg. Verslaving: Tijdschrift over verslavingsproblematiek, 2, 47-58.

Van Der Vorst, H. (2007). The Key to the Cellar Door. The Role of the Family in Adolescents' Alcohol Use. Nijmegen: RU Radboud Universiteit Nijmegen. Van Der Vorst, H., Engels, R. C. M. E., Dekovic, M., Meeus, W., \& Vermulst, A. A. (2007). Alcohol-specific rules, personality and adolescents' alcohol use: A longitudinal person-environment study. Addiction, 102, 1064-1075.

Van Der Vorst, H., Engels, R. C. M. E., Meeus, W., \& Dekovic, M. (2006). The impact of alcohol-specific rules, parental norms about early drinking and parental alcohol use on adolescents' drinking behavior. Journal of Child Psychology and Psychiatry, 47, 1299-1306.

Van Der Vorst, H., Engels, R. C. M. E., Meeus, W., Dekovic, M., \& Van Leeuwe, J. (2005). The role of alcohol-specific socialization on adolescents drinking behaviour. Addiction, 100.

Van Hoof, J. J. (2010). Sweet sixteen and never been drunk? Adolescent alcohol use, predictors and consequences. Enschede, The Netherlands: University of Twente.

Van Hoof, J. J., Van Noordenburg, M., \& De Jong, M. D. T. (2008). Happy hours and other alcohol discount in cafés: Prevalence and effects on underage adolescents. Journal of Public Health Policy, 29, 340-352.
Van Laar, M. W., Cruts, A. A. N., Van Ooyen-Houben, M. M. J., Meijer, R. F. Brunt, T., Croes, E. A., et al. (2011) Nationale drug monitor 2010. Utrecht: Trimbos-instituut.

Van Laar, M. W., Cruts, A. N. N., Verdurmen, J. E. E., Van Ooyen-Houben, M. M. J., \& Meijer, R. F. (2008). Nationale drug monitor jaarbericht 2007. Utrecht: Trimbos Instituut.

Van Zundert, R., Van Der Vorst, H. Vermulst, A. A., \& Engels, R. M. C. E. (2006). Pathways to alcohol use among Dutch students in regular education and education for adolescents with behavioral problems: The role of parenta alcohol use, general parenting practices, and alcohol-specific parenting practices. Journal of Family Psychology, 20, 456 567.

Vanheusden, K., Van Lenthe, F. J., Mulder, C. L., Van Der Ende, J., Van De Mheen, D., Mackenbach, J. P., et al. (2008). Patterns of association between alcohol consumption and internalizing and externalizing problems in young adults. Journal of Studies on Alcohol and Drugs, 69, 49-57.

Wachs, T. D. (1992). The nature of nurture. Newbury Park, CA: Sage.

Wagenaar, A. C. (1993). Research effects public policy: the case of the legal drinking age in the United States. Addiction, $88,75-81$. 
Wagenaar, A. C., Finnegan, J., Wolfson, M., Anstine, P., Williams, C., \& Perry, C. (1993). Where and how do adolescents abtain alcoholic beverages. Public Health Reports, 108.

Wagenaar, A. C., Murray, D. M., \& Gehan, J. P. (2000b). Communities mobilizing for change on alcohol (CMCA): effects of a randomized trial on arrests and traffic crashes. Addiction, 95, 209-217.

Wagenaar, A. C., Murray, D. M., Gehan J. P., Wolfson, M., Forster, J. L., Toomey, T. L., et al. (2000a). Communities Mobilizing for Change on Alcohol: Outcomes from a randomized community trial. Journal of Studies on Alcohol, 61, 85-94. Wagenaar, A. C., \& Perry, C. L. (1994)

Community strategies for the reduction of youth drinking: Theory and applications. Journal of Research on Adolescence, 4, 319-345.

Wagenaar, A. C., Salois, M. J., \& Komro, K. A. (2009). Effects of beverage alcoho price and tax levels on drinking: A metaanalysis of 1003 estimates from 112 studies. Addiction, 104, 179-190.

Wagenaar, A. C., \& Toomey, T. L. (2002). Effects of minimum drinking age laws: Review and analyses of the literature from 1960 to 2000. Journal of Studies on Alcohol, Supplement No. 14, 206-225.

Wallack, L. (1990). Two approaches to health promotion in the mass media. World Health Forum, 11, 143-164.
Wechsler, H., Davenport, A., Dowdall,

G., Moeykens, B., \& Castillo, S. (1994).

Health and behavioral consequences of binge drinking in college: A national survey of students at 140 campuses. Journal of the American Medical Association, 272, 1672-1677.

Wechsler, H., Kuo, M., Lee, H., \& Dowdall, G. (2000). Environmental correlates of underage alcohol use and related problems of college students. American Journal of Preventive Medicine, 19, 24-29.

Wells, J. E., Horwood, L. J., \& Fergusson, B. M. (2004). Drinking patterns in mid-adolescence and outcomes in late adolescence and early adulthood. Addiction, 99, 1529-1541.

Westling, E., Andrews, J. A., Hampson, S. E., \& Peterson, M. (2008). Pubertal timing and substance use: The effect of gender, parental monitoring and deviant peers. Journal of Adolescent Health, 42, 555-563.

WHO (2004). Globus status report on atcohol and health. Geneva, Zwitserland: World Health Organization

WHO (2011). Globus status report on alcohol and health. Geneva, Zwitserland: World Health Organization.

Wichstrom, L. (2001). The impact of pubertal timing on adolescents' alcoho use. Journal of Research on Adolescence, 11, 131-150.
Williams, S., \& Mulhall, P. (2005). Where public school students in Illinois get cigarettes and alcohol: Characteristics of minors who use different sources. Prevention Science, 6, 47-57.

Wilsterman, M. E. F., Dors, N., Sprij, A. J., \& Wit, J. M. (2004). Kliniek en beleid bij jongeren met alcoholintoxicatie op de afdelingen spoedeisende hulp in de regio Den Haag, 1999-2000 [Treatment and policy on youth alcohol intoxication in first aid departments.in the Den Haag region, 1999-2000.]. Nederlands Tijdschrift voor de Geneeskunde, 148, 1496-1500.

Yu, J. (2003). The association between parental alcohol-related behaviors and children's drinking. Drug and Alcohol 

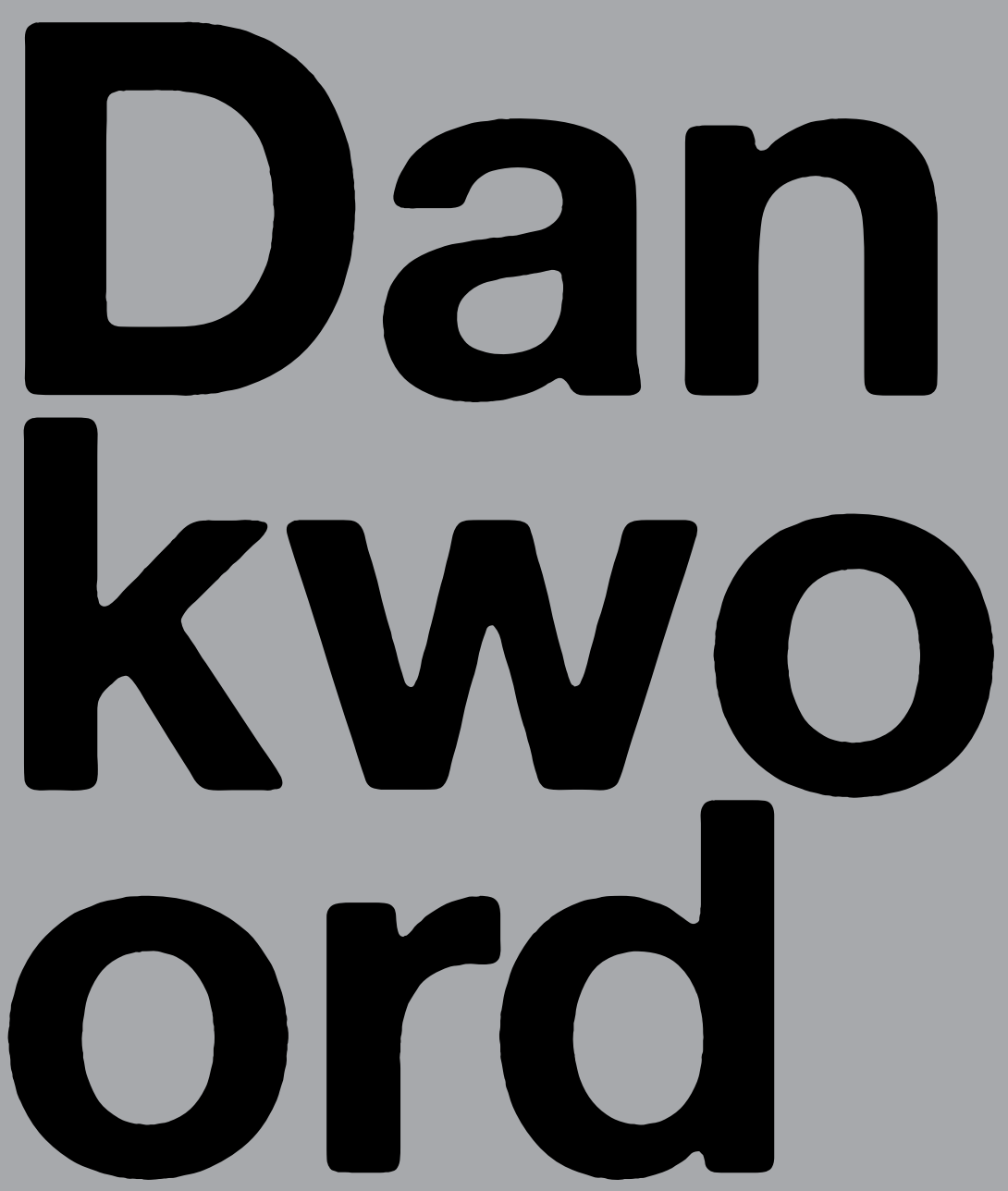


\section{Bedankt, thanks}

Ronald, je deur stond altijd open, goede raad wanneer ik vastliep en zeker ook de vrijheid gekregen die je als AIO ook nodig hebt om er je 'eigen' onderzoek van te maken. Ik vond het fijn om als een van je laatste AIO's met je te hebben mogen samenwerken.

Mijn andere promotoren, Dike en Rutger, voor de prettige samenwerking.

194 De vele assistenten, in het bijzonder Mieke en Leonieke, zonder jullie was dit project nooit zo succesvol en gezellig geworden.

Een constante factor op de werkvloer was zeker ook de goulash club. Leuke etentjes, discussies en vooral gezelligheid! Paul, voor het sparren.

Ook alle externe partijen die betrokken zijn geweest bij het implementeren van de interventies (STAP, de nVWA, de interventiegemeenten, locale GGD en verslavingszorg en het oudercomité).
Special thanks to Emmanuel and Sandra Kuntsche for welcoming me in Lausanne, showing me around and for all the dinner invitations and good conversations. Emmanuel, for all the constructive feedback.

We are indeed story tellers!

Sally Casswell, Taisia Huckle, and Chris Wilkins for the warm welcome at SHORE in New Zealand, showing me around and the inspiring collaboration.

Judith and Leonieke, voor de ongelimiteerde gezelligheid op onze voormalige kamer samen en dat jullie mijn paranimfen willen zijn.

Mam, pap, voor alle steun!

Ramon, zonder jou was dit proefschrift natuurlijk nooit zo mooi geworden! lk verheug me al op ons volgende 'life-event'! 


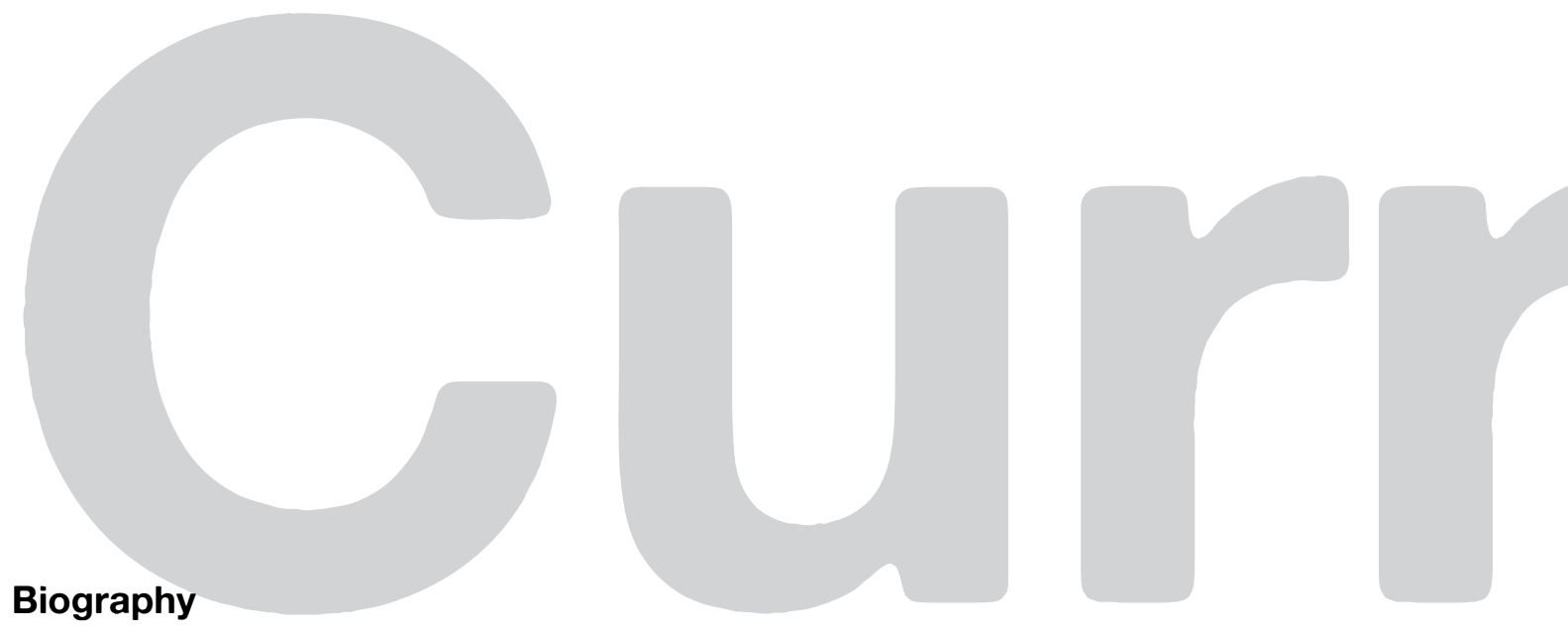

\section{Biography}

Karen Schelleman-Offermans was born on December 16th, 1981 in Slenaken (the Netherlands). After she graduated from high school she received the Sacred Heart scholarship to study (major: dance; minor: photography) for two semesters at DePaul University in Lake Forest, IL, United States.

Here after, she moved back to the Netherlands to study biological developmen-

tal psychology (B.A. 2005, M.A. with distinction 2007) at Maastricht University. During her master study she studied one semester at the Humboldt University in Berlin with a focus on child and youth psychology and psychiatry. In 2006 she began a psychology trainee-internship at Groenengezondheidszorg in Heerlen (the Netherlands) and accepted a post as psychologist in 2007.

In January 2008 she started her PhD-project at the Health Promotion department of Maastricht University which focused on the impact of environmental influences (parental, community and policy influences) and intrapersonal factors (drinking motives) on the use of alcohol by adolescents. During her PhD-project she received the CAPHRI travel grant for talented young researchers and visited two leading international research institutes for three months; Addiction Info in Switzerland and the Centre for Social and Health Outcomes Research and Evaluation in New Zealand.

Up to now, she presented her research at six international conferences and two national conferences. For her paper regarding the predictive power of drinking motives on future adolescents' alcohol use she obtained the 2010 Kettil Bruun Society Early Career Scientist Award. Karen Schelleman-Offermans currently works as a post-doc researcher at the Health Promotion department of Maastricht University.

\section{Publications}

d.d. 13.04 .2012

\section{Published}

Schelleman-Offermans, K., Knibbe, R. A., Kuntsche, E., \& Casswell, S. (in press). Effects of a natural community intervention intensifying alcohol law enforcement combined with a restrictive alcohol policy on adolescent alcohol use. Journal of Adolescent Health.

Schelleman-Offermans, K., Kuntsche, E., \& Knibbe, R. A. (2011). Associations between drinking motives and adolescents' alcohol use; A full cross-lagged panel study. Addiction, 106, 1270-1278.

Schelleman-Offermans, K., Knibbe, R. A., Engels, R. C. M. E., \& Burk, W. J. (2011). The effect of pubertal and psychosocial timing on adolescents' alcohol use: What role does alcohol-specific parenting play? Journal of Youth and Adolescence, 40, 1302-1314.

Schelleman-Offermans, K. \& Merckelbach, H. (2010). Fantasy proneness as a confounder of verbal lie detection tools. Journal of Investigative Psychology and Offender Profiling, 7, 247-260.

\section{Submitted}

Schelleman-Offermans, K., Knibbe, R. A., \& Kuntsche, E. Het motivationele model van alcoholgebruik: Voorspellen drinkmotieven veranderingen in het drinkgedrag van Nederlandse jongeren?

Schelleman-Offermans, K., Knibbe, R. A., \& Van de Mheen, D. Effects of a community intervention restricting retail and social alcohol availability for adolescents on retailers and parents: A quasi-experimental study.

Schelleman-Offermans, K., Knibbe, R. A., \& Kuntsche, E. Preventing adolescent alcohol use: Effects of a two-year quasi-experimental community intervention intensifying formal and informal control

Schelleman-Offermans, K., Knibbe, R. A., \& Kuntsche, E. Are the effects of early pubertal timing on alcohol initiation mediated by peers and/or parents? A longitudinal study.

Crutzen, R., Kuntsche, E., \& Schelleman-Offermans, K. Changes in drinking motives, behaviour and related consequences over time: a full cross-lagged panel study. 


\section{Scientific reports}

Schelleman-Offermans, K., Knibbe, R.A., \& Derickx, M. Ontwikkelingen in drankgebruik, drinksituaties en verkrijgbaarheid van drank bij jongeren in Amersfoort: Resultaten van de derde meting (2011). Maastricht: Maastricht University.

Schelleman-Offermans, K., Knibbe, R.A., \& Derickx, M. Ontwikkelingen in drankgebruik, drinksituaties en verkrijgbaarheid van drank bij jongeren in Emmen: Resultaten van de derde meting (2011). Maastricht: Maastricht University.

Schelleman-Offermans, K., Knibbe, R.A., \& Derickx, M. Ontwikkelingen in drankgebruik, drinksituaties en verkrijgbaarheid van drank bij jongeren in Arnhem: Resultaten van de derde meting (2011). Maastricht: Maastricht University.

Schelleman-Offermans, K., Knibbe, R.A., \& Derickx, M. Ontwikkelingen in drankgebruik, drinksituaties en verkrijgbaarheid van drank bij jongeren in Emmen: Resultaten van de tweede meting (2010). Maastricht: Maastricht University.

Schelleman-Offermans, K., Knibbe, R.A., \& Derickx, M. Ontwikkelingen in drankgebruik, drinksituaties en verkrijgbaarheid van drank bij jongeren in Amersfoort: Resultaten van de tweede meting (2010). Maastricht: Maastricht University.

Schelleman-Offermans, K., Knibbe, R.A., Derickx, M. Ontwikkelingen in drankge198 bruik, drinksituaties en verkrijgbaarheid van drank bij jongeren in Arnhem: Resultaten van de tweede meting (2010). Maastricht: Maastricht University.

Schelleman-Offermans, K., \& Knibbe, R.A. Aanpak drankgebruik van jongeren: meningen van ouders, verstrekkers en professionals uit gemeenten en gezondheidszorg; een onderzoek in drie Nederlandse gemeenten (2009). Maastricht: Maastricht University.

Schelleman-Offermans, K., Knibbe, R.A., \& Derickx, M. Jongeren van 13 tot en met 15 jaar in Amersfoort: Drankgebruik en wat ouders ervan vinden (2009). Maastricht: Maastricht University.

Schelleman-Offermans, K., Knibbe, R.A., \& Derickx, M. Jongeren van 13 tot en met 15 jaar in Emmen: Drankgebruik en wat ouders ervan vinden (2009). Maastricht: Maastricht University.

Knibbe, R.A., Schelleman-Offermans, K., \& Derickx, M. Jongeren van 13 tot en met 15 jaar in Arnhem: Drankgebruik en wat ouders ervan vinden (2009). Maastricht: Maastricht University. 


\section{Growing up getting drunk Development and prevention of adolescent alcohol use}

Karen Schelleman-Offermans

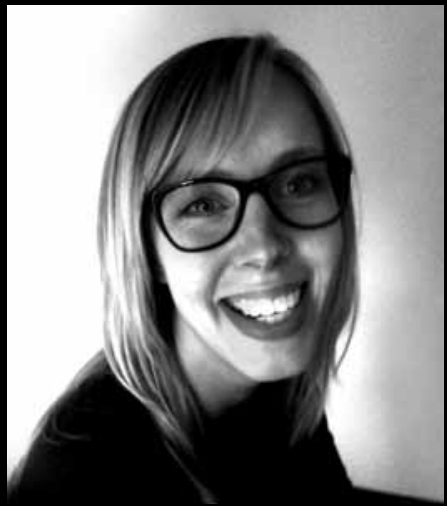

In high-income countries, alcohol use is one of the leading risk factors for burden of disease among adolescents.

This stresses the necessity to determine important factors predicting the development of adolescent alcohol use and to develop effective alcohol prevention strategies.

In this thesis, the social ecological paradigm is used as an overarching framework to understand the interplay between adolescents, their social environments, the legal environment, and the community they live in.

Conclusions contain important recommendations for prevention.

About the author

Karen Schelleman-Offermans (1981) studied biological developmental psychology (B.A. 2005, M.A. with distinction 2007) at Maastricht University, the Netherlands. In January 2008 she started her PhDproject at the Health Promotion department of Maastricht University. For her paper regarding the predictive power of drinking motives on future adolescents' alcohol use (published in Addiction) she received the 2010 Kettil Bruun Society Early Career Scientist Award.

Karen Schelleman-Offermans currently works as a post-doc researcher at the Health Promotion department of Maastricht University. Her research interests include developmental psychology in general, adolescent risk behaviors such as alcohol use, and the role of peers, parents and the community in the development and prevention of adolescent risk behaviors. 